\title{
Untersuchungen zum Fettsäuretransport durch zelluläre und peroxisomale Membranen
}

\author{
Dissertation \\ zur Erlangung des Doktorgrades \\ der Mathematisch-Naturwissenschaftlichen Fakultäten \\ der Georg-August-Universität zu Göttingen
}

vorgelegt von

Michael Scharnewski

aus

Stade

Göttingen 2009 
Referent: $\quad$ Prof. Dr. I. Feußner

Korreferent: Dr. I. Heilmann

Tag der Disputation: 19.01.2010 


\section{Inhaltsverzeichnis}

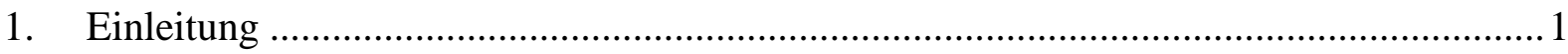

$1.1 \quad$ Fettsäuretransport durch die Plasmamembran ....................................................... 1

1.1.1 Acyl-CoA-Synthetasen in S. cerevisiae ....................................................... 1

1.1.2 Fettsäuretransport durch die Plasmamembran in Saccharomyces cerevisiae ......2

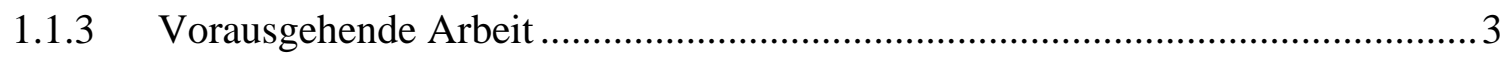

1.2 Fettsäuretransport durch die peroxisomale Membranen....................................... 4

1.2.1 Peroxisomen .................................................................................... 4

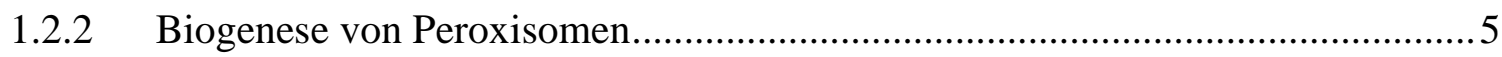

1.2.3 Metabolitentransport durch die peroxisomale Membran....................................6

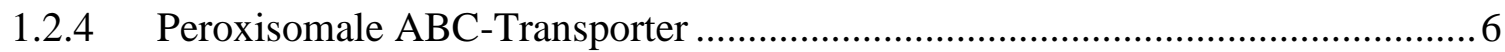

1.2.5 Peroxisomale ABC-Transporter aus Saccharomyces cerevisiae …......................

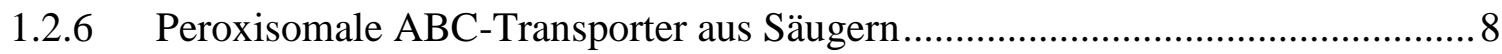

1.2.7 Peroxisomale ABC-Transporter aus Arabidopsis thaliana ................................ 12

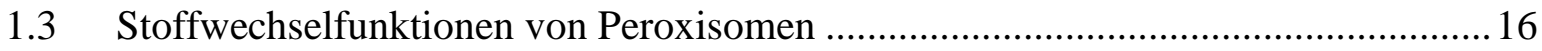

1.3.1 Stoffwechselfunktionen von Peroxisomen in Saccharomyces cerevisiae ........... 16

1.3.2 Peroxisomale Acyl-CoA-Thioesterasen ..................................................... 18

1.3.3 Stoffwechselfunktionen von Peroxisomen in Arabidopsis thaliana .................. 19

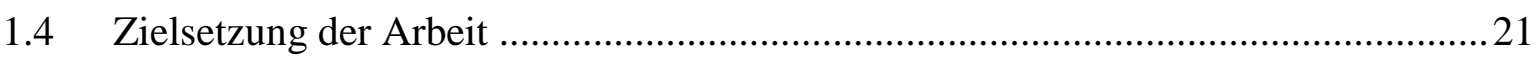

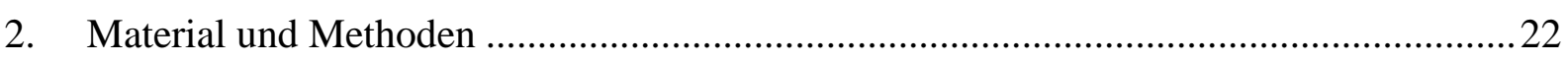

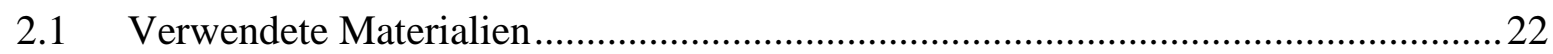

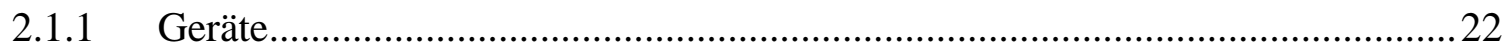

2.1.2 Chemikalien und molekularbiologische Reagenzien .....................................2 23

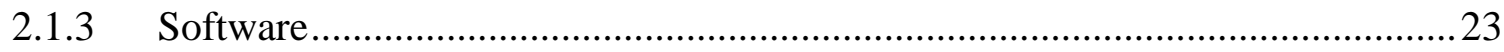

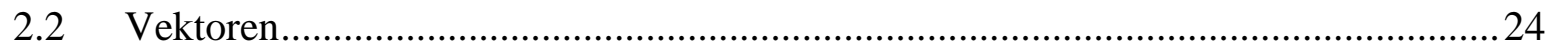

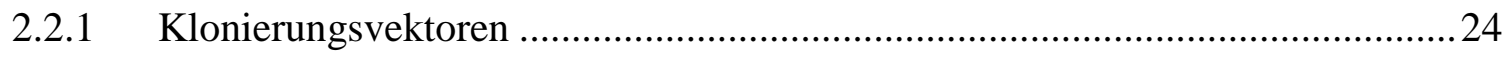

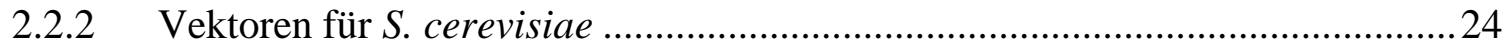




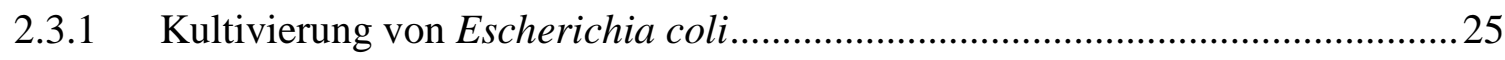

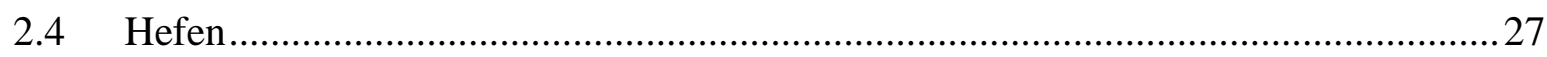

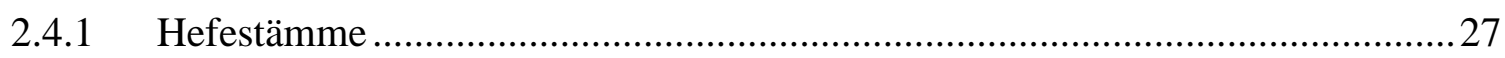

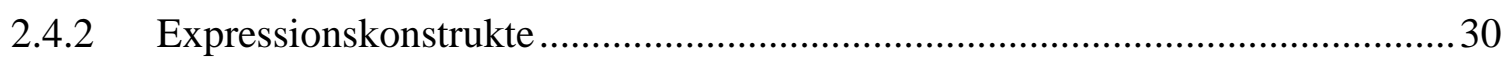

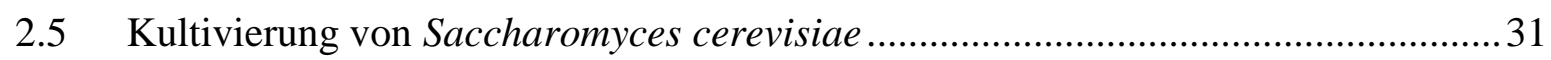

2.5.1 Medien für die Kultivierung von Saccharomyces cerevisiae ............................ 31

2.5.2 Modellierung des Wachstums von Saccharomyces cerevisiae ........................... 34

2.6 Die Polymerasen-Kettenreaktion (PCR) ......................................................... 34

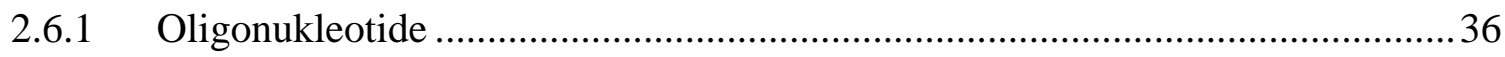

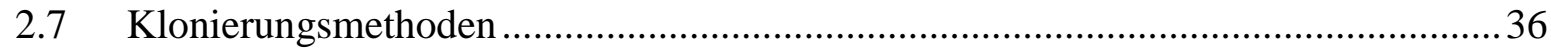

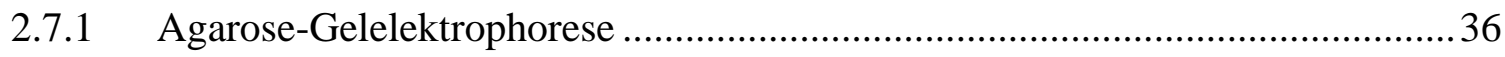

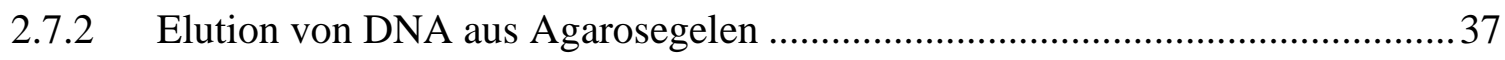

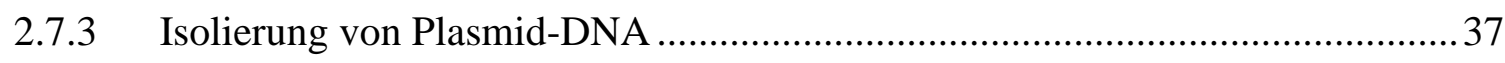

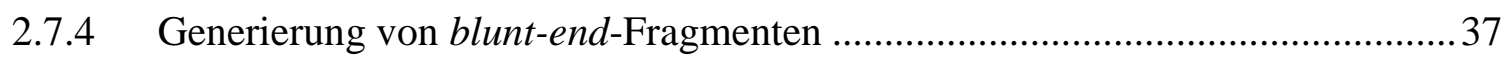

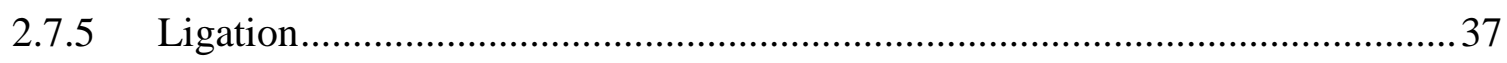

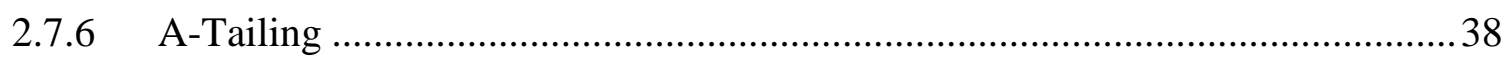

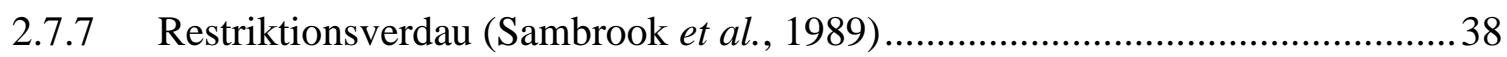

2.7.8 Sequenzierung von DNA-Fragmenten ..................................................... 38

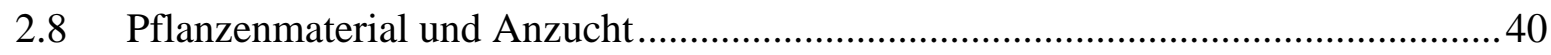

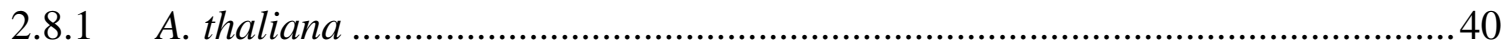

2.8.2 Oberflächensterilisation von A. thaliana-Saatgut......................................... 40

2.8.3 Anzucht von A. thaliana auf MS-Medium ..................................................... 41

2.8.4 Anzucht von A. thaliana auf Erde ........................................................... 41

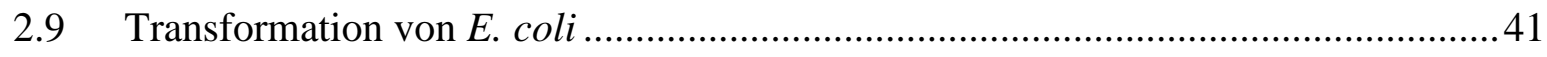

2.9.1 Präparation chemisch kompetenter E. coli-Zellen zur HitzeschockTransformation (Inoue et al., 1990).......................................................................... 41

2.9.2 Transformation kompetenter E. coli-Zellen ................................................ 42 
2.10 Transformation von Saccharomyces cerevisiae (modifiziert nach

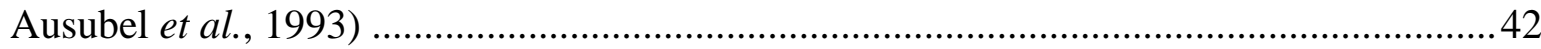

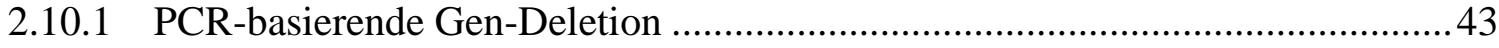

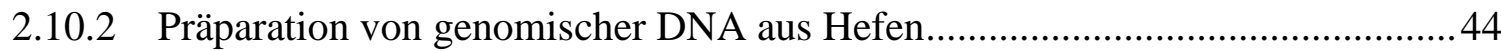

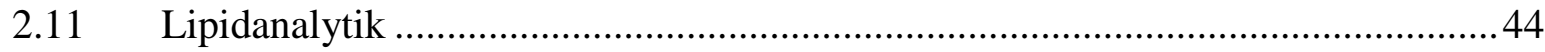

2.11.1 Lipidanalytik mittels Gaschromatographie ............................................... 44

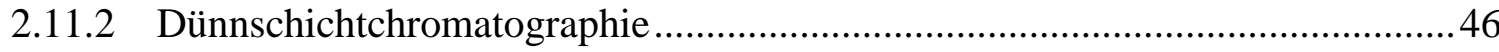

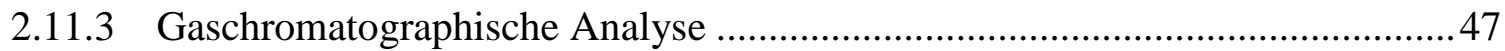

2.11.4 Fütterung von Saccharomyces cerevisiae mit radioaktiv markierten Fettsäuren

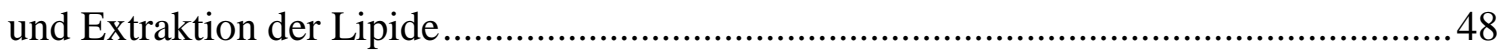

2.12 HPLC (High performance liquid chromatography) ............................................. 49

2.12.1 Extraktion von Acyl-CoA-Estern aus S. cerevisiae (modifiziert nach Rosendal und Knudsen, 1992).

2.12.2 Extraktion von Acyl-CoA-Ester aus A. thaliana (Larson und Graham, 2001) ..50

2.12.3 Derivatisierung von Acyl-CoA-Estern (Larson und Graham, 2001) .................51

2.12.4 HPLC-Analyse von Acyl-etheno-CoA-Estern (Larson und Graham, 2001)......51

2.13 Extraktion und Bestimmung der Phytohormone aus A. thaliana ............................53

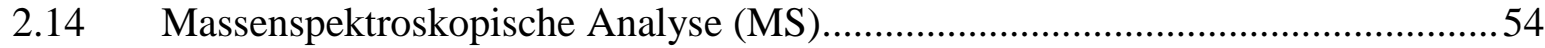

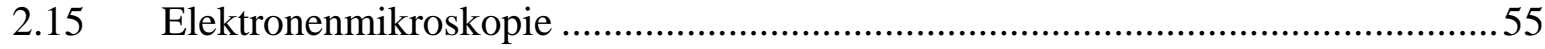

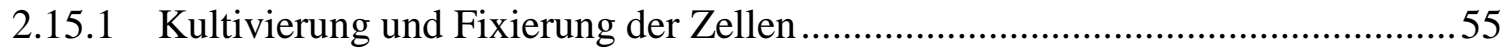

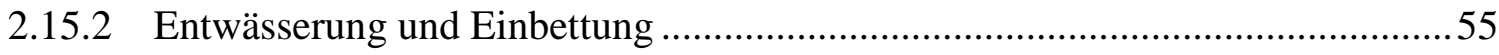

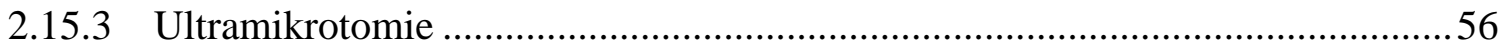

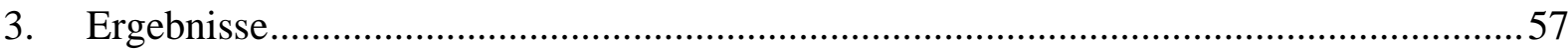

3.1 Fettsäuretransport durch die zelluläre Membran in Saccharomyces cerevisiae ........57

3.1.1 Fat1p ist zuständig für die restliche Acyl-CoA-Synthetase-Aktivität in der Mutante YB526 57

3.1.2 Fat1p ist fähig, die fehlende Acyl-CoA-Synthetase-Aktivität in der Mutante MS51 teilweise zu komplementieren 59 
3.1.3 Der Fettsäuretransport durch die Plasmamembran findet in Abwesenheit von jeglicher Acyl-CoA-Synthetase-Aktivität statt

3.1.4 Die Richtung des Fettsäuretransports ist abhängig von dem metabolischen Zustand der Zelle

3.1.5 Morphologische Eigenschaften von MS51 66

3.2 Untersuchungen zum Fettsäuretransport durch die peroxisomale Membran durch den ABC-Transporter PXA1 in Arabidopsis thaliana .... 68

3.2.1 Komplementationsstudien mit dem heterologen ABC-Transporter PXA1 und der heterologen Acyl-CoA-Synthetase LACS7 aus Arabidopsis thaliana in Saccharomyces cerevisiae 68

3.2.2 Die Folgen von Einschränkungen in der $\beta$-Oxidation auf die Regulierung des Acyl-CoA-Pools in Saccharomyces cerevisiae.....

3.3 Die Rolle des peroxisomalen ABC-Transporters PXA1 im Stoffwechsel während der Dunkelphase in Arabidopsis thaliana

3.3.1 Verstärkte Akkumulation von freien Fettsäuren während verlängerter Dunkelphase in den Blättern der pxal-Mutante 88

3.3.2 Die Akkumulation von freien Fettsäuren in der pxal-Mutante nach verlängerter Dunkelphase wird durch Zugabe von Saccharose unterdrückt 91

3.3.3 Massive Akkumulation von Jasmonsäure bei andauernder Dunkelphase 92

4. Diskussion 94

4.1 Fettsäuretransport durch die Plasmamembran in Saccharomyces cerevisiae..... 94

4.2 Untersuchungen zum Fettsäuretransport durch die peroxisomale Membran durch den ABC-Transporter PXA1 in Arabidopsis thaliana ....

4.2.1 Die Folgen von Einschränkungen in der $\beta$-Oxidation auf die Regulierung des Acyl-CoA-Pools in Saccharomyces cerevisiae. 101

4.3 Die Rolle des peroxisomalen ABC-Transporters PXA1 auf den Stoffwechsel während der Dunkelphase in Arabidopsis thaliana. 105

5. Zusammenfassung ....... 112

5.1 Fettsäuretransport durch die Plasmamembran in Saccharomyces cerevisiae 112 
5.2 Untersuchungen zum Fettsäuretransport durch die peroxisomale Membran durch den ABC-Transporter PXA1 in Arabidopsis thaliana 113

5.3 Die Rolle des peroxisomalen ABC-Transporters PXA1 auf den Stoffwechsel während der Dunkelphase in Arabidopsis thaliana ............................................................ 114

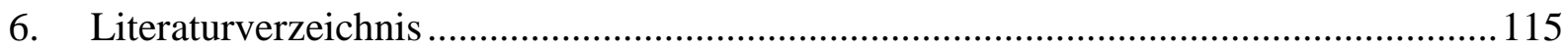

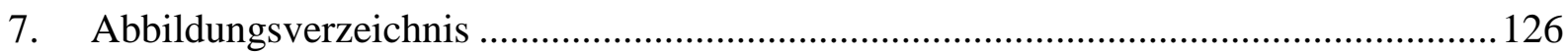

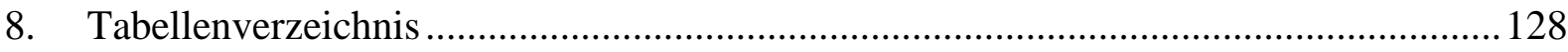

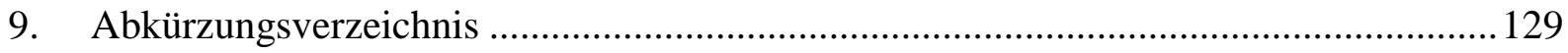

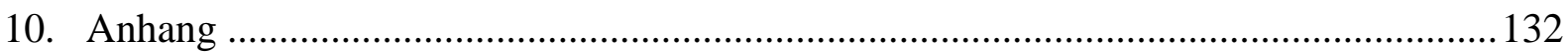




\section{Einleitung}

Die Abgrenzung der Zellen von der Umwelt war die Voraussetzung für die Entstehung des Lebens. Verantwortlich für die Abgrenzung sind biologische Membranen, die aus einer Lipiddoppelschicht mit angelagerten und integralen Proteinen bestehen. Durch die biologische Membran wird eine Barriere gebildet, die einerseits die Zelle vor unerwünschtem Durchtritt bestimmter Moleküle schützt und andererseits einen selektiven Durchtritt anderer Moleküle ermöglichen soll. In der Zelle sorgen die zellulären Membranen für die Abgrenzung der verschiedenen Zellkompartimente, wodurch biochemische Prozesse räumlich voneinander getrennt und unter optimalen Bedingungen durchgeführt werden können. Für den selektiven Durchtritt bestimmter Moleküle durch die zellulären Membranen sind spezielle Transportsysteme verantwortlich. Die Existenz vieler dieser Transportsysteme ergibt sich zwingend aus bekannten Stoffwechselwegen, die molekulare Funktionsweise und häufig sogar die Identität der beteiligten Proteinkomponenten selbst sind jedoch bis heute in vielen Fällen unbekannt. So ist beispielsweise der Transportmechanismus, der die Aufnahme exogener oder den Export endogener Fettsäuren durch die Plasmamembran vermittelt, trotz intensiver Forschung und einer Vielzahl von Publikationen weiterhin unverstanden. Der Transport von Fettsäuren durch biologische Membranen soll daher das zentrale Thema dieser Arbeit sein. Als Beitrag zur Aufklärung dieser Fragestellung werden die Modellorganismen Saccharomyces cerevisiae und Arabidopsis thaliana herangezogen und speziell der Transport von Fettsäuren zum einen durch die Plasmamembran und zum anderen durch die Membran der Peroxisomen betrachtet.

\subsection{Fettsäuretransport durch die Plasmamembran}

\subsubsection{Acyl-CoA-Synthetasen in S. cerevisiae}

Fettsäuren sind an einer Vielzahl von zellulären Prozessen beteiligt. Unter anderem dienen Fettsäuren als strukturelle Komponenten von Membranlipiden und repräsentieren eine wichtige Energiequelle für den Metabolismus der Zelle. Außerdem spielen Fettsäuren eine wichtige Rolle bei der Modifikation von Proteinen und bei der transkriptionalen Regulation. Die Voraussetzung für den Eintritt in zelluläre Prozesse ist die Überführung der CarboxylFunktion einer Fettsäure in eine aktivierte Form. Diese Aktivierung wird in den meisten 
Organismen durch Acyl-CoA-Synthetasen durchgeführt, indem freie Fettsäuren durch Thioesterifizierung in aktivierte CoA-Ester überführt werden. Acyl-CoA-Synthetasen gehören zur Enzym-Superfamilie der AMP-bindenden Proteine. So ist die Aktivierung der Fettsäuren essentiell für den Eintritt in den $\beta$-Oxidationszyklus und spielt eine wichtige Rolle bei der Aufnahme von exogenen Fettsäuren (Fulda et al., 2002, Zou et al., 2003). In S. cerevisiae wurden fünf Acyl-CoA-Synthetasen identifiziert: Faa1p, Faa2p, Faa3p, Faa4p und Fat1p (Duronio et al., 1992, Knoll et al., 1994, Johnson et al., 1994a, Watkins et al., 1998). FAA1 und FAA4 kodieren Acyl-CoA-Synthetasen, die an der Aktivierung importierter Fettsäuren beteiligt sind (Faergeman et al., 2001). Die Funktionen von Faa1p und Faa4p scheinen teilweise zu überlappen, wobei die messbare enzymatische Aktivität von Faalp deutlich dominanter ist. Das Fehlen einer dieser beiden Acyl-CoA-Synthetasen kann gleichwohl durch die Aktivität des jeweils anderen Enzyms kompensiert werden (Johnson et al., 1994a). Untersuchungen zeigten einen drastisch reduzierten Acyl-CoA-Pool in der faal $\Delta$ faa $4 \Delta$ Mutante im Vergleich zum Wildtyp (Faergeman et al., 2001). Demnach spielen Faa1p und Faa4p eine essentielle Rolle bei der Aufrechterhaltung des Acyl-CoA-Pools. FAA2 kodiert die einzige bekannte peroxisomale Acyl-CoA-Synthetase in S. cerevisiae, die an der Aktivierung endogener mittelkettiger Fettsäuren (MFCA) beteiligt ist (Knoll et al., 1994, Johnson et al., 1994a, Johnson et al., 1994b, Hettema et al., 1996). Über die biologische Funktion von Faa3p sind gegenwärtig keine Daten verfügbar. Als fünfte Acyl-CoA-Synthetase in S. cerevisiae wurde FAT1 identifiziert. Ursprünglich wurde FAT1 aufgrund hoher Sequenzhomologie zu einem humanen Fettsäuretransporter untersucht und ebenfalls als Transportprotein eingeordnet (Faergeman et al., 1997). Spätere Untersuchungen wiesen jedoch Acyl-CoASynthetase-Aktivität von Fat1p nach (Watkins et al., 1998). Fat1p besitzt demnach eine Präferenz für die Aktivierung sehr langkettiger Fettsäuren und ist am endoplasmatischen Retikulum und in den Lipidkörperchen lokalisiert (Natter et al., 2005).

\subsubsection{Fettsäuretransport durch die Plasmamembran in Saccharomyces cerevisiae}

Die Acyl-CoA-Synthetasen überführen hydrophobe Fettsäuren in die entsprechenden wasserlöslichen CoA-Ester. Aufgrund dieser Funktion wird den Acyl-CoA-Synthetasen eine Schlüsselrolle beim intrazellulären Fettsäuretransfer zwischen den Kompartimenten und bei der Aufnahme von exogenen Fettsäuren zugeschrieben. Die Beteiligung von Acyl-CoASynthetasen am Fettsäuretransport wurde zum ersten Mal durch das Modell der vektoriellen Acylierung in E. coli beschrieben. Demnach interagiert ein Fettsäuretransporter mit einer 
Acyl-CoA-Synthetase beim Transport von Fettsäuren (Overath et al., 1969). Auch bei S. cerevisiae wird eine derartige Kopplung des Imports durch Fat1p und Aktivierung der Fettsäuren über die Acyl-CoA-Synthetasen Faa1p und Faa4p diskutiert und in Anlehnung an das Modell aus E. coli ebenfalls als vektorielle Acylierung bezeichnet (Zou et al., 2003). Bei dem Modell der vektoriellen Acylierung in S. cerevisiae ist Fat1p direkt an der Aufnahme und Transport von Fettsäuren durch die Plasmamembran beteiligt. Dabei bilden Fat1p und die Acyl-CoA-Synthetase Faa1p oder Faa4p einen Komplex, bei dem begleitend mit der Trennung von der Membran, die Fettsäuren verestert und so für den weiteren Metabolismus zugänglich werden. Kritisch eingestuft wird das Modell angesichts der Tatsache, dass eine Assoziation von Fatlp mit der Plasmamembran bislang nicht nachgewiesen werden konnte. Ein alternatives Modell für den Transport der Fettsäuren durch biologische Membranen favorisiert einen passiven Mechanismus. Dieses Modell schlägt eine einfache Diffusion für den Transport von freien Fettsäuren vor, der durch einen sogenannten Flip-FlopMechanismus erfolgt (Kamp und Hamilton, 2006).

Unterschiedliche Ansätze zeigten den Einfluss von Acyl-CoA-Synthetasen auf den Fettsäuremetabolismus in Hefe. So konnte beispielsweise durch die Deletion von FAAl ein Fettsäuresekretions-Phänotyp induziert werden (Michinaka et al., 2003).

\subsubsection{Vorausgehende Arbeit}

Erste Untersuchungen in unserer Arbeitsgruppe zeigten, dass die alleinige Deletion von FAA1 nicht ausreicht, um den Fettsäuresekretions-Phänotyp zu induzieren. Vielmehr führt erst die kombinierte Deletion der Acyl-CoA-Synthetasen FAAl und FAA4 in S. cerevisiae zu einem massiven Fettsäuretransfer aus den Zellen in das umgebende Kulturmedium. Demnach ist die Aktivität von Faa1p oder Faa4p notwendig, um freie Fettsäuren während der exponentiellen Wachstumsphase dem Stoffwechsel der Zelle zu erhalten. Während der stationären Wachstumsphase wurde bei der faal $\Delta$ faa4 $\Delta$-Doppelmutante ein Re-Import der vorher sekretierten freien Fettsäuren sowie ein drastischer Anstieg der freien intrazellulären Fettsäuren beobachtet. Eine wichtige Erkenntnis unserer Studie war, dass, obwohl die postulierte Interaktion zwischen Fat1p und Faa1p oder Faa4p durch die Deletion von FAA1 und FAA4 unterbunden war, trotzdem eine Aufnahme exogener Fettsäuren während der stationären Phase stattfinden konnte. Die zusätzliche Deletion von FAT1 im Hintergrund der Doppelmutante faal $\Delta$ faa $4 \Delta$ führte zu keiner Änderung des zweiphasigen FettsäuretransportPhänotyps. Diese Ergebnisse widersprechen der These, dass Fat1p oder Faa1p und Faa4p eine 
essentielle Rolle beim Import exogener freier Fettsäuren spielen. Auch die Mutanten, bei denen sämtliche FAA-Gene inaktiviert wurden (YB526, MS51 und MS612), zeigten den gleichen Phänotyp. Dadurch konnte gezeigt werden, dass die Aufnahme exogener Fettsäuren unabhängig von jeglicher Acyl-CoA-Synthetase-Aktivität ist. Trotz drastischer Akkumulation von freien intrazellulären Fettsäuren in der faal $\Delta$ faa $4 \Delta$-Mutante, wurde keine gravierende Auswirkung auf das Wachstumsverhalten beobachtet. Weitergehende Untersuchungen zeigten, dass die akkumulierten Fettsäuren in den Zellen nicht der de novo-Synthese direkt entstammen, sondern vielmehr im Rahmen von Lipidabbau- oder Lipidumbau-Prozessen freigesetzt werden. Den Acyl-CoA Synthetasen Faa1p und Faa4p kann somit eine Rolle beim Recycling von freigesetzten endogenen Fettsäuren zugeordnet werden (Scharnewski et al., 2008).

\subsection{Fettsäuretransport durch die peroxisomale Membranen}

\subsubsection{Peroxisomen}

Peroxisomen sind multifunktionelle Organellen eukaryotischer Zellen, die weder eigene Ribosomen noch DNA enthalten und von einer einfachen Doppelmembran umgeben sind. Die Größe, Anzahl und der Proteingehalt der Peroxisomen werden hauptsächlich durch den Organismus, den Zelltyp und exogene Faktoren bestimmt (van den Bosch et al., 1992, Veenhuis und Harder, 1988, Veenhuis et al., 2003). Charakteristisch für Peroxisomen ist die Vielzahl an Matrix-Enzymen, die entsprechend in vielen verschiedenen Stoffwechselwegen und Entgiftungsreaktionen eingebunden sind. In Pflanzenzellen sind die Peroxisomen unter anderem an der Biosynthese von Phytohormonen und der Photorespiration sowie am Glyoxylatzyklus beteiligt, während sie in Säugerzellen an der Plasmalogenbiosynthese und der Gallensäuresynthese beteiligt sind (van den Bosch et al., 1992, Theodoulou et al., 2006). Eine wichtige peroxisomale Funktion in Hefezellen ist der Abbau von Methanol (Veenhuis, 1992). Unabhängig von diesen verschiedenen Stoffwechselfunktionen in unterschiedlichen Organismen sind vermutlich alle Peroxisomen zur $\beta$-Oxidation von Fettsäuren fähig. Während in menschlichen Zellen der Abbau der Fettsäuren verteilt in Peroxisomen und Mitochondrien stattfindet, beschränkt sich die $\beta$-Oxidation in Pflanzen und Hefen ausschließlich auf die Peroxisomen (Kunau et al., 1988). Ein weiteres charakteristisches Merkmal der Peroxisomen ist die Induzierbarkeit der Proliferation und des Metabolismus. Diese Fähigkeit ermöglicht z.B. ein schnelles Anpassen des Organismus an sich ändernde 
metabolische Erfordernisse. Dementsprechend wird je nach Bedarf die Anzahl, Größe und der Proteingehalt von Peroxisomen durch Induktion der ändernden Umgebung angepasst. Die Proliferation der Peroxisomen von Hefen wird unter anderem durch Methanol, Alkane und Ölsäure induziert (Veenhuis et al., 1987). Aufgrund dieser Anpassungsfähigkeit ist die Hefe S. cerevisiae in der Lage auf einem Medium zu wachsen, das Ölsäure (C18:1) als einzige Kohlenstoffquelle enthält (Erdmann et al., 1989). Diese Wachstumsbedingung führt zu einer verstärkten Proliferation von Peroxisomen und einem drastischen Anstieg der Expression von Genen, die peroxisomale Proteine kodieren. In Gegenwart von Glukose werden dagegen die Gene mit peroxisomalen Funktionen reprimiert (Gurvitz und Rottensteiner, 2006). Da sich der Abbau langkettiger Fettsäuren durch $\beta$-Oxidation bei Hefe ausschließlich auf die Peroxisomen beschränkt, sind die Zellen bei der Verwertung von Ölsäure als einzige Kohlenstoffquelle auf ein intaktes $\beta$-Oxidationssystem angewiesen. Beinhaltet das Kulturmedium Glukose, so sind funktionelle Peroxisomen für die Hefen verzichtbar (Erdmann et al., 1989). Für die Identifikation und Charakterisierung noch unbekannter peroxisomaler Proteine werden diese Eigenschaften der Hefen genutzt. So können Hefe-Mutanten mit Einschränkungen in der $\beta$ Oxidation oder peroxisomalen Biogenese durch einen Wachstumsdefekt auf Ölsäure identifiziert werden (Erdmann et al., 1989).

\subsubsection{Biogenese von Peroxisomen}

Die ersten Modelle zur Biogenese von Peroxisomen basierten auf elektronenmikroskopischen Analysen, die einen engen Kontakt zwischen Peroxisomen und dem Endoplasmatischen Retikulum (ER) zeigten. Aufgrund dieser morphologischen Untersuchungen wurde von einer direkten Abschnürung der Peroxisomen vom ER ausgegangen (Novikoff und Novikoff, 1972). Nachfolgende Untersuchungen zeigten, dass die Matrix- und Membranproteine im Zytosol an freien Polyribosomen synthetisiert und posttranslational in die Peroxisomen importiert werden (Rachubinski et al., 1984). Daraus resultierend wurde von autonomen Organellen ausgegangen, die sich wie Chloroplasten oder Mitochondrien durch Wachstum und Teilung vermehren (Lazarow und Fujiki, 1985). Unterstützt wurde diese These durch die Entdeckung von peroxisomalen Erkennungssignalen (PTS1 und PTS2) und der damit verbundenen eigenen Protein-Import-Maschinerie. Durch die peroxisomale Erkennungssignale (PTS1 und PTS2) werden Matrixproteine von Peroxinen erkannt und anschließend in die Peroxisomen importiert (Subramani, 1998). Allerdings haben neuere Studien eine Abschnürung der Peroxisomen vom ER eindeutig belegen können (Hoepfner et 
al., 2005). Aufgrund dieser und weiterführender Studien wurden neue modifizierte Modelle zur Biogenese der Peroxisomen vorgeschlagen. Diesen Modellen zu Folge schnüren sich präperoxisomale Vesikel vom ER ab, die dann $\mathrm{zu}$ einer Organelle fusionieren und sich ihrerseits über Wachstum und Teilung vermehren (Titorenko und Mullen, 2006, Tabak et al., 2006, Hettema und Motley, 2009).

\subsubsection{Metabolitentransport durch die peroxisomale Membran}

Die Beteiligung der Peroxisomen an zahlreichen Stoffwechselwegen erfordert einen regulierten Import und Export von Metaboliten durch die peroxisomale Membran. Für den Transport von Metaboliten besitzen die Peroxisomen eine Vielzahl von spezialisierten Transportsystemen. Ein Beispiel für spezialisierte Transporter stellen die Mitglieder der Superfamilie von ABC-Transporter dar. So wurden in Hefen, Pflanzen und Säugetieren peroxisomale ABC-Transporter identifiziert, die eine essentielle Funktion bei der Aufnahme von Fettsäuren im Zuge der $\beta$-Oxidation haben.

\subsubsection{Peroxisomale ABC-Transporter}

Die ABC-Transporter bilden eine große Familie von strukturell ähnlichen Proteinen, die unter anderem durch die Existenz einer ATP-Bindungsdomäne charakterisiert sind. Es handelt sich um Transmembranproteine, die einen meist unidirektionalen aktiven Transport verschiedenster Substrate durch die biologischen Membranen vermitteln. Die für den Transport notwendige Energie wird aus der Hydrolyse von ATP gewonnen (Dean und Annilo, 2005). Charakteristisch für die ABC-Proteine ist ihr Aufbau aus vier funktionellen Domänen. Dazu gehören zwei Transmembrandomänen (TMD) mit mehreren $\alpha$-Helices, die den eigentlichen Transportweg bilden, sowie zwei Nukleotid-Bindungsdomänen (NBD). In eukaryoten Zellen besteht ein ABC-Transporter entweder aus einem einzelnen Protein mit der Topologie TMD-NBD-TMD-NBD (NBD-TMD-NBD-TMD) und wird in diesem Fall als Volltransporter bezeichnet, oder er setzt sich aus zwei sogenannten Halbtransportern mit der Topologie TMD-NBD (NBD-TMD) zusammen. Durch Dimerisierung können zwei Halbtransporter einen funktionalen Transporter bilden (Rottensteiner und Theodoulou, 2006, Theodoulou et al., 2006). Basierend auf der Sequenzhomologie zwischen den NukleotidBindungsdomänen (NBD) werden die ABC-Transporter in verschiedene Subfamilien unterteilt. Jedes Mitglied einer Subfamilie besitzt normalerweise dieselbe Domänenstruktur 
(Dean et al., 2001, Theodoulou et al., 2006). Peroxisomale ABC-Transporter gehören der Subfamilie D an. Bis auf einen pflanzlichen Vertreter sind alle anderen Mitglieder der Subfamilie D Halbtransporter mit der Domänenstruktur TMD-NBD (Dean et al., 2001).

\subsubsection{Peroxisomale ABC-Transporter aus Saccharomyces cerevisiae}

In der Hefe S. cerevisiae wurden Pat1p (Pxa2p) und Pat2p (Pxa1p) als peroxisomale ABCTransporter der Subfamilie D identifiziert (Bossier et al., 1994, Shani et al., 1995). Pat1p und Pat2p sind integrale Membranproteine und bilden zusammen durch Heterodimerisierung einen funktionalen Transporter (Hettema et al., 1996). Für die Aufklärung der Funktionalität von Pat1p-Pat2p wurde die Eigenschaft der Hefe S. cerevisiae genutzt, auf einem Medium zu wachsen, das Fettsäuren als einzige Kohlenstoffquelle enthält (Erdmann et al., 1989). Die Einzelmutanten pat $1 \Delta$ und pat $2 \Delta$ und die Doppelmutante pat1 1 pat $2 \Delta$ zeigten ein eingeschränktes Wachstum und eine stark reduzierte $\beta$-Oxidation auf Medium mit Ölsäure (C18:1) als einziger Kohlenstoffquelle. Das Zelllysat dieser Mutanten zeigte dagegen keine Störung der $\beta$-Oxidation. Diese Studien führten zu der Annahme, dass Pat1p-Pat2p am Transport von Fettsäuren in das peroxisomale Lumen beteiligt sei (Hettema et al., 1996). Interessanterweise wurden bei den Transporter-Mutanten keine deutlichen Einschränkungen der $\beta$-Oxidation auf Medium mit mittelkettigen Fettsäuren (MCFA) nachgewiesen. Demnach könnte der Fettsäuretransport durch die peroxisomale Membran über zwei voneinander unabhängige Mechanismen erfolgen. Dabei wird unterschieden zwischen dem Pat1p-Pat2p abhängigen Transport von langkettigen Fettsäuren (LCFA) und dem Pat1p-Pat2p unabhängigen Transport von mittelkettigen Fettsäuren (MCFA) (Visser et al., 2007). Unterstützt wurde diese Hypothese durch weiterführende Studien mit der faa2 $\Delta$-Mutante. Faa2p ist die einzige bekannte peroxisomale Acyl-CoA-Synthetase in S. cerevisiae und ist an der Aktivierung endogener MFCAs beteiligt (Knoll et al., 1994, Johnson et al., 1994b,

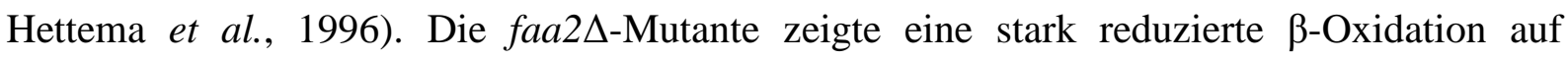
Medium mit MFCAs. Dagegen wurde keine Einschränkung der $\beta$-Oxidation auf Medium mit langkettigen Fettsäuren Ölsäure (C18:1) oder Palmitinsäure (C16:0) nachgewiesen. Zusätzliche Messungen mit der Doppelmutante pat $1 \Delta$ faa2 $\Delta$ zeigten weder auf MCFAs noch auf LCFAs detektierbare $\beta$-Oxidation. Um genauere Details über die Funktionalität von Pat1p-Pat2p zu bekommen, wurde Faa2p durch Entfernen des peroxisomalen Targeting-

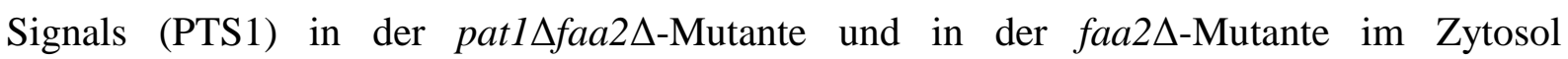
fehllokalisiert. Die anschließenden $\beta$-Oxidation-Aktivitätsmessungen auf Medium mit 
Laurinsäure (C12:0) zeigten, dass unter diesen Bedingungen der Import von mittelkettigen, aktivierten Fettsäuren in die Peroxisomen von Pat1p-Pat2p abhängig ist (Hettema et al., 1996, Verleur et al., 1997, van Roermund et al., 2008). Der Transportmechanismus für den Import von freien Fettsäuren in das peroxisomale Lumen ist weitestgehend unbekannt (Hettema et al., 1996, Theodoulou et al., 2006). Beide postulierten Transportwege für Fettsäuren in die Peroxisomen sind in der Abb. 1 dargestellt.

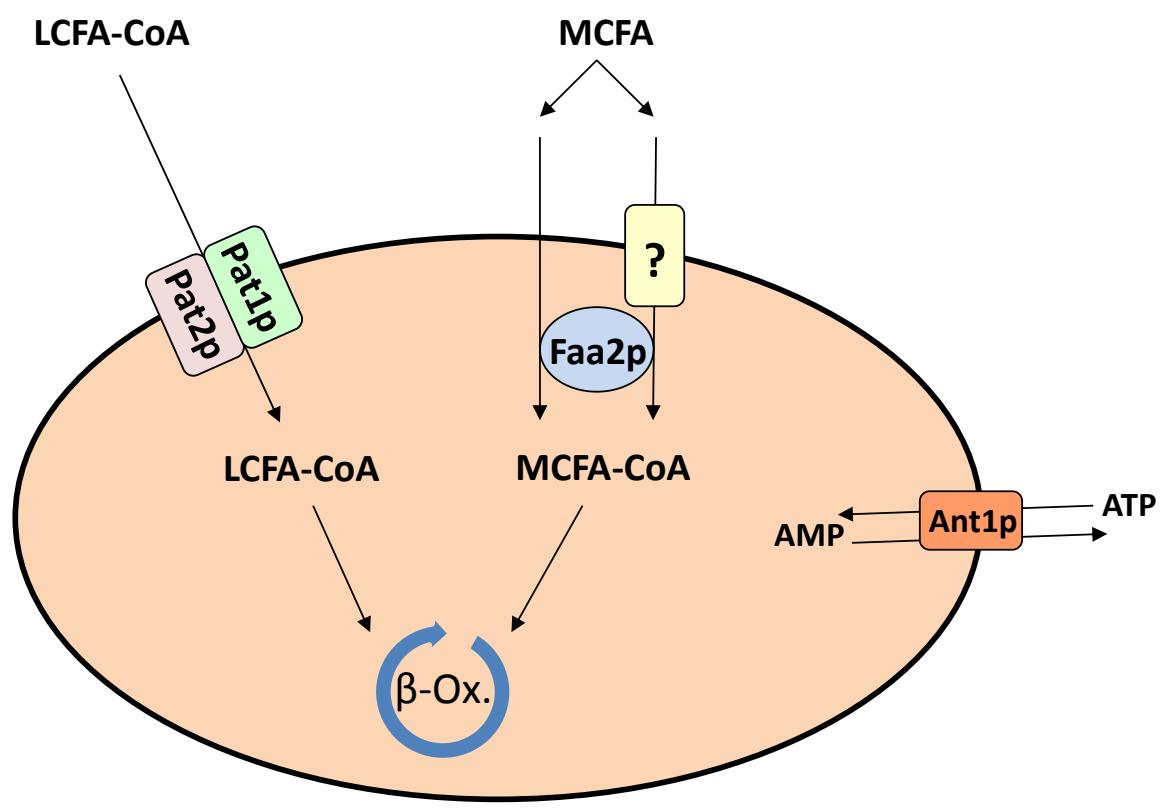

Abb. 1: Modell zum Fettsäuretransport durch die peroxisomale Membran in S. cerevisiae (Hettema et al., 1996). Der Transportweg der Fettsäuren über die peroxisomale Membran ist in Hefe abhängig von der Kettenlänge der Fettsäuren. Langkettige Fettsäuren (LCFA) werden im Zytosol von Acyl-CoA-Synthetasen aktiviert und anschließend als Acyl-CoA-Ester durch Pxa1p-Pxa2p in die peroxisomale Matrix transportiert. Mittelkettige Fettsäuren (MCFA) passieren die peroxisomale Membran entweder durch einfache Diffusion oder einen unbekannten Transporter. Die Aktivierung der mittelkettigen Fettsäuren erfolgt durch die peroxisomalen Acyl-CoA-Synthetase Faa2p. Für den Transport von ATP ist Ant1p verantwortlich.

\subsubsection{Peroxisomale ABC-Transporter aus Säugern}

In Säugetieren sind vier peroxisomale ABC-Transporter identifiziert worden: ALDP (ABCD1), ALDR (ABCD2), PMP70 (ABCD3) und PMP69 (ABCD4) (Mosser et al., 1993, Lombard-Platet et al., 1996, Kamijo et al., 1990, Holzinger et al., 1997). Besonders umfangreiche Untersuchungen wurden für ALDP (ABCD1) durchgeführt, da für dieses Protein ein Zusammenhang mit der neurodegenerativen Krankheit Adrenoleukodystrophie nachgewiesen werden konnte. Die Adrenoleukodystrophie (X-ALD) ist eine X-chromosomal vererbte peroxisomale Stoffwechselerkrankung, bei der typischerweise das zentrale 
Nervensystem und die Nebennierenrinde befallen werden. Mutationen im ALDP-Gen sind Auslöser für X-ALD. Bei dieser Krankheit kommt es aufgrund der gestörten peroxisomalen $\beta$-Oxidation zu einer Anhäufung von sehr langkettigen Fettsäuren (VLCFA) im Gehirn, Plasma, Fibroplasten und in der Nebennierenrinde (Moser et al., 1981). Besonders die Akkumulation von langkettigen Fettsäuren (VLCFA) im Plasma hat große Bedeutung bei der Diagnoseerstellung von X-ALD (Kemp und Wanders, 2007).

Das Gen ALDP kodiert für 745 Aminosäuren, die ein integrales peroxisomales Membranprotein mit einer zytosolischen ATP-Bindungsdomäne ausbilden (Mosser et al., 1994, Watkins et al., 1994). Komplementations-Experimente mit dem homologen ALDP-Gen in Fibroplasten von Patienten mit X-ALD wurden erfolgreich durchgeführt. Die Expression von $A L D P$ führte bei diesen Experimenten zur Wiederherstellung einer funktionsfähigen $\beta$ Oxidation von VLCFAs (Shinnoh et al., 1995) und einer Reduktion des abnormen VLCFAGehalts auf Wildtyp-Niveau (Cartier et al., 1995). Dieses Ergebnis unterstützt die These, dass Mutationen im ALDP-Gen Auslöser für X-ALD sind (Cartier et al., 1995, Braiterman et al., 1999). Eine große Varianz an verschiedenen Mutationstypen wurde im Zusammenhang mit X-ALD beschrieben (Smith et al., 1999, Kemp et al., 2001, Dodd et al., 1997). Den größten Anteil stellen dabei Missense-Mutationen dar, die einen Effekt auf wichtige funktionelle Domänen haben (Smith et al., 1999). In der ATP-Bindungsdomäne (NBD) lokalisierte Missense-Mutationen können sich z.B. negativ auf die ATP-Bindungskapazität oder die ATPase-Aktivität auswirken (Roerig et al., 2001). Bestimmte Mutationen verursachen sogar ein komplettes Fehlen von ALDP (Watkins et al., 1995). Interessanterweise gibt es bei XALD jedoch keine generelle Korrelation zwischen dem Mutationstyp und dem Phänotyp (Smith et al., 1999, Kemp et al., 2001). So führt das Fehlen von ALDP bei verschiedenen Patienten zu sehr unterschiedlichen Phänotypen. Zudem wurde das Fehlen von Symptomen oder auch ein sehr spätes Einsetzen des Krankheitsbeginns bei Knockout-Mäusen beobachtet (Lu et al., 1997, Forss-Petter et al., 1997, Kobayashi et al., 1997).

Die biochemische Funktion von ALDP konnte bis heute nicht eindeutig geklärt werden. Die vermutete Funktion von ALDP als Transporter für freie VLCFAs oder mit CoA veresterte VLCFAs basiert auf der peroxisomalen Fehlfunktion, die den Transport von VLCFAs oder VLCFA-CoAs vom Zytoplasma in das peroxisomale Lumen verhindert und dadurch eine Anhäufung von VLCFAs verursacht (Berger und Gartner, 2006). In einer weiteren Hypothese wurde ALDP mit einer direkten Beteiligung am Transport oder der Stabilisierung von VLACS (Acyl-CoA-Synthetase mit einer Substratspezifität für sehr langkettige Fettsäuren) in Verbindung gebracht (Mosser et al., 1993, Smith et al., 1999, Contreras et al., 1994). Der 
Nachweis von immunoreaktiver VLACS in der peroxisomalen Matrix von X-ALDFibroplasten aus Menschen und Mäusen deutete darauf hin, dass ALDP weder eine Funktion als Transporter noch als Stabilisator des VLACS-Proteins besitzt (Yamada et al., 1999, Steinberg et al., 1999, Smith et al., 2000). Mehrere Untersuchungen beschäftigten sich mit der Frage, ob zwischen ALDP und VLACS eine funktionelle Interaktion besteht und inwieweit die Akkumulation von VLCFAs von der $\beta$-Oxidation-Aktivität abhängt. Untersuchungen mit Mäusen zeigten eine normal ablaufende $\beta$-Oxidation in verschiedenen XALD-Zellen, obwohl VLCFAs akkumulierten (McGuinness et al., 2003). Dieses Ergebnis widersprach der Hypothese, dass die Anhäufung von VLCFAs durch eine eingeschränkte $\beta$ Oxidation verursacht wird. In Mäusen ohne peroxisomaler VLACS wurde zwar eine um 50 \% reduzierte $\beta$-Oxidation festgestellt, jedoch keine Zunahme des VLCFA-Gehalts (Heinzer et $a l ., 2003)$. Die Expression von VLACS in X-ALD-Zellen führte zu einer erhöhten $\beta$-Oxidation (Heinzer et al., 2002). Demzufolge sind die peroxisomale $\beta$-Oxidation und die Akkumulation von VLCFAs nicht miteinander gekoppelt. Folglich hat ALDP keinen direkten Einfluss auf die VLACS-Aktivität und der VLCFA-Spiegel wird nicht durch eine direkte Wechselwirkung zwischen VLACS und ALDP reguliert (Theodoulou et al., 2006). Gestützt wurde diese Hypothese durch die Entdeckung einer verstärkten Elongation von Fettsäuren in Fibroplasten mit einer gestörten Biogenese von Peroxisomen oder in X-ALD-Fibroplasten (Tsuji et al., 1984, Koike et al., 1991, Berger und Gartner, 2006). Die nachgewiesene erhöhte Elongation von gesättigten und einfach ungesättigten Fettsäuren führen zur Akkumulation von VLCFAs (Kemp et al., 2005). Der Zusammenhang zwischen einer Mutation im ALDP-Gen und der erhöhten Elongation der Fettsäuren ist weitestgehend ungeklärt. Insgesamt ist die Datenlage bezüglich ALDP teilweise sehr widersprüchlich und die eigentliche Funktion nicht vollständig aufgeklärt.

Für ein besseres Verständnis der Funktionalität von ALDP wurde Hefe als Modellsystem herangezogen. Aufgrund der hohen Sequenzhomologien zwischen den hefeeigenen Proteinen Pat1p und Pat2p und dem humanen ALDP wurde auch für ALDP eine Funktion als Transporter von Acyl-CoA-Estern vermutet. Die Hefe-Doppelmutante pat1 $\Delta$ pat $2 \Delta$ zeigt auf Ölsäure eine deutlich eingeschränkte $\beta$-Oxidationskapazität sowie ein reduziertes Wachstum. Die heterologe Expression des ABC-Transporters ALDP in der Hefe-Doppelmutante

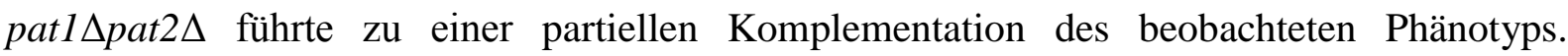
Insbesondere führte die Zugabe der Fettsäuren Palmitinsäure (C16:0), Ölsäure (C18:1), Behensäure (C22:0) und Tetracosahexaensäure (C24:6) zu einer hohen $\beta$-Oxidations-Aktivität in der mit $A L D P$ transformierten pat1 $\triangle$ pat $2 \Delta$-Mutante. Diese hohe $\beta$-Oxidations-Aktivität in 
Gegenwart dieser Fettsäuren weist auf eine mögliche Substratspezifität von ALDP für diese Fettsäuren hin (van Roermund et al., 2008). Insgesamt betrachtet, deuten die Beobachtungen auf eine Beteiligung von ALDP am Transport von Acyl-CoA-Estern durch die peroxisomale Membran hin.

Die Funktionen der anderen drei peroxisomalen ABC-Transporter in Säugetieren sind weitestgehend ungeklärt. PMP70 (ABCD3) war der erste identifizierte peroxisomale $\mathrm{ABC}$ Transporter, der hauptsächlich in der Leber exprimiert wird (Kamijo et al., 1990). Die Überexpression von PMP70 in CHO-Zellen (Zellen aus den Ovarien chinesischer Hamster) zeigte eine erhöhte peroxisomale $\beta$-Oxidation von langkettigen Fettsäuren (LCFA). Diese Studien belegten eine Beteiligung von PMP70 am Transport langkettiger Fettsäuren durch die peroxisomale Membran (Imanaka et al., 1999). Andere Untersuchungen führten zu der Annahme, dass PMP70 am Transport von 2-Methylacyl-CoA-Ester beteiligt sein könnte (Jimenez-Sanchez, 2000). Studien über die Funktionalität von PMP69 (ACBD4) sind gegenwärtig nicht bekannt.

ALDRP (ABCD2) zeigt eine deutliche Sequenzhomologie zu ALDP (88 \% ähnliche und $67 \%$ identische AS) und wird hauptsächlich im Gehirn und Herz exprimiert (Lombard-Platet et al., 1996, Holzinger et al., 1997). Durch Überexpressionen von ALDRP in Aldp(-/-) Mäusen und humanen X-ALD-Fibroplasten konnte der VLCFA-Spiegel normalisiert werden (Ferrer et al., 2005, Pujol et al., 2004). Aufgrund dieser Studien und der hohen Sequenzhomologie wird von einer überlappenden Funktion von ALDP und ALDRP ausgegangen. Demnach könnten ALDP und ALDRP identische Funktionen besitzen, die aber in unterschiedlichen Zelltypen wirksam werden (Ferrer et al., 2005, Pujol et al., 2004).

Die peroxisomalen Halbtransporter bilden durch Dimerisierung einen funktionellen Transporter (Rottensteiner und Theodoulou, 2006, Theodoulou et al., 2006). Ob diese hauptsächlich Homodimere oder mit einem zelltypspezifischen Partner Heterodimere bilden, konnte noch nicht eindeutig geklärt werden. Durch mehrere Studien wurden sowohl Homodimerisierung als auch Heterodimerisierung von ALDP, ALDRP und PMP70 in vitro nachgewiesen (Smith et al., 1999, Tanaka et al., 2002). Aufgrund der sehr unterschiedlichen Expressionsmuster in den verschiedenen Geweben wird eine Heterodimierisierung in vivo jedoch für unwahrscheinlich gehalten (Lombard-Platet et al., 1996, Troffer-Charlier et al., 1998, Ferrer et al., 2005). Weitere Studien zeigten, dass ALDP und PMP70 hauptsächlich als Homodimere in der peroxisomalen Membran vorliegen (Guimaraes et al., 2004, Hillebrand et al., 2007, van Roermund et al., 2008). 


\subsubsection{Peroxisomale ABC-Transporter aus Arabidopsis thaliana}

In Arabidopsis thaliana wurde PXA1 als peroxisomaler ABC-Transporter der Subfamilie D identifiziert. PXA1 ist auch unter den Namen CTS (COMATOSE), PED3 und ACN2 bekannt (Zolman et al., 2001, Footitt et al., 2002, Hayashi et al., 2002, Hooks et al., 2007). Im Gegensatz zu peroxisomalen ABC-Transportern aus Säugetieren oder Hefen kodiert PXAl einen Volltransporter mit der Topologie TMD-NBD-TMD-NBD. Beide Hälften des Proteins sind jeweils ungefähr zu $35 \%$ identisch mit dem humanen peroxisomalen ABC-Transporter ALDP. Vieles spricht für eine konservierte Proteinstruktur von peroxisomalen ABCTransportern in Pflanzen. Beispielsweise zeigen zwei peroxisomale Volltransporter aus Oryza sativa ebenfalls eine hohe Sequenzhomlogie zu ALDP (Garcia et al., 2004). Weitere peroxisomale Volltransporter werden aufgrund von Sequenzhomologie in Hordeum vulgare und anderen Gräsern vermutet (Theodoulou et al., 2006, Dietrich et al., 2009).

PXA1 wurde durch mehrere unabhängige Untersuchungen identifiziert. Die ped3- und die pxal-Allele von PXAl wurden aufgrund ihrer Resistenz gegenüber 2,4Dichlorphenoxybutyrat (2,4-DB) und Indol-3-Buttersäure (IBA) isoliert (Hayashi et al., 1998, Zolman et al., 2001, Hayashi et al., 2002). Analog zur $\beta$-Oxidation von Fettsäuren durchlaufen IBA und 2,4-DB ebenfalls einen Zyklus der $\beta$-Oxidation. Durch die Verkürzung um zwei Kohlenstoffatome wird 2,4-DB bzw. IBA zu 2,4-Dichlorphenoxyessigsäure (2,4-D) bzw. Indol-3-Essigsäure (IAA) umgewandelt. Das Auxin IAA und das Herbizid 2,4-D (synthetisches Auxin) sind Wachstumsregulatoren, die in erhöhten Konzentrationen das Streckungswachstum der Wurzeln hemmen. Aufgrund einer unterbrochenen $\beta$-Oxidation kann in der ped3- und pxal-Mutante kein IAA bzw. 2,4-D gebildet werden und somit unterbleibt die wachstumshemmende Wirkung dieser beiden Substanzen. Aufgrund verhinderter $\beta$-Oxidation sind beide Mutanten nicht in der Lage das im Samen gespeicherte Samenöl für die Keimlingsentwicklung $\mathrm{zu}$ nutzen und sind daher für die Keimlingsetablierung auf den Zusatz von Zucker im Medium angewiesen (Zolman et al., 2001, Baker et al., 2006).

Für das cts-Allel von PXA1 wurde zusätzlich zu den beschriebenen Eigenschaften der anderen Mutantenallele eine verhinderte Keimung aufgrund verstärkter Dormanz festgestellt. Die Keimung und Etablierung der Keimlinge ließ sich nur durch mechanische Behandlung der Samen und Zugabe von Saccharose in das Wachstumsmedium erreichen (Russell et al., 2000). Die Gründe für die unterschiedliche Auswirkung der einzelnen Mutantenallele auf die Dormanz sind bislang nicht aufgeklärt. Des Weiteren wurde durch elektronenmikroskopische 
Untersuchungen an Kotyledonen bei ctsl-Keimlingen ein eingeschränkter Abbau der Speicherlipide nachgewiesen. Ebenfalls wurde in der cts1-Mutante ein erhöhter Acyl-CoASpiegel festgestellt, wobei insbesondere erhöhte Mengen an 20:0-CoA, 20:1-CoA und 22:0CoA detektiert wurden. Arachinsäure (C20:0), Eicosensäure (C20:1) und Erucasäure (C22:1) sind typische Marker für Speicherlipide in A. thaliana (Footitt et al., 2002). Eine Anhäufung von Acyl-CoA wurde darüber hinaus auch in anderen $\beta$-Oxidations-Mutanten beobachtet (Theodoulou et al., 2006). Basierend auf diesen Ergebnissen wird eine Beteiligung von PXA1 am Transport von Acyl-CoAs oder Fettsäuren vermutet.

Neben dem Transport über die peroxisomale Membran ist außerdem die Aktivierung der Fettsäuren durch Esterifizierung mit $\mathrm{CoA}$ essentiell für den Eintritt in den $\beta$ Oxidationszyklus. In A. thaliana wurden LACS6 und LACS7 als peroxisomale Acyl-CoASynthetasen identifiziert (Fulda et al., 2002). Die lacs6 lacs7-Doppelmutante zeigte analog zu der cts1-Mutante einen eingeschränkten Abbau der Speicherlipide und der damit verbundenen Blockade in der Keimlingsentwicklung, sowie eine Akkumulation von VLCFA-CoAs. Demnach findet offensichtlich eine Fettsäureaktivierung nach erfolgtem Transport in die Peroxisomen statt und es sind sowohl die peroxisomalen Acyl-CoA-Synthetasen LACS6/LACS7, als auch der PXA1-Transporter für den Abbau von Fettsäuren essentiell. Dieses Ergebnis steht im Gegensatz zu den Beobachtungen in Hefe, wo die intraperoxisomale Aktivierung der Fettsäuren für die $\beta$-Oxidation nicht essentiell ist. Diese Daten deuten möglicherweise auf einen unterschiedlichen Mechanismus des ABC-Transporters in Pflanzen und Hefe hin. Es ist daher weiterhin schwierig den einzelnen Proteinkomponenten im pflanzlichen System eine exakte Rolle bei der Einleitung des Fettsäureabbaus zuzuweisen. Eine Möglichkeit wäre eine Beteiligung von PXA1 am Transport von freien Fettsäuren und die dadurch erforderliche Aktivierung innerhalb der Peroxisomen durch LACS6/LACS7 (Abb. 2). Alternativ könnte der Transport von Fettsäuren durch die peroxisomale Membran über zwei unabhängige Wege ablaufen. Demnach ist PXA1 am Transport von Acyl-CoAs beteiligt, während freie Fettsäuren durch einen unbekannten Transportmechanismus in die Peroxisomen gelangen und anschließend durch LACS6/LACS7 aktiviert werden müssen (Fulda et al., 2002, Fulda et al., 2004). Bislang konnte noch nicht nachgewiesen werden, ob eine direkte Wechselwirkung zwischen PXA1 und LACS6/LACS7 für den Import von Fettsäuren notwendig ist.

Eine weitere postulierte Funktion von PXA1 ist die Beteiligung an der Synthese von Jasmonsäure (JA) (Theodoulou et al., 2005). Die Synthese von JA beginnt in den Chloroplasten, wo die aus der chloroplastidären Membran stammende $\alpha$-Linolensäure (C18:3) 
zu 12-Oxophytodiensäure (OPDA) umgewandelt wird. Anschließend wird OPDA aus den Chloroplasten exportiert und unter Beteiligung von PXA1 in die Peroxisomen importiert. Dort wird OPDA reduziert und danach durch die $\beta$-Oxidation zu JA umgewandelt (Schaller et al., 2000). Aufgrund der Detektierbarkeit reduzierter Mengen von JA in der ctsl-Mutante wird eine zusätzliche Möglichkeit der Aufnahme für die Vorstufen von JA in die Peroxisomen vermutet (Theodoulou et al., 2005).

Weitere Studien zeigten eine Beteiligung von PXA1 am Import von Acetat in die Peroxisomen. Das importierte Acetat wird nach dem Import in den Glyoxylatzyklus überführt (Hooks et al., 2007). Alle Studien zusammengefasst lässt ein breites Substrat-Spektrum von PXA1 vermuten.

Neben der Etablierung des Keimlings spielt die $\beta$-Oxidation in Pflanzen auch eine wichtige Rolle während der natürlichen Seneszenz. Darüber hinaus zeigten Microarray-Experimente einen erhöhten Transkriptgehalt von PXAl und vieler an der $\beta$-Oxidation beteiligter Gene auch während dunkelheitinduzierter Seneszens (Buchanan-Wollaston et al., 2005, van der Graaff et al., 2006). 


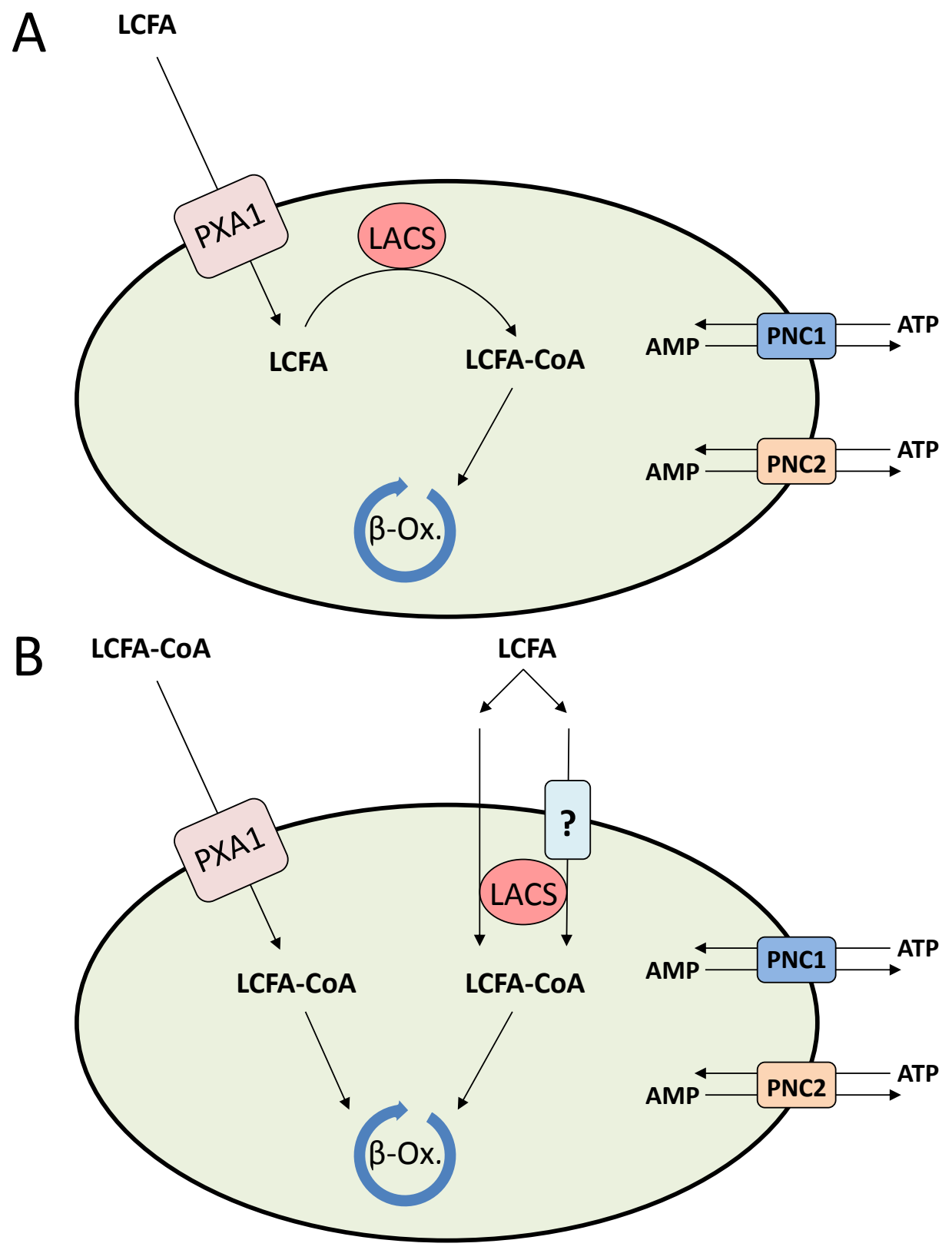

Abb. 2: Modelle zum Fettsäuretransport durch die peroxisomale Membran in A. thaliana (Fulda et $\boldsymbol{a l . ,}$ 2002, Fulda et al., 2004). (A) Der Transport der langkettigen Fettsäuren (LCFA) über die peroxisomale Membran erfolgt durch den ABC-Transporter PXA1. Die Aktivierung der langkettigen Fettsäuren in der peroxisomalen Matrix erfolgt durch eine peroxisomale Acyl-CoA-Synthetase (LACS). Für den Transport von ATP sind PNC1 und PNC2 verantwortlich. (B) Alternativ könnte der Transport von Fettsäuren durch die peroxisomale Membran über zwei unabhängige Wege ablaufen. Demnach ist PXA1 am Transport von aktivierten Fettsäuren (LCFA-CoA) beteiligt, während freie Fettsäuren (LCFA) durch einen unbekannten Transportmechanismus in die Peroxisomen gelangen und anschließend durch eine Acyl-CoA-Synthetase (LACS) aktiviert werden. Der Transport von ATP erfolgt durch PNC1 und PNC2. 


\subsection{Stoffwechselfunktionen von Peroxisomen}

\subsubsection{Stoffwechselfunktionen von Peroxisomen in Saccharomyces cerevisiae}

Die Hefe S. cerevisiae ist in der Lage auf verschiedenen Kohlenstoffquellen zu wachsen. Eine Kultivierung von Hefen auf Medium mit Fettsäuren als einziger Kohlenstoffquelle hat einen positiven Effekt auf die Transkription von Genen, die Proteine der $\beta$-Oxidation kodieren. (Kunau et al., 1988). In Hefen beschränkt sich der Abbau von Fettsäuren durch $\beta$ Oxidation ausschließlich auf die Peroxisomen (Kunau et al., 1988). Die $\beta$-Oxidation ist ein zyklischer Prozess bestehend aus vier Reaktionsschritten, die in S. cerevisiae durch drei Proteine ausgeführt werden (Hiltunen et al., 2003). Bevor die Fettsäure in den $\beta$ Oxidationszyklus eintritt, muss diese durch Esterifizierung mit CoA aktiviert werden Der erste Schritt des Zyklus, die Oxidation von Acyl-CoA, wird durch die Acyl-CoA-Oxidase Fox1p (Pox1p) durchgeführt. Dabei wird FAD zu FADH 2 reduziert. Anschließend wird durch Hydratisierung trans- $\Delta^{2}$-Enoyl-CoA zu 3-Hydroxyacyl-CoA durch das bifunktionelle Enzym Fox2p (Mfe2p) umgewandelt. Fox2p (Mfe2p) ist auch verantwortlich für den nächsten Schritt, wobei 3-Hydroxyacyl-CoA zu 3-Ketoacyl-CoA katalysiert wird. Dabei wird $\mathrm{NAD}^{+} \mathrm{zu}$ $\mathrm{NADH}+\mathrm{H}^{+}$reduziert. Abschließend wird durch die Thiolase Fox3p (Pot1p) 3-Ketoacyl-CoA in Acetyl-CoA und ein um zwei Kohlenstoffatome verkürztes Acyl-CoA umgewandelt (Dmochowska et al., 1990, Qin et al., 1999, Hiltunen et al., 2003). S. cerevisiae ist in der Lage ungesättigte Fettsäuren mit cis- und trans-Konfiguration abzubauen (Gurvitz et al., 2001). Für den Abbau von ungesättigten Fettsäuren werden zusätzliche Enzyme benötigt. Beim Abbau von ungesättigten Fettsäuren entstehen für die $\beta$-Oxidation zunächst nicht direkt abbaubare Intermediate, die erst durch zusätzliche Isomerisierung wieder in den $\beta$-OxidationZyklus eintreten können. In $S$. cerevisiae sind Ecilp $\left(\Delta^{3}-\Delta^{2}\right.$-Enoyl-CoA-Isomerase) und Dcilp $\left(\Delta^{3,5}-\Delta^{2,4}\right.$ - Dienoyl-CoA-Isomerase) für die Isomerisierung zuständig (Gurvitz et al., 1998, Gurvitz et al., 1999). Neuere Studien konnten die Funktion von Dcilp als Isomerase allerdings nicht bestätigen (Ntamack et al., 2009). Der Abbau von ungesättigten Fettsäuren mit Doppelbindungen an geraden Positionen benötigt ein weiteres Enzym. Die NADPHabhängige Reaktion wird durch Sps19p (2,4-Dienoyl-CoA-Reduktase) durchgeführt. Das entstandene Zwischenprodukt trans- $\Delta^{3}$-Enoyl-CoA wird durch Ecilp zu trans- $\Delta^{2}$-Enoyl-CoA umgesetzt und anschließend durch die $\beta$-Oxidation weiter abgebaut (Gurvitz et al., 1997).

Das durch die $\beta$-Oxidation gebildete Acetyl-CoA wird entweder für die Energiegewinnung in den Mitochondrien verwendet oder zur Biosynthese neuer Verbindungen herangezogen. In jedem Fall müssen die Acetyl-Einheiten vorher die peroxisomale Membran überqueren. 
Dieser Transport durch die peroxisomale Membran erfolgt nicht spontan, sondern erfordert Transportsysteme (van Roermund et al., 1995). Drei verschiedene Exportwege wurden für Acetyl-Einheiten in S. cerevisiae postuliert: Eine Möglichkeit ist demnach der Transport über den Glyoxylatzyklus. Der komplette Glyoxylatzyklus verteilt sich auf die Kompartimente Peroxisom und Cytosol. Durch die räumliche Aufteilung ist eine Überwindung der peroxisomalen Membran von Intermediaten aus dem Glyoxylatzyklus notwendig. Die Einschleusung der Acetyl-Einheiten in den Glyoxylatzyklus wird durch Cit2p (Citratsynthese) auf der peroxisomalen Seite durchgeführt. Dabei wandelt Cit2p Acetyl-CoA und Oxalacetat in Citrat um. Das eigentliche Endprodukt Succinat überquert die peroxisomale Membran durch einen unbekannten Transportmechanismus. Der zweite Exportweg wird wahrscheinlich durch die von Cat2p (peroxisomale Carnitin-Acyltransferase) katalysierte Umwandlung von Acetyl-CoA in Carnitinester ermöglicht. Der Transportmechanismus der Carnitinester durch die peroxisomale Membran konnte bislang noch nicht geklärt werden. Die dritte Möglichkeit besteht in der hydrolytischen Spaltung von Acetyl-CoA in Acetat und freies CoA und dem Transport des freien Acetats durch die peroxisomale Membran (Visser et al., 2007, van Roermund et al., 1995).

Wenig ist bekannt über die Verfügbarkeit von CoA in der peroxisomalen Matrix. Innerhalb der Peroxisomen wird freies CoA für die Aktivierung der freien Fettsäuren und für die Thiolyse von 3-Ketoacyl-Acyl benötigt. Eine Quelle für freies CoA liefert der von Pat1pPat2p abhängige Import von Acyl-CoAs in das peroxisomale Lumen. Importiertes Acyl-CoA als einzige Quelle für freies CoA würde jedoch nicht für die Aktivierung von Fettsäuren und den $\beta$-Oxidationszyklus ausreichen. Dementsprechend werden andere notwendige Quellen vermutet. Unterstützt wird diese Vermutung durch die Beobachtung, dass die pat1 1 pat $2 \Delta$ Mutante in der Lage ist in Abwesenheit des peroxisomalen ABC-Transporters erfolgreich mittelkettige Fettsäuren mittels $\beta$-Oxidation abzubauen (Hettema et al., 1996). Da die peroxisomale Membran nicht durchlässig für freies CoA ist (Antonenkov et al., 2004), wird ein peroxisomaler Transporter für freies CoA postuliert, der allerdings bislang nicht nachgewiesen werden konnte. Der einzige bislang diskutierte CoA-Transporter wurde in den Mitochondrien entdeckt. In der inneren Mitochondrienmembran wurde Leu5p als Mitglied der MCF(mitochondrial carrier protein)-Familie identifiziert. Die Deletion von LEU5 führte zu einer starken Abnahme des mitochondrialen CoA-Spiegels, aber nicht zu einer Änderung des CoA-Gehalts im Zytosol. Darauf basierend wurde eine Funktion von Leu5p als CoATransporter postuliert. Ein vergleichbarer Transporter für den Import von CoAs in Peroxisomen wird angenommen (Prohl et al., 2001). Über den peroxisomalen Export von 
CoAs ist ebenfalls nur wenig bekannt. Es wird spekuliert, dass Nudix-Hydrolasen das CoA in 3',5'-ADP und 4'-Phosphopantethein spalten und diese Moleküle dann über die peroxisomalen Membran transportiert werden (Hunt und Alexson, 2008). In S. cerevisiae wurde Pcd1p als peroxisomale Nudix-Hydrolase identifiziert (Cartwright et al., 2000). Für die weitere Metabolisierung von 3',5'-ADP und 4'-Phosphopantethein gibt es gegenwärtig keine gesicherten Informationen. Der Export von 3',5'-ADP könnte möglicherweise durch den Adenin-Nukleotid-Transporter (Ant1p) reguliert werden (Palmieri et al., 2001, Visser et al., 2002). 4'-Phosphopantethein wird als Substrat für die Synthese von CoA an der äußeren mitochondrialen Membran diskutiert (Leonardi et al., 2005).

\subsubsection{Peroxisomale Acyl-CoA-Thioesterasen}

Acyl-CoA-Thioesterasen katalysieren die hydrolytische Spaltung von Acyl-CoAs in Fettsäuren und freies CoA. Durch die Spaltung von Acyl-CoAs nehmen Thioesterasen Einfluss auf die Regulierung des CoA-Pools. Studien zeigten, dass schon leicht erhöhte Mengen von CoAs einen inhibitorischen Effekt auf bestimmte peroxisomale Acyl-CoAThioesterasen haben (Hunt und Alexson, 2002, Soling und Rescher, 1985). Eine Hypothese beschreibt die Funktion bestimmter peroxisomalen Acyl-CoA-Thioesterasen als CoA-Sensor (Hunt und Alexson, 2008). Demnach könnten peroxisomale Acyl-CoA-Thioesterasen die Aufgabe haben, den CoA-Spiegel auf einem bestimmten Niveau zu stabilisieren, um die Versorgung für die $\beta$-Oxidation und Aktivierung der freien Fettsäuren sicherzustellen. In $S$. cerevisiae wurde die peroxisomale Thioesterase Tes1p (Pte1p) identifiziert (Jones et al., 1999). Untersuchungen in vitro zeigten für Tes1p eine Substratspezifität für kurzkettige AcylCoAs und verzweigte Acyl-CoAs. Für Tes1p wird eine regulierende Funktion auf die Aktivität der gesamten $\beta$-Oxidation vermutet (Maeda et al., 2006). In Abb. 3 wird die postulierte regulierende Funktion von Tes1p dargestellt.

Weitere Studien zeigten eine Beteiligung von Tes1p an der $\beta$-Oxidation von Ölsäure. Die tes1 $\Delta$-Mutante zeigte auf Ölsäure (C18:1) ein eingeschränktes Wachstum. Palmitinsäure (C16:0) hatte dagegen keinen Einfluss auf das Wachstumsverhalten der tes $1 \Delta$-Mutante. Nach Zugabe von Ölsäure wurde im Wildtyp ein Zwischenprodukt (3,5-Tetradecadiensäure) der $\beta$ Oxidation identifiziert, das in der tes $1 \Delta$-Mutante nicht nachgewiesen werden konnte. Demnach katalysiert Tes1p die hydrolytische Spaltung von 3,5-Tetradecadienoyl-CoA in 3,5Tetradecadiensäure und CoA. Darauf basierend wird vermutet, dass Ölsäure durch einen Tes1p-abhängigen $\beta$-Oxidationsweg abgebaut werden kann (Ntamack et al., 2009). 


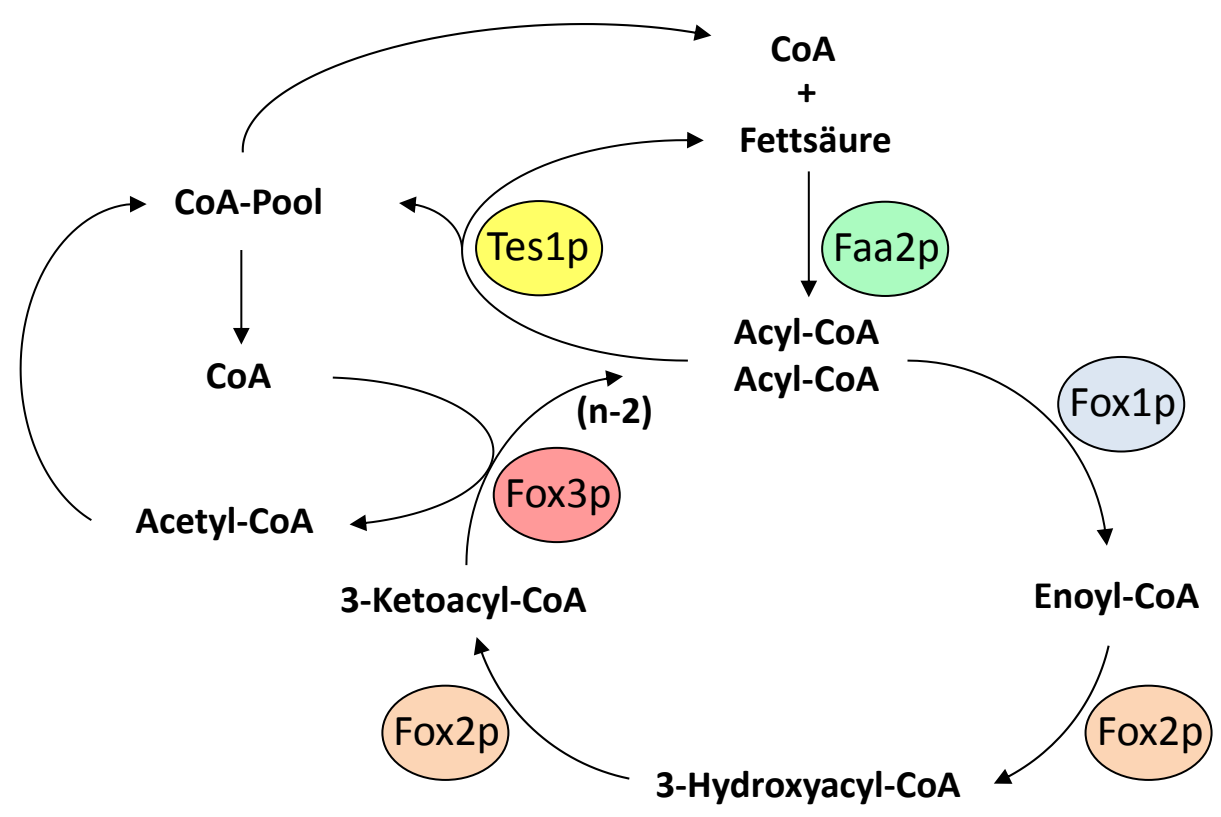

Abb. 3: Modell für die Regulierung der $\beta$-Oxidation durch die peroxisomale Acyl-CoAThioesterase Tes1p (Maeda et al., 2006). Durch die Interaktion zwischen der peroxisomale AcylCoA-Thioesterase (Tes1p) und der peroxisomale Acyl-CoA-Synthetase (Faa2p) wird der CoA-Level stabil gehalten. Die Stabilisierung des CoA-Pools ist notwendig für die Aufrechterhaltung der Aktivität der Ketoacyl-CoA-Thiolase (Fox3p). Fox1p (Acyl-CoA-Oxidase); Fox2p (Multifunktionelles Enzym); Fox3p (Ketoacyl-CoA-Thiolase); Faa2p (Acyl-CoA-Synthetase); Tes1p (Thioesterase).

\subsubsection{Stoffwechselfunktionen von Peroxisomen in Arabidopsis thaliana}

Charakteristisch für die pflanzlichen Peroxisomen ist die Vielzahl an unterschiedlichen Stoffwechselfunktionen. In Pflanzenzellen sind die Peroxisomen z.B. an der Biosynthese von Phytohormonen, Photorespiration, $\beta$-Oxidation von Fettsäuren und am Glyoxylatzyklus beteiligt. Die $\beta$-Oxidation ist nicht nur in den Abbau von Fettsäuren involviert, sondern spielt auch bei der Synthese von Signalmolekülen wie Indol-3-Essigsäure (IAA) und Jasmonsäure (JA) eine wichtige Rolle (Baker et al., 2006). JA und dessen Derivate haben eine besonders bedeutende Funktion als Signalmoleküle bei der Abwehr von biotischem und abiotischem Stress. Eine entscheidende Rolle innerhalb der JA-Signalkaskade spielen die Aminosäurekonjugate von JA. Mehrere Studien zeigten, dass das Jasmonsäure-IsoleucinKonjugat (JA-Ile) als eine biologische aktive Form des Hormons wirkt. Zusätzliche bioaktive Konjugate von JA werden vermutet (Thines et al., 2007, Chini et al., 2009). Das Substrat für die Synthese von Jasmonsäure sind ungesättigte Fettsäuren. In A. thaliana wird JA entweder aus Hexadecatriensäure (C16:3) oder Linolensäure (C18:3) gebildet (Weber et al., 1997) (Turner et al., 2002). Die meisten Enzyme für den Linolsäure-abhängigen Syntheseweg konnten identifiziert werden (Baker et al., 2006). Die aus der der chloroplastidären Membran 
stammende $\alpha$-Linolensäure (C18:3) wird durch die 13-Lipoxygenase (13-LOX) zu 13Hydroperoxyoctadecatriensäure umgewandelt. Die Allenoxidsynthase (13-AOS) katalysiert das instabile Zwischenprodukt 12,13-Epoxyoctadecatriensäure. Anschließend zyklisiert die Allenoxidcyclase (AOC) das Epoxid zu 12- Oxophytodiensäure (OPDA). OPDA wird aus den Chloroplasten exportiert und wahrscheinlich unter Beteiligung von PXA1 in die Peroxisomen importiert (Theodoulou et al., 2005). In den Peroxisomen wird OPDA durch die 12Oxophytodiensäure-Reduktase (OPR3) zu 12-Oxophytoensäure (OPC:8) umgesetzt (Schaller et al., 2000). OPC:8 wird vermutlich durch eine spezielle CoA-Ligase aktiviert (Schneider et $a l ., 2005)$ und anschließend in den $\beta$-Oxidationszyklus überführt, bei dem nach drei Zyklen letztendlich JA entsteht. Die Synthese von Indol-3-Essigsäure (IAA) ist ebenfalls von der $\beta$ Oxidation abhängig. Indol-3-Buttersäure (IBA) wird durch PXA1 in die Peroxisomen importiert und durch einen $\beta$-Oxidationszyklus in IAA umgewandelt (Zolman et al., 2001). Vermutet wird außerdem eine Beteiligung der $\beta$-Oxidation an der Synthese von Salicylsäure (Baker et al., 2006). 


\subsection{Zielsetzung der Arbeit}

Im ersten Abschnitt dieser Arbeit sollte der Mechanismus des Fettsäure-Imports in pflanzliche Peroxisomen untersucht werden. Im Mittelpunkt stand dabei die Rolle des membranintegralen ABC-Transporters PXA1 und dessen Interaktion mit den beiden peroxisomalen für langkettige Fettsäuren spezifischen Acyl-CoA-Synthetasen (LACS6 und LACS7). In Arabidopsis sind peroxisomale LACS für den Abbau von Fettsäuren während der Keimlingsentwicklung essentiell. Inwieweit dies an ihrer Beteiligung am Import von Fettsäuren begründet liegt, soll in diesem Projekt hinterfragt werden. In Hefen ist gleichfalls ein ABC-Transporter für den Import der Fettsäuren in die Peroxisomen zuständig, aber eine peroxisomale LACS ist nicht involviert. Diese Ergebnisse deuten auf einen unterschiedlichen Mechanismus des ABC-Transporters in Pflanzen und Hefen hin. Durch gegenseitige Komplementation von Hefe- und Arabidopsis-Mutanten soll dieser Mechanismus hinterfragt werden und außerdem geklärt werden, ob der Fettsäure-Transport in Arabidopsis direkte Wechselwirkungen zwischen PXA und LACS erfordert. Zusätzlich sollte durch die Manipulation des peroxisomalen Acyl-CoA-Pools in S. cerevisiae weitere Erkenntnisse bezüglich des Ablaufs von Transport der Fettsäuren durch die peroxisomale Membran und anschließender Metabolisierung durch die $\beta$-Oxidation gewonnen werden.

Im zweiten Abschnitt dieser Arbeit sollte durch einen bislang nicht beschriebenen Phänotyp der Plasmamembran-Fettsäuretransport in S. cerevisiae näher untersucht werden. Verursacht durch die Deletion der Acyl-CoA-Synthetasen FAAl und FAA4 ist dieser Phänotyp durch der durch einen massiven Export von freien Fettsäuren während der exponentiellen Phase und einen Re-Import von freien Fettsäuren während der stationären Phase sowie einen drastischen Anstieg intrazellulärer Fettsäuren charakterisiert. Im Rahmen der vorliegenden Arbeit wurde dieser Phänotyp genutzt, um einen im Detail noch nicht verstandenen Transportmechanismus von freien Fettsäuren durch die Plasmamembran in S. cerevisiae genauer zu untersuchen.

Im dritten Abschnitt dieser Arbeiten stand im Mittelpunkt die Beobachtung, dass die pxalMutante durch eine verlängerte Dunkelphase massiv beeinträchtigt wird. Eine Verlängerung der Dunkelphase führte bei pxal-Pflanzen zum vollständigen Absterben. Um Hintergründe des beobachteten Phänotyps zu beleuchten, sollten Metabolitenprofile von der pxal-Mutante und Wildtyp für verschiedene Stadien der Dunkelphase erstellt werden. 


\section{Material und Methoden}

\subsection{Verwendete Materialien}

\subsubsection{Geräte}

\begin{tabular}{ll}
\hline Geräte & Bezugsquelle \\
\hline Agilent GC 6890 Series & Agilent (Waldheim, Deutschland) \\
Agilent LC 1100 Series & Agilent (Waldheim, Deutschland) \\
Agilent 5973 Network mass selective & Agilent (Waldheim, Deutschland) \\
detector & \\
Elektrophorese-Kammer/Gelträger & peQ-Lab Bioctechnologie (Erlangen, Deutschland) \\
IDA Gel-Detektionssystem & Raytest (Straubenhardt, Deutschland) \\
Mastercycle personal & Eppendorf AG (Hamburg, Deutschland) \\
Mastercycle gradient & Eppendorf AG (Hamburg, Deutschland) \\
Netzgerät: Consort E143 & Sigma-Aldrich (Steinheim, Deutschland) \\
Phosphoimager FLA-3000 & Fujifilm (Düsseldorf, Deutschland) \\
Photometer Ultrospec 1100 pro & Amersham Pharmacia (Freiburg, Deutschland) \\
TLC/HPTLC-Sprayer & CAMAG (Berlin, Deutschland) \\
TLC Plate Heater & CAMAG (Berlin, Deutschland) \\
TLC Spray Cabinet & CAMAG (Berlin, Deutschland) \\
Kühlzentrifuge 5810 R & Eppendorf AG (Hamburg, Deutschland) \\
Kühlzentrifuge 5415 R & Eppendorf AG (Hamburg, Deutschland) \\
Tischzentrifuge 5415 D & Eppendorf AG (Hamburg, Deutschland) \\
\hline
\end{tabular}




\subsubsection{Chemikalien und molekularbiologische Reagenzien}

\begin{tabular}{|c|c|}
\hline $\begin{array}{l}\text { Chemikalien und molekularbiologische } \\
\text { Reagenzien }\end{array}$ & Bezugsquelle \\
\hline Acetonitril & Acros Organics (Geel, Belgien) \\
\hline Antarctic Phosphatase & New England Biolabs (Ipswich, USA) \\
\hline $\begin{array}{l}\text { Big Dye }{ }^{\circledR} \text { Terminator v1.1 Cycle } \\
\text { Sequencing Kit }\end{array}$ & Applied Biosystems (Warrington, UK) \\
\hline $\begin{array}{l}\text { EDAC (N-(3-Dimethylaminopropyl)-N- } \\
\text { ethylcarbodiimid hydrochlorid) }\end{array}$ & Fluka Biochemika (Steinheim, Deutschland) \\
\hline Expand $^{\mathrm{TM}}$ High Fidelity-Pölymerase & Roche (Grenzbach, Deutschland) \\
\hline Geneticin G418-Sulfat & Gibco (Paisley, UK) \\
\hline $\begin{array}{l}\text { Master Pure }{ }^{\mathrm{TM}} \text { Yeast DNA Purification } \\
\text { Kit }\end{array}$ & $\begin{array}{l}\text { Epicentre }{ }^{\circledR} \text { Biotechnologies Madison (Wisconsin, } \\
\text { USA) }\end{array}$ \\
\hline MTBE (Methyl-tert-butylether) & Sigma-Aldrich (München, Deutschland) \\
\hline Nourseothricin (clonNAT) & WERNER Bioagents (Jena, Deutschland) \\
\hline NucleoSpin ${ }^{\circledR}$ Extract II & Macherey-Nagel (Düren, Deutschland) \\
\hline NucleoSpin ${ }^{\mathrm{TM}}$ Plasmid & Macherey-Nagel (Düren, Deutschland) \\
\hline $\begin{array}{l}\text { PfuUltra }{ }^{\mathrm{TM}} \text { High-Fidelity DNA- } \\
\text { Polymerase }\end{array}$ & Stratagene (Heidelberg, Deutschland) \\
\hline pGEM $^{\circledR}$-T Vector System I & Promega (Madison, USA) \\
\hline Phusion ${ }^{\mathrm{TM}}$ DNA-Polymerase & Finnzymes (Espoo, Finnland) \\
\hline SeaKem ${ }^{\circledR}$ LE Agarose & Biozym (Hess. Oldendorf, Deutschland) \\
\hline TaKaRa Ex Taq ${ }^{\text {TM }}$ DNA Polymerase & Cambrex BioScience (Potsdam, Deutschland) \\
\hline Yeast nitrogen base w/o amino acids & Q-BIOgene (Heidelberg, Deutschland) \\
\hline
\end{tabular}

Alle weiteren verwendeten Chemikalien wurden, soweit nicht anders erwähnt, von den Firmen Acros (Geel, Belgien), Duchefa (Haarlem, Niederlande), Invitrogen (Karlsruhe, Deutschland), Merck (Darmstadt, Deutschland), Promega (Madison, USA), Roth (Karlsruhe, Deutschland), Sigma-Aldrich (München, Deutschland) oder Serva (Heidelberg, Deutschland) bezogen.

\subsubsection{Software}

\begin{tabular}{ll}
\hline Programm & Bezugsquelle \\
\hline AIDA & Raytest (Straubenhardt, Deutschland) \\
ChemStation & Agilent-Technologies, (Waldheim, Deutschland) \\
Vector NTI Advanced 10 & Invitrogen (Karlsruhe, Deutschland) \\
\hline
\end{tabular}




\subsection{Vektoren}

\subsubsection{Klonierungsvektoren}

In dieser Arbeit wurden folgende Klonierungsvektoren verwendet:

Tab. 1: Klonierungsvektoren für E. coli

\begin{tabular}{lll}
\hline Vektor & Selektionsmarker & Bezugsquelle \\
\hline pGEM $^{\circledR}-\mathrm{T}-$ Vektor & $\mathrm{Amp}^{\mathrm{R}}$ & Promega (Mannheim, Deutschland) \\
pJET1.2 & $\mathrm{Amp}^{\mathrm{R}}$ & $\begin{array}{l}\text { Fermentas GmbH (St. Leon-Rot, } \\
\end{array}$ \\
& & Deutschland) \\
\hline
\end{tabular}

\subsubsection{Vektoren für S. cerevisiae}

In dieser Arbeit wurden folgende Expressionsvektoren verwendet:

Tab. 2: Expressionsvektoren für S. cerevisiae

\begin{tabular}{|c|c|c|}
\hline Vektor & Selektionsmarker & Bezugsquelle \\
\hline pYES2 & $\mathrm{Amp}^{\mathrm{R}}$ URA3 & $\begin{array}{l}\text { Invitrogen (Karlsruhe, } \\
\text { Deutschland) }\end{array}$ \\
\hline $\mathrm{pYES} 2 / \mathrm{CT}$ & $\mathrm{Amp}^{\mathrm{R}}$ URA3 & $\begin{array}{l}\text { Invitrogen (Karlsruhe, } \\
\text { Deutschland) }\end{array}$ \\
\hline pYES2CGK & Amp ${ }^{R}$ URA3 kanMX4 & diese Arbeit \\
\hline pYES2CGK2 & kanMX4 & diese Arbeit \\
\hline pYES2CGKL & kanMX4 LEU & $\begin{array}{l}\text { M. Fulda (Abt. Biochemie der } \\
\text { Pflanze, Georg-August- } \\
\text { Universität Göttingen) }\end{array}$ \\
\hline pYM-N14 & $\mathrm{Amp}^{\mathrm{R}}$ kanMX4 & $\begin{array}{l}\text { Euroscarf (Frankfurt, } \\
\text { Deutschland) }\end{array}$ \\
\hline
\end{tabular}

\section{pYES2CGK}

Das Fragment mit GPD-Promotor und der kanMX4-Kassette wurde mittels Restriktionsverdau durch XbaI und BglII aus dem Vektor pYM-N6 herausgeschnitten und mit dem durch SspI linearisierten Expressionsvektor pYES2/CT ligiert.

\section{pYES2CGK2}

Aus pYES2CGK wurden zusätzlich die Selektionsmarker $\mathrm{AMP}^{\mathrm{R}}$ und URA3 entfernt, indem mit NheI und BspHI verdaut wurde, die Schnittstellen mit T4-Polymerase aufgefüllt und die Enden ligiert wurden. 
Tab. 3: Deletionsvektoren für $S$. cerevisiae

\begin{tabular}{lll}
\hline Vektor & Selektionsmarker & Bezugsquelle \\
\hline pAG25/ADH & natMX4 & Scharnewski (Diplomarbeit) \\
pAG32/CYC & hygMX4 & Scharnewski (Diplomarbeit) \\
pUG6 & kanMX4 & $($ Gueldener et al., 2002)) \\
\hline
\end{tabular}

\subsection{Bakterien}

Der in dieser Arbeit verwendeten Bakterienstämme sind in der Tab. 4 aufgeführt.

Tab. 4: Verwendeter Bakterienstamm

\begin{tabular}{lll}
\hline Stamm & Genotyp & Referenz \\
\hline E. coli XL1-Blue & $\begin{array}{l}\text { recA1 endA1 gyrA96 thi-1, hsdR17 supE44 } \\
\text { relA1 lac,[F‘ proAB, lacq, lacZ4M15, Tn10 } \\
\left.\left(\mathrm{Tet}^{\mathrm{R}}\right)\right]\end{array}$ & (Bullock et al., 1987) \\
& & \\
\hline
\end{tabular}

\subsubsection{Kultivierung von Escherichia coli}

Die Kultivierung von E. coli erfolgte auf festem oder flüssigem Medium (2.3.1.1) bei $37{ }^{\circ} \mathrm{C}$. Die Flüssigkulturen wurden durch Schütteln (200 Upm) belüftet. Zur Selektion plasmidhaltiger Zellen wurden den Medien nach dem Autoklavieren geeignete Antibiotika zugegeben. 


\subsubsection{Medien für die Kultivierung von Escherichia coli}

\section{Luria Bertani (LB) -Medium (Sambrook et al., 1989)}

$1 \% \quad(w / v) \quad$ Trypton

$0,5 \%(\mathrm{w} / \mathrm{v}) \quad$ Hefeextrakt

$1 \% \quad(\mathrm{w} / \mathrm{v}) \quad \mathrm{NaCl}$

Der $\mathrm{pH}-$ Wert wurde mit $\mathrm{NaOH}$ auf 7,5 eingestellt.

Für die Herstellung von Festmedium wurden $2 \%$ Micro Agar (w/v) dem Flüssigmedium hinzugefügt. Das fertig angesetzte Medium wurde für $20 \mathrm{~min}$ bei $120^{\circ} \mathrm{C}$ autoklaviert.

SOB-Medium (Hanahan, 1983)

$2 \% \quad(w / v) \quad$ Pepton

$0,5 \% \quad(\mathrm{w} / \mathrm{v}) \quad$ Hefeextrakt

$0,06 \% \quad(\mathrm{w} / \mathrm{v}) \quad \mathrm{NaCl}$

$0,018 \%(\mathrm{w} / \mathrm{v}) \quad \mathrm{KCl}$

nach dem Autoklavieren steril zugegeben:

$1 \mathrm{mM} \mathrm{MgSO}_{4}$

$1 \mathrm{mM} \mathrm{MgCl} l_{2}$

\subsubsection{Medienzusätze für $E$. coli}

Dem Medium wurden zur Selektion, entsprechend der Resistenz der Bakterien, Antibiotika folgender Endkonzentration zugesetzt:

\begin{tabular}{lcc}
\hline Antibiotikum & Stammlösung & Endkonzentration \\
\hline Carbenicillin & $100 \mathrm{mg} / \mathrm{ml}$ & $100 \mathrm{mg} / \mathrm{l}$ \\
Kanamycin & $30 \mathrm{mg} / \mathrm{ml}$ & $30 \mathrm{mg} / \mathrm{l}$ \\
\hline
\end{tabular}




\subsubsection{Blau-Weiß-Selektion}

Bei Klonierung in den pGEM $^{\circledR}-\mathrm{T}$ - Vektor wurde zum Nachweis positiver Transformanten die Blau-Weiß-Selektion ( $\beta$-Galaktosidase-Selektion) genutzt. Hierzu wurde den Selektionsplatten IPTG (Isopropyl- $\beta$-D-thiogalaktosid) und X-Gal (5-Bromo-4-chloro-3indolyl- $\beta$-D-galaktosid) zugesetzt.

IPTG-Lösung:

Stammlösung: $100 \mathrm{mM}$ IPTG in $\mathrm{ddH}_{2} \mathrm{O}$.

Endkonzentration im Medium: $200 \mu \mathrm{M}$

X-Gal-Lösung:

Stammlösung $2 \%$ (w/v) X-Gal in Dimethylforamid

Endkonzentration im Medium: 0,004\%

\subsection{Hefen}

\subsubsection{Hefestämme}

Die in dieser Arbeit verwendeten S. cerevisiae-Stämme sind in der Tab. 5 aufgeführt.

Tab. 5: Verwendete Hefestämme

\begin{tabular}{|c|c|c|}
\hline Stamm & Genotyp & Referenz \\
\hline YB332 & MATa ura3-52 his34200 ade2-101 lys2-801 leu2-3,112 & (Johnson et al., 1994a) \\
\hline YB485 & $\begin{array}{l}\text { MATa ura3-52 his3 } 200 \text { ade2-101 lys2-801 leu2-3,112 } \\
\text { faa2A::LEU2 }\end{array}$ & (Johnson et al., 1994a) \\
\hline YB525 & $\begin{array}{l}\text { MATa ura3-52 his3 } 200 \text { ade2-101 lys2-801 leu2-3,112 } \\
\text { faal } \Delta:: H I S 3 \text { faa4D::LYS2 }\end{array}$ & (Johnson et al., 1994a) \\
\hline YB526 & $\begin{array}{l}\text { MATa ura3-52 his3 } 200 \text { ade2-101 lys } 2-801 \text { leu2-3,112 } \\
\text { faal } \Delta:: H I S 3 \text { faa2 } \Delta:: \text { LEU2 faa3 } \Delta:: L E U 2 \text { faa } 4 \Delta:: L Y S 2\end{array}$ & (Johnson et al., 1994a) \\
\hline AS1 & 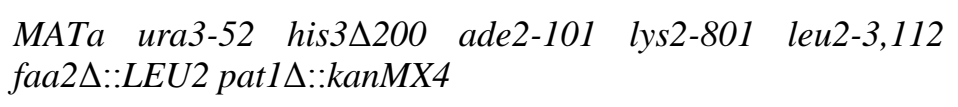 & $\begin{array}{l}\text { A. Struß (Doktorarbeit, } \\
\text { Universität Göttingen) }\end{array}$ \\
\hline AS2 & $\begin{array}{l}\text { MATa ura3-52 his3 } 200 \text { ade2-101 lys2-801 leu2-3,112 } \\
\text { pat1 } \Delta:: \text { kanMX4 }\end{array}$ & $\begin{array}{l}\text { A. Struß (Doktorarbeit, } \\
\text { Universität Göttingen) }\end{array}$ \\
\hline AS110 & 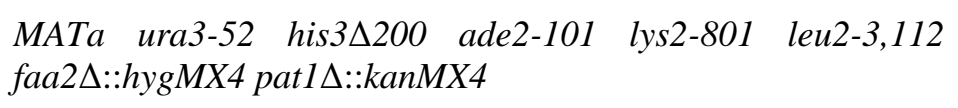 & diese Arbeit \\
\hline
\end{tabular}




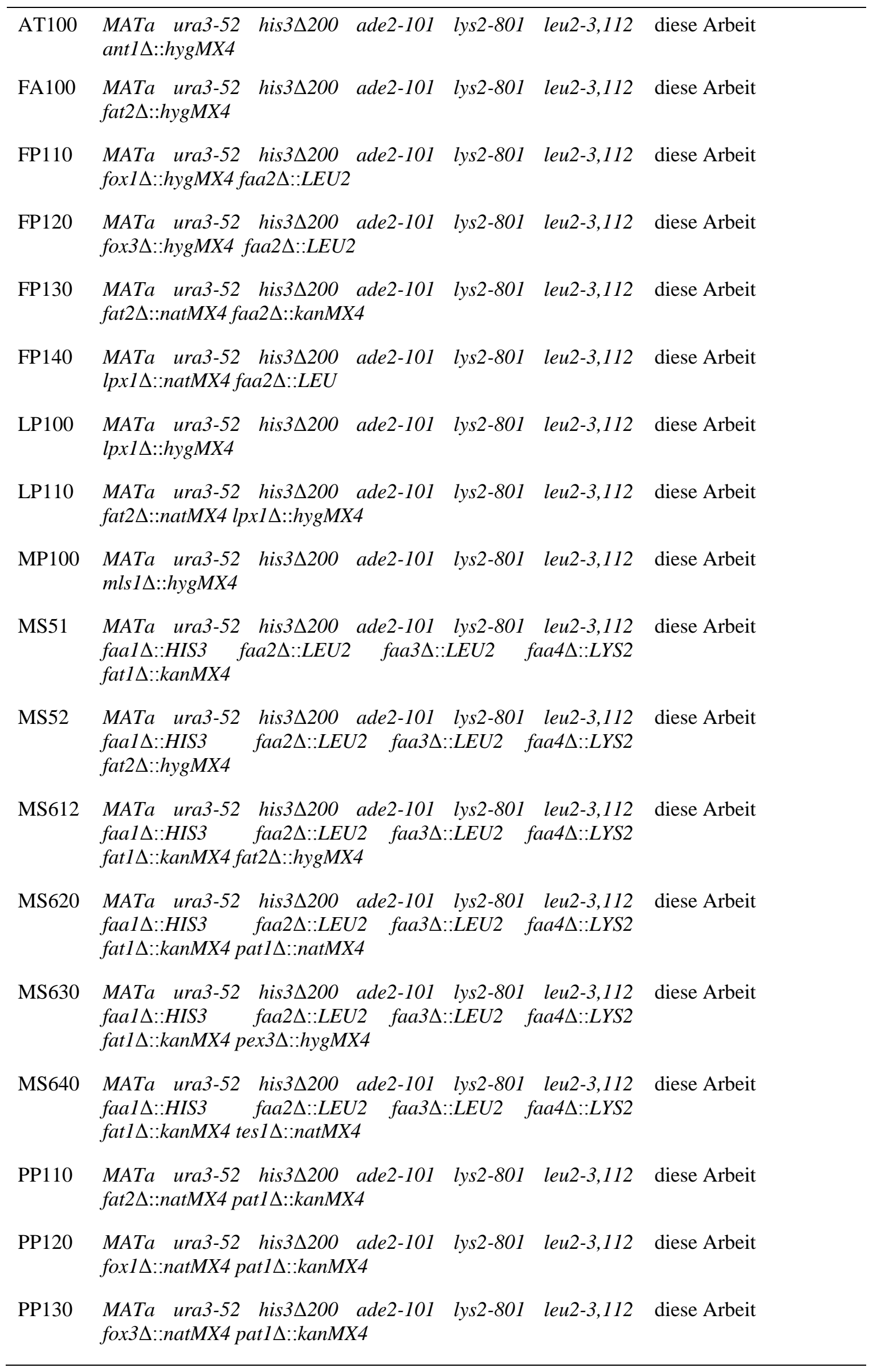




\footnotetext{
PP140 MATa ura3-52 his3 200 ade2-101 lys2-801 leu2-3,112 diese Arbeit lpx1 $\triangle::$ natMX4 pat1 $\triangle:: k a n M X 4$

PP150 MATa ura3-52 his3 200 ade2-101 lys2-801 leu2-3,112 diese Arbeit mls1 $1:$ hygMX4 pat1 $:: k a n M X 4$

PP210 MATa ura3-52 his3 200 ade2-101 lys2-801 leu2-3,112 diese Arbeit

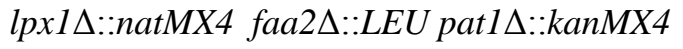

PX100 MATa ura3-52 his34200 ade2-101 lys2-801 leu2-3,112 diese Arbeit pex3 $\triangle:$ :hygMX4

TP100 MATa ura3-52 his3 200 ade2-101 lys2-801 leu2-3,112 diese Arbeit tes $1 \Delta:$ :natMX4

TP110 MATa ura3-52 his3 200 ade2-101 lys2-801 leu2-3,112 diese Arbeit ant $1 \Delta:$ hygMX4 tes $1 \Delta::$ natMX4

TP120 MATa ura3-52 his3 200 ade2-101 lys2-801 leu2-3,112 diese Arbeit faa2 $\triangle:: L E U 2$ tes $1 \Delta::$ natMX4

TP121 MATa ura3-52 his3 200 ade2-101 lys2-801 leu2-3,112 diese Arbeit faa2 $\Delta::$ hygMX4 tes $1 \Delta::$ natMX4

TP130 MATa ura3-52 his34200 ade2-101 lys2-801 leu2-3,112 diese Arbeit fat $2 \Delta::$ hygMX4 tes $1 \Delta::$ natMX4

TP140 MATa ura3-52 his3 200 ade2-101 lys2-801 leu2-3,112 diese Arbeit fox $1 \Delta::$ hygMX4 tes $1 \Delta::$ natMX4

TP150 MATa ura3-52 his3 200 ade2-101 lys2-801 leu2-3,112 diese Arbeit fox3 $\Delta::$ hygMX4 tes $1 \Delta::$ natMX4

TP160 MATa ura3-52 his3 200 ade2-101 lys2-801 leu2-3,112 diese Arbeit lpx1 $\triangle::$ hygMX4 tes $1 \Delta::$ natMX4

TP170 MATa ura3-52 his3 200 ade2-101 lys2-801 leu2-3,112 diese Arbeit pat $1 \Delta:: k a n M X 4$ tes $1 \Delta::$ natMX4

TP210 MATa ura3-52 his3 200 ade2-101 lys2-801 leu2-3,112 diese Arbeit faa2 $\Delta:: L E U$ pat1 $\Delta:: k a n M X 4$ tes $1 \Delta::$ natMX4

TP220 MATa ura3-52 his3 200 ade2-101 lys2-801 leu2-3,112 diese Arbeit fox $1 \Delta::$ hygMX4 pat1 $1:$ kanMX4 tes $1 \Delta::$ natMX4

XP100 MATa ura3-52 his34200 ade2-101 lys2-801 leu2-3,112 diese Arbeit fox $1 \Delta::$ hygMX4

XP103 MATa ura3-52 his3 200 ade2-101 lys2-801 leu2-3,112 diese Arbeit fox3 $\triangle:$ :hygMX4

XP110 MATa ura3-52 his34200 ade2-101 lys2-801 leu2-3,112 diese Arbeit fat $2 \Delta::$ hygMX4 fox $1 \Delta::$ natMX4

XP113 MATa ura3-52 his3 200 ade2-101 lys2-801 leu2-3,112 diese Arbeit fat $2 \Delta::$ hygMX4 fox $3 \Delta::$ natMX4
} 


\subsubsection{Expressionskonstrukte}

Tab. 6: Expressionsvektoren für Hefe

\begin{tabular}{ll}
\hline Plasmid & Genotyp \\
\hline pYES2-ScFAA1 & URA3 FAA1 \\
pYES2-ScFAA3 & URA3 FAA3 \\
pYES2-ScFAT1 & URA3 FAT1 \\
pYES2/CT-ScPAT1 & URA3 PAT1 \\
pYES2CGK-ScFAA2 & GPD ${ }_{\text {Prom }}$ kanMX4 URA3 FAA2 \\
pYES2CGK-ScFAA2PTS & GPD Prom $_{\text {kanMX4 URA3 FAA2PTS }}$ URA3 PXA1 \\
pYES2/CT- AtPXA1 & ScPAT1 Prom_Term URA 2 LACS7 \\
pYES2CGK-AtLACS7 & GPD Prom kanMX4 LEU LAC \\
\hline
\end{tabular}

\subsubsection{Klonierungsstrategie von AtPXA1 in pYES2/CT unter der Kontrolle des hefeeigenen Promotors und Terminators von YKL188C}

Für die Optimierung der heterologen Expression von AtPXAl in S. cerevisiae wurden der hefeeigene Promotor und der Terminator von YKL188C (PAT1) verwendet. Zur Amplifikation der Promoter- und Terminatorsequenz via PCR diente genomische DNA aus $S$. cerevisiae als Matrize. Für die Amplifikation von AtPXAl wurde cDNA als Template für die PCR-Reaktion verwendet. Die Sequenzen der verwendeten Oligonucleotide sind im Anhang verzeichnet. Nach der PCR-Reaktion wurden die amplifizierten DNA-Fragmente einzeln in den pGEM $^{\circledR}$-T-Vektor (Fermentas, St. Leon-Rot, Deutschland) ligiert (2.7.5). Anschließend wurde mit Hilfe der angefügten Restriktionsschnittstellen das Terminator-Fragment durch NcoI / ApaI Verdau isoliert und zusätzlich zu dem bereits klonierten Promotor in den entsprechen geschnittenen pGEM $^{\circledR}$-T-Vektor eingefügt. Danach wurde der offene Leserahmen von AtPXAI durch EcoRI / SphI Verdau isoliert und zwischen Promotor und Terminator in den entsprechend verdauten pGEM $^{\circledR}$-T-Vektor eingefügt. Die Sequenz des fertigen Konstruktes wurde mittels Sequenzierung (2.7.8) verifiziert. Abschließend wurde durch einen Verdau mit NotI das Konstrukt aus dem pGEM ${ }^{\circledR}-\mathrm{T}-$ Vektor herausgeschnitten und mit dem durch NotI linearisierten Expressionsvektor pYES2/CT (Invitrogen, Karlsruhe, Deutschland) ligiert. 


\subsection{Kultivierung von Saccharomyces cerevisiae}

Die Kultivierung der Hefe $S$. cerevisiae erfolgte auf festem oder in flüssigem Medium (2.5.1) bei $30{ }^{\circ} \mathrm{C}$. Flüssigkulturen wurden durch Schütteln bei $215 \mathrm{Upm}$ belüftet. Um eine optimale Durchlüftung der Zellen zu gewährleisten, wurde der Volumenanteil des Kulturmediums auf maximal $20 \%$ des Gesamtvolumens des Erlenmeyerkolbens begrenzt. Die S. cerevisiaeZellen wurden je nach Anwendung in unterschiedlichen Medien angezogen. Für die Herstellung von Festmedien wurden jeweils $2 \%$ (w/v) Micro-Agar (Duchefa, Haarlem, Niederlande) hinzugefügt.

\subsubsection{Medien für die Kultivierung von Saccharomyces cerevisiae}

\section{YEPD-Medium (Vollmedium)}

$1 \% \quad(w / v)$ Hefeextrakt

$2 \% \quad(\mathrm{w} / \mathrm{v})$ Pepton

$2 \%(w / v)$ Glukose

\section{YEPR-Medium (Vollmedium)}

$1 \%(\mathrm{w} / \mathrm{v})$ Hefeextrakt

$2 \% \quad(\mathrm{w} / \mathrm{v})$ Pepton

nach dem Autoklavieren steril zugeben:

$2 \%(\mathrm{w} / \mathrm{v})$ Raffinose 


\section{SD-Medium (Selektionsmedium)}

$0,17 \%(\mathrm{w} / \mathrm{v}) \quad$ Yeast nitrogen base w/o amino acids (Q-BIOgene, Heidelberg, Deutschland)

$0,5 \%(\mathrm{w} / \mathrm{v}) \quad$ Ammoniumsulfat

$2 \%(\mathrm{w} / \mathrm{v}) \quad$ Glukose (Festmedium)

$2 \% \quad(w / v) \quad$ Raffinose (bei Vorkulturen)

$2 \%(\mathrm{w} / \mathrm{v}) \quad$ Galaktose (Expressionskulturen)

Die erforderlichen L-Aminosäuren wurden entsprechend der Selektion zugegeben. Als Dropout-Pulver diente die unten aufgeführte CSM-Mixtur.

\section{Complete Supplement Mixture (CSM)}

$\begin{array}{lr}\text { Adenin (Hemisulfat) } & 10 \mathrm{mg} / \mathrm{l} \\ \text { L-Arginin }(\mathrm{HCl}) & 50 \mathrm{mg} / \mathrm{l} \\ \text { L-Aspartat } & 80 \mathrm{mg} / 1 \\ \text { L-Histidin }(\mathrm{HCl}) & 20 \mathrm{mg} / 1 \\ \text { L-Isoleucin (HCl) } & 50 \mathrm{mg} / 1 \\ \text { L-Leucin } & 100 \mathrm{mg} / 1 \\ \text { L-Lysin (HCl) } & 50 \mathrm{mg} / 1 \\ \text { L-Methionin } & 20 \mathrm{mg} / 1 \\ \text { L-Phenylalanin } & 50 \mathrm{mg} / 1 \\ \text { L-Threonin } & 100 \mathrm{mg} / 1 \\ \text { L-Tryptophan } & 50 \mathrm{mg} / 1 \\ \text { L-Tyrosin } & 50 \mathrm{mg} / 1 \\ \text { Uracil } & 20 \mathrm{mg} / 1 \\ \text { L-Valin } & 140 \mathrm{mg} / 1\end{array}$




\section{MM-Medium (Minimalmedium)}

Vorkultur für Tropftests, Induktion der Proliferation von Peroxisomen und Modellierung des Wachstums von Saccharomyces cerevisiae in ölsäurehaltigem Medium:

$0,17 \%$ (w/v) Yeast nitrogen base w/o amino acids (Q-BIOgene, Heidelberg, Deutschland)

$0,5 \%(\mathrm{w} / \mathrm{v}) \quad$ Ammoniumsulfat

$0,1 \%(\mathrm{w} / \mathrm{v}) \quad$ Hefeextrakt

$0,3 \%(\mathrm{w} / \mathrm{v}) \quad$ Glukose

Die erforderlichen L-Aminosäuren wurden entsprechend (Sherman et al., 1986) zugesetzt.

Minimal-Medium für die Modellierung des Wachstums von Saccharomyces cerevisiae in ölsäurehaltigem Flüssigmedium:

$0,17 \%$ (w/v) Yeast nitrogen base w/o amino acids (Q-BIOgene, Heidelberg, Deutschland)

$0,5 \%(\mathrm{w} / \mathrm{v}) \quad$ Ammoniumsulfat

$0,1 \%(\mathrm{w} / \mathrm{v}) \quad$ Hefeextrakt

$0,1 \%(\mathrm{v} / \mathrm{v}) \quad$ Ölsäure

$0,2 \%(\mathrm{v} / \mathrm{v}) \quad$ Tween 80

Der $\mathrm{pH}$-Wert wurde mit Kaliumphosphatpuffer auf 6,0 eingestellt.Die erforderlichen LAminosäuren wurden entsprechend (Sherman et al., 1986) zugesetzt.

\section{Minimal-Medium für Tropftests:}

Für Tropftests auf ölsäure-haltigem Medium wurde der oben angeführten Mischung 2\% Agar zugesetzt. Für die Kontrolle wurde die Ölsäure als Kohlenstoffquelle weggelassen. 


\section{YBO-Medium (Medium für die Induktion der Proliferation von Peroxisomen)}

$0,3 \%(\mathrm{w} / \mathrm{v}) \quad$ Hefeextrakt

$0,5 \% \quad(w / v) \quad$ Pepton

$0,1 \%(\mathrm{v} / \mathrm{v}) \quad$ Ölsäure

$0,2 \%(\mathrm{v} / \mathrm{v}) \quad$ Tween 80

$0,5 \%(\mathrm{w} / \mathrm{v}) \quad$ Kaliumphosphatpuffer, $\mathrm{pH} 6,0$

\subsubsection{Medienzusätze}

Dem Medium wurden zur Selektion, entsprechend der Resistenz der Hefe-Zellen, Antibiotika folgender Endkonzentrationen zugesetzt:

\begin{tabular}{lcc}
\hline Antibiotikum & Stammlösung & Endkonzentration \\
\hline Hygromycin B & $300 \mathrm{mg} / \mathrm{ml}$ & $300 \mathrm{mg} / \mathrm{l}$ \\
Nourseothricin (clonNAT) & $100 \mathrm{mg} / \mathrm{ml}$ & $100 \mathrm{mg} / \mathrm{l}$ \\
Geneticin (G418) & $250 \mathrm{mg} / \mathrm{ml}$ & $250 \mathrm{mg} / \mathrm{l}$ \\
\hline
\end{tabular}

\subsubsection{Modellierung des Wachstums von Saccharomyces cerevisiae}

Eine Übernachtkultur wurde in $20 \mathrm{ml}$ Medium (2.5.1) im $100 \mathrm{ml}$ Erlenmeyerkolben auf eine $\mathrm{OD}_{600}$ von 0,3 verdünnt. Von dieser Zellkultur wurden Proben zur Bestimmung der optischen Dichte während der exponentiellen und stationären Phase entnommen. Die Bestimmung der optischen Dichte erfolgte photometrisch (Photometer Ultrospec 1100 pro, Amersham Pharmacia, Freiburg, Deutschland) bei einer Wellenlänge von $600 \mathrm{~nm}$.

\subsection{Die Polymerasen-Kettenreaktion (PCR)}

Die Polymerasen-Kettenreaktion (Saiki et al., 1989) wird zur selektiven Amplifizierung von DNA-Fragmenten benötigt. Das Prinzip beruht auf der zyklischen Wiederholung eines Temperaturprogramms, das abwechselnd Denaturierung, Annealing und Polymerisation der DNA erlaubt. Benötigt werden alle Komponenten, die auch bei einer in vivo DNA-Synthese vorhanden sein müssen. Dazu gehören eine DNA-Matrize und eine Initiationsstelle für die DNA-Polymerase. Des Weiteren werden neben der thermostabilen DNA-Polymerase die vier Desoxyribonukleotide (dATP, dCTP, dGTP und dTTP) benötigt. 
Die Startpunkte für die in vitro DNA-Synthese werden durch kurze Oligonukleotide (Primer) festgelegt, welche an eine komplementäre DNA-Sequenz hybridisieren und durch die Polymerase verlängert werden können. Bei bekannter Nukleotidsequenz werden zwei die zu amplifizierende Region flankierende PCR-Primer eingesetzt. Der eine Primer bindet an den Strang der Ziel-DNA, wohingegen der andere Primer in einigem Abstand vom ersten Primer an den komplementären Strang bindet. Die Richtungen dieser beiden Polymerisationsreaktionen laufen aufeinander $\mathrm{zu}$ und überlappen schließlich. Im Verlauf mehrerer Zyklen erfolgt auf diese Weise eine exponentielle Amplifizierung des DNAAbschnitts.

Das PCR Programm (Tab. 7) wurde je nach Zusammenstellung der Primer entsprechend modifiziert und ist daher nur als Grundlage für die tatsächlich verwendeten Programme zu verstehen. In dieser Arbeit wurde das PfuUltra ${ }^{\mathrm{TM}}$ High-Fidelity-PCR-System (Stratagene, La Jolla, USA), das Expand ${ }^{\mathrm{TM}}$ High Fidelity PCR-System (Roche, Grenzbach, Deutschland) oder das Phusion ${ }^{\mathrm{TM}}$ High-Fidelity PCR Kit (Finnzymes, Espoo, Finnland) nach Anweisung der Hersteller verwendet.

Die PCR wurde für analytische Zwecke in $20 \mu \mathrm{l}$ und für präparative Zwecke in $50 \mu 1$ Reaktionsvolumen durchgeführt.

Tab. 7: Standard-Temperaturprofil einer PCR-Reaktion:

\begin{tabular}{lcc}
\hline \multicolumn{1}{c}{ Schritt } & Dauer & Temperatur \\
\hline 1. Denaturierung & $3-5 \mathrm{~min}$ & $98{ }^{\circ} \mathrm{C}$ \\
2. Denaturierung & $30 \mathrm{~s}$ & $98{ }^{\circ} \mathrm{C}$ \\
4. Annealing & $30 \mathrm{~s}$ & $\mathrm{~T}_{\mathrm{m}}-5{ }^{\circ} \mathrm{C}$ \\
5. Elongation & $1 \mathrm{~min}$ pro kb & $72{ }^{\circ} \mathrm{C}$ \\
& Die Schritte 2. -4. wurden 30-35 x wiederholt & \\
6. Elongation & 5 min & $72{ }^{\circ} \mathrm{C}$ \\
\hline
\end{tabular}

Das Temperaturoptimum ist von der Schmelztemperatur $\mathrm{T}_{\mathrm{m}}\left({ }^{\circ} \mathrm{C}\right)$ und somit von der Sequenz des jeweiligen Primers abhängig und wurde einer Länge von 17 bis 24 Nukleotiden nach folgender Formel (Suggs et al., 1981) berechnet:

$\operatorname{Tm}\left[{ }^{\circ} \mathrm{C}\right]=2 \cdot($ Summe A $+\mathrm{T})+4 \cdot($ Summe $\mathrm{G}+\mathrm{C})$ 


\subsubsection{Oligonukleotide}

Die Sequenzen der in dieser Arbeit verwendeten Primer (Invitrogen, Karlsruhe, Deutschland) sind im Anhang aufgeführt.

\subsection{Klonierungsmethoden}

\subsubsection{Agarose-Gelelektrophorese}

Zur Auftrennung von PCR-Produkten und DNA-Restriktionsansätze wurde die horizontale Agarose-Gelelektrophorese eingesetzt. Für die aufzutrennenden DNA-Fragmente wurden in Abhängigkeit der erwarteten Fragmentgrößen 0,7 - 1\%-ige Agarosegele (w/v) verwendet. Zur Herstellung der Agarose wurde diese in 1 x TAE-Puffer in der Mikrowelle gelöst und anschließend in die Gelträger gegossen. Die zu trennenden DNA-Proben wurden mit 1/6 Volumen Auftragspuffer versetzt und ca. $10 \mu \mathrm{l}$ des Gemisches wurden in die Geltaschen gefüllt. Um die Größen der DNA-Fragmente zuordnen zu können, wurden $3 \mu \mathrm{l}$ des Längenstandards GeneRuler ${ }^{\mathrm{TM}} 1$ kb DNA Ladder (Fermentas, St. Leon-Rot, Deutschland) verwendet. Die Auftrennung erfolgte bei 90 - $120 \mathrm{~V}$ in $1 \mathrm{x}$ TAE als Laufpuffer. Für die Auswertung wurden die Gele nach der Elektrophorese in einer Ethidiumbromid-Färbelösung $(10 \mu \mathrm{g} / \mathrm{ml}$ in ddH2O) für 15 bis 20 min inkubiert. Durch UV-Licht $(\lambda=312 \mathrm{~nm})$ konnten anschließend die DNA-Fragmente im Gel-Detektionssystem AIDA (Raytest, Straubenhardt, Deutschland) visualisiert und dokumentiert werden.

TAE-Puffer $(50 \mathrm{x}): \quad 2 \mathrm{M}$ Tris/HCl $(\mathrm{pH} 7,0)$

1 M Essigsäure

0,05 M EDTA (pH 8,0)

DNA-Probenpuffer: $\quad 0,1 \%(\mathrm{w} / \mathrm{v}) \mathrm{SDS}$

$40 \%$ (w/v) Glycerin

100 mM EDTA

$0,025 \%(w / v)$ Bromphenolblau

$0,025 \%(w / v)$ Xylencyanolblau 


\subsubsection{Elution von DNA aus Agarosegelen}

Für die Aufreinigung eines PCR-Produkts oder eines Restriktionsverdaus wurden diese über eine präparative Agarose-Gelelektrophorese (2.7.1) aufgetrennt und anschließend mit dem NucleoSpin $^{\circledR}$ Extract II (Macherey-Nagel, Düren, Deutschland) nach Anleitung des Herstellers aus dem Gel eluiert. Die Lagerung der aufgereinigten DNA-Fragmente erfolgte bei $-20{ }^{\circ} \mathrm{C}$.

\subsubsection{Isolierung von Plasmid-DNA}

Für die Plasmid-Isolierung wurden $5 \mathrm{ml}$ LB-Medium mit den jeweils geeigneten Antibiotika mit Zellen der betreffenden Bakterienkultur inokuliert und über Nacht bei $37^{\circ} \mathrm{C}$ geschüttelt. Anschließend wurden die Plasmide entsprechend des Handbuches des Nucleospin ${ }^{\text {TM }}$ Plasmid Kit (Macherey-Nagel Düren, Deutschland) nach Anleitung des Herstellers isoliert. Alle im Handbuch als optional gekennzeichneten Schritte wurden durchgeführt. Die Lagerung der isolierten Plasmide erfolgte bei $-20^{\circ} \mathrm{C}$.

\subsubsection{Generierung von blunt-end-Fragmenten}

Zum Glätten der Enden (blunt-end) von restringierter DNA wurde die T4 DNA Polymerase (Fermentas, St-Leon-Rot, Deutschland) nach Angaben des Herstellers verwendet.

\subsubsection{Ligation}

Über Ligation können DNA-Fragmente in Vektoren integriert werden. Die Verknüpfung erfolgt mittels Ligasen, welche die Bildung einer Phosphodiesterbindung zwischen der 3'Hydroxylgruppe und 5'-Phosphatgruppe zweier DNA-Stränge katalysieren. Die T4-DNALigase (Fermentas, St. Leon-Rot, Deutschland) wurde entsprechend des Herstellerprotokolls verwendet. Die gereinigten PCR-Fragmente wurden dabei im 3- bis 5-fachen molaren Überschuss zu den zu ligierenden Vektoren eingesetzt, um die Wahrscheinlichkeit einer Selbstligation des Vektors zu verringern. Für Ligationsreaktionen von PCR-Fragmenten in den pGEM-T Vektor wurde das pGEM-T ${ }^{\circledR}$-Vektor System I Kit (Promega, Madison, USA) nach Herstellerangaben verwendet. Die Ligationsansätze wurden bei $16^{\circ} \mathrm{C}$ über $\mathrm{Nacht}$ inkubiert und anschließend direkt für die Transformation eingesetzt. 


\subsubsection{A-Tailing}

Die für die Ligation in den Vektor pGEM $^{\circledR}$-T eingesetzten PCR-Fragmente müssen an beiden Enden einen 3'-A-Überhang besitzen (sticky-ends), welcher mit dem 3'-T-Überhang des pGEM $^{\circledR}$-T Vektors ligiert. Um PCR-Fragmente, die glatte Enden (blunt-ends) besitzen, mit dem pGEM $^{\circledR}-\mathrm{T}-$ Vektor ligieren zu können, wurde ein A-Tailing durchgeführt, das die notwendigen 3'-A-Überhänge erzeugte.
A-Tailing:
$31 \mu 1$ DNA
$2 \mu 120 \times$ Tfl-Puffer
$4 \mu \mathrm{lgCl} 2(25 \mathrm{mM})$
$1 \mu 1 \mathrm{dNTPs}(10 \mathrm{mM})$
$2 \mu \mathrm{l}$ Tfl-Polymerase $(1 \mathrm{u} / \mu \mathrm{l})$

Der Ansatz wurde 30 min bei $72{ }^{\circ} \mathrm{C}$ inkubiert.

\subsubsection{Restriktionsverdau (Sambrook et al., 1989)}

Restriktionsendonukleasen spalten doppelsträngige DNA sequenzspezifisch durch Hydrolyse kovalenter Bindungen. Dabei werden 4-8 bp lange, häufig palindromische Sequenzen erkannt und geschnitten. Die Restriktion von DNA erfolgte, je nach Enzym, für 1-3 h bei $37{ }^{\circ} \mathrm{C}$ oder über Nacht bei $37^{\circ} \mathrm{C}$. Das Ergebnis der Restriktion wurde durch Agarose-Gelelektrophorese überprüft (2.7.1) und die erhaltenen Fragmente über präparative Agarosegele (2.7.2) aufgereinigt.

\subsubsection{Sequenzierung von DNA-Fragmenten}

Die Sequenzierung der DNA-Fragmente erfolgte nach der Methode nach (Sanger et al., 1977) mit Hilfe einer automatischen Sequenziermaschine (ABI PRISM ${ }^{\circledR} 3100$ Genetic Analyzer, Applied Biosystems, Foster City, USA). Für die Sequenzierungsreaktion wurde der ABI PRISM $^{\circledR}$ BigDye $^{\mathrm{TM}}$ Terminator Cycle Sequencing Ready Reaction Kit v1.1 verwendet. 
Dazu wurde der PCR-Ansatz unter den unten beschriebenen PCR-Bedingungen inkubiert. Anschließend wurde das Gemisch in ein 1,5 ml Gefäß transferiert, zur DNA-Fällung mit $5 \mu 1$ 0,125 mM EDTA und $60 \mu 196 \%$ Ethanol (v/v) versetzt und für 15 min bei RT inkubiert. Im Anschluss wurde $15 \mathrm{~min}$ bei $20000 \mathrm{x} g$ und $4^{\circ} \mathrm{C}$ zentrifugiert. Der Überstand wurde verworfen und das Pellet in $60 \mu 170 \%$ Ethanol (v/v) gewaschen. Die Probe wurde wie oben angegeben zentrifugiert und der Überstand erneut verworfen. Die Probe wurde 1 min bei $90^{\circ} \mathrm{C}$ getrocknet, in $30 \mu 1$ Wasser aufgenommen und dann beim Sequenzierungsservice-Labor abgegeben.

Reaktionsansatz: $\quad 1,0 \mu \mathrm{l}$ DNA aus der Plasmidisolierung (200-300 ng)

$1,5 \mu 1$ Ready-Reaction Mix

$1,0 \mu 1$ Primer

$6,5 \mu \mathrm{ldd} \mathrm{H}_{2} \mathrm{O}$

\begin{tabular}{lcc}
\hline \multicolumn{1}{c}{ Schritt } & Dauer & Temperatur \\
\hline 1. Denaturierung & $1 \mathrm{~min}$ & $96{ }^{\circ} \mathrm{C}$ \\
2. Denaturierung & $10 \mathrm{~s}$ & $96{ }^{\circ} \mathrm{C}$ \\
3. Annealing & $10 \mathrm{~s}$ & $55^{\circ} \mathrm{C}$ \\
4. Elongation & $4 \mathrm{~min}$ & $60{ }^{\circ} \mathrm{C}$ \\
Die Schritte 2. bis 4. wurden $25 \mathrm{x}$ wiederholt & \\
5. Termination & halten & $10{ }^{\circ} \mathrm{C}$ \\
\hline
\end{tabular}




\subsection{Pflanzenmaterial und Anzucht}

\subsubsection{A. thaliana}

Tab. 8: Neben den Ökotypen Wassilewskija (WS) und Columbia (Col-0) wurden folgende Mutanten-Linien verwendet:

\begin{tabular}{|c|c|c|c|c|c|}
\hline Protein & AGI Code & Allel & Mutagen & Ökotyp & Referenz \\
\hline PXA1 & At4g39850 & $\begin{array}{l}\text { pxal-2 } \\
\text { SALK_002100 }\end{array}$ & $\begin{array}{l}\text { T-DNA- } \\
\text { Insertion }\end{array}$ & Col-0 & Alonso et al., 2003 \\
\hline PXA1 & At4g39850 & $\begin{array}{l}\text { pxal-9 } \\
\text { SALK_019334 }\end{array}$ & $\begin{array}{l}\text { T-DNA- } \\
\text { Insertion }\end{array}$ & Col-0 & Alonso et al., 2003 \\
\hline LACS6 LACS7 & $\begin{array}{l}\text { At3g05970 } \\
\text { At5g27600 }\end{array}$ & lacs6-1 lacs7-1 & $\begin{array}{l}\text { T-DNA- } \\
\text { Insertion }\end{array}$ & WS & Fulda et al., 2004 \\
\hline KAT2 & At2g33150 & kat2-1 & $\begin{array}{l}\text { T-DNA- } \\
\text { Insertion }\end{array}$ & WS & Germain et al., 2001 \\
\hline MFP2 & At3g06860 & SALK_098016 & $\begin{array}{l}\text { T-DNA- } \\
\text { Insertion }\end{array}$ & Col-0 & Alonso et al., 2003 \\
\hline
\end{tabular}

\subsubsection{Oberflächensterilisation von $A$. thaliana-Saatgut}

Die Anzucht von A. thaliana auf MS-Medium erfolgte mit oberflächensterilisiertem Saatgut. $\mathrm{Zu}$ 10-80 mg Samen wurde $1 \mathrm{ml} 70 \%$ Ethanol (v/v) hinzugegeben und für 1 min langsam geschwenkt. Nach dem Absinken der Samen wurde das Ethanol abgenommen und die Samen in einer $1 \%$-igen Natriumhypochlorit-Lösung (w/v) mit 0,1\% Triton X-100 (v/v) für 20 min schwenkend inkubiert. Danach wurden die Samen viermal in sterilem $\mathrm{ddH}_{2} \mathrm{O}$ gewaschen. Nach dem letzten Waschschritt wurde das Saatgut in 0,1 \%-igem Agar (w/v) aufgenommen und bei $4{ }^{\circ} \mathrm{C}$ für mindestens 2 Tage inkubiert. Dieses Vorgehen dient dem Brechen der Dormanz und führt zu einer synchronisierten Keimung der Samen. 


\subsubsection{Anzucht von A. thaliana auf MS-Medium}

4,3 g/l (1x MS) bzw. 2,2 g/l (1/2x MS) MS-Mischung (Duchefa, Haarlem, Niederlande) und 7 g/l Mikroagar wurden mit destilliertem Wasser versetzt. Wenn erforderlich wurde $1 \%$ Saccharose (w/v) hinzugefügt. Der pH-Wert wurde vor dem Autoklavieren mit KOH auf 5.9 eingestellt. Das oberflächensterilisierte und stratifizierte Saatgut (2.8.2) wurde auf MSMedium ausgelegt und für 10-12 Tage unter Langtag-Bedingungen (16 h Tag bei $120 \sim \mu \mathrm{E} / 8$ h Nacht) angezogen. Die Temperatur während der Lichtphase betrug $22-24{ }^{\circ} \mathrm{C}$ und während der Dunkelphase $18-20{ }^{\circ} \mathrm{C}$.

\subsubsection{Anzucht von A. thaliana auf Erde}

Für die Anzucht von A. thaliana in den Klimakammern wurde entweder Saatgut direkt auf Erde ausgelegt oder etablierte Keimlinge von MS-Platten (2.8.3) auf Erde (Frühstorfer Erde ${ }^{\circledR}$ Typ: EP Nr. 340, Industrie-Erdenwerk Archut, Lauterbach-Wallenrod, Deutschland) umgesetzt. Die Pflanzen wurden unter Langtag-Bedingungen $(16 \mathrm{~h}$ Tag bei $120 \sim \mu \mathrm{E} / 8 \mathrm{~h}$ Nacht) angezogen. Bei konstanter Luftfeuchtigkeit von $60 \%$ betrug die Temperatur während der Lichtphase 20 - $24{ }^{\circ} \mathrm{C}$ und während der Dunkelphase $18-22{ }^{\circ} \mathrm{C}$.

Für die Behandlung durch eine ausgedehnte Dunkelphase wurden die Pflanzen 21 Tage nach der Keimung den Bedingungen einer verlängerten Nachtphase $\left(22^{\circ} \mathrm{C}\right)$ ausgesetzt.

\subsection{Transformation von E. coli}

\subsubsection{Präparation chemisch kompetenter $E$. coli-Zellen zur Hitzeschock- Transformation (Inoue et al., 1990)}

Für die Präparation kompetenter E. coli-Zellen wurden $10 \mathrm{ml}$ LB-Medium mit dem entsprechendem Antibiotikum und einer E. coli-Kolonie inokuliert und über Nacht bei $37^{\circ} \mathrm{C}$ geschüttelt. Mit 2,5 ml Übernachtkultur wurden $250 \mathrm{ml} \mathrm{SOB-Medium} \mathrm{beimpft} \mathrm{und} \mathrm{für} 2 \mathrm{~h}$ bei $37{ }^{\circ} \mathrm{C}$ inkubiert. Anschließend wurde die Kultur bei $16{ }^{\circ} \mathrm{C}$ bis zu einer $\mathrm{OD}_{600}$ von 0,4 angezogen. Das Zellwachstum wurde durch 10 min Inkubation auf Eis gestoppt und die Zellen durch Zentrifugation bei $5000 \mathrm{~g}$ für $10 \mathrm{~min}$ bei $4{ }^{\circ} \mathrm{C}$ sedimentiert. Das Pellet wurde in $80 \mathrm{ml}$ vorgekühltem TB-Puffer aufgenommen und anschließend unter gleichen Bedingungen wie zuvor zentrifugiert. Die sedimentierten Zellen wurden in $20 \mathrm{ml}$ vorgekühltem TB-Puffer 
aufgenommen und mit 1,4 ml Dimethylsulfoxid (DMSO) versetzt. Nach 10 min Inkubation auf Eis wurden die Zellen aliquotiert und in flüssigem Stickstoff schockgefroren. Die Lagerung der kompetenten Zellen erfolgte bei $-80^{\circ} \mathrm{C}$.

TB-Puffer: $\quad 10 \mathrm{mM}$ Pipes $(\mathrm{pH} 6,7 \mathrm{mit} \mathrm{KOH})$

$15 \mathrm{mM} \mathrm{CaCl}_{2}$

$250 \mathrm{mM} \mathrm{KCl}$

$55 \mathrm{mM} \mathrm{MnCl}_{2}$

Die Lösung wurde sterilfiltriert.

\subsubsection{Transformation kompetenter $E$. coli-Zellen}

Für einen Transformationsansatz wurden $200 \mu$ kompetenter Zellen (XL1-Blue) auf Eis aufgetaut. $\mathrm{Zu}$ den Zellen wurde 5 - $10 \mu$ l Ligationsansatz (2.7.5) gegeben und der Ansatz für ca. $30 \mathrm{~min}$ auf Eis inkubiert. Anschließend wurden die Zellen für $45 \mathrm{~s}$ bei $42{ }^{\circ} \mathrm{C}$ einem Hitzeschock ausgesetzt und danach für 1 min auf Eis gestellt. Nach Zugabe von $800 \mu$ SOBMedium wurden die Zellen für 60 min bis 90 min unter Schütteln bei $37^{\circ} \mathrm{C}$ inkubiert. Die Transformationsansätze wurden anschließend auf LB-Platten mit entsprechenden Antibiotika ausplattiert und über Nacht bei $37^{\circ} \mathrm{C}$ inkubiert.

\subsection{Transformation von Saccharomyces cerevisiae (modifiziert nach Ausubel et al., 1993)}

Die Transformation von S. cerevisiae erfolgt nach der Lithiumacetat-Methode. Diese Methode beruht auf der Tatsache, dass Alkali-Kationen Hefezellen für die DNA-Aufnahme kompetent machen. Die Transformation erfolgt dann mittels Zugabe von Polyethylenglycol 4000 (PEG) und einem Hitzeschock.

Eine Übernachtkultur in $10 \mathrm{ml}$ YEPD-Medium wurde auf eine $\mathrm{OD}_{600}$ von 0,3 verdünnt. Nach der Inkubation bei $30^{\circ} \mathrm{C}$ bis zu einer $\mathrm{OD}_{600}$ von 0,8 bis 1,2 wurden die Zellen in einem $15 \mathrm{ml}$ Falcon-Tube durch Zentrifugation mit 1600 x $g$ bei RT für 3 min sedimentiert. Der Überstand wurde verworfen und das Pellet in $10 \mathrm{ml}$ steril filtriertes $\mathrm{ddH}_{2} \mathrm{O}$ resuspendiert. Anschließend 
wurden die Zellen unter identischen Bedingungen wie zuvor sedimentiert. Der Überstand wurde wiederum verworfen und das Zellpellet in 0,4 $\mathrm{ml} \mathrm{0,1} \mathrm{M} \mathrm{Lithiumacetat} \mathrm{resuspendiert.}$ Die Suspension wurde in 2 x $200 \mu \mathrm{l}$ aufgeteilt und jeweils in 1,5 ml Eppendorfgefäß überführt, so dass die kompetenten Zellen direkt für die Transformation eingesetzt werden konnten. Für die Transformation wurden entweder $1-3 \mu$ g Plasmid-DNA oder 30 bis $50 \mu 1$ aufgereinigter PCR-Ansatz (2.10.1) zugegeben. Bei dieser Vorgehensweise wurden zusätzlich $25 \mu$ l Heringssperma-DNA (direkt vor Gebrauch für 10 min bei $65{ }^{\circ} \mathrm{C}$ inkubiert) mit dem zu transformierenden PCR-Ansatz vermischt. Anschließend erfolgte eine Zugabe von jeweils $800 \mu \mathrm{l}$ PEG-Lösung. Der Ansatz wurde kräftig geschwenkt und für $30 \mathrm{~min}$ bei $30{ }^{\circ} \mathrm{C}$ inkubiert. Der Hitzeschock wurde anschließend 25 min bei $42{ }^{\circ} \mathrm{C}$ durchgeführt. Nach dem Hitzeschock wurden die Zellen durch Zentrifugation mit $5200 \mathrm{x} g$ für 1 min pelletiert. Der Überstand wurde danach vorsichtig verworfen und das Zellpellet in $1 \mathrm{ml}$ YEPD resuspendiert. Die Inkubationszeit betrug $2 \mathrm{~h}-3 \mathrm{~h}$ bei $30^{\circ} \mathrm{C}$ Darauf folgend wurden die Zellen durch Zentrifugation mit $1700 \mathrm{x} g$ bei RT für 1 min sedimentiert und das Zellpellet in $200 \mu \mathrm{l}$ YEPDMedium resuspendiert. Die Ansätze wurden zur Selektion auf antibiotikahaltigen YEPDPlatten ausplattiert und bei $30{ }^{\circ} \mathrm{C}$ für $3-4$ Tage inkubiert.

PEG-Lösung: $\quad 40 \%(w / v)$ PEG4000

$100 \mathrm{mM}$ LiAC

$10 \mathrm{mM}$ Tris $\mathrm{HCl}$

$1 \mathrm{mM}$ EDTA $(\mathrm{pH} 8,0)$

\subsubsection{PCR-basierende Gen-Deletion}

Um die verschiedenen Gen-Deletionen herzustellen, wurde die PCR-basierende Methode von (Wach et al., 1994) verwendet. Diese Technik basiert auf der Tatsache, dass homologe Rekombination in Hefe sehr effizient mit linearen DNA-Fragmenten stattfindet. Das lineare DNA-Fragment, das sowohl die Resistenz-Kassette enthält, als auch Sequenzen, die eine homologe Rekombination in den zu deletierenden Genlokus erlauben, wurde durch eine PCR erstellt. Dazu wurden ca. 64 Basen lange Oligonukleotide benötigt, bei denen 18-19 Basen komplementär zu genormten Primerbindungsstellen verschiedener Resistenz-Kassetten sind und die restlichen ca. 45 Basen bezüglich des Templates überhängen und spezifisch für die homologe Rekombination in das Hefegenom sind. Als Sequenzbereiche für die homologe 
Rekombination wurden wie in den etablierten genomweiten Deletionsprojekten jeweils der 5'-Bereich vor dem zu deletierenden Gen einschließlich dem Startcodon gewählt, sowie der 3'-Bereich hinter dem zu deletierenden Gen einschließlich dem Stopcodon. Auf diese Weise wird der offene Leserahmen des Zielgens komplett deletiert. Plasmid-DNA mit der jeweiligen Resistenz-Kassette wurde als Template für die PCR eingesetzt, mit der das Deletionskonstrukt synthetisiert wurde. Die PCR wurde mittels Agarosegelelektrophorese überprüft. Das korrekte PCR-Produkt wurde durch Transformation in kompetente Hefezellen überführt, die anschließend auf Selektionsplatten ausplattiert wurden. Von den resistenten Transformanten wurde genomische DNA präpariert (2.10.2) und die erfolgreiche Deletion mittels KontrollPCRs überprüft (2.6).

\subsubsection{Präparation von genomischer DNA aus Hefen}

Für die Präparation von genomischer DNA aus Hefen wurde das Master Pure ${ }^{\mathrm{TM}}$ Yeast DNA Purification Kit (Epicentre ${ }^{\circledR}$ Biotechnologies Madison, Wisconsin, USA) verwendet. Im Unterschied zur Anleitung des Herstellers erfolgte die Aufnahme mit $\mathrm{ddH}_{2} \mathrm{O}$ anstelle des empfohlenen Puffers. Die Lagerung der isolierten genomischen DNA erfolgte bei $-20{ }^{\circ} \mathrm{C}$.

\subsection{Lipidanalytik}

\subsubsection{Lipidanalytik mittels Gaschromatographie}

\subsubsection{Zellernte von Saccharomyces cerevisiae für die GC-Analytik}

$2 \mathrm{ml}$ einer S. cerevisiae-Kultur wurden in ein $2 \mathrm{ml}$ Reaktionsgefäß überführt und die Zellen bei $1700 \mathrm{x} g$ für $3 \mathrm{~min}$ sedimentiert. $1 \mathrm{ml}$ des Überstandes wurden in ein $1,5 \mathrm{ml}$ Reaktionsgefäß überführt und für die Analyse der extrazellulären Fettsäuren verwendet. Für die Analyse der intrazellulär freien und intrazellulär veresterten Fettsäuren wurde das

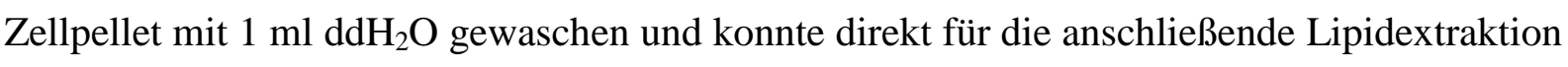
verwendet oder bei $-20{ }^{\circ} \mathrm{C}$ gelagert werden.

\subsubsection{Lipidextraktion aus Saccharomyces cerevisiae}

Für die Extraktion der Lipide aus S. cerevisiae wurde eine modifizierte Methode nach (Bligh und Dyer, 1959) verwendet, welche auf einer Chloroform-Methanol-Extraktion beruht. Für 
die Analyse der intrazellulär freien und veresterten Fettsäuren wurde das Zellpellet in $1 \mathrm{ml}$ $\mathrm{ddH}_{2} \mathrm{O}$ resuspendiert und in ein $10 \mathrm{ml}$ Schliffglas mit Glasperlen $(\varnothing 0,25$ bis $0,5 \mathrm{~mm})$ zum Aufschluss der Zellen gegeben. Der Überstand mit den freien Fettsäuren wurde ebenso in ein $10 \mathrm{ml}$ Schliffglas überführt. Die Extraktionslösung setzte sich aus $25 \mu 11 \mathrm{M} \mathrm{HCl}$, dem internen Standard Heptadecansäure für freie Fettsäuren und Triheptadecanoat für veresterte Fettsäuren) und $3 \mathrm{ml}$ Chloroform-Methanol (2:1, v/v) zusammen. Die Extraktionslösung mit dem Pellet wurde 3 min kräftig geschüttelt. Anschließend wurden die Lipide durch starkes Schütteln im Kühlraum bei $4{ }^{\circ} \mathrm{C}$ für 2 Stunden extrahiert.

Für eine deutliche Phasentrennung wurde nach der Extraktion $1 \mathrm{ml}$ 0,9 \% NaCl-Lösung zugegeben und bei 160 x $g$ für 5 min zentrifugiert. Danach wurde die untere organische Phase mit einer Glaspipette in ein neues Schliffglas transferiert und unter einem Stickstoffstrom bis zur Trockene eingeengt. Der gewonnene Lipidextrakt wurde in $100 \mu 1$ Chloroform-Methanol $(1: 1, \mathrm{v} / \mathrm{v})$ aufgenommen und bei $-20^{\circ} \mathrm{C}$ aufbewahrt. Jeweils $50 \mu 1$ des Lipidextraktes wurde für die Methylierung (2.11.1.4) der freien Fettsäuren und für die Transmethylierung (2.11.1.5) von veresterten Fettsäuren verwendet.

\subsubsection{Lipidextraktion aus Arabidopsis thaliana}

150 - 200 mg unter flüssigem Stickstoff gemörsertes Blattmaterial wurde für die Analyse der Lipide aus A. thaliana eingesetzt. Das gemörserte Blattmaterial wurde in ein Schliffglas überführt und in $3 \mathrm{ml}$ Extraktionslösung (2.11.1.2) durch kräftiges Schütteln bei $4{ }^{\circ} \mathrm{C}$ für 90 min extrahiert. Anschließend wurde $1 \mathrm{ml} \mathrm{0,9 \%} \mathrm{NaCl-Lösung} \mathrm{zugegeben} \mathrm{und} \mathrm{bei} 160 \mathrm{x} g$ für 5 min zentrifugiert. Danach wurde die untere organische Phase in ein neues Schliffglas transferiert und unter einem Stickstoffstrom bis zur Trockene eingeengt. Der gewonnene Lipidextrakt wurde in $100 \mu$ l Chloroform-Methanol (1:1, v/v) aufgenommen und bei $-20{ }^{\circ} \mathrm{C}$ aufbewahrt. Für die Methylierung (2.11.1.4) $80 \mu \mathrm{l}$ und für die Transmethylierung (2.11.1.5) $20 \mu 1$ des Lipidextraktes verwendet.

\subsubsection{Methylierung der freien Fettsäuren}

Für die Methylierung (Stumpe et al., 2001) wurde die bei der Lipid-Extraktion (2.11.1.2 und 2.11.1.3) erhaltene Chloroform-Methanol-Phase unter Stickstoff bis zur Trockene eingeengt und mit Methanol auf $400 \mu 1$ aufgefüllt. Anschließend wurden $10 \mu 1$ einer EDAC-Lösung $(0,1$ g 1-Ethyl-3-(3-Dimethyl-aminopropyl)carbodiimid)/ $1 \mathrm{ml}$ Methanol) zur Probe gegeben und 
für $2 \mathrm{~h}$ bei RT inkubiert. Die Reaktion wurde durch Zugabe von $200 \mu$ l gesättigtes $\mathrm{NaCl}$ gestoppt. Zur Extraktion der methylierten Fettsäuren wurde $1 \mathrm{ml}$ Hexan zugegeben und das Gemisch kräftig geschüttelt. Durch Zentrifugation bei 200 x $g$ für 2 min wurde das Gemisch in zwei Phasen getrennt. Die obere Hexanphase wurde vorsichtig mit einer Glaspipette in ein 1,5 ml Eppendorfgefäß überführt und unter Stickstoff bis zur Trockene eingeengt. Der Rückstand wurde in $10 \mu \mathrm{l}$ Acetonitril aufgenommen und stand damit für die Gaschromatographie bereit.

\subsubsection{Transmethylierung von veresterten Fettsäuren}

Für die basenkatalysierte Transmethylierung (Christie, 1982) wurde der Lipidextrakt (2.11.1.2 und 2.11.1.3) in einem $2 \mathrm{ml}$ Reaktionsgefäß unter Stickstoff bis zur Trockene eingeengt. Anschließend wurde die Probe in $333 \mu \mathrm{l}$ Methanol:Toluol $(2: 1, \mathrm{v} / \mathrm{v})$ und $167 \mu 10,5 \mathrm{M}$ Natriummethoxid aufgenommen. Das Gemisch wurde bei RT für 20 min inkubiert. Zur Extraktion der transmethylierten Fettsäuren wurde $1 \mathrm{ml}$ Hexan zugegeben und das Gemisch kräftig geschüttelt. Die Reaktion wurde durch Zugabe von $500 \mu 11 \mathrm{M} \mathrm{NaCl}$ und $50 \mu \mathrm{HCl}$ (32\%) gestoppt.

Durch Zentrifugation bei 5000 x $g$ für 1 min wurde das Gemisch in 2 Phasen getrennt. Die obere Hexanphase wurde vorsichtig mit einer Glaspipette in ein 1,5 ml Eppendorfgefäß überführt und unter Stickstoff bis zur Trockene eingeengt. Der Rückstand wurde in $10 \mu 1$ Acetonitril aufgenommen und stand damit für die Gaschromatographie bereit.

\subsubsection{Dünnschichtchromatographie}

\subsubsection{Dünnschichtchromatographie für Lipidextrakte}

Die einzelnen Lipidklassen wurden mit Hilfe der Dünnschichtchromatographie (DC) aufgetrennt. Die Dünnschichtplatten (Kieselgel 60, 10 x $20 \mathrm{~cm}$ oder 20 x $20 \mathrm{~cm}$; Merck, Darmstadt, Deutschland) wurden mit dem Gesamtlipidextrakt (2.11.1.2 und 2.11.1.3) beladen. Für die Auftrennung der Neutrallipide diente Hexan/Diethylether/Eisessig (80:20:1, v/v/v) und für die Auftrennung der Phospholipide Chloroform/Methanol/Eisessig (65:25:8, v/v/v) als Laufmittel. Authentische Lipidstandards dienten der Identifizierung der Lipide. Die Visualisierung der Lipide erfolgte für analytische Zwecke durch Inkubation in einer $\mathrm{CuSO}_{4}$ Lösung (10 g CuSO 4 x $\left.5 \mathrm{H}_{2} \mathrm{O}, 92 \mathrm{ml} \mathrm{H}_{2} \mathrm{O}, 8 \mathrm{ml} \mathrm{H}_{3} \mathrm{PO}_{4}\right)$ und anschließender Erhitzung der Dünnschichtplatte auf $180{ }^{\circ} \mathrm{C}$. Für präparative Zwecke wurden die Lipide im Anschluss an die 
Auftrennung durch $0.2 \%$ 8-anilino-1-naphthalene-sulfonic acid (ANS) unter UV-Licht $(\lambda=$ $365 \mathrm{~nm}$ und $254 \mathrm{~nm}$ ) visualisiert. Anschließend wurden die einzelnen Fraktionen mit dem Kieselgel von der Dünnschichtplatte abgekratzt und direkt für die Transmethylierung der Fettsäuren eingesetzt (2.11.1.5).

\subsubsection{Analyse von Triacylglycerolen (TAG) aus Arabidopsis thaliana}

Für die Quantifizierung von TAG wurden 180 - 200 mg gemörsertes Blattmaterial verwendet. Als interner Standard wurde $3 \mu \mathrm{g}$ Triheptadecanoat eingesetzt. Nach der Extraktion (2.11.1.3) wurde der gesamte Lipidextrakt auf die Dünnschichtplatte (Kieselgel 60, 10 x $20 \mathrm{~cm}$ oder 20 x 20 cm; Merck, Darmstadt, Deutschland) aufgetragen. Die abgekratzte Fraktion (2.11.2.1) wurde direkt für die Transmethylierung (2.11.1.5) eingesetzt.

\subsubsection{Analyse von Triacylglycerolen (TAG) aus Saccharomyces cerevisiae}

Das Zellsediment von einer $10 \mathrm{ml}$ S.cerevisiae-Kultur $\left(\mathrm{OD}_{600} \geq 6\right)$ wurde in $1 \mathrm{ml} \mathrm{ddH}_{2} \mathrm{O}$ resuspendiert und in ein Glasreaktionsgefäß mit Glasperlen $(\varnothing 0,25$ bis $0,5 \mathrm{~mm})$ überführt. Nach der Zugabe der Extraktionslösung (3 ml Chloroform/Methanol (2:1, v/v), 10 - $15 \mu \mathrm{g}$ Triheptadecanoat und $25 \mu \mathrm{l} 1 \mathrm{M} \mathrm{HCl}$ ) wurde die Probe für 5 min kräftig geschüttelt. Anschließend wurden die Lipide durch sehr intensives Schütteln bei $4{ }^{\circ} \mathrm{C}$ für 3 Stunden extrahiert. Nach abgeschlossener Extraktion (2.11.1.2) wurde die der gesamte Lipidextrakt auf die Dünnschichtplatte aufgetragen. Die abgekratzte Fraktion (2.11.2.1) wurde direkt für die Transmethylierung (2.11.1.5) eingesetzt.

\subsubsection{Gaschromatographische Analyse}

Fettsäuremethylester (FAME) sind bei hohen Temperaturen in die Gasphase überführbar. Diese Eigenschaft wurde während der gaschromatographischen Trennung mit der Agilent GC 6890 Serie ausgenutzt. Die Auswertung der Signalflächen erfolgte mit der ChemStationSoftware (Rev. A. 10.02; Agilent, Waldbronn, Deutschland). 
Säule:

122-2332, DB-23, $30 \mathrm{~m}$ x 0,25 mm, Filmdicke $0,25 \mu \mathrm{m}$

(J\&W Scientific, Agilent, Böblingen, Deutschland)

Trägergas: $\quad$ Helium (konstante Flussrate: $1 \mathrm{ml} / \mathrm{min}$ )

Injektion: $\quad$ Split-Modus, $220^{\circ} \mathrm{C}$

Detektor: $\quad$ Flammen-Ionisations-Detektor (FID)

Temperatur- Gradient für Hefe:

\begin{tabular}{ccc}
\hline${ }^{\circ} \mathbf{C} / \mathbf{m i n}$ & Temperatur & Dauer \\
\hline & $150{ }^{\circ} \mathrm{C}$ & $1 \mathrm{~min}$ \\
10 & $170{ }^{\circ} \mathrm{C}$ & $0 \mathrm{~min}$ \\
4 & $200{ }^{\circ} \mathrm{C}$ & $0 \mathrm{~min}$ \\
25 & $250^{\circ} \mathrm{C}$ & $0 \mathrm{~min}$ \\
& $250{ }^{\circ} \mathrm{C}$ & $4 \mathrm{~min}$ \\
\hline
\end{tabular}

Temperatur-Gradient für Pflanzen:

\begin{tabular}{ccc}
\hline${ }^{\circ} \mathbf{C} / \mathbf{m i n}$ & Temperatur & Dauer \\
\hline \multirow{2}{*}{8} & $150^{\circ} \mathrm{C}$ & $1 \mathrm{~min}$ \\
25 & $200^{\circ} \mathrm{C}$ & $0 \mathrm{~min}$ \\
& $250^{\circ} \mathrm{C}$ & $0 \mathrm{~min}$ \\
& $250^{\circ} \mathrm{C}$ & $6 \mathrm{~min}$ \\
\hline
\end{tabular}

\subsubsection{Fütterung von Saccharomyces cerevisiae mit radioaktiv markierten Fettsäuren und Extraktion der Lipide}

Eine Übernachtkultur wurde in $100 \mathrm{ml}$ YEPR-Medium auf eine optische Dichte OD $_{600}$ von 0,3 verdünnt. Die Zellen wurden bis zur stationären Phase $(48 \mathrm{~h})$ bei $30{ }^{\circ} \mathrm{C}$ und $210 \mathrm{Upm}$ geschüttelt. Von jeder Kultur wurden $4 \mathrm{ml}$ Zellsuspension in $13 \mathrm{ml}$ Plastikröhrchen überführt, $0,27 \mu \mathrm{Ci}{ }^{14} \mathrm{C}$-Ölsäure $\left[1-{ }^{14} \mathrm{C}\right]$ hinzugegeben und die Proben für weitere $24 \mathrm{~h}$ bei $30{ }^{\circ} \mathrm{C}$ und $210 \mathrm{Upm}$ geschüttelt. Anschließend wurden jeweils $3 \mathrm{ml}$ Kultur in einem $2 \mathrm{ml}$ 
Reaktionsgefäß mit Glasperlen bei 950 x $g$ für 5 min pelletiert und zweimal in $0,1 \mathrm{M}$ $\mathrm{NaHCO}_{3}$ gewaschen. Das Zellpellet wurde in $1,5 \mathrm{ml}$ Chloroform-Methanol (2:1, v/v) aufgenommen und $50 \mu \mathrm{HCl}(32 \%)$ hinzugefügt. Die Ansätze wurden für 5 min stark geschüttelt und anschließend weitere $5 \mathrm{~h}$ bei RT geschüttelt. Nachfolgend wurden $500 \mu \mathrm{l}$ 0,45\% NaCl-Lösung hinzugefügt und eine Phasentrennung mittels Zentrifugation bei $950 \mathrm{x}$ $g$ für 5 min durchgeführt. Die untere Phase wurde in ein 1,5 ml Reaktionsgefäß transferiert und unter einem Stickstoffstrom bis zur Trockene eingeengt. Der Lipidextrakt wurde in $40 \mu 1$ Chloroform-Methanol (1:1, v/v) aufgenommen und bei $-20^{\circ} \mathrm{C}$ gelagert.

\subsubsection{Dünnschichtchromatographie radioaktiv markierter Lipidextrakte}

$10 \mu 1$ des Lipidextrakts wurden auf eine Dünnschichtplatte (Kieselgel 60, $20 \times 20 \mathrm{~cm}$; Merck, Darmstadt, Deutschland) aufgetragen. Authentische Lipidstandards dienten der Identifizierung der Lipide. Für die Auftrennung der Lipide wurden zwei verschieden Laufmittel genutzt. Die Phospholipide wurden in Essigsäuremethylester/Isopropanol/Chloroform/Methanol/0,25\% $\mathrm{KCl}$ (w/v) (25/25/28/10/7, v/v/v/v/v) aufgetrennt. Nachdem die Proben eine Laufstrecke von etwa zwei Drittel zurückgelegt hatten, wurde die DC-Alufolie getrocknet und für die Auftrennung der Neutrallipide von den freien Fettsäuren in Chloroform/Aceton (80/20, v/v) und $1 \%$ Ammoniak ein weiteres Mal entwickelt.

Eine computergestützte Visualisierung radioaktiv-markierter Fettsäuren und Lipide wurde mittels Phosphoimaging durchgeführt. Die Exposition erfolgte bei Raumtemperatur für $24 \mathrm{~h}$. Anschließend wurden die Signale durch den Phosphoimager FLA3000 (Fujifilm, Düsseldorf, Deutschland) ausgelesen und mit der Software AIDA ausgewertet.

\subsection{HPLC (High performance liquid chromatography)}

\subsubsection{Extraktion von Acyl-CoA-Estern aus S. cerevisiae (modifiziert nach Rosendal und Knudsen, 1992)}

$\mathrm{Zu} 10 \mathrm{ml}$ einer $S$. cerevisiae-Kultur $\left(\mathrm{OD}_{600} \geq 6\right)$ wurde $1 / 10$ Vol. 6,6 M Perchlorsäure hinzugegeben. Die Zellen wurden bei 3200 x $g$ für 5 min bei $4{ }^{\circ} \mathrm{C}$ sedimentiert. Das Pellet wurde in $3 \mathrm{ml} 10 \mathrm{mM}$ Perchlorsäure gewaschen und nach erneuter Zentrifugation bei $-80{ }^{\circ} \mathrm{C}$ gelagert oder sofort zur Extraktion der Acyl-CoA-Ester verwendet. 
Alle folgenden Schritte der Extraktion wurden auf Eis durchgeführt. Als interner Standard wurden Heptadecanoyl-CoA (0,05 nmol) mitgeführt. Das Zellpellet wurde in $800 \mu 1 \mathrm{ddH}_{2} \mathrm{O}$. aufgenommen Nach der Zugabe von $3 \mathrm{ml}$ Chloroform/Methanol (2:1, v/v) und Glasperlen (Ø 0,25 bis 0,5 mm), erfolgte der Zellaufschluss durch kräftiges Schütteln (Vortex) für $10 \mathrm{~min}$ und leichteres Schütteln für $30 \mathrm{~min}$ bei $4{ }^{\circ} \mathrm{C}$. Anschließend wurden $1 \mathrm{ml}$ Chloroform und $1 \mathrm{ml}$ $\mathrm{ddH}_{2} \mathrm{O}$ hinzugegeben und die Probe erneut für $30 \mathrm{~s}$ stark geschüttelt. Die Phasentrennung erfolgte im nachfolgenden Zentrifugationsschritt $3200 \mathrm{x} g$ für 5 min bei $4{ }^{\circ} \mathrm{C}$. Nach Entnahme der Ober- und der Unterphase wurde die verbleibende acyl-CoA-haltige Interphase unter Stickstoff bis zur Trockene eingeengt.

Die Extraktion der Acyl-CoA-Ester erfolgte durch Zugabe von $400 \mu 1$ Extraktionspuffer, $10 \mu \mathrm{l}$ gesättigter Ammoniumsulfatlösung und 1,2 ml Chloroform/Methanol (1:2, v/v) und anschließendes kräftiges Schütteln für mindestens 3 min. Die Ansätze wurden nun für 20 min bei Raumtemperatur inkubiert und danach für 5 min bei $3200 \times g$ und $4{ }^{\circ} \mathrm{C}$ zentrifugiert. Der Überstand wurde in ein 1,5 ml Reaktionsgefäß überführt, mögliche feste Rückstände für $2 \mathrm{~min}$ bei $20.000 \times \mathrm{g}$ pelletiert und der klare Überstand anschließend in ein 1,5 ml Reaktionsgefäß transferiert. Der Überstand wurde bei $50{ }^{\circ} \mathrm{C}$ unter Stickstoff bis zur Trockene eingeengt und zur Derivatisierung (2.12.3) eingesetzt.

Extraktionspuffer: $2 \mathrm{ml}$ Isopropanol

$2 \mathrm{ml} \mathrm{KH}_{2} \mathrm{PO}_{4}(\mathrm{pH} \mathrm{7,2)}$

$50 \mu 1$ Essigsäure

$80 \mu \mathrm{l} \mathrm{BSA}(50 \mathrm{mg} / \mathrm{ml}$, entfettet)

\subsubsection{Extraktion von Acyl-CoA-Ester aus A. thaliana (Larson und Graham, 2001)}

50 - $70 \mathrm{mg}$ unter flüssigem Stickstoff gemörsertes Blattmaterial wurden in ein Eppendorfgefäß überführt und in $200 \mu$ Extraktionspuffer (2.12.1) homogenisiert. Als interner Standard wurde Heptadecanoyl-CoA (37,5 pmol) hinzugefügt. In den nachfolgenden Waschschritten wurden Lipide und Pigmente entfernt. Nach Zugabe von $300 \mu 1$ Waschpuffer (Petroleum Ether $40-60{ }^{\circ} \mathrm{C}$ gesättigt mit Isopropanol/Wasser (1:1, v/v) wurden die Proben für 1 min bei 100 x $g$ zentrifugiert und die Oberphase verworfen. Dieser Schritt wurde dreimal wiederholt. Anschließend wurden $5 \mu$ gesättigte Ammoniumsulfatlösung und $600 \mu \mathrm{l}$ 
Methanol/Chloroform (2:1, v/v) zugegeben. Die Ansätze wurden gemischt und für 20 min bei RT inkubiert. Nach Zentrifugation bei 16000 x $g$ für 2 min wurde der Überstand in ein neues Eppendorfgefäß überführt und bei $50{ }^{\circ} \mathrm{C}$ unter einem Stickstoffstrom bis zur Trockene eingedampft und zur Derivatisierung (2.12.3) eingesetzt.

\subsubsection{Derivatisierung von Acyl-CoA-Estern (Larson und Graham, 2001)}

$\mathrm{Zu}$ den bis zur Trockene eingeengten Proben wurden $200 \mu \mathrm{l}$ Derivatisierungsreagenz gegeben. Die Derivatisierung der Acyl-CoA-Ester erfolgte in Gegenwart von Chloroacetaldehyd für $20 \mathrm{~min}$ bei $85{ }^{\circ} \mathrm{C}$. Dabei wurde die Adenineinheit des Coenzyms A durch eine fluoreszierende etheno-Gruppe modifiziert. Die Proben konnten direkt zur HPLCAnalyse verwendet oder bei $-20{ }^{\circ} \mathrm{C}$ gelagert werden.

Derivatisierungsreagenz: $\quad 0,5 \mathrm{M}$ Chloroacetaldehyd

$$
\begin{aligned}
& 0,15 \text { M Citratpuffer }(\mathrm{pH} 4,0) \\
& 0,5 \%(\mathrm{w} / \mathrm{v}) \mathrm{SDS}
\end{aligned}
$$

\subsubsection{HPLC-Analyse von Acyl-etheno-CoA-Estern (Larson und Graham, 2001)}

Die HPLC-Analysen wurden mit einem Agilent 1100 HPLC-System (Agilent, Waldbronn, Deutschland) durchgeführt. Für die Auftrennung der Acyl-etheno-CoA-Ester (2.12.3) wurde eine LUNA 150 x 2,0 mm Säule (Phenomenex, Aschaffenburg, Deutschland) verwendet. Als Vorsäule wurde eine 4 x 2 mm Phenyl-Propyl-Säule (Phenomenex, Aschaffenburg, Deutschland) benutzt. Die Acyl-etheno-CoA-Ester wurden unter alkalischen Bedingungen in der Gegenwart von Triethylamin von der Säule eluiert. Die Detektion erfolgte mit einem Fluoreszenzdetektor. Die Anregungswellenlänge betrug $230 \mathrm{~nm}$ und die Emissionswellenlänge $420 \mathrm{~nm}$. Mit der ChemStation-Software (Rev. A. 10.02; Agilent, Waldbronn, Deutschland) wurden die Signalflächen integriert und quantifiziert. 


\section{Laufmittel}

\begin{tabular}{ll} 
A & $\mathrm{H}_{2} \mathrm{O} /$ Essigsäure $(100: 1 \mathrm{v} / \mathrm{v})$ \\
$B$ & Acetonitril/ $\mathrm{H}_{2} \mathrm{O} /$ Essigsäure $(90: 9: 1 \mathrm{v} / \mathrm{v} / \mathrm{v})$ \\
$C$ & $\mathrm{H}_{2} \mathrm{O} /$ Triethylamin $(100: 0,25 \mathrm{v} / \mathrm{v})$ \\
$D$ & Acetonitril/ $/ \mathrm{H}_{2} \mathrm{O}(90: 10 \mathrm{v} / \mathrm{v})$ \\
\hline
\end{tabular}

Gradient:

\begin{tabular}{cccccc}
\hline Zeit (min) & \% C & \% C & \% D & Fluss (ml/min) & $\begin{array}{c}\text { Druck } \\
(\text { bar })\end{array}$ \\
\hline 0 & 10 & 0 & 0 & 0,4 & 300 \\
5 & 80 & 0 & 0 & 0,4 & 300 \\
5,1 & 0 & 80 & 0 & 0,4 & 300 \\
7 & 0 & 97 & 3 & 0,4 & 300 \\
10 & 0 & 95 & 5 & 0,4 & 300 \\
10,1 & 0 & 95 & 5 & 0,4 & 300 \\
50 & 0 & 55 & 45 & 0,4 & 300 \\
51,1 & 0 & 0 & 100 & 0,4 & 300 \\
52 & 0 & 0 & 100 & 0,4 & 300 \\
62 & 0 & 0 & 100 & 0,4 & 300 \\
62,1 & 10 & 0 & 0 & 0,4 & 300 \\
\hline
\end{tabular}




\subsection{Extraktion und Bestimmung der Phytohormone aus A. thaliana}

Für die MTBE-Extraktion (Matyash et al., 2008) der Phytohormone wurden 100 - 150 mg unter flüssigem Stickstoff gemörsertes Blattmaterial in ein Kimble-Glas überführt und in 0,75 $\mathrm{ml}$ Methanol und 2,5 ml MTBE (Methyl-tert-butylether) homogenisiert. Anschließend wurde der interne Standardmix hinzugefügt und die Proben für $1 \mathrm{~h}$ bei RT im Dunkeln geschüttelt. Nach Zugabe von $600 \mu 1 \mathrm{ddH}_{2} \mathrm{O}$ wurden die Proben für $15 \mathrm{~min}$ bei $450 \mathrm{x} g$ zentrifugiert und der Überstand in ein neues Kimble-Glas überführt. Der Unterphase wurden $0,7 \mathrm{ml}$ $\mathrm{MetOH} / \mathrm{H}_{2} \mathrm{O}(3: 2,5$, v/v) und 1,3 ml MTBE (Methyl-tert-butylether) zugegeben und nach kräftigem Schütteln für 15 min bei 450 x $g$ zentrifugiert. Beide Überstände wurden vereinigt und unter Stickstoff eingedampft. Der Rückstand wurde mit MetOH in ein $1,5 \mathrm{ml}$ Eppendorfgefäß überführt und erneut unter Stickstoff bis zur Trockene eingeengt. In $20 \mu 1$ $\mathrm{MeCN}$ wurde der Extrakt durch starkes Schütteln aufgenommen. Nach anschließender Zugabe von $80 \mu \mathrm{l} \mathrm{H}_{2}$ /HOAc wurden die Proben für 2 min bei 20000 x $g$ pelletiert und der klare Überstand in ein HPLC-Glas mit Einsatz überführt. Die Proben konnten direkt zur Analyse verwendet oder bei $-20{ }^{\circ} \mathrm{C}$ gelagert werden.

Die Extraktion wurde unter geringem Lichteinfluss durchgeführt, um eine Photoisomerisation von $\mathrm{ABA} z u$ trans-ABA zu verhindern.

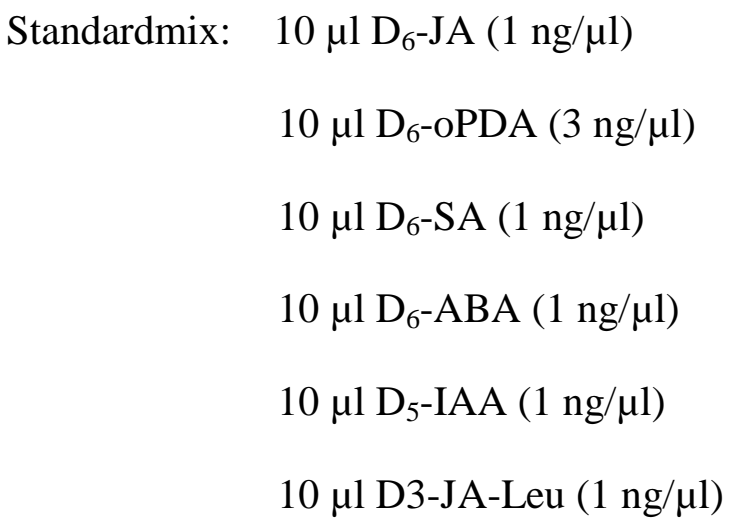




\subsection{Massenspektroskopische Analyse (MS)}

Zur massenspektrometischen (MS) Analyse der unbekannten Intermediate wurden die entsprechenden HPLC-Fraktionen zehnfach in 85:15:0,1 Methanol:Wasser:Essigsäure verdünnt. Mit einer Flussrate von 250 nl/min wurden $5 \mu 1$ in ein „Applied Biosystems“ 4000 Hybrid-Triplequadrupol/Lineare-Ionenfalle-Massenspektrometer (MDS Sciex, Ontario, Canada) infundiert. Die Nanoelektrospray-Analyse von negativen Ionen erfolgte mit einer Chip-gesteuerten Ionenquelle (TriVersa NanoMate; Advion BioSciences, Ithaca, NY, USA) bei einer Ionisierungsspannung von $1.25 \mathrm{kV}$ und einem Gasdruck von 0.2 psi. Die Ionen wurden in einem Massenbereich von $m / z 450$ bis 1100 mit „unit“-Massenauflösung bei einem Entclusterungspotential von $-180 \mathrm{~V}$ sowie einem Eingangspotential von $-10 \mathrm{~V}$ detektiert. Zur weiteren Identifizierung dieser Intermediate wurden Produktionen-Analysen durchgeführt, um die entsprechenden Fragmentionen zu detektieren. Diese Tandem-MS-Analysen wurden in einem Massenbereich von $\mathrm{m} / z, 50$ bis 1100 und bei einer Kollisionsenergie von -55 bis $-63 \mathrm{~V}$ mit Stickstoff in der Kollisionszelle, einem Entclusterungspotential von -180 V sowie einem Eingangspotential von -10 V durchgeführt. Die Fragmentionen wurden mit einer Schrittweite von 0.1 Da und bei den Geräteeinstellungen für ,unit“-Massenauflösung detektiert. 


\subsection{Elektronenmikroskopie}

\subsubsection{Kultivierung und Fixierung der Zellen}

Die Kultivierung der S. cerevisiae-Zellen erfolgte in YPER Medium (2.5.1) bei $30^{\circ} \mathrm{C}$. Von dieser Zellkultur wurden Proben während exponentieller und stationärer Phase entnommen und die Zellen durch Zentrifugation sedimentiert(10 min bei $5000 \mathrm{x} g$ ). Anschließend wurden die Zellen in 1x Phosphat-gepufferter Saline (PBS) gewaschen und für 90 min auf Eis in einer Fixierlösung aus 0,3\% (v/v) Glutaraldehyd und 0,5\% Formaldehyd (angesetzt aus Paraformaldehyd) inkubiert. Nach Ablauf der Inkubationszeit wurden die Zellen dreimal mit eiskalter PBS (mit zusätzlich 10 mM Glycin) gewaschen. Aus den Proben wurden 50 -150 $\mu 1$ Aliquots in Eppendorfgefäße überführt und mit 1,5\%-igem (w/v) Bacto-Agar (in PBS) vermischt, der bei $45{ }^{\circ} \mathrm{C}$ flüssig gehalten wurde. Nachdem Erstarren des Agars wurde die Probe aus dem Gefäß herausgelöst und in kleine Blöckchen von ca. $1 \mathrm{~mm}$ Länge zerteilt.

\subsubsection{Entwässerung und Einbettung}

Die Agarblöckchen wurden in Schraubdeckelgläschen überführt und mit wässriger MethanolLösung bzw. Kunstharzlösung nach unten aufgeführtem Schema infiltriert.

\begin{tabular}{|c|c|c|}
\hline Medium & $\begin{array}{l}\text { Inkubationszeit (angegeben } \\
\text { sind Mindestzeiten für } \\
\text { Bakterien) }\end{array}$ & Inkubationstemperatur \\
\hline $\begin{array}{l}15 \%(w / v) \text { Methanol in } \\
d_{d H_{2} O}\end{array}$ & $15 \mathrm{~min}$ & $0^{\circ} \mathrm{C}$ \\
\hline $30 \%$ Methanol & $30 \mathrm{~min}$ & $0^{\circ} \mathrm{C}$ \\
\hline $50 \%$ Methanol & $30 \mathrm{~min}$ & $-20^{\circ} \mathrm{C}$ \\
\hline $70 \%$ Methanol & $30 \mathrm{~min}$ & $-35^{\circ} \mathrm{C}$ \\
\hline $95 \%$ Methanol & $30 \mathrm{~min}$ & $-35^{\circ} \mathrm{C}$ \\
\hline $100 \%$ Methanol & $2 \times 30 \mathrm{~min}$ & $-35^{\circ} \mathrm{C}$ \\
\hline $\begin{array}{l}50 \% \text { Methanol/50 \% Lowicryl } \\
\text { K4M Harz }\end{array}$ & $1 \mathrm{~h}$ & $-35^{\circ} \mathrm{C}$ \\
\hline $33 \%$ Methanol/66 \% Harz & $2 \mathrm{~h}$ & $-35^{\circ} \mathrm{C}$ \\
\hline $100 \%$ Harz & $\begin{array}{l}1 \mathrm{x} \text { kurz wechseln, dann über } \\
\text { Nacht }\end{array}$ & $-35^{\circ} \mathrm{C}$ \\
\hline
\end{tabular}


Die Proben wurden anschließend in mit frischem Kunstharz gefüllte Gelatinekapseln überführt. Das Harz wurde jeweils für mindestens $24 \mathrm{~h}$ bei $-35^{\circ} \mathrm{C}$ und anschließend für 3 Tage bei RT mit UV-Licht (360 nm) polymerisiert.

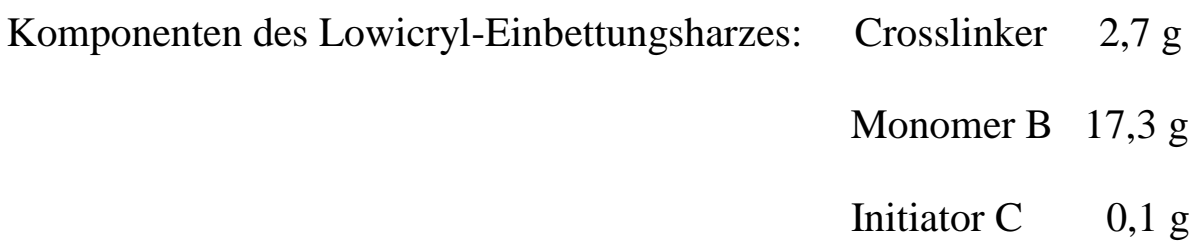

\subsubsection{Ultramikrotomie}

Die Polymerisierten Proben wurden mit einer Diamantfräse (TM 60, Feichert, Österreich) angespitzt, so dass ein Pyramidenstumpf mit einer quadratischen Spitze von maximal 0,5 $\mathrm{mm}^{2}$ Oberfläche entstand. Die Dünnschnitte wurden mit einem Ultramikrotom (Ultrotome III, LKB, Bromma, Schweden) unter Verwendung von Glasmessern angefertigt. Die Ultradünnschnitte hatten eine Dicke von 80-100 nm und wurden mit formvarbeschichteten Nickelgrids aufgenommen. Die Grids wurden bis zur weiteren Verwendung mit der Schnittseite auf Tropfen Phosphat-gepufferter Saline (PBS) abgelegt.

Die Elektronenmikroskopie wurde mit Hilfe des Philips EM 301 Transmissionelektronenmikroskops (Philips, Eindhoven, Niederlande) durchgeführt. 


\section{Ergebnisse}

\subsection{Fettsäuretransport durch die zelluläre Membran in Saccharomyces cerevisiae}

Verursacht durch die Doppeldeletion der Acyl-CoA-Synthetasen FAA1 und FAA4 wurde ein Phänotyp etabliert, der durch einen massiven Export von freien Fettsäuren während der exponentiellen Phase und einen Re-Import von freien Fettsäuren während der stationären Phase charakterisiert ist. Der Re-Import von freien Fettsäuren resultiert in einem drastischen Anstieg der intrazellulären Fettsäuren (Scharnewski et al., 2008). Im Rahmen der vorliegenden Arbeit wurde dieser Phänotyp genutzt, um einen im Detail noch nicht verstandenen Transportmechanismus von freien Fettsäuren durch die Plasmamembran in $S$. cerevisiae genauer zu untersuchen. Für die Durchführung weiterer Transportstudien wurde als Ausgangpunkt dieser Untersuchungen die Mutante YB526 (faal $\Delta$ faa2 $\Delta$ faa $3 \Delta f a a 4 \Delta$ ) verwendet, bei der alle vier bekannten Acyl-CoA-Synthetasen inaktiviert wurden.

\subsubsection{Fat1p ist zuständig für die restliche Acyl-CoA-Synthetase-Aktivität in der Mutante YB526}

Um den Fettsäuretransport in Abwesenheit jeglicher Acyl-CoA-Synthetase-Aktivität untersuchen $\mathrm{zu}$ können, wurden im Hintergrund der Mutante YB526 $(f a a 1 \Delta f a a 2 \Delta f a a 3 \Delta f a a 4 \Delta)$ zusätzlich mögliche Kandidatengene inaktiviert, die für Proteine mit Acyl-CoA-Synthetase-Aktivität kodieren könnten. Neben den FAA-Genen wurde außerdem für Fat1p Acyl-CoA-Synthetase-Aktivität in vitro nachgewiesen. Dabei zeigte sich, dass Fat1p eine Präferenz für die Aktivierung sehr langkettiger Fettsäuren besitzt (Watkins et al., 1998). FAT1 wurde daher in dem Hintergrund der Mutante YB526 deletiert und auf diese Weise die Mutante MS51 (faal $\Delta$ faa $2 \Delta f a a 3 \Delta f a a 4 \Delta f a t 1 \Delta$ ) erzeugt. Die zusätzliche Deletion von FAT1 führte zu einer noch stärkeren Akkumulation von freien Fettsäuren in den Zellen im Vergleich zur Mutante YB526 (Scharnewski et al., 2008). Dies ließ eine Beteiligung von Fat1p als Acyl-CoA-Synthetase an der Aktivierung freier Fettsäuren vermuten. Außerdem wurde das Gen FAT2 in Hefe identifiziert, welches eine hohe Sequenzähnlichkeit zu FAT1 aufweist. Enzymatische Daten sind für Fat2p nicht verfügbar aber aufgrund der Sequenzähnlichkeit kann über eine Funktion als Acyl-CoA-Synthetase spekuliert werden. Die 
Expression von FAT2 wird durch Ölsäure induziert und das Enzym Fat2p ist in den Peroxisomen lokalisiert (Blobel und Erdmann, 1996). Daher wurde FAT2 in den Mutanten YB526 und MS51 deletiert und dadurch die Mutanten MS52 (YB526 + fat2A) und MS612 $(\mathrm{MS} 51+$ fat2 $\Delta)$ hergestellt. Für einen in vivo-Nachweis der Acyl-CoA-Synthetase-Aktivität wurden verschiedene Stämme mit radioaktiv markierter Ölsäure inkubiert. Die exogenen freien Fettsäuren können nur nach einer erfolgreichen Überführung in den zellulären AcylCoA-Pool, vermittelt durch die Acyl-CoA-Synthetasen, in die verschiedenen Lipide inkorporiert werden. Vor der Zugabe von radioaktiv markierter Ölsäure wurden die Stämme YB332, YB526, MS51, MS52 und MS612 bis zur frühen stationären Phase in YPR-Medium kultiviert. Anschließend wurden die Zellen in Gegenwart von radioaktiv markierter Ölsäure inkubiert. Nach 24 Stunden wurden die Zellen abgeerntet und die Lipide extrahiert. Die Auftrennung der Lipide erfolgte mittels Dünnschichtchromatographie und die inkorporierte Radioaktivität wurde durch ein Radiogramm analysiert (Abb. 4). Wie erwartet, zeigte der Wildtyp für alle Phospholipide und Neutrallipide intensive Signale, während das Signal für die freien Fettsäuren aufgrund der hohen Inkorporationsrate sehr schwach ausgeprägt war. Im Vergleich zum Wildtyp zeigte die Mutante YB526 einen stark reduzierten Einbau der radioaktiv markierten Fettsäure in die Lipide. Die Signale waren ausreichend intensiv, um den Einbau der Fettsäuren in sämtliche Phospholipide (PC, PE, PS und PI) und Neutrallipide (TAG und EE) zweifelsfrei nachweisen zu können. Für die Mutante MS52 ergab der Versuch ein fast identisches Ergebnis wie für YB526. Demnach scheint Fat2p unter den gegebenen Versuchsbedingungen nicht an der Aktivierung importierter freier Fettsäuren beteiligt zu sein. Dagegen wurden bei den Mutanten MS51 und MS612 keine Inkorporation der applizierten Ölsäure in die verschiedenen Lipidklassen nachgewiesen. Das Signal für die freien Fettsäuren war dementsprechend sehr intensiv. Dieses Ergebnis deutet darauf hin, dass in diesen Stämmen keine exogenen Fettsäuren mehr aktiviert werden können. Interessanterweise wurde bei allen Mutanten ein zusätzliches Lipid festgestellt. Dieses Lipid wurde mittels entsprechender Standardsubstanz und Dünnschichtchromatographie als Fettsäureethylester identifiziert. Demzufolge können vermutlich freie Fettsäuren ohne Acyl-CoA-SynthetaseAktivität in Fettsäureethylester umgesetzt werden. Durch das Markierungs-Experiment konnte gezeigt werden, dass allein Fat1p für die verbliebene Acyl-CoA-Synthetase-Aktivität in der Mutante YB526 verantwortlich ist. 


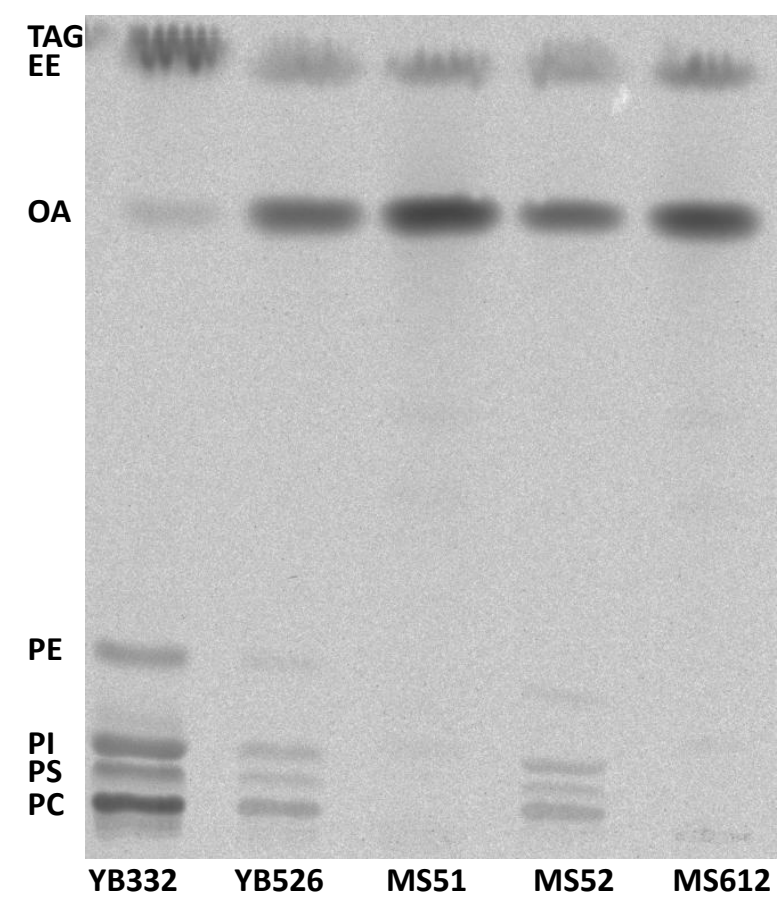

Abb. 4: Fat1p ist verantwortlich für die verbliebene Acyl-CoA-Synthetase-Aktivität in der Mutante YB526. Dünnschichtchromatogramm von Lipidextrakten von verschiedenen Hefestämmen gefüttert mit radioaktiv markierter Ölsäure. Die Hefen wurden in Gegenwart der radioaktiv markierten Ölsäure für $20 \mathrm{~h}$ kultiviert. Die Präparation der Lipidextrakte erfolgte nach der in Abschnitt 2.11.1.2 beschriebenen Methode. Stämme mit Fat1p (YB526, MS52) zeigten eine Inkorporation der supplementierten Ölsäure, während in Abwesenheit von Fatlp und der Faa-Proteine keine Inkorperation von supplementierter Fettsäure nachgewiesen werden konnte. Triacylglycerin (TAG), Phosphatidylcholin (PC), Phosphatidylethanolamin (PE), Phosphatidylinositol (PI), Phosphatidylserin (PS), Fettsäureethylester (EE). Dargestellt ist das repräsentative Ergebnis von drei unabhängigen Experimenten.

\subsubsection{Fat1p ist fähig, die fehlende Acyl-CoA-Synthetase-Aktivität in der Mutante MS51 teilweise zu komplementieren}

Nachdem festgestellt worden ist, dass die Deletion von FAT1 im Hintergrund der Mutante YB526 zum vollständigen Verlust der Aktivierung von exogenen Fettsäuren führt, sollte durch ein zusätzliches Experiment eine direkte Beteiligung von Fat1p an der Aktivierung von freien Fettsäuren in vivo nachgewiesen werden. Hierzu wurde ein Versuch durchgeführt, bei dem FAT1 in der Mutante MS51 überexprimiert wurde. Zum Vergleich wurden zusätzlich die charakterisierten Acyl-CoA-Synthetasen FAA1 und FAA3 als Positiv-Kontrollen verwendet. Als Negativ-Kontrolle diente die Mutante MS51 mit dem enthaltenen Leervektor. Die Zellen wurden in CSM-Medium angezogen. Nach anschließender Entnahme der Proben und Lipidextraktion erfolgte die Analyse der Fettsäurezusammensetzung mittels Gaschromatographie (GC). Die Aktivität der exprimierten Acyl-CoA-Synthetase wurde nicht direkt durch einen Enzymtest bestimmt, sondern indirekt durch Ermittlung der Konzentration 
der freien Fettsäuren in der Mutante MS51. Dabei wurde davon ausgegangen, dass eine höhere Acyl-CoA Synthetase Aktivität eine stärkere Reduktion der freien Fettsäurekonzentration in den Zellen bewirkt.

Die höchste Acyl-CoA-Synthetase-Aktivität zeigten FAAl bzw. FAA3 (Abb. 5). Diese erhöhte Aktivität äußerte sich in sehr geringen Mengen an freien Fettsäuren und erhöhten Konzentrationen veresterter Fettsäuren. Im Vergleich dazu resultierte die Überexpression von FAT1 in einer geringeren Reduktion der Konzentration freier Fettsäuren. Gegenüber der Negativ-Kontrolle wurde jedoch eine deutliche Reduktion der Konzentration von freien Fettsäuren festgestellt. Die Konzentration der veresterten Fettsäuren in den Kulturen mit FAT1-Überexpression war vergleichbar mit den Kulturen der FAA3-Überexpression (Abb. 5). Im Vergleich zu der Überexpression von FAT1 wurden bei der Negativ-Kontrolle aufgrund nicht möglicher Aktivierung von freien Fettsäuren signifikant geringere Mengen an veresterten Fettsäuren detektiert. Korrelierend mit der geringen Konzentration veresterter Fettsäuren wurden sehr hohe Mengen an freien Fettsäuren gemessen. Aufgrund des Vergleiches mit der Kontrolle konnte somit in vivo indirekt eine Beteiligung von Fat1p an der Aktivierung der freien Fettsäuren nachgewiesen werden. Demnach ist Fat1p fähig, die fehlende Acyl-CoA-Synthetase-Aktivität in der Mutante MS51 teilweise zu komplementieren.

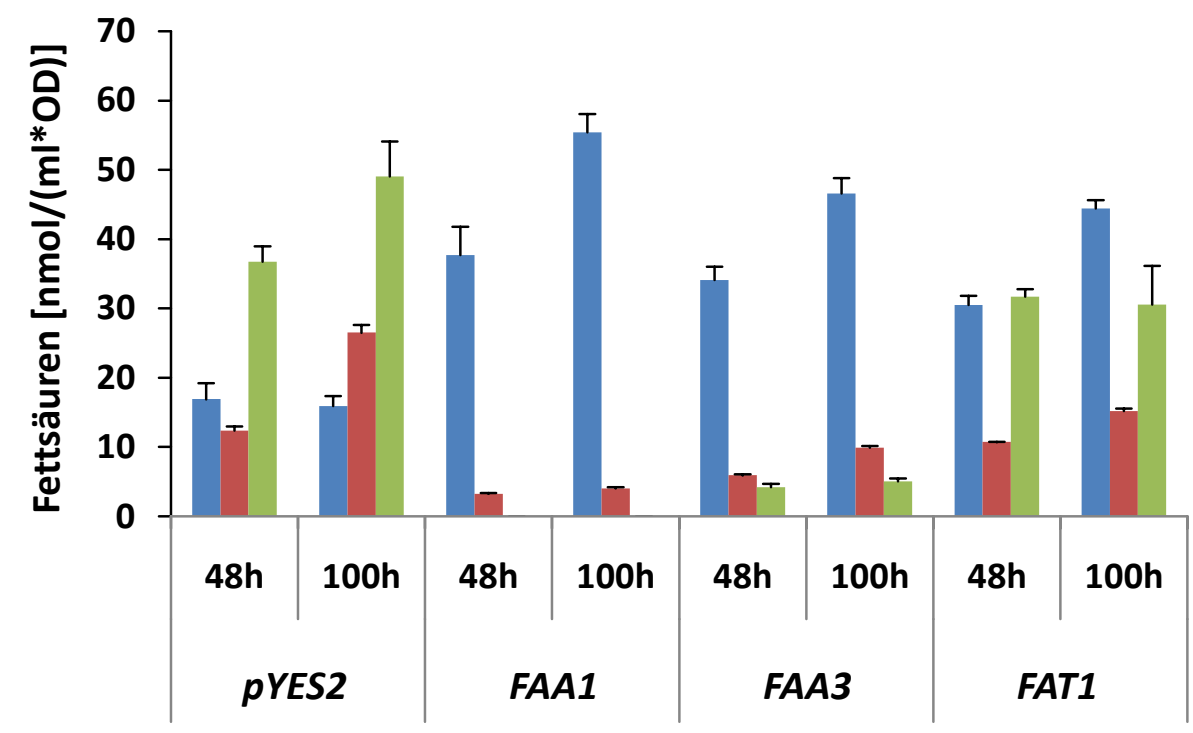

Abb. 5: Fat1p ist fähig, die fehlende Acyl-CoA-Synthetase-Aktivität in der Mutante MS51 teilweise zu komplementieren. Zur Überexpression von FAA1, FAA3 und FAT1 in MS51 wurden die Zellen in CSM-Medium kultiviert. Die Gesamtkonzentration der veresterten Fettsäuren (blaue Balken), der freien Fettsäuren in den Zellen (rote Balken) und der freien Fettsäuren im Medium (grüne Balken) wurde in spätlogarithmischer Phase (48 h) und stationärer Phase (100 h) gemessen. Die Daten zeigen die Mittelwerte mit Standardabweichung von drei unabhängigen Experimenten. 


\subsubsection{Der Fettsäuretransport durch die Plasmamembran findet in Abwesenheit von jeglicher Acyl-CoA-Synthetase-Aktivität statt}

In dieser Studie sollte nachgewiesen werden, dass der Fettsäuretransport durch die Plasmamembran in Abwesenheit jeglicher Acyl-CoA-Synthetase-Aktivität stattfinden kann. Die bislang erhaltenen Daten können nicht zweifelsfrei belegen, dass die zunächst exogenen und später mit den Zellen assoziierten Fettsäuren tatsächlich durch die Membran transportiert wurden und anschließend intrazellulär metabolisch verfügbar waren. Die erhaltenen Ergebnisse ließen sich ebenso mit der Annahme erklären, dass exogene freie Fettsäuren im Zuge des Re-Imports während der stationären Phase die Plasmamembran nicht vollständig passieren, sondern aufgrund ihrer lipophilen Eigenschaften in der Membran akkumulieren und somit dem Lipid-Metabolismus nicht zugeführt werden. Der tatsächliche Import exogener freier Fettsäuren während der stationären Phase sowie der Nachweis, dass die importierten freien Fettsäuren in der Zelle für weitere metabolische Prozesse zur Verfügung stehen können, sollte daher durch ein weiteres experimentelles Verfahren dargestellt werden. Um einen tatsächlichen Fettsäuretransport durch die Plasmamembran in vivo nachzuweisen, wurde nach einer Möglichkeit gesucht, die importierten freien Fettsäuren durch eine enzymatische Aktivität in der Zelle zu modifizieren. Die Isomerase aus Propionibacterium acnes (PAI) wurde als eines der wenigen Enzyme identifiziert, welches in der Lage ist, freie Fettsäuren direkt und ohne vorherige Aktivierung umzusetzen (Hornung et al., 2005). Die Isomerase PAI ist im Zytoplasma von $P$. acnes lokalisiert und wandelt dort Linolsäure (LA; $18: 2^{\triangle 9 Z, 12 Z}$ ) in das konjugierte Isomer (CLA; 18:2 $2^{\Delta 10 E, 12 Z}$ ) um. Für den Nachweis, dass der Fettsäuretransport durch die Plasmamembran nicht von einer Aktivierung durch Acyl-CoASynthetasen abhängig ist, wurde PAI in der Mutante MS51 exprimiert. In diesem Experiment wurden die Zellen in der frühen stationären Wachstumsphase mit LA gefüttert, um eine starke Sekretion der freien Fettsäuren während der exponentiellen Phase zu umgehen und dadurch einen direkten Export der gebildeten CLA zu verhindern. Für die anschließende Lipidanalytik sollte das durch PAI gebildete CLA detektiert werden und somit indirekt als Marker für die metabolische Verfügbarkeit von importierten freien Fettsäuren in den Zellen genutzt werden.

Überraschenderweise wurde durch die Zugabe von LA die Richtung des Transportes der freien Fettsäuren beeinflusst. Der für die stationäre Phase typische Fettsäureimport in die Zellen wechselte nach LA-Zugabe zu einer vorübergehenden Phase der Sekretion. Besonders deutlich wurde dieser Effekt bei Palmitinsäure (C16:0) beobachtet (Tab. 9). Schon 30 min nach der Zugabe von LA stieg die Konzentration von C16:0 im Medium um $72 \%$ an und nahm umgekehrt um $17 \%$ in den Zellen ab. Es ist zu vermuten, dass aufgrund der induzierten 
Sekretion der freien Fettsäuren auch geringe Mengen von CLA im Medium gemessen wurden. Unabhängig davon konnte gezeigt werden, dass importierte LA durch die Isomerase PAI in den Zellen zu CLA umgesetzt werden kann. Basierend auf der Gesamtsumme der detektierten LA im Medium und in der Zelle wurde der prozentuale Anteil des gebildeten CLA für eine detaillierte Betrachtung bestimmt. 30 min nach der Zugabe von LA war der Anteil von CLA in den Zellen eindeutig höher als im Medium (Tab. 9). Wie erwartet, wurden aufgrund der fehlenden Acyl-CoA-Synthetase-Aktivität weder LA noch CLA als veresterte Fettsäuren nachgewiesen. Anhand dieser Daten konnte gezeigt werden, dass ein tatsächlicher Transport durch die Plasmamembran ohne Acyl-CoA-Synthetasen-Aktivität erfolgen kann und die importierten Fettsäuren für weitere metabolische Prozesse innerhalb der Zelle zur Verfügung stehen. Die vollständigen Fettsäureprofile sind im Anhang 4 abgebildet.

Tab. 9: Expression von PAI in MS51. Bestimmung der Konzentration der freien Fettsäuren im Medium und der freien Fettsäure in MS51 während der stationären Phase vor und nach Zugabe von Linolsäure (LA). $0 \mathrm{~h}$ bezeichnet Zeitpunkt direkt vor Zugabe von LA. Die Daten zeigen die Mittelwerte mit Standardabweichung von drei unabhängigen Experimenten.

\begin{tabular}{|c|c|c|c|c|}
\hline & \multicolumn{2}{|c|}{ 16:0 (nmol/mL) } & \multicolumn{2}{|c|}{ LA (nmol/mL) } \\
\hline & Medium & Zelle & Medium & Zelle \\
\hline $\mathrm{Oh}$ & $15,39 \pm 0,4$ & $48,40 \pm 0,3$ & 0,00 & 0,00 \\
\hline $0,5 \mathrm{~h}$ & $26,52 \pm 0,9$ & $40,30 \pm 2,7$ & $104,41 \pm 7,8$ & $70,47 \pm 7,9$ \\
\hline $3 \mathrm{~h}$ & $35,06 \pm 2,5$ & $41,59 \pm 1,0$ & $107,10 \pm 4,6$ & $114,22 \pm 6,4$ \\
\hline $24 \mathrm{~h}$ & $25,10 \pm 3,8$ & $55,80 \pm 1,1$ & $49,74 \pm 6,6$ & $95,96 \pm 1,3$ \\
\hline \multirow[t]{3}{*}{$96 \mathrm{~h}$} & $8,19 \pm 1,2$ & $64,81 \pm 4,6$ & $5,12 \pm 0,5$ & $52,83 \pm 5,3$ \\
\hline & \multicolumn{2}{|c|}{ CLA (nmol/mL) } & \multicolumn{2}{|c|}{$\%$ CLA von $\sum 18: 2$} \\
\hline & Medium & Zelle & Medium & Zelle \\
\hline $\mathrm{Oh}$ & 0,00 & 0,00 & - & - \\
\hline $0,5 \mathrm{~h}$ & $1,39 \pm 0,1$ & $3,29 \pm 0,3$ & $0,78 \pm 0,1$ & $1,83 \pm 0,1$ \\
\hline $3 \mathrm{~h}$ & $9,81 \pm 0,2$ & $12,18 \pm 0,1$ & $4,03 \pm 0,2$ & $5,02 \pm 1,8$ \\
\hline $24 \mathrm{~h}$ & $29,43 \pm 3,0$ & $57,38 \pm 2,1$ & $12,64 \pm 0,9$ & $24,70 \pm 1,9$ \\
\hline $96 \mathrm{~h}$ & $12,05 \pm 0,6$ & $120,01 \pm 4,3$ & $6,34 \pm 0,2$ & $63,20 \pm 0,2$ \\
\hline
\end{tabular}




\subsubsection{Die Richtung des Fettsäuretransports ist abhängig von dem metabolischen Zustand der Zelle}

Der bereits beschriebene Phänotyp, hervorgerufen durch die Deletion der zwei Acyl-CoASynthetasen FAAl und FAA4, zeichnet sich durch einen massiven Export von freien Fettsäuren während der exponentiellen Phase und einen Re-Import von freien Fettsäuren während der stationären Phase aus (Scharnewski et al., 2008).

Um einen genaueren Einblick in den Zusammenhang von Wachstumsphase der Zellen und Richtung des Fettsäuretransportes zu erhalten, wurde die Möglichkeit untersucht, den Transport durch Änderungen in der Zusammensetzung des Kulturmediums zu manipulieren. Dabei wurden die Zellen der Mutante MS51 zunächst in raffinosehaltigem Vollmedium angezogen. Nach dem Erreichen der stationären Phase und dem damit verbundenen Einsetzen des Re-Imports der freien Fettsäuren wurde erneut Raffinose als Kohlenhydratquelle zugegeben. Für die Kontrollen wurde stattdessen Wasser zugegeben. Nach anschließendem Abernten der Zellen und des Mediums wurden Lipidextrakte präpariert und die extrazellulären und intrazellulären freien Fettsäuren sowie die veresterten Fettsäuren mittels Gaschromatographie (GC) quantifiziert.

Die Messungen zeigten, dass direkt nach der Zugabe von Raffinose eine erhöhte Menge an freien Fettsäuren durch Sekretion in das Medium freigesetzt wurde (Abb. 6A). Zeitgleich stoppte die Akkumulation der freien Fettsäuren in den Zellen (Abb. 6B). Eine signifikante Änderung der Konzentration der veresterten Fettsäuren fand in diesem Zeitraum nicht statt (Abb. 6C). Als Basis für die folgenden Vergleiche diente die Menge der Fettsäuren, die vor der Zugabe von Raffinose bzw. Wasser ermittelt wurden. Bei der Kontrolle wurde innerhalb von $30 \mathrm{~h}$ nach Zugabe von Wasser eine Abnahme der freien Fettsäuren um $13 \%$ im Medium festgestellt (Abb. 6A). Diese Abnahme war verbunden mit einem Anstieg der intrazellulären freien Fettsäuren (Abb. 6B). Im Gegensatz zu der Kontrolle nahm nach Zugabe von Raffinose die Menge der freien Fettsäuren um $88 \%$ im Medium zu (Abb. 6A). Dagegen hielt sich im gleichen Zeitraum die Menge der freien Fettsäuren in den Zellen konstant. Nachdem die zugegebene Raffinose ungefähr $95 \mathrm{~h}$ nach Zugabe aufgebraucht war, setzten der Re-Import von freien Fettsäuren aus dem Medium und die damit verbundene Akkumulation der freien Fettsäuren in den Zellen wieder ein (Abb. 6B). Aus diesen Ergebnissen lässt sich schließen, dass die Richtung des Transportes von freien Fettsäuren umkehrbar ist und durch den metabolischen Zustand der Zellen reguliert wird. 

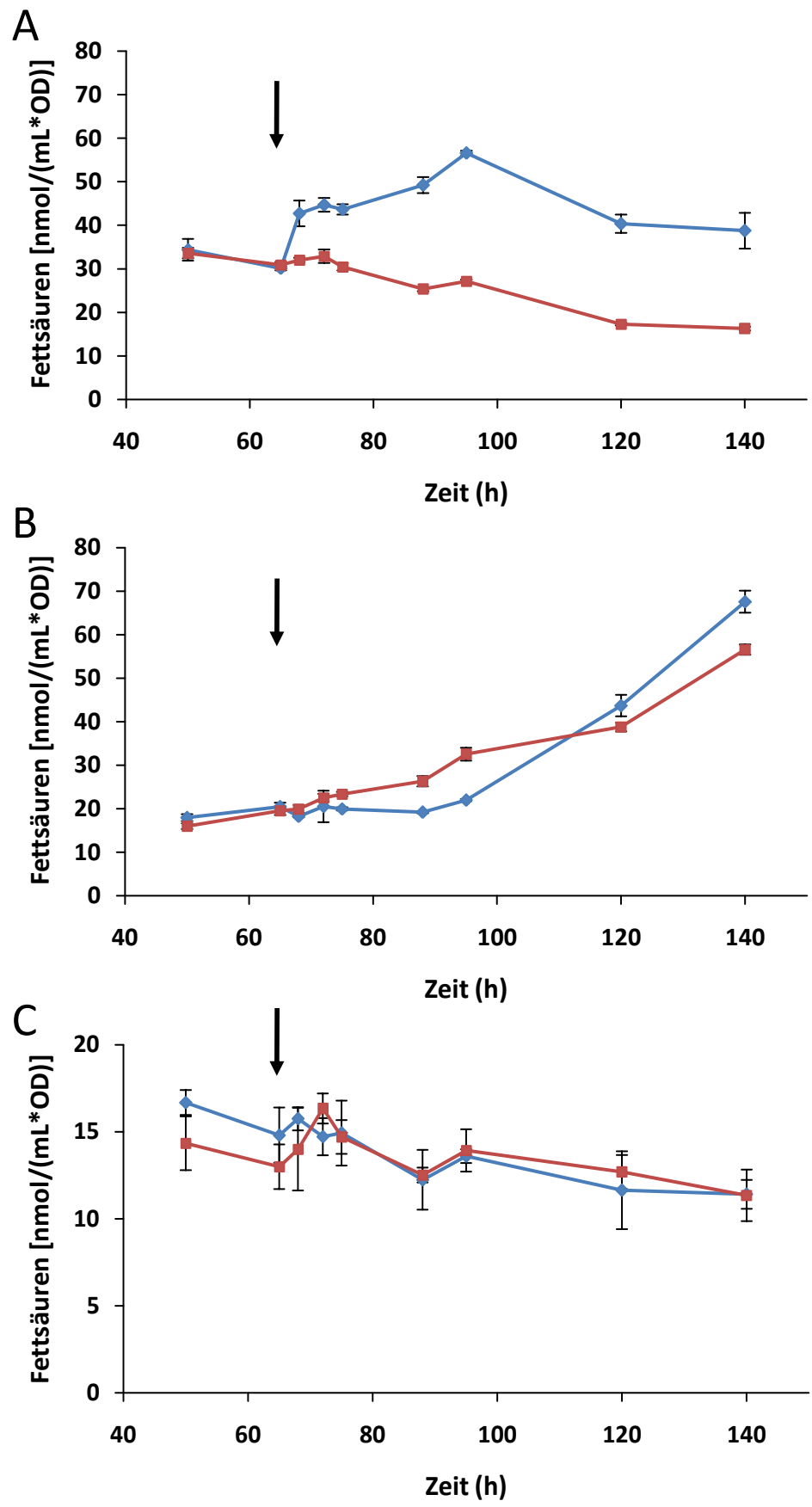

Abb. 6: Die Richtung des Fettsäuretransports ist abhängig von dem metabolischen Zustand der Zelle. Einfluss von Zucker auf die Richtung des Fettsäuretransportes. Fütterungsversuch mit MS51. Die Zugabe von Raffinose erfolgte während stationärer Phase. Fütterungsversuch mit MS51. Zugabe von Raffinose während stationärer Phase. Raffinose (blaue Linien) wurde nach $65 \mathrm{~h}$ (Pfeile) zugegeben. Für die Kontrolle (rote Linien) wurde Wasser zugegeben. Gesamtkonzentration der freien Fettsäuren im Medium (A), freien Fettsäuren in den Zellen (B) und veresterte Fettsäuren (C). Die Daten zeigen die Mittelwerte mit Standardabweichung von drei unabhängigen Experimenten. 

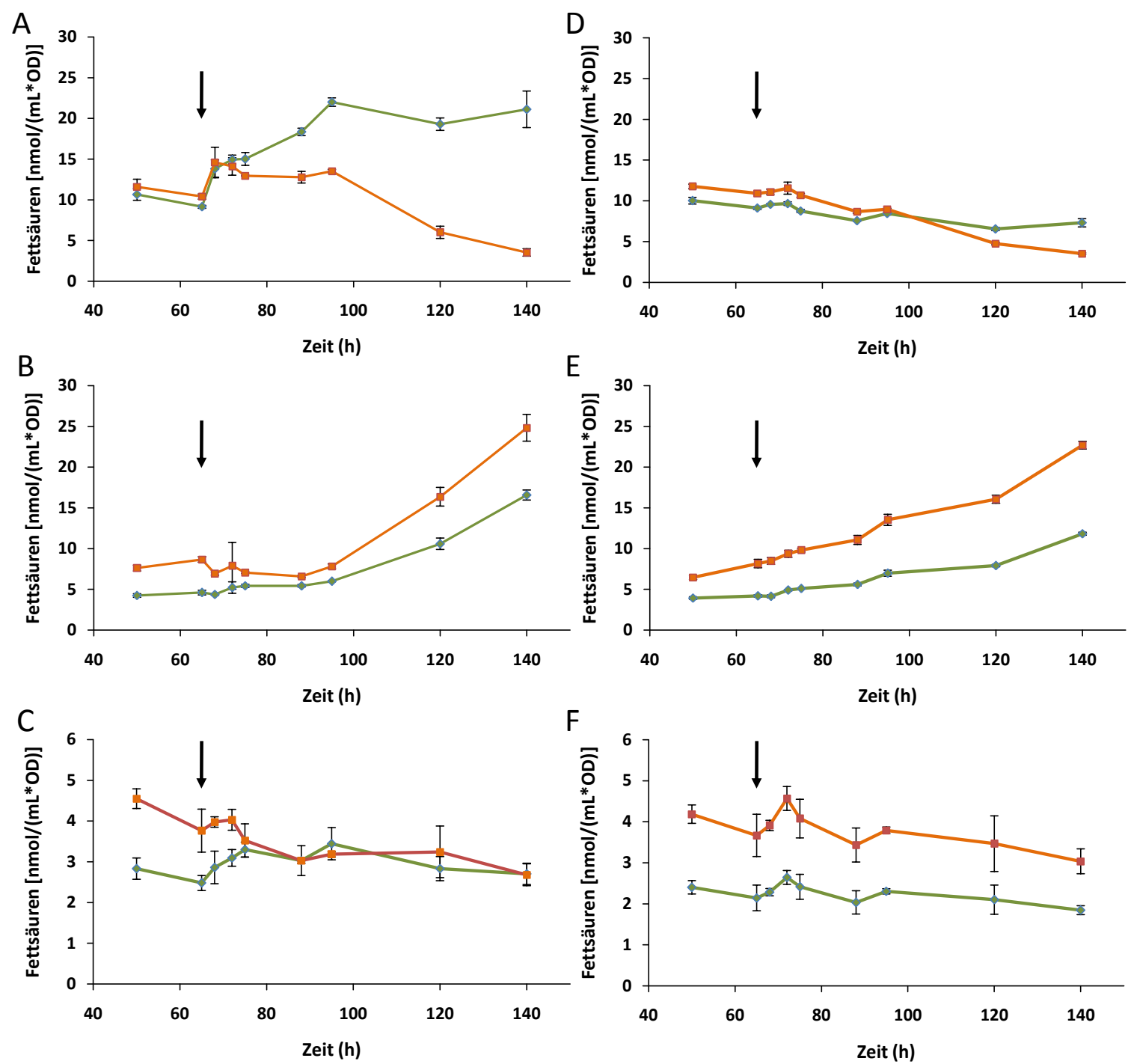

Abb. 7: Verhältnis von Palmitinsäure (C16:0) zu Palmitoleinsäure (C16:1). Einfluss von Zucker auf die Zusammensetzung des Fettsäure-Pools. Fütterungsversuch mit MS51.Die Zugabe von Raffinose erfolgte während stationärer Phase. Raffinose (A-C) wurde nach 65 h (Pfeile) zugegeben. Für die Kontrolle (D-F) wurde Wasser zugegeben. Konzentration von C16:0 und C16:1 im Medium (A,D), von C16:0 und C16:1 in den Zellen (B,E) und von C16:0 und C16:1 als veresterte Fettsäuren (C,F). Die Daten zeigen die Mittelwerte mit Standardabweichung von drei unabhängigen Experimenten.

Interessanterweise hatte die Zugabe von Raffinose in das Kulturmedium auch Auswirkungen auf das Fettsäureprofil der Zellen. Besonders deutlich wird dieser Sachverhalt bei der Betrachtung des Verhältnisses von Palmitinsäure (C16:0) zu Palmitoleinsäure (C16:1) (Abb. 7). Die Zugabe von Raffinose führte unmittelbar zu einer verstärkten Sekretion der beiden Fettsäuren in das Medium. Die detektierten Konzentrationen von C16:0 und C16:1 im Medium waren $3 \mathrm{~h}$ nach der Zugabe von Raffinose identisch. Im weiteren Verlauf des Experimentes verschob sich das Verhältnis signifikant zugunsten C16:0. Nach 95 h wurde 
fast doppelt so viel C16:0 als C16:1 im Medium detektiert. Obwohl die Konzentration von C16:0 im Medium deutlich höher als die von C16:1 war (Abb. 7A), setzte der Re-Import nach 95 h viel intensiver für C16:1 ein (Abb. 7A). Das Verhältnis von C16:0 zu C16:1 innerhalb der Zellen wurde dagegen nicht durch die zugegebene Raffinose beeinflusst. Allerdings führte das Einsetzen des Re-Imports nach 95 h (Abb. 7A) zu einer Änderung der Zusammensetzung der freien Fettsäuren in den Zellen (Abb. 7B). Im Gegensatz zu der Zusammensetzung der freien Fettsäuren in den Zellen wurde ein deutlicher Effekt auf das Profil der veresterten Fettsäuren festgestellt, der sich durch ein Angleichen der Konzentrationen von C16:0 und C16:1 äußerte (Abb. 7C). Zusammenfassend lässt sich aus den Daten auf Mechanismen schließen, die es den Zellen erlauben auch ohne Acyl-CoA-Synthetasen-Aktivität die Konzentration und die Zusammensetzung der intrazellulären freien Fettsäuren unter bestimmten Wachstumsbedingungen stabil zu halten.

\subsubsection{Morphologische Eigenschaften von MS51}

Die Mutante MS51 ist unter anderem durch einen drastischen Anstieg intrazellulärer freier Fettsäuren während der stationären Phase charakterisiert. Im Vergleich zum Wildtyp wurde eine bis zu 50-fach erhöhte Menge an freien Fettsäuren in den Zellen gemessen (Scharnewski et al., 2008). Obwohl erwartet wurde, dass sich diese erhöhten Konzentrationen aufgrund des amphiphilen Charakters von freien Fettsäuren negativ auf das Wachstum der Zellen auswirken würden, zeigte das Wachstumsverhalten von MS51 im Vergleich zum Wildtyp überraschenderweise keine gravierenden Unterschiede. Um festzustellen, ob die erhöhten Fettsäurekonzentrationen einen Einfluss auf die subzelluläre Morphologie der Hefezellen haben, wurde die Mutante MS51 mittels Elektronenmikroskopie analysiert. Wie in (Abb. 8B) dargestellt, zeigten Zellen der Mutante in der exponentiellen Wachstumsphase ein leicht geweitetes ER. Unterschiede in der Struktur der Plasmamembran oder anderen Organellen wurden nicht festgestellt (Abb. 8B). In den Wildtyp-Zellen wurde ein eher unauffälliges ER vorgefunden (Abb. 8A). Bei der Betrachtung von Zellen aus der stationären Phase fiel ein stark ausgedehntes ER in den Mutanten-Zellen auf (Abb. 8C,F,G). Als dunkel kontrastierte fadenförmige Struktur mit stark ausgeweitetem Lumen durchzieht das ER die gesamte Zelle (Abb. 8G). Das ausgeweitete Lumen wurde besonders beim peripheren ER beobachtet (Abb. 8C). Dabei scheint das Lumen mit dunklem, lamellenartigem Material ausgefüllt zu sein (Abb. 8C). Diese Anomalien wurden in allen Zellen der Mutante vorgefunden. Dagegen wurde in keiner der betrachteten Wildtyp-Zellen eine Veränderung des ER nachgewiesen. Die 
elektronenmikroskopische Aufnahmen deuten daraufhin, dass diese Zellen anscheinend die Möglichkeit besitzen größere Mengen an freien Fettsäuren im ER zu deponieren.
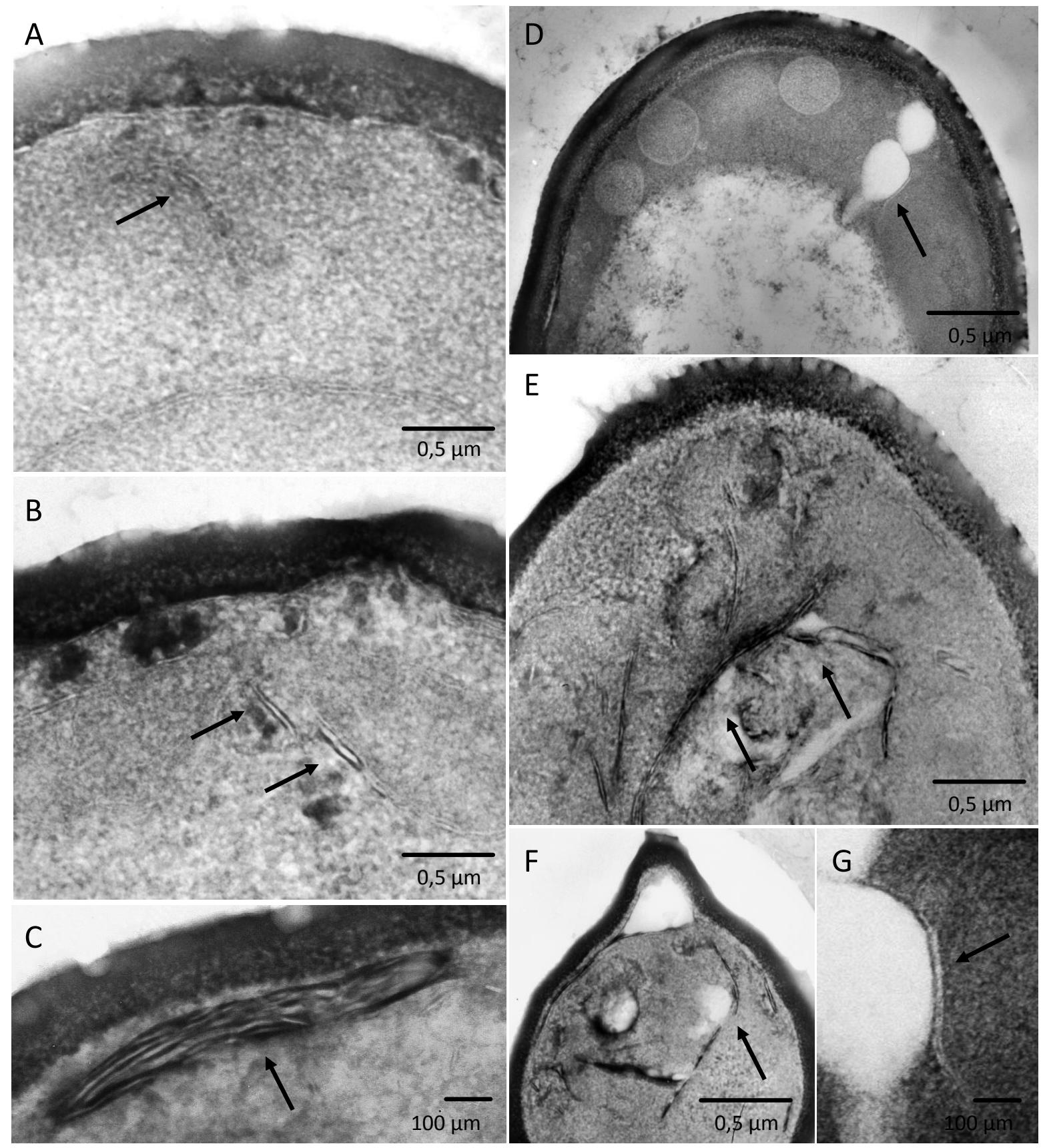

Abb. 8: Morphologische Eigenschaften von MS51. Elektronenmikroskopische Aufnahmen von MS51 und Wildtyp. Übersicht Wildtyp (A,D,G) und MS51 (B,C,E,F). Unauffälliges ER (Pfeil) im Wildtyp während exponentieller Phase (A). Leicht geweitetes ER in der Mutante während exponentieller Phase (B). Unauffälliges ER (Pfeile) im Wildtyp während stationärer Phase (D,G). Stark ausgedehntes ER (Pfeile) in den Mutanten-Zellen während stationärer Phase (C,E,F). Die elektronenmikroskopischen Aufnahmen wurden im Rahmen einer Kooperation von Dr. Michael Hoppert (Institut für Mikrobiologie und Genetik, Georg-August-Universität, Deutschland) durchgeführt. 


\subsection{Untersuchungen zum Fettsäuretransport durch die peroxisomale Membran durch den ABC-Transporter PXA1 in Arabidopsis thaliana}

Der Mechanismus des Fettsäure-Imports in Peroxisomen von Saccharomyces cerevisiae ist teilweise sehr detailliert beschrieben. Ausgehend von dem etablierten Modell der Hefe sollte in diesem Teilabschnitt der Arbeit versucht werden, den identifizierten pflanzlichen peroxisomalen ABC-Transporter PXA1 durch Komplementationsversuche in Hefe besser zu charakterisieren. Darüber hinaus sollte eine mögliche direkte Protein-ProteinWechselwirkung zwischen dem membranintegralen ABC-Transporter PXA1 und den beiden peroxisomalen Acyl-CoA-Synthetasen LACS6 und LACS7 überprüft werden. Im zweiten Abschnitt dieser Studie sollten durch die Manipulation des peroxisomalen Acyl-CoA-Pools in S. cerevisiae weitere Erkenntnisse bezüglich des Ablaufs von Transport der Fettsäuren durch die peroxisomale Membran und der anschließender Metabolisierung durch die $\beta$-Oxidation gewonnen werden.

\subsubsection{Komplementationsstudien mit dem heterologen ABC-Transporter PXA1 und der heterologen Acyl-CoA-Synthetase LACS7 aus Arabidopsis thaliana in Saccharomyces cerevisiae}

In der Einleitung wurde die Problematik dargestellt, die sich bei dem Versuch ergeben, das für Hefe erstellte Modell über die Funktionsweise des peroxisomalen ABC-Transporters auf Pflanzen zu übertragen. Insbesondere die intraperoxisomale Aktivierung von Fettsäuren, die in Pflanze, nicht aber in Hefe, für die $\beta$-Oxidation essentiell ist, wirft Fragen bezüglich der Substratspezifität des jeweiligen ABC-Transporters auf. Um diese Problematik genauer zu beleuchten, wurden Komplementationsstudien mit pflanzlichen Genen in den entsprechenden Hefemutanten durchgeführt.

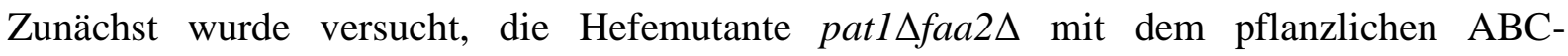
Transporter PXAl zu komplementieren. In einem erweiterten Ansatz wurde versucht die Mutante pat $1 \triangle$ faa $2 \Delta$ durch Koexpression von PXA1 und dem pflanzlichen peroxisomalen Protein LACS7 zu komplementieren. Dazu wurde ein in der Literatur beschriebenes Verfahren verwendet, mit dem sich die Komplementation durch einen Wachstumstest in Flüssigmedium mit Ölsäure als einziger Kohlenstoffquelle überprüfen lässt (van Roermund et al., 2008). Für den Komplementationsversuch wurden die Expressionskonstrukte pYES2/CT-AtPXA1, pYES2CGK-AtLACS7, pYES2/CT-ScPAT1 und pYES2CGK-ScFAA2 für die Transformation 


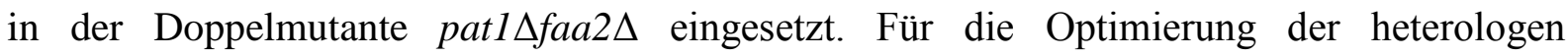
Expression von PXAl in S. cerevisiae wurden der hefeeigene Promotor und der Terminator von YKL188C (PAT1) verwendet (2.4.2.1.). Als Negativ-Kontrolle diente die mit dem Leervektor pYES2/CT oder pYES2CGK transformierte Doppelmutante pat1 $\Delta$ faa2 $\Delta$. Zum Vergleich wurde der Wildtyp mit den enthaltenen Leervektoren pYES2/CT und pYES2CGK verwendet. Als Positiv-Kontrolle diente die Komplementation von patl $\Delta$ faa $2 \Delta$ mit dem homologen ABC-Transporter PAT1 und der homologen Acyl-CoA-Synthetase FAA2.

Die Expression von PXAl alleine bewirkte keine Veränderung im Wachstumsverhalten der Doppelmutante pat $1 \Delta$ faa $2 \Delta$. Wie in Abb. 9 zu erkennen, wurde ein identisches Wachstumsverhalten wie bei der Negativ-Kontrolle beobachtet. Im Gegensatz zu der Expression von PXA1 verbesserte die alleinige Expression von LACS7 das Wachstum der Doppelmutante in ähnlicher Weise, wie es für die Expression der hefeeigenen Acyl-CoA Synthetase $F A A 2$ festgestellt wurde. Während des gesamten Experiments wurde bei pat1 $\triangle$ faa2D_LACS7 eine höhere optische Dichte als bei der Negativ-Kontrolle oder bei pat1 $\triangle$ faa2 $\triangle \_P X A 1$ gemessen. Eine noch höhere Wachstumsrate wurde durch die Koexpression von LACS7 und PXAl in der Doppelmutante erreicht. Nach $120 \mathrm{~h}$ wurde bei

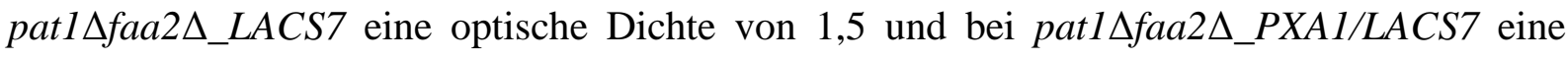
optische Dichte von 2,5 gemessen. Die Koexpression zeigte einen vergleichbaren Effekt wie die alleinige Expression des endogenen PATl Gens. Allerdings konnten auch die erfolgreichsten Komplementationen zu keinem Zeitpunkt des Experiments die Wachstumsrate des Wildtyps wieder herstellen. Es kann jedoch festgehalten werden, dass die alleinige Expression des pflanzlichen ABC-Transporters PXA1 anders als das entsprechende hefeeigene Protein Pat1p nicht in der Lage ist, den Wachstumsphänotyp der Doppelmutante pat1 $\Delta$ faa $2 \Delta$ in Gegenwart von Ölsäure zu komplementieren. Vielmehr führt erst die kombinierte Expression der pflanzlichen Proteine PXA1 und LACS7 zu einer Wachstumsrate, die vergleichbar zu der Expression des endogenen ABC-Transporters Pat1p ist. 

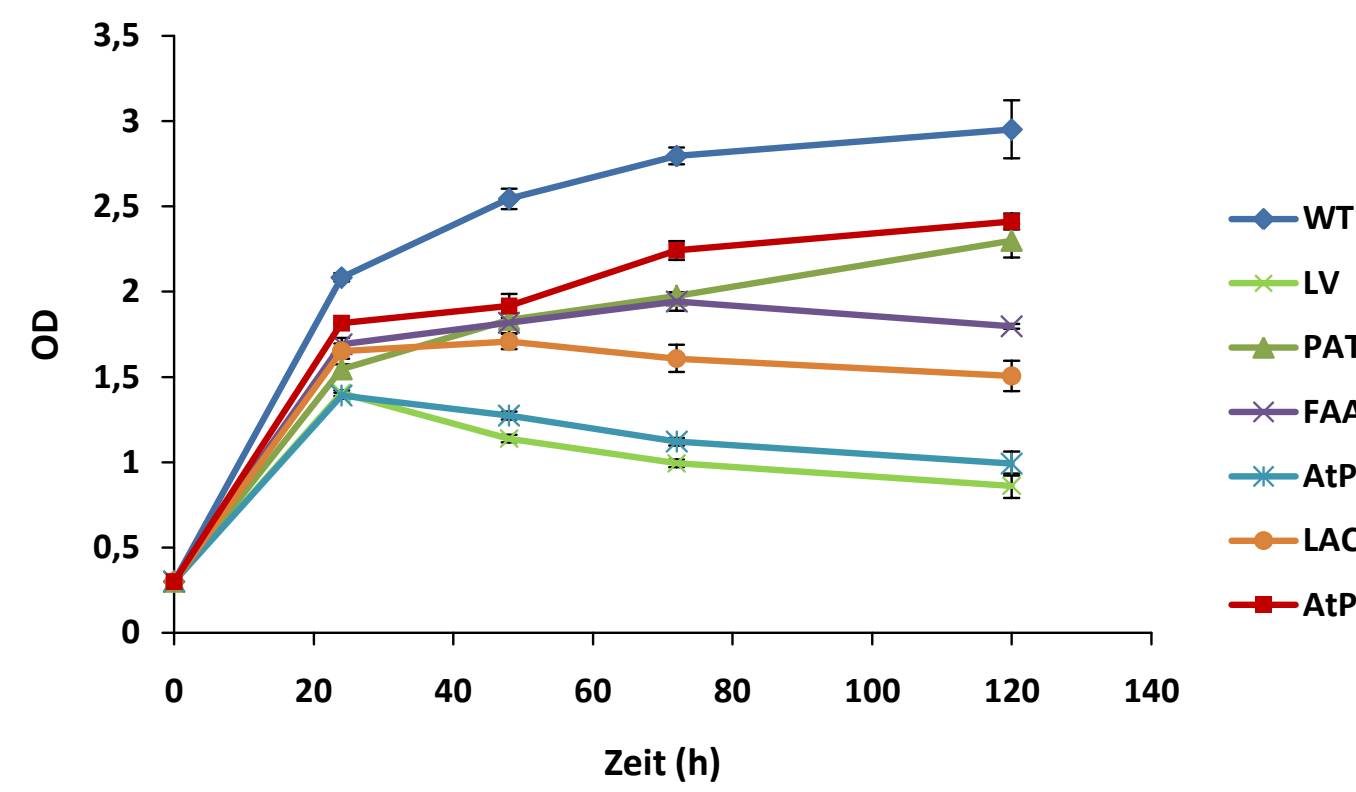

$\times \mathbf{L V}$

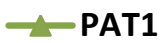

$\because$ FAA2

*-AtPXA1

- LACS7

AtPXA1LACS7

Abb. 9: Wachstumsverhalten von pat1 $\Delta$ faa $2 \Delta$ bei Komplementationen mit der heterologen AcylCoA-Synthetase LACS7 und dem heterologen ABC-Transporter PXA1 aus Arabidopsis in Medium mit Ölsäure. Es wurde die $\mathrm{OD}_{600}$ in Abhängigkeit von der Wachstumszeit der Kultur bestimmt. Die Daten zeigen die Mittelwerte mit Standardabweichung von drei unabhängigen Experimenten.

\subsubsection{Die Folgen von Einschränkungen in der $\beta$-Oxidation auf die Regulierung des Acyl-CoA-Pools in Saccharomyces cerevisiae}

Um einen detaillierteren Einblick in den Ablauf von Transport der Fettsäuren durch die peroxisomale Membran und anschließender Metabolisierung durch die $\beta$-Oxidation in $S$. cerevisiae zu erhalten, wurde in einem ersten Ansatz versucht, die Regulierung des AcylCoA-Pools in den Peroxisomen zu manipulieren. Ein geeigneter Kandidat für dieses Vorhaben ist die peroxisomale Acyl-CoA-Thioesterase Tes1p (Jones et al., 1999). Thioesterasen katalysieren die hydrolytische Spaltung von Acyl-CoAs zu freien Fettsäuren und freiem CoA und haben dadurch einen regulierenden Einfluss auf den Acyl-CoA-Pool. Die hydrolytische Spaltung von Acyl-CoA stellt die Rückreaktion von Faa2p dar. Zu diesem Zweck wurde TES1 in den entsprechenden Hefemutanten inaktiviert. Außerdem wurden weitere Gene deletiert, die für Proteine mit einer direkten oder indirekten Beteiligung am Import von Fettsäuren in die Peroxisomen oder am Abbau der Fettsäuren durch $\beta$-Oxidation kodieren. In dem im folgendem beschriebenen Experiment sollte anhand eines etablierten Verfahrens das Wachstumsverhalten der einzelnen Mutanten auf Minimalmedium mit Ölsäure als einziger Kohlenstoffquelle überprüft werden (Hettema et al., 1996). Dazu wurden sogenannte Tropftests durchgeführt, bei denen die Hefezellen für mindestens $24 \mathrm{~h}$ in 
Minimalmedium mit Glukose angezogen und anschließend in Verdünnungsreihen auf Minimalmedium mit Ölsäure als einziger Kohlenstoffquelle getropft wurde. Für die Kontrolle wurde Minimalmedium ohne Ölsäure verwendet. Bei der Beschreibung dieses etablierten Wachstumstests wurde auf die weithin gebräuchliche Wortwahl der Ölsäure als einziger Kohlenstoffquelle zurückgegriffen. Streng genommen ist diese Beschreibung unrichtig, da in Abwesenheit von jeglicher Kohlenstoffquelle außer Ölsäure im Minimalmedium das Wachstum der Hefezellen so stark eingeschränkt ist, dass selbst für den Wildtyp kein Wachstum zu beobachten wäre. Da Hefezellen jedoch in der Lage sind, Hefeextrakt als alternative Kohlenstoffquelle für das Wachstum zu akzeptieren, wurde dem Minimalmedium bei den Experimenten eine sehr geringe Menge an Hefeextrakt $(0,1 \%$, w/v) hinzugefügt. Diese geringen Mengen alternativer Kohlenstoffquellen reichen aus, um nach mehrtägiger Inkubation für ein deutlich detektierbares Wachstum zu sorgen.

Die Zugabe der Ölsäure führte zu keiner Einschränkung des Wachstums beim Wildtyp. Während sich bei Deletion von TES1 bzw. FAA2 ebenfalls keine Auswirkung auf das Wachstumsverhalten in Gegenwart von Ölsäure zeigte, wurde bei der Einzelmutante patl $\Delta$

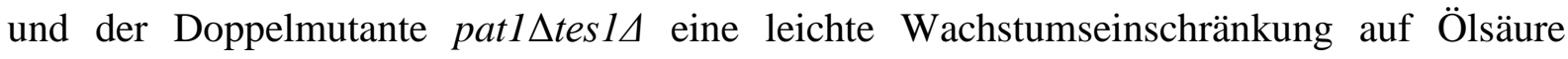
nachgewiesen (Abb. 10) Wie bereits in der Literatur beschrieben (Hettema et al., 1996), wurde bei der Doppelmutante pat $1 \Delta$ faa2 $\Delta$ ein deutlich reduziertes Wachstum in Gegenwart von Ölsäure beobachtet. Überraschenderweise zeigte diese Doppelmutante jedoch auf dem entsprechenden Medium ohne zugesetzte Ölsäure kein eingeschränktes Wachstum, sondern ein identisches Wachstumsverhalten wie der Wildtyp. Wie weiterführende Tests belegten, beruht dieses Wachstum auf der geringen Menge zugesetzten Hefeextrakts. Diese Ergebnisse lassen sich am einfachsten mit der Annahme erklären, dass das eingeschränkte Wachstum der Mutanten auf Ölsäure nicht, wie in der Literatur beschrieben (Hettema et al., 1996), auf mangelnder Energieversorgung aufgrund behinderter Nutzung der Ölsäure beruht, sondern vielmehr auf der toxischen Wirkung der Ölsäure. Die toxische Wirkung der Ölsäure auf HefeMutanten wurde bereits in der Literatur beschrieben. Die publizierten Daten zeigten, dass eine Vielzahl von Einfachmutanten auf Ölsäure im Kulturmedium äußerst sensibel reagieren und teilweise bereits bei geringen Konzentrationen kein Wachstum mehr zeigen (Lockshon et al.,

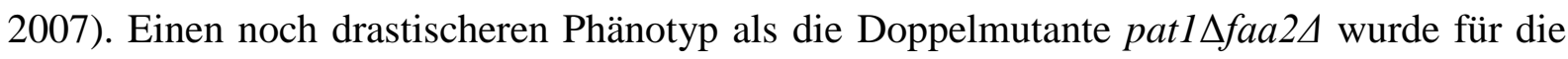
Doppelmutante tes $1 \Delta$ faa $2 \Delta$ festgestellt. Bei dieser Mutante wurde weder auf Minimalmedium mit Ölsäure noch auf Minimalmedium ohne Ölsäure Wachstum nachgewiesen. Auf Medium mit Raffinose ist das Wachstum von tes $1 \Delta$ faa2 $\Delta$ dagegen kaum vom Wildtyp zu unterscheiden. Überraschenderweise kann der drastische Phänotyp dieser Mutante durch die 
zusätzliche Deletion von PAT1 teilweise aufgehoben werden. Es zeigte sich bei dieser Dreifachmutante ein Wachstumsverhalten, das in etwa dem der Doppelmutante pat1 $\Delta$ faa2A entspricht.

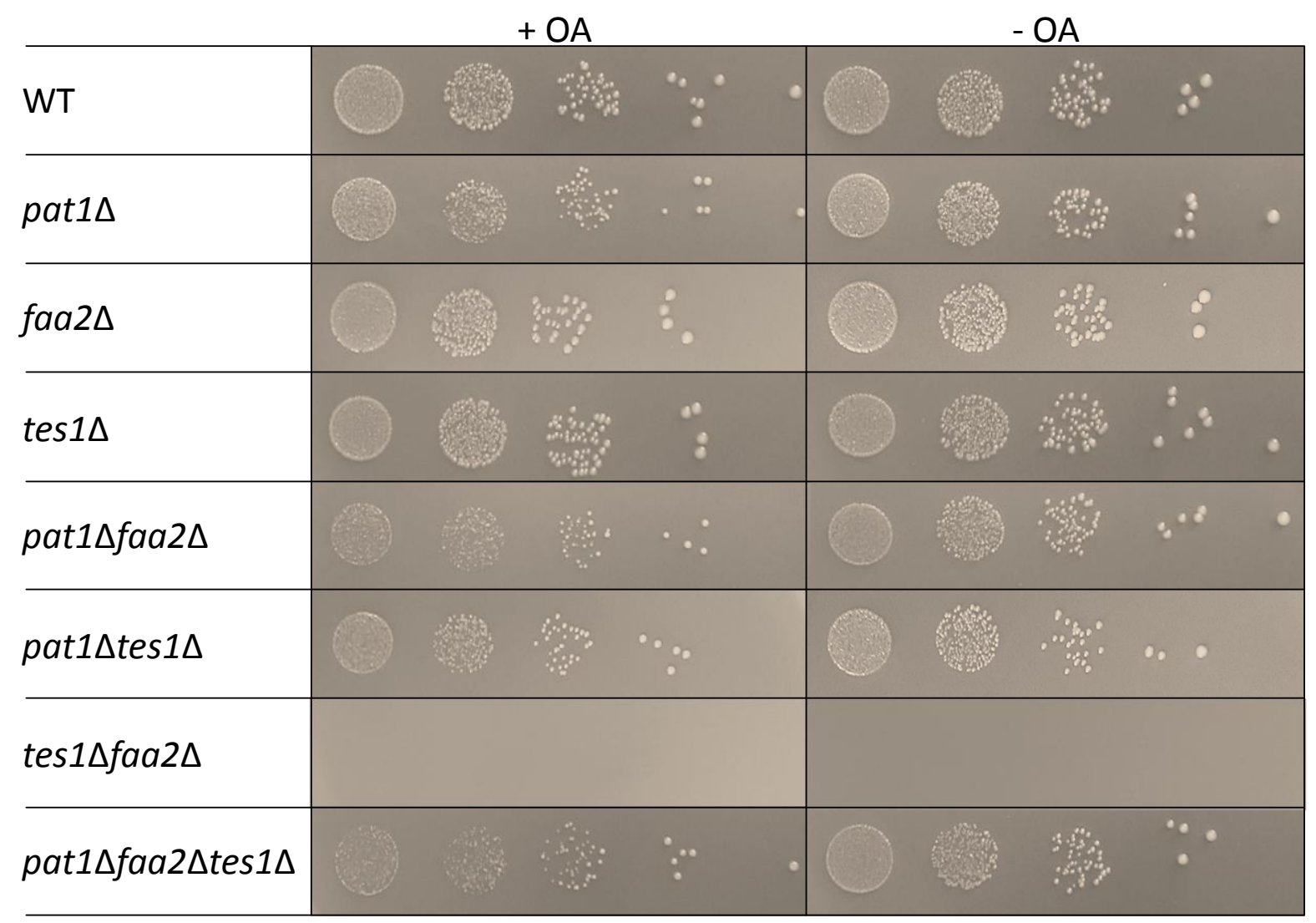

Abb. 10: Wachstumsanalyse verschiedener Mutanten mit eingeschränkter oder vollständig unterbundener $\boldsymbol{\beta}$-Oxidation auf Medium mit Ölsäure. Zellen wurden für $24 \mathrm{~h}$ in Minimalmedium angezogen und nach anschließendem Waschen zu einer Zelldichte von $\mathrm{OD}_{600}=0,1$ verdünnt. Nach einer sukzessiven 10-fach Verdünnung der Zellen wurden $5 \mu \mathrm{l}$ der Ansätze auf die Agarplatten getropft und für 12 Tage bei $30{ }^{\circ} \mathrm{C}$ inkubiert. Für die Kontrolle wurde Minimalmedium ohne Ölsäure benutzt. Dargestellt ist das repräsentative Ergebnis von drei unabhängigen Experimenten.

Da die Proteine Faa2p und Tes1p im Stoffwechsel der Hefe die Bildung bzw. Spaltung von Acyl-CoA-Thioestern katalysieren und somit faktisch antagonistisch wirken sollten, war zunächst erwartet worden, dass sich das Wachstumsverhalten der Doppelmutante tes $1 \Delta$ faa $2 \Delta$ nicht wesentlich von dem der entsprechenden Einzelmutanten unterscheiden sollte. Der beobachtete Wachstumsphänotyp der Doppelmutante ist somit erstaunlich und kann mit dem bisherigen Stoffwechselmodell nicht ohne weiteres in Einklang gebracht werden. Um den Wachstumsphänotyp der Doppelmutante tes $1 \Delta$ faa $2 \Delta$ besser einordnen zu können, wurde zunächst die Deletion von ANT1 im Wildtyp und im Hintergrund der Einzelmutante tes1 $\triangle$ durchgeführt. Ant1p ist der einzige in den Peroxisomen lokalisierte ATP-Transporter (van Roermund et al., 2001, Palmieri et al., 2001). Durch die Deletion von ANT1 sollte die ATP- 
Versorgung der Peroxisomen blockiert werden, und damit die ATP-abhängige Aktivierung der freien Fettsäuren durch Faa2p unterbunden werden. Dementsprechend wurde vermutet, dass die Deletion von ANT1 die gleiche Auswirkung wie die Deletion von FAA2 im Hintergrund der Einzelmutante tes $1 \Delta$ haben könnte. Wie in Abb. 11 dargestellt, verursachte die Deletion von ANT1 im Hintergrund der Einzelmutante tesl $\triangle$ tatsächlich den gravierenden Phänotyp, der durch das Ausbleiben jeglichen Wachstums auf Minimalmedium gekennzeichnet ist. Die Einzelmutante antls zeigte dagegen unter unseren Versuchsbedingungen keinen Phänotyp (Abb. 11). Um zu klären, ob der drastische Phänotyp der Doppelmutante tes $1 \Delta$ faa $2 \Delta$ in Zusammenhang mit einer eingeschränkten $\beta$-Oxidation steht, sollte dieser Stoffwechselweg alternativ durch die Deletion der Acyl-CoA-Oxidase FOX1 bzw. der Keto-Acyl-CoA-Thiolase FOX3 blockiert werden. Für Fox1p und Fox3p existieren keine Isoenzyme, so dass die Deletion von FOX1 oder FOX3 zu einer vollständigen Blockierung der $\beta$-Oxidation führt. Die jeweils einzelnen Deletionen von FOX1 bzw. FOX3

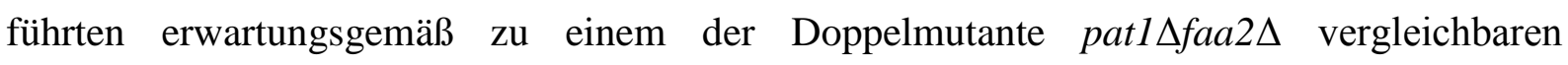
moderaten Phänotyp, der durch deutlich reduziertes Wachstum in Gegenwart von Ölsäure gekennzeichnet ist. Die Deletion von FOX1 oder FOX3 im Hintergrund der Einzelmutanten faa $2 \Delta$ oder tes $1 \Delta$ führte dagegen in jeglicher Kombination (tes $1 \Delta$ fox $1 \Delta$, tes $1 \Delta$ fox $3 \Delta$, faa $2 \Delta$ fox $1 \Delta$ und faa $2 \Delta$ fox $3 \Delta$ ) $\mathrm{zu}$ dem bei der Doppelmutante tes $1 \Delta$ faa $2 \Delta$ beobachteten drastischen Wachstumsphänotyp (Abb. 11). Basierend auf diesen Ergebnissen sollte durch eine weitere Mutantenanalyse untersucht werden, ob der drastische Wachstumsphänotyp eher durch generell fehlenden peroxisomalen Stoffwechsel oder aber durch eine Fehlfunktion des Stoffwechsels innerhalb der Peroxisomen verursacht wird. Hierfür wurde PEX3 im Wildtyp deletiert. Durch die Deletion von PEX3 wird die Bildung der Peroxisomen unterbunden (Hohfeld et al., 1991). Die Einzelmutante pex3s zeigte einen zu der Doppelmutante pat1 $\Delta$ faa $2 \Delta$ vergleichbaren moderaten Phänotyp, was darauf hindeutet, dass der drastische Phänotyp auf einen fehlgeleiteten Stoffwechsel innerhalb der Peroxisomen zurück zu führen ist (Abb. 11). 


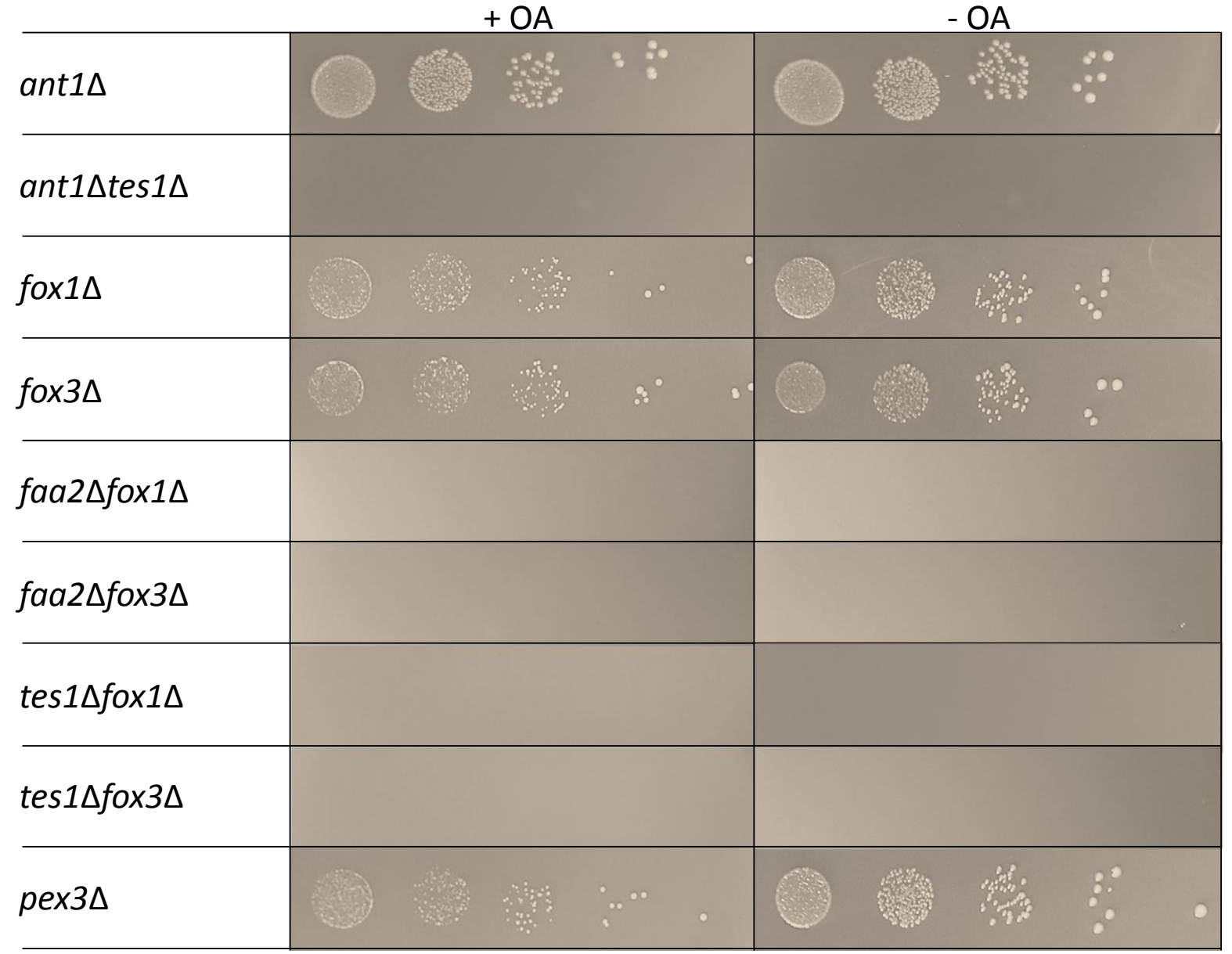

Abb. 11: Wachstumsanalyse verschiedener Mutanten mit eingeschränkter oder vollständig unterbundener $\beta$-Oxidation auf Medium mit Ölsäure. Zellen wurden für $24 \mathrm{~h}$ in Minimalmedium angezogen und nach anschließendem Waschen zu einer Zelldichte von $\mathrm{OD}_{600}=0,1$ verdünnt. Nach einer sukzessiven 10-fach Verdünnung der Zellen wurden $5 \mu \mathrm{l}$ der Ansätze auf die Agarplatten getropft und für 12 Tage bei $30{ }^{\circ} \mathrm{C}$ inkubiert. Für die Kontrolle wurde Minimalmedium ohne Ölsäure benutzt. Dargestellt ist das repräsentative Ergebnis von drei unabhängigen Experimenten.

\subsubsection{In Mutanten ohne Acyl-CoA-Synthetase-Aktivität hat die Zugabe von Ölsäure keinen Einfluss auf das Wachstumsverhalten}

In der anschließenden Versuchsreihe sollte anhand von Mutanten mit eingeschränkter oder vollständig fehlender Acyl-CoA-Synthetase-Aktivität überprüft werden, ob die Anwesenheit von Ölsäure selbst oder die Stoffwechselintermediate der Ölsäure toxisch auf das Wachstum der Hefezellen wirkt. Dazu wurden TES1, PAT1 und PEX3 im Hintergrund der Mutante MS51 deletiert. Überraschenderweise zeigten alle Mutanten (YB525, YB526 und MS51) mit Einschränkungen in der Acyl-CoA-Synthetase-Aktivität nur geringe Wachstumseinschränkungen auf Minimalmedium mit Ölsäure. Die Deletion von TES1 und PAT1 im Hintergrund der Mutante MS51 hatte keinen nachweisbaren Einfluss auf das Wachstumsverhalten, obwohl die zuvor als kritisch beschriebenen Kombinationen 
pat $1 \Delta$ faa $2 \Delta$ und insbesondere tes $1 \Delta$ faa $2 \Delta$ Bestandteil der hier untersuchten Genotypen sind. Demnach kann durch zusätzliche Deletionen von Acyl-CoA-Synthetasen der drastische Wachstumsphänotyp der Doppelmutante tes $1 \Delta f a a 2 \Delta$ teilweise aufgehoben werden. Nur die Deletion von PEX3 im Hintergrund der MS51 Mutante wirkte sich einschränkend auf das Wachstumsverhalten aus (Abb. 12). Diese Ergebnisse könnten ein Hinweis darauf sein, dass die Ölsäure nicht direkt als freie Fettsäure, sondern erst durch die Aktivierung zu Acyl-CoA toxisch auf Mutanten mit eingeschränkter oder blockierter $\beta$-Oxidation wirkt.

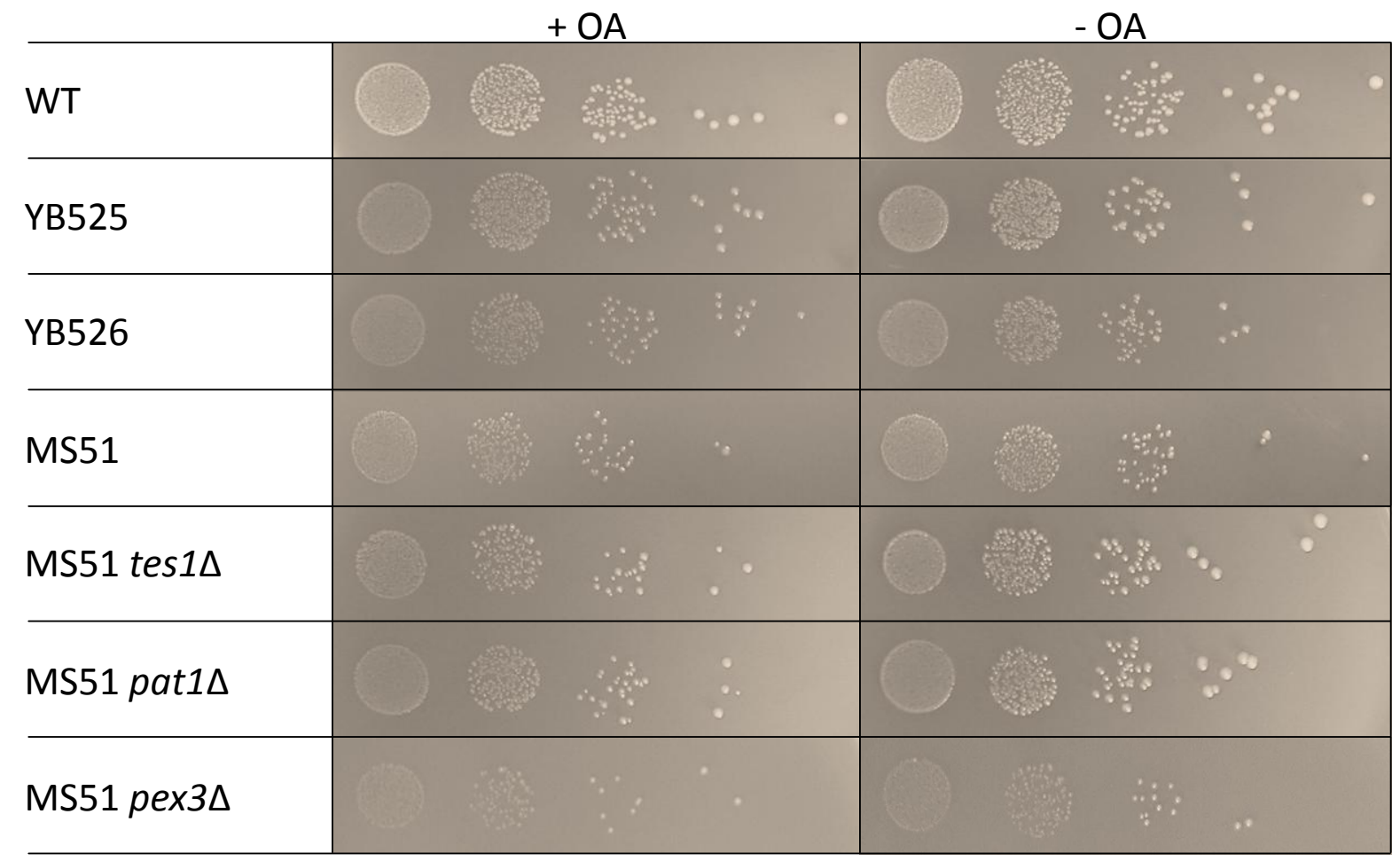

Abb. 12: Wachstumsanalyse verschiedener Mutanten mit eingeschränkter oder vollständig fehlender Acyl-CoA-Synthetase-Aktivität auf Medium mit Ölsäure. Zellen wurden für $24 \mathrm{~h}$ in Minimalmedium angezogen und nach anschließendem Waschen zu einer Zelldichte von $\mathrm{OD}_{600}=0,1$ verdünnt. Nach einer sukzessiven 10-fach Verdünnung der Zellen wurden $5 \mu$ der Ansätze auf die Agarplatten getropft und für 12 Tage bei $30{ }^{\circ} \mathrm{C}$ inkubiert. Für die Kontrolle wurde Minimalmedium ohne Ölsäure benutzt. Dargestellt ist das repräsentative Ergebnis von drei unabhängigen Experimenten.

Der Importmechanismus von freien Fettsäuren in das peroxisomale Lumen konnte bis heute nicht vollständig aufgeklärt werden. Denkbar wäre, dass die freien Fettsäuren nicht durch die peroxisomale Membran transportiert, sondern direkt aus der peroxisomalen Membran freigesetzt werden. Die freigesetzten Fettsäuren könnten anschließend durch Faa2p aktiviert und in den $\beta$-Oxidation-Zyklus überführt werden. In $S$. cerevisiae wurde die peroxisomale Lipase Lpx1p identifiziert (Thoms et al., 2008). Die Expression von LPX1 ist durch Zugabe von Ölsäure induzierbar. Peroxisomen in der Einzelmutante lpxls zeigten anomale 
Morphologien, die durch intraperoxisomale Vesikel oder Einstülpungen charakterisiert sind. In dem nun folgenden Experiment sollte eine eventuelle Beteiligung von Lpx1p an der $\beta$ Oxidation überprüft werden. Dafür wurden durch Deletionen die Einzelmutante $\operatorname{lpx} 1 \Delta$ und die Doppelmutanten pat $1 \Delta l p x 1 \Delta$, faa2 $\Delta l p x 1 \Delta$ und tes $1 \Delta l p x l \Delta$ hergestellt. Während die

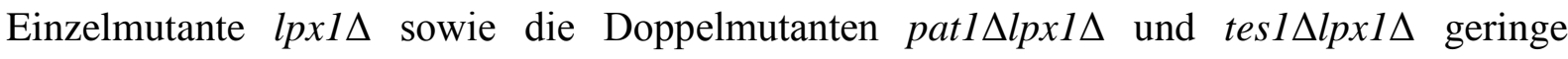
Wachstumseinschränkungen zeigten, führte die Kombination faa2 $\Delta$ lpxl $1 \Delta \mathrm{zu}$ einem mit der

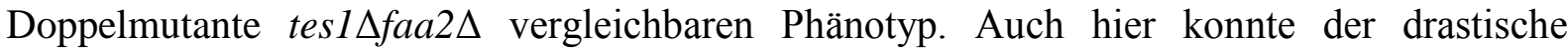
Phänotyp durch die zusätzliche Deletion von PAT1 im Hintergrund dieser Mutante teilweise aufgehoben werden (Abb. 13).

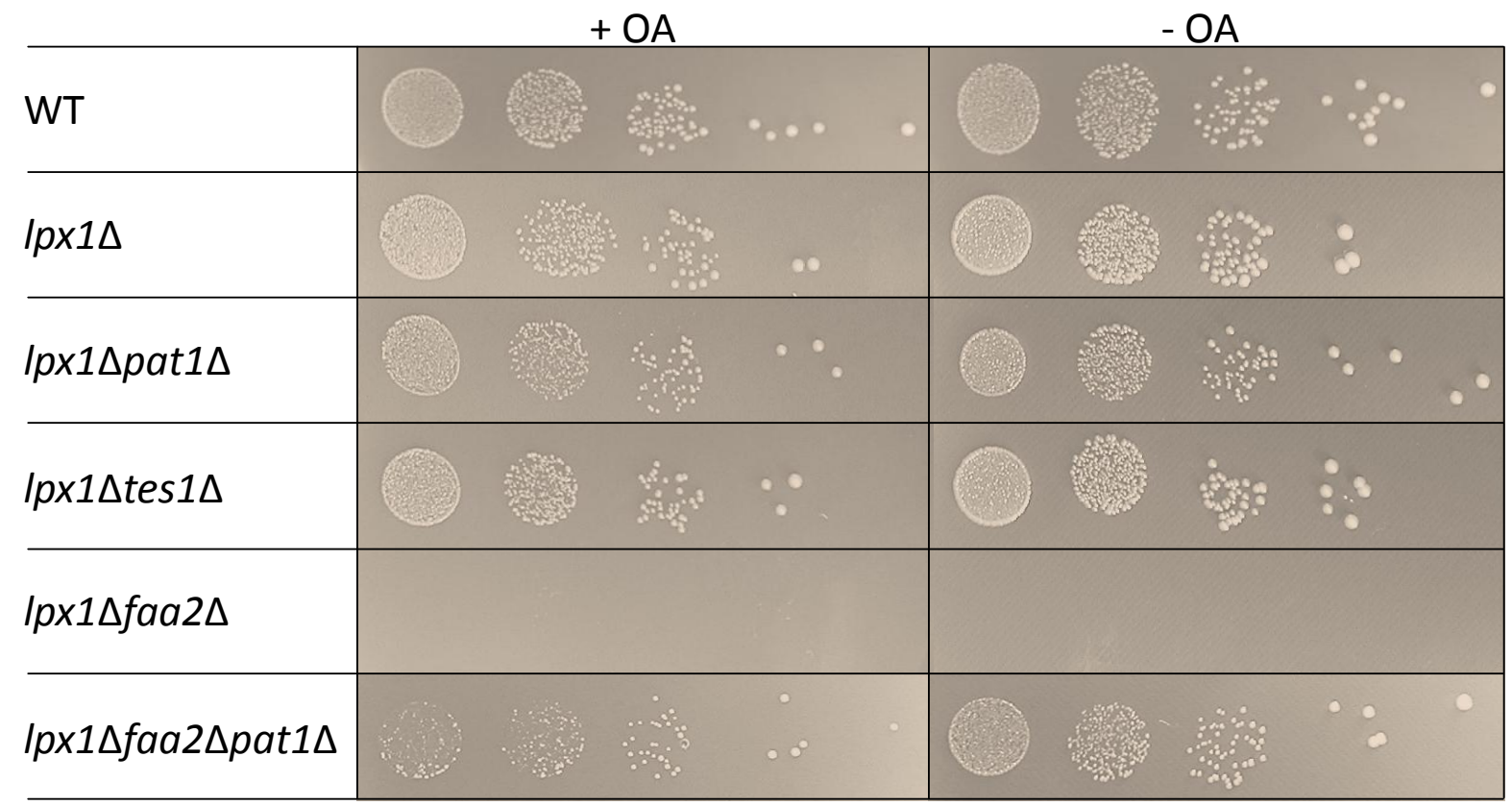

Abb. 13: Wachstumsanalyse verschiedener Mutanten mit vollständig fehlender Lipase-Aktivität in den Peroxisomen auf Medium mit Ölsäure. Zellen wurden für $24 \mathrm{~h}$ in Minimalmedium angezogen und nach anschließendem Waschen zu einer Zelldichte von $\mathrm{OD}_{600}=0,1$ verdünnt. Nach einer sukzessiven 10-fach Verdünnung der Zellen wurden $5 \mu$ der Ansätze auf die Agarplatten getropft und für 12 Tage bei $30{ }^{\circ} \mathrm{C}$ inkubiert. Für die Kontrolle wurde Minimalmedium ohne Ölsäure benutzt. Dargestellt ist das repräsentative Ergebnis von drei unabhängigen Experimenten.

Das durch die $\beta$-Oxidation gebildete Acetyl-CoA wird entweder für die Energiegewinnung in den Mitochondrien verwendet oder zur Synthese neuer Verbindungen herangezogen. In jedem Fall müssen die Acetyl-Einheiten vorher die peroxisomale Membran überqueren. Eine Möglichkeit für diese Ausschleusung ist der Transport über den Glyoxylatzyklus, an dem die Malat-Synthase Mls1p beteiligt ist. Es wurde gezeigt, dass die Einzelmutante $m l s 1 \Delta$ nicht auf Minimalmedium mit Ölsäure als einziger Kohlenstoffquelle wächst (Kunze et al., 2002). Aufgrund der bislang beschriebenen Ergebnisse wurde vermutet, dass eventuell auch in 
diesem Fall eine komplexere Störung des peroxisomalen Stoffwechsels für den beobachteten Wachstumsphänotyp verantwortlich sein könnte. In diesem Fall sollte die Deletion von PAT1 im Hintergrund der $m l s 1 \Delta$-Mutante dazu führen, dass der vorher beschriebene Wachstumsphänotyp wenigstens teilweise aufgehoben würde. In dem entsprechenden Experiment konnte nach vier Tagen ein eindeutiger Unterschied im Wachstumsverhalten Zwischen der Einzelmutante $m l s 1 \Delta$ und der Doppelmutante mls $1 \Delta$ pat $1 \Delta$ nachgewiesen werden. Die Einzelmutante zeigte eine stärkere Einschränkung im Wachstumsverhalten auf Minimalmedium mit Ölsäure als die Doppelmutante. Nach 12 Tagen jedoch wiesen beide Mutanten ein ähnliches Wachstumsverhalten auf (Abb. 14).

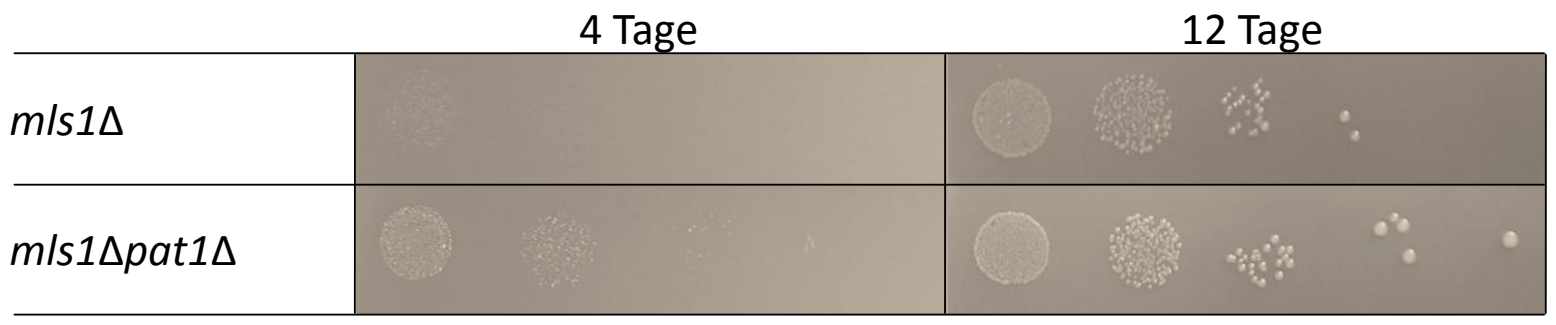

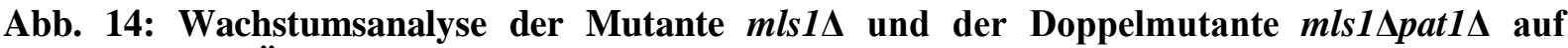
Medium mit Ölsäure. Zellen wurden für $24 \mathrm{~h}$ in Minimalmedium angezogen und nach anschließendem Waschen zu einer Zelldichte von $\mathrm{OD}_{600}=0,1$ verdünnt. Nach einer sukzessiven 10 fach Verdünnung der Zellen wurden $5 \mu \mathrm{l}$ der Ansätze auf die Agarplatten mit Ölsäure getropft und für 4 oder 12 Tage bei $30{ }^{\circ} \mathrm{C}$ inkubiert. Dargestellt ist das repräsentative Ergebnis von drei unabhängigen Experimenten.

Anhand dieser Daten konnte dargestellt werden, dass die Einschränkung oder sogar komplette Blockierung der $\beta$-Oxidation zu zwei verschiedene Wachstumsphänotypen führen kann. Dabei wird unterschieden zwischen Mutanten mit eingeschränktem Wachstum auf Minimalmedium mit Ölsäure und Mutanten, die in Abwesenheit von Zucker auf den verwendeten Minimalmedien überhaupt kein Wachstum zeigen. Der jeweilige Wachstumsphänotyp kann entweder durch zusätzliche Deletionen der Acyl-CoA-Synthetasen FAA1 und FAA4 oder durch Deletion von PATl aufgehoben bzw. teilweise aufgehoben werden. 


\subsubsection{Wachstumsanalyse verschiedener Mutanten mit eingeschränkter oder verhinderter $\beta$-Oxidation auf Minimalmedium mit Glukose}

Im abschließenden Tropftest wurde Glukose als Kohlenstoffquelle verwendet, um die Lebensfähigkeit der Doppelmutante tes $1 \Delta f a a 2 \Delta$ nachzuweisen. Zusätzlich wurden noch andere Mutanten mit verhinderter oder eingeschränkter $\beta$-Oxidation überprüft. Alle geprüften Mutanten zeigten ein identisches Wachstumsverhalten auf Minimalmedium mit Glukose als einzige Kohlenstoffquelle (Abb. 15). Durch das Experiment konnte dargestellt werden, dass der drastische Phänotyp der Doppelmutante tes1 $\Delta$ faa2s von der Zusammensetzung des Kulturmediums abhängt.

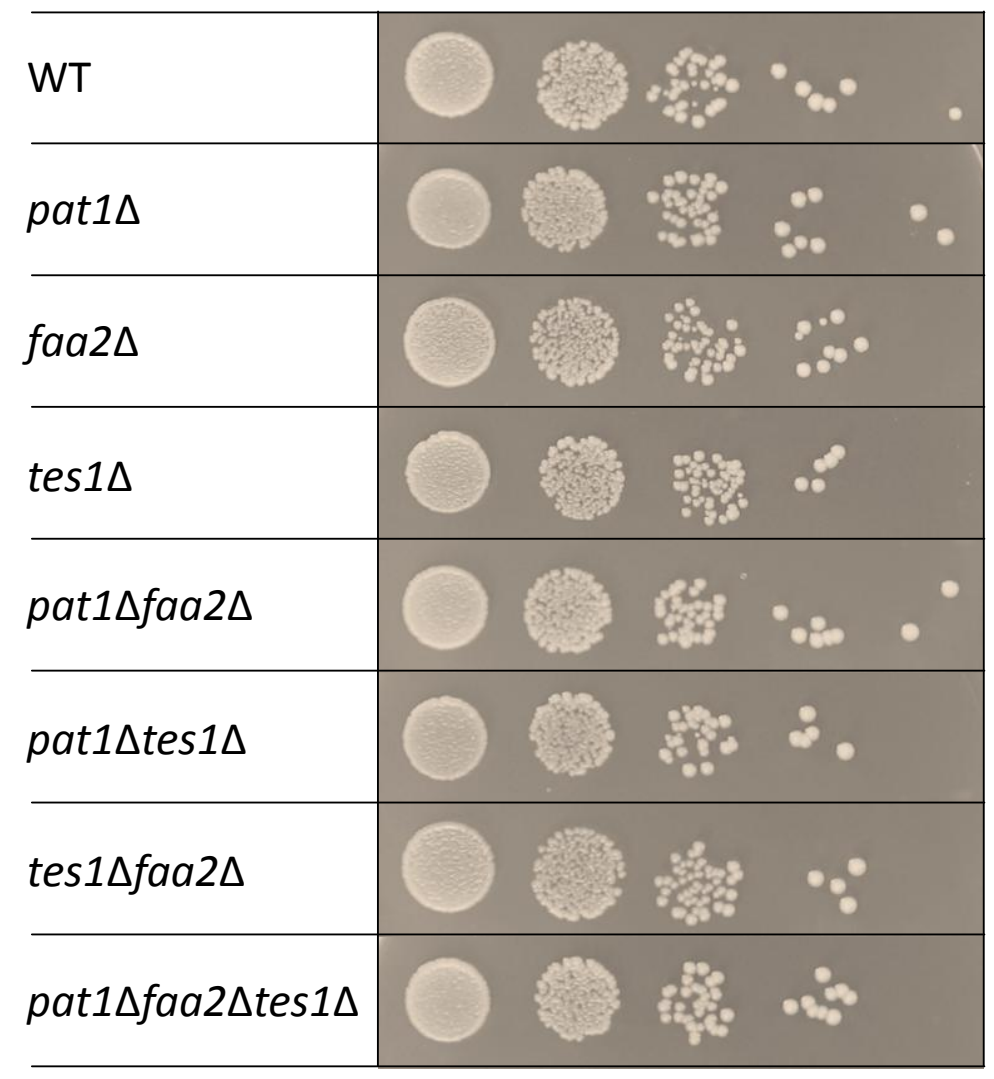

Abb. 15: Wachstumsanalyse verschiedener Mutanten mit eingeschränkter oder vollständig unterbundener $\beta$-Oxidation auf Minimalmedium mit Glukose. Zellen wurden für $24 \mathrm{~h}$ in Minimalmedium mit Glukose angezogen und nach anschließendem Waschen zu einer Zelldichte von $\mathrm{OD}_{600}=0,1$ verdünnt. Nach einer sukzessiven 10-fach Verdünnung der Zellen wurden $5 \mu 1$ der Ansätze auf die Agarplatten mit Glukose getropft und für 4 Tage bei $30{ }^{\circ} \mathrm{C}$ inkubiert. Dargestellt ist das repräsentative Ergebnis von drei unabhängigen Experimenten. 


\subsubsection{Akkumulation von Acyl-CoA-Estern während der stationären Phase in Mutanten mit Einschränkungen in der $\beta$-Oxidation}

Zur weiteren Charakterisierung der Mutanten mit Einschränkungen in der $\beta$-Oxidation wurden Acyl-CoA-Ester-Profile erstellt. Für dieses Experiment wurden verschiedene Mutanten und der Wildtyp in Vollmedium mit Raffinose kultiviert. Nach $48 \mathrm{~h}$ und $96 \mathrm{~h}$ Kultivierung wurden die Zellen abgeerntet. Nach der Extraktion und Derivatisierung der Acyl-CoAs erfolgte die Analyse mittels HPLC. Die Acyl-CoA-Konzentration nahm in allen Mutanten während der stationären Phase zu. Dagegen blieb die Gesamtmenge an Acyl-CoAs im Wildtyp konstant. Im Vergleich zum Wildtyp wurden in allen Mutanten - mit Ausnahme der Doppelmutante tes $1 \Delta$ faa2 $\Delta$ - höhere Acyl-CoA-Konzentrationen nach $96 \mathrm{~h}$ gemessen. Die geringsten Gesamtmengen an Acyl-CoAs wurden bei der Doppelmutante tes $1 \Delta$ faa $2 \Delta$ bestimmt. Im Vergleich zur Doppelmutante tes $1 \Delta$ faa $2 \Delta$ wurde beispielsweise nach $96 \mathrm{~h}$ eine 5-fach höhere Acyl-CoA-Konzentration in der Dreifachmutante tes $1 \Delta$ faa2 $\Delta$ pat1 nachgewiesen (Abb. 16). Zusammenfassend lässt sich aus den Daten schießen, dass eine Einschränkung in der $\beta$-Oxidation in den Hefezellen zu einer Anreicherung von Acyl-CoAEstern während der stationären Phase führen kann.

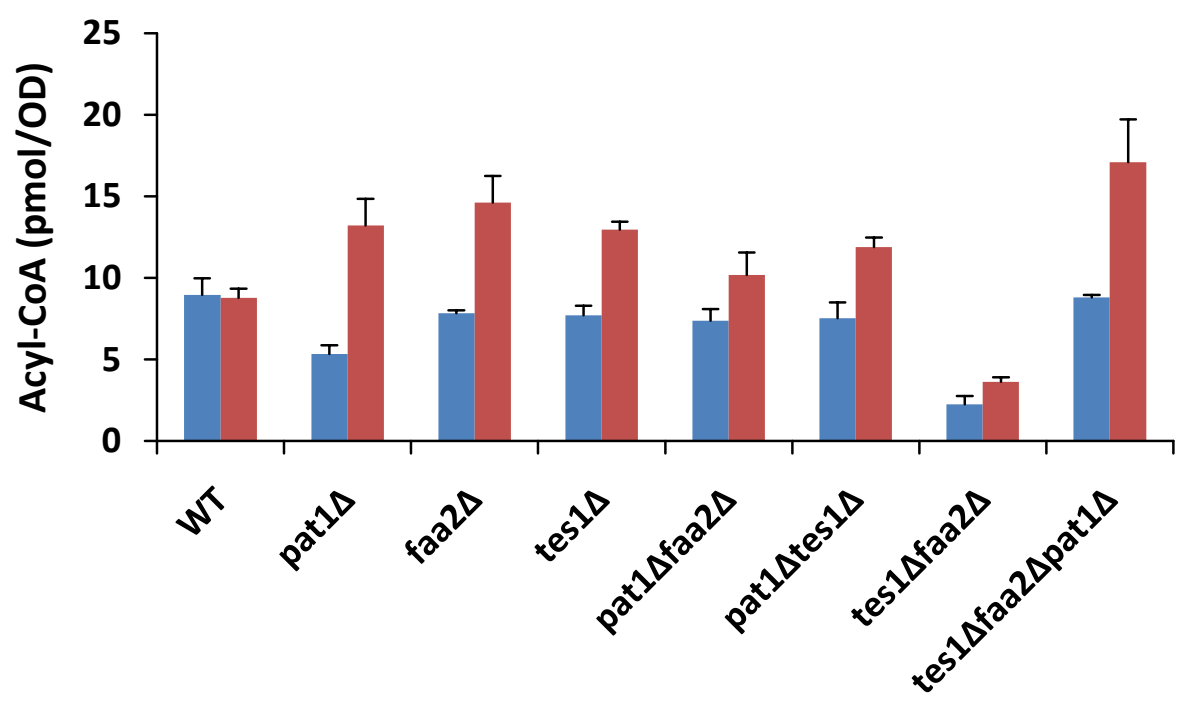

Abb. 16: Akkumulation von Acyl-CoA-Estern während der stationären Phase in Mutanten mit Einschränkungen in der $\boldsymbol{\beta}$-Oxidation. Auf die optische Dichte bezogene Gesamtmenge der AcylCoAs in Wildtyp und Mutanten mit Einschränkungen in der $\beta$-Oxidation nach $48 \mathrm{~h}$ (blaue Balken) und $96 \mathrm{~h}$ (rote Balken) in YPR. Es wurde Heptadecanoyl-CoA (17:0-CoA) als interner Standard zur Berechnung der Mengen an Acyl-CoAs zu den verschiedenen Zeitpunkten mitgeführt. Die detektierten Signale wurden mittels Co-Injektion der einzelnen Fettsäure-CoA-Standards identifiziert. Die AcylCoA-Ester wurden mittels HPLC bestimmt. Die Daten zeigen die Mittelwerte mit Standardabweichung von drei unabhängigen Experimenten. 
Die Acyl-CoA-Profile der Doppelmutanten pat $1 \Delta$ faa $2 \Delta$ und pat $1 \Delta t e s 1 \Delta$ enthielten neben den in Hefe nativen Signalen der langkettigen Acyl-CoAs überraschenderweise zusätzliche Signale. Teilweise konnten diese nach Vergleich mit den Retentionszeiten authentischer Standards identifiziert werden. Eine zusätzliche Identifizierung mittels Massenspektronomie steht noch aus. In beiden Doppelmutanten wurden demnach erhöhte Mengen an Acetyl-CoA, Succinyl-CoA und Buturyl-CoA vorgefunden. Zusätzlich wurde in der Doppelmutante pat1 $\Delta$ faa $\Delta$ unnatürlich hohe Mengen an 10:0-CoA bestimmt (Abb. 17). 


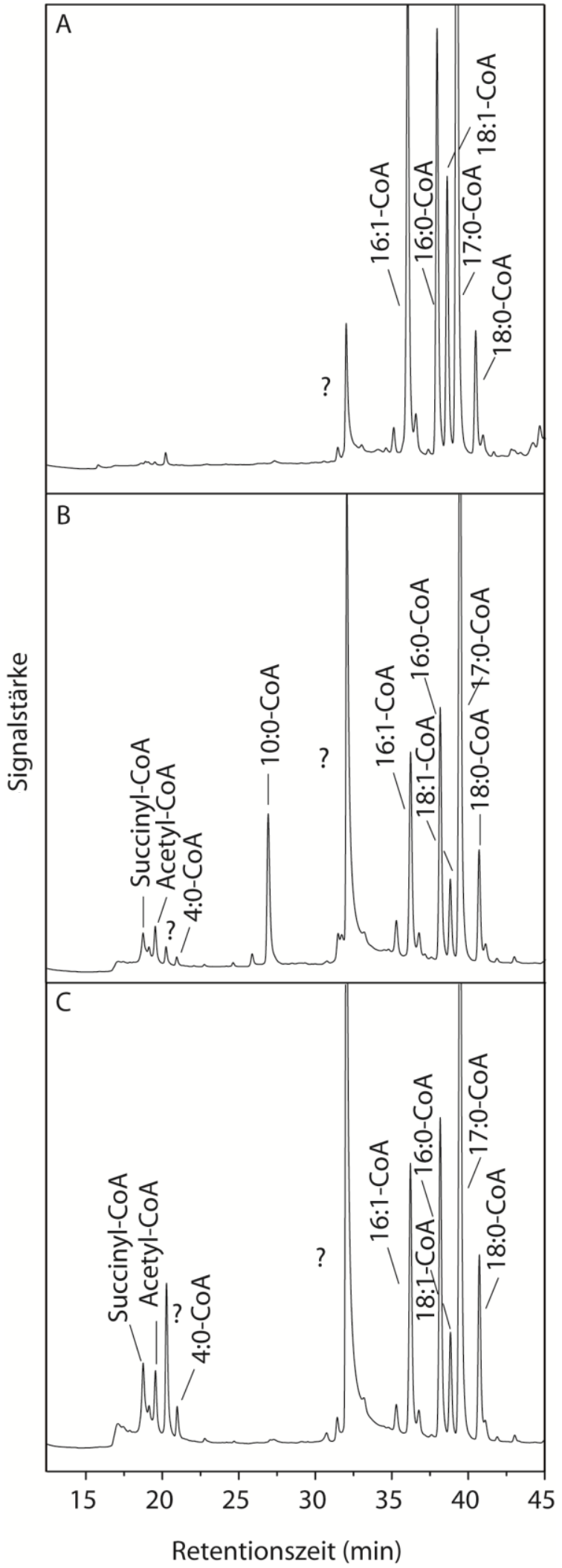

Abb. 17: Acyl-CoA-Profile von Mutanten mit Einschränkungen in der $\beta$-Oxidation und Wildtyp. Dargestellt sind repräsentative HPLC-Profile von Wildtyp (A), der Doppelmutante pat $1 \Delta$ faa2 $\Delta$ (B) und der Doppelmutante pat1 $\Delta$ tes $1 \Delta$ (C). Die CoA-Ester wurden durch Vergleich mit den Retentionszeiten authentischer Standards identifiziert. Dargestellt ist das repräsentative Ergebnis von drei unabhängigen Experimenten. 


\subsubsection{Bestimmung von Acyl-CoA-Estern im Wildtyp und Mutanten bei Wachstum in Gegenwart von Ölsäure}

In diesem Experiment sollte überprüft werden, ob sich die exogene Ölsäure auf die Regulierung des Acyl-CoA-Pools auswirkt und dadurch einen toxischen Effekt auf Mutanten mit eingeschränkter $\beta$-Oxidation verursacht. Die Zellen wurden für $12 \mathrm{~h}$ in YBO-Medium inkubiert. Nach anschließender Entnahme der Proben und Extraktion erfolgte die Analyse der Acyl-CoA-Zusammensetzung mittels HPLC. Mit dem Wildtyp vergleichbare Acyl-CoAMengen wurden in den Einzelmutanten pat $1 \Delta$, faa $2 \Delta$, tes $1 \Delta$ und pex3 $\Delta$ bestimmt. Erhöhte Acyl-CoA-Konzentrationen wurden in den Mutanten fox $1 \Delta$, fox3 $\Delta, \operatorname{lpx} 1 \Delta$, pat1 1 tes $1 \Delta$, pat $1 \Delta$ faa $2 \Delta$ und pat $1 \Delta$ faa $2 \Delta$ tes $1 \Delta$ gemessen. Im Vergleich zum Wildtyp deutlich erniedrigte Acyl-CoA-Konzentrationen wurden in den Mutanten tes $1 \Delta$ faa $2 \Delta, \operatorname{lpx} 1 \Delta$ faa $2 \Delta$, fox $1 \Delta$ faa $2 \Delta$ und tes $1 \Delta$ fox $1 \Delta$ festgestellt (Abb. 18). Die geringsten Mengen an Acyl-CoAs wurden in der Doppelmutante tes $1 \Delta$ faa $2 \Delta$ bestimmt. In der Dreifachmutante pat $1 \Delta$ faa $2 \Delta$ tes $1 \Delta$ wurde eine 25-fach höhere Acyl-CoA-Konzentration als in der tes $1 \Delta$ faa $\Delta \Delta$-Mutante gemessen.

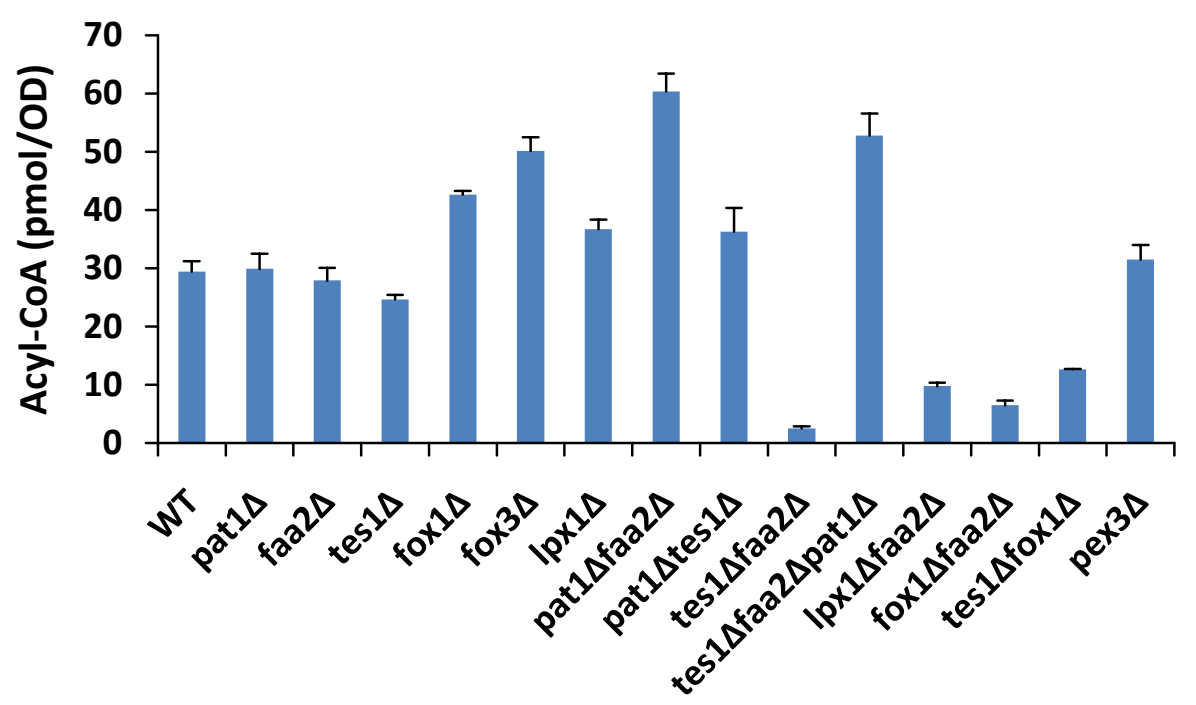

Abb. 18: Bestimmung von Acyl-CoA-Estern im Wildtyp und in den Mutanten mit Einschränkungen in der $\boldsymbol{\beta}$-Oxidation nach Zugabe von Ölsäure. Auf die optische Dichte bezogene Gesamtmenge der Acyl-CoAs in Wildtyp und Mutanten mit Einschränkungen in der $\beta$-Oxidation nach $12 \mathrm{~h}$ in YBO-Medium. Es wurde Heptadecanoyl-CoA (17:0-CoA) als interner Standard zur Berechnung der Mengen an Acyl-CoAs zu den verschiedenen Zeitpunkten mitgeführt. Die Acyl-CoAEster wurden mittels HPLC bestimmt. Die detektierten Signale wurden mittels Co-Injektion der einzelnen Fettsäure-CoA-Standards identifiziert. Die Daten zeigen die Mittelwerte mit Standardabweichung von drei unabhängigen Experimenten. 
Nachdem die Acyl-CoA-Konzentrationen bestimmt wurden, sollte untersucht werden, ob eine Korrelation zwischen dem Acyl-CoA-Spiegel und dem Wachstumsverhalten der Zellen besteht. Dazu wurden die optischen Dichten der zuvor beschriebenen Hefekulturen bestimmt. Verglichen mit dem Wildtyp zeigten die Einzelmutanten pat $1 \Delta$ und tes $1 \Delta$ ein identisches Wachstumsverhalten. Ein leicht eingeschränktes Wachstumsverhalten zeigte die Mutante faa $2 \Delta$ (Abb. 19). In allen drei Mutanten wurde eine dem Wildtyp-Niveau entsprechende Acyl-CoA-Konzentration gemessen (Abb. 19). Mutanten (fox $1 \Delta$, fox $3 \Delta, \operatorname{lpx} 1 \Delta$, pat1 1 tes $1 \Delta$, pat $1 \Delta$ faa $2 \Delta$ und pat1 $\Delta$ faa $2 \Delta t e s 1 \Delta)$, bei denen erhöhte Acyl-CoA-Konzentrationen nachgewiesen worden sind, zeigten ein eingeschränktes Wachstum. Ein sehr stark eingeschränktes Wachstum zeigten die Doppelmutanten tes $1 \Delta f a a 2 \Delta, \operatorname{lpx} 1 \Delta$ faa $2 \Delta$, fox $1 \Delta$ faa $2 \Delta$ und tes $1 \Delta$ fox $1 \Delta$. Bei diesen Mutanten wurden sehr geringe Mengen an AcylCoAs gemessen. Diese Beobachtungen deuten darauf hin, dass tatsächlich eine Korrelation zwischen Acyl-CoA-Spiegel und Wachstum besteht.

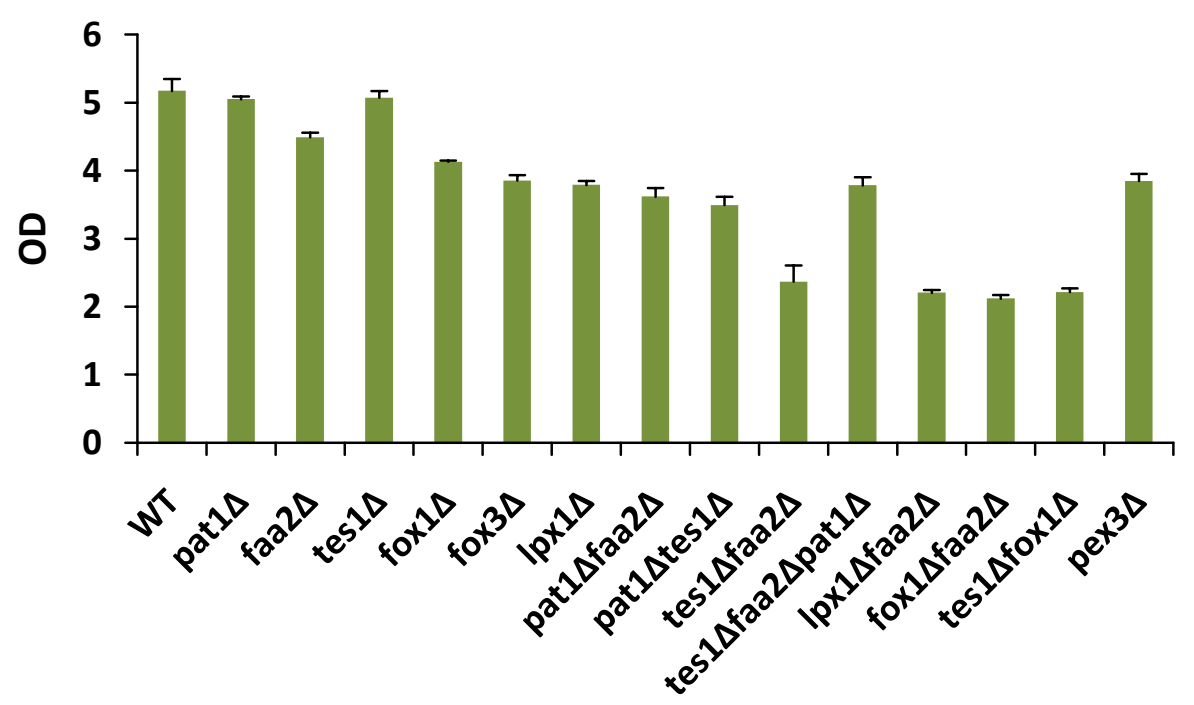

Abb. 19: Wachstumsverhalten von Mutanten mit Einschränkungen in der $\beta$-Oxidation nach Zugabe von Ölsäure. Bestimmung der $\mathrm{OD}_{600}$ der Hefekulturen nach $12 \mathrm{~h}$ Kultivierung in YBOMedium. Die Daten zeigen die Mittelwerte mit Standardabweichung von drei unabhängigen Experimenten.

Das Acyl-CoA-Profil der Doppelmutante tes $1 \Delta f a a 2 \Delta$ enthielt auch bei dieser Versuchsreihe neben den in Hefe nativ vorkommenden langkettigen Acyl-CoAs ein zusätzliches, bislang unbekanntes Signal. Eine Identifizierung mittels Massenspektronomie erfolgte. 


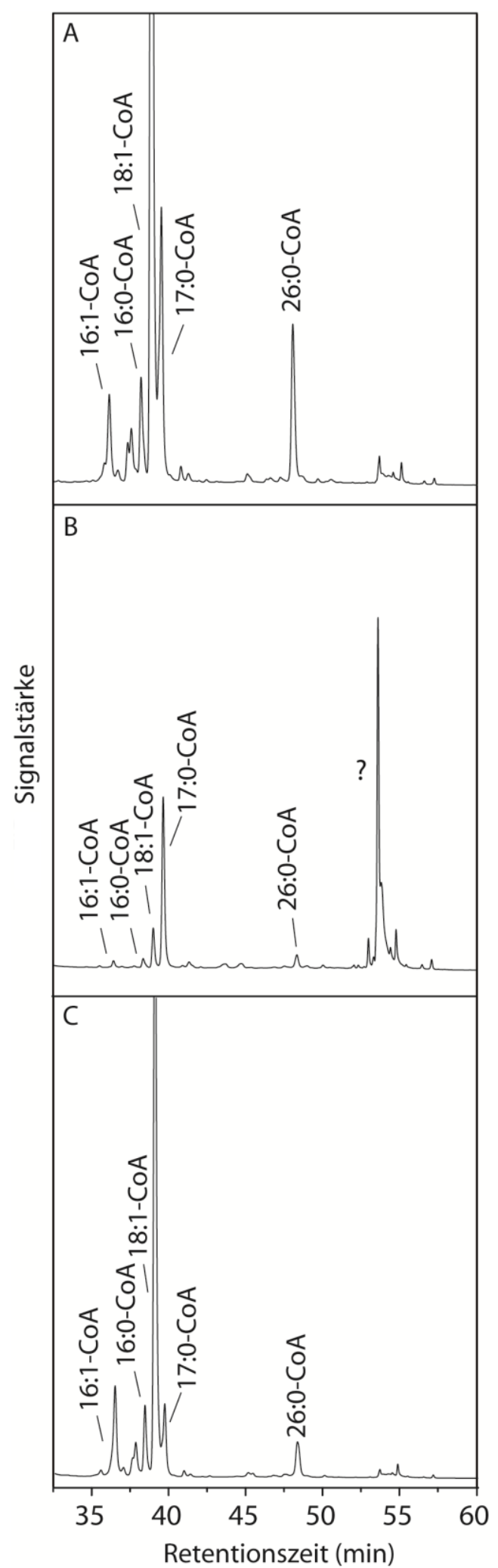

Abb. 20: Acyl-CoA-Profile von Mutanten mit Einschränkungen in der $\beta$-Oxidation und Wildtyp nach Zugabe von Ölsäure. Dargestellt sind repräsentative HPLC-Profile von Wildtyp (A), der Doppelmutante tes $1 \Delta f a a 2 \Delta$ (B) und der Dreifachmutante pat $1 \Delta t e s 1 \Delta$ faa $\Delta \Delta(\mathbf{C})$. Die Acyl-CoA-Ester wurden durch Vergleich mit den Retentionszeiten authentischer Standards identifiziert. Dargestellt ist das repräsentative Ergebnis von drei unabhängigen Experimenten. 

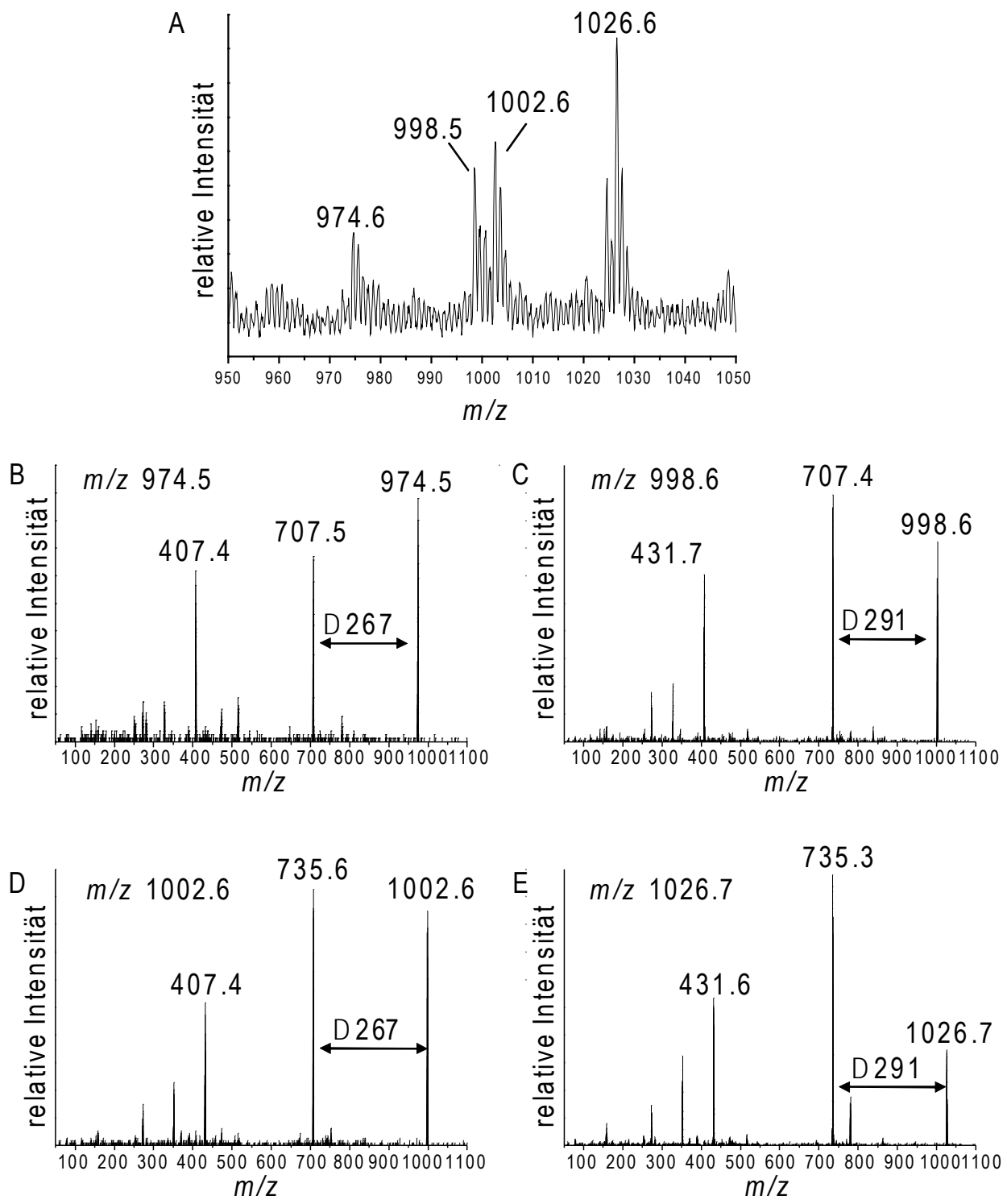

$\mathrm{F}$

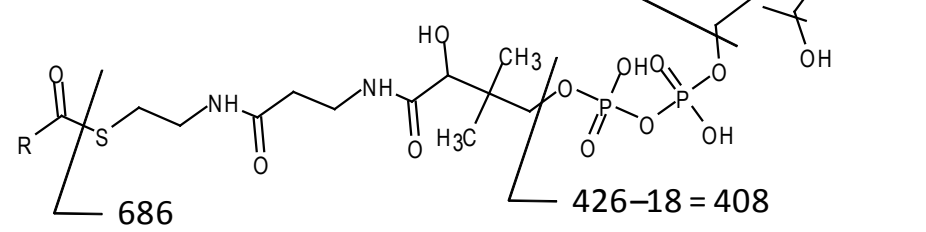

Abb. 21: Tandem-MS-Analyse des bei der Doppelmutante tes1 $1 \mathrm{faa} 2 \Delta$ nach Zugabe von Ölsaure bei vorgefundenen unbekannten Substanzen. (A) Massenspektrum von Acyl-CoA-Estern und etheno-Derivaten. (B-E) Auf $\mathrm{m} / \mathrm{z}$ 974.5, 998.5, 1002.6 und 1026.7 extrahierte Produkt-Ionen-Spektren. (F) Mögliche Fragmentionenmuster von Acyl-Dephospho-CoA. Bei R könnte es sich um ein AcylRest mit einer Kettenlänge von C20 (B, C) bzw C22 (D, E) handeln. Die Messungen wurden von Dr. Cornelia Göbel (Institut für Biochemie der Pflanzen, Georg-August-Universität, Deutschland) durchgeführt. 


\subsubsection{Massenspektroskopische Analyse der unbekannten Substanz, die in der Doppelmutante tes1 $\Delta$ faa $2 \Delta$ nach Zugabe von Ölsäure detektiert worden ist}

Um weitere Informationen über die Identität des unbekannten Signals Abb. 21 zu bekommen, wurde eine Analyse mittels Massenspektrometrie durchgeführt. Nach durchgeführter HPLCAnalyse wurden die entsprechenden Fraktionen wie in 2.14 beschrieben weiter in einem Tandem-MS-Experiment analysiert.

Im Massenspektrum Abb. 21 waren vier Massen-Signale mit m/z 974.5, 998.5, 1002.6 und 1026.7 zu erkennen. Die entsprechenden Tandem-MS-Spektren wiesen ein Fragmentionenmuster auf, das auf Acyl-Dephospho-CoA hindeutet. Zwei von den MassenSignalen, und zwar mit $m / z 974.5$ und 1002.6 sind auf freie Acyl-Dephospho-CoAs und die anderen auf die entsprechenden etheno-Derivate $(\Delta m / z 24)$ zurückzuführen. Die Interpretation der Fragmentspektren wurde mittels einer Datenbanksuche (LipidMaps) ermittelt. Die Masse des Acyl-Restes deutet auf eine desaturierte C20- bzw C22-Kette hin. Weitere Untersuchungen für eine zweifelsfreie Identifizierung der vorgefundenen Acyl-DephosphoCoAs werden in Zukunft noch durchgeführt.

\subsubsection{Akkumulation von TAG während der stationären Phase in Mutanten mit Einschränkungen in der $\beta$-Oxidation}

Bei der pxal-Mutante von Arabidopsis thaliana konnten wir nach langanhaltender Dunkelphase eine verstärkte Akkumulation von TAG in den Blättern nachweisen (Kunz et al., 2009). Genauso wie bei dem pflanzlichen peroxisomalen ABC-Transporter PXA1, wird auch bei dem peroxisomalen ABC-Transporter Pat1p-Pat2p aus $S$. cerevisiae eine Beteiligung am Import von aktivierten Fettsäuren durch die peroxisomale Membran vermutet (Hettema et al., 1996, Zolman et al., 2001). Mit dem folgenden Experiment sollte überprüft werden, ob sich diese Beobachtung generalisieren lässt und sich die Deletion des peroxisomalen $\mathrm{ABC}$ Transporters auch in der Hefe $S$. cerevisiae auf die TAG-Akkumulation auswirkt. Dazu

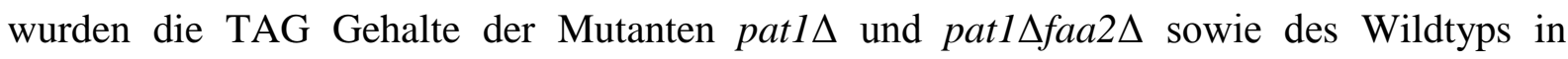
verschiedenen Wachstumsstadien analysiert. Die Zellen wurden in YPR-Medium kultiviert, die Lipide extrahiert und die durch Dünnschichtchromatographie isolierte TAG-Fraktion mittels Gaschromatographie quantifiziert. Die Ergebnisse zeigen eine stetige Zunahme der TAG-Konzentrationen während der stationären Phase in den Mutanten pat1 $\Delta$ und pat1 $\Delta$ faa $2 \Delta$. Dagegen wurde im Wildtyp eine kontinuierliche Abnahme der TAGKonzentrationen festgestellt. Nach $150 \mathrm{~h}$ wurde in der Doppelmutante pat1 $\Delta$ faa2 $\Delta$ ungefähr 
die doppelte Menge an TAG wie im Wildtyp detektiert (Abb. 22). Zusammenfassend lässt sich aus den Daten schließen, dass eine Einschränkung der $\beta$-Oxidation in $S$. cerevisiae zu einer Akkumulation von TAG während der stationären Phase führen kann. Das Fehlen der Aktivität des peroxisomalen ABC-Transporters kann somit sowohl in A. thaliana als auch in der Hefe S. cerevisiae zur Akkumulation von TAG führen.

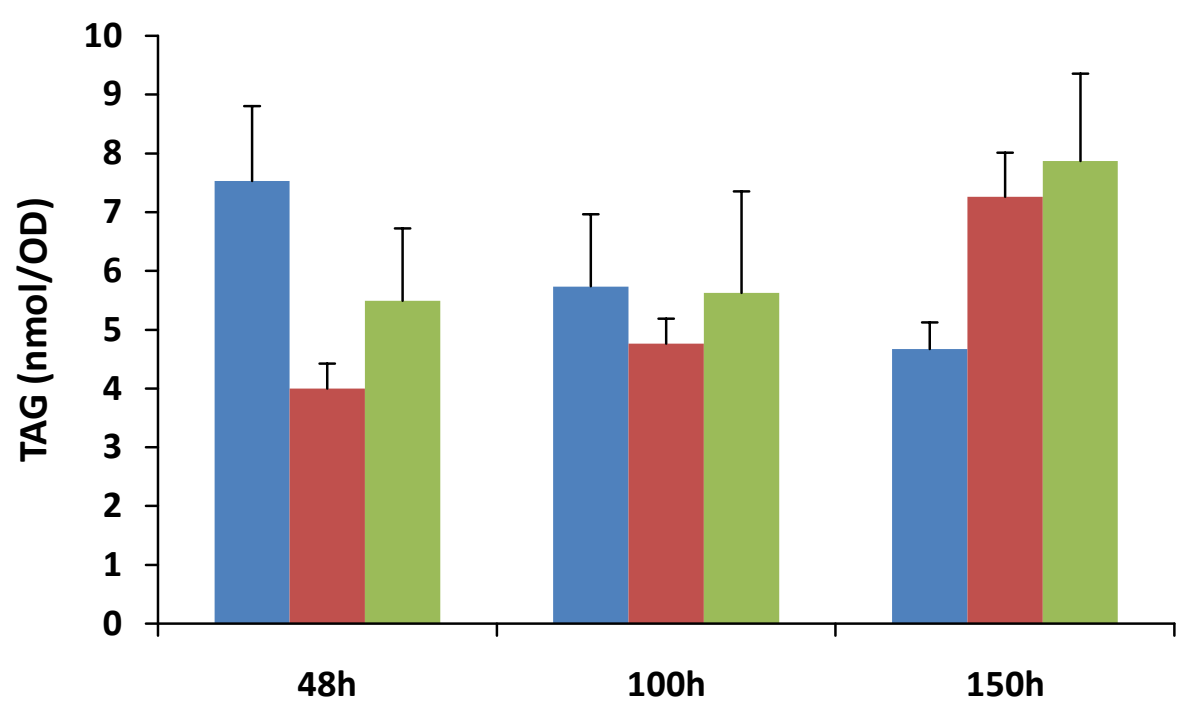

Abb. 22: Quantifizierung von TAG in Mutanten mit Einschränkungen in der $\beta$-Oxidation. Auf die optische Dichte bezogene Gesamtmenge von TAG in Wildtyp (blaue Balken) und in pat1 $\Delta$ Mutante (rote Balken) sowie patl $\Delta$ faa $\Delta$ (grüne Balken) nach 48 h, $100 \mathrm{~h}$ und $150 \mathrm{~h}$ in YPR. Nach anschließendem Abernten der Zellen wurden Lipidextrakte präpariert und mittels Dünnschichtchromatographie aufgetrennt. Die TAG-Fraktion wurde isoliert und gaschromatographisch analysiert. Die Daten zeigen die Mittelwerte mit Standardabweichung von drei unabhängigen Experimenten.

\subsection{Die Rolle des peroxisomalen ABC-Transporters PXA1 im Stoffwechsel während der Dunkelphase in Arabidopsis thaliana}

Im Rahmen der Kooperation mit Herrn Prof. Flügge (Botanisches Institut, Universität zu Köln, Deutschland) zur Etablierung von Transportstudien wurde in der Arbeitsgruppe von Herrn Prof. Flügge bei einer Routineuntersuchung an der pxal-Mutante in Arabidopsis nach verlängerter Dunkelphase ein neuartiger, drastischer Phänotyp beobachtet. Eine Verlängerung der Dunkelphase von $8 \mathrm{~h}$ auf $36 \mathrm{~h}$ führte zum vollständigen Absterben der pxal-Pflanzen, während die Wildtyppflanzen zu diesem Zeitpunkt keine Symptome zeigten. Schon nach $20 \mathrm{~h}$ wurden erste visuelle Symptome in Form von Blattläsionen festgestellt. Bei den Blättern setzte trotz ausreichender Wasserversorgung eine massive Welke ein. Typische Merkmale einer Seneszenz konnten jedoch nicht nachgewiesen werden (Anhang 5) (Kunz et al., 2009). 


\subsubsection{Verstärkte Akkumulation von freien Fettsäuren während verlängerter Dunkelphase in den Blättern der pxal-Mutante}

Eine postulierte Funktion von PXA1 ist die Beteiligung am Fettsäuretransport durch die peroxisomale Membran (Hayashi et al., 1998, Zolman et al., 2001, Footitt et al., 2002). Es stellte sich somit die Frage, inwiefern sich eine durch $P X A 1$-Deletion erfolgte Einschränkung der $\beta$-Oxidation auf die Überlebensfähigkeit der Pflanze in verlängerter Dunkelphase auswirken kann. In einem ersten Experiment wurde untersucht, ob eine eingeschränkte $\beta$ Oxidation von Fettsäuren zu einer Erhöhung der Gehalte von freien Fettsäuren in Blättern führt. Dazu wurden die Pflanzen nach insgesamt 21 Tagen Anzucht für 8 - 28 h im Dunkeln inkubiert. Nach anschließendem Abernten des Blattmaterials wurden Lipidextrakte präpariert und die freien Fettsäuren mittels Gaschromatographie (GC) quantifiziert. Während die Konzentration der freien Fettsäuren in der pxal-Mutante nach 28 h Dunkelphase um ein 13faches anstieg, hielt sich der Fettsäurespiegel im Wildtyp konstant (Abb. 23A). Die Daten zeigten, dass besonders die Konzentrationen der freien Fettsäuren Palmitinsäure (C16:0), Hexadecatriensäure (C16:3) Linolsäure (C18:2) und $\alpha$-Linolensäure (C18:3) während langanhaltender Dunkelphase anstieg (Abb. 23A). Ein besonderes Augenmerk wurde hierbei auf C16:3 gelegt. C16:3 wurde zu keinem Zeitpunkt im Pool der freien Fettsäuren im Wildtyp nachgewiesen. In der pxal-Mutante konnte freies C16:3 erst nach 16 h Dunkelheit detektiert werden. In veresterter Form ist C16:3 eine nur in Lipiden der chloroplastidären Membran vorkommende Fettsäure (Ohlrogge et al., 1991). Die Detektion von C16:3 deutet darauf hin, dass der Hauptteil der detektierten freien Fettsäuren mit großer Wahrscheinlichkeit aus der chloroplastidären Membran stammt. Die Akkumulation der freien Fettsäuren bei langanhaltender Dunkelheit wird anscheinend durch eine eingeschränkte $\beta$-Oxidation verursacht. Verstärkt wird diese These durch Studien mit der Mutante der $\beta$-Ketoacyl-CoAThiolase kat2. So konnte bei der kat2-Mutante ein zwar schwächer ausgeprägter, aber doch zu der pxal-Mutante vergleichbarer Phänotyp nach langanhaltender Dunkelphase beobachtet werden (Anhang 5). Um ein vollständigeres Bild der metabolischen Situation zu erhalten, sollten im nächsten Schritt Acyl-CoA-Profile erstellt werden. Es liegt nahe, dass eine Veränderung des Pools von freien Fettsäuren sich direkt auf den Acyl-CoA-Pool auswirkt. Deswegen wurden die Mengen der aktivierten Fettsäuren mit denen der freien Fettsäuren nach $0 \mathrm{~h}, 20 \mathrm{~h}$ und $28 \mathrm{~h}$ anhaltender Dunkelphase verglichen. Die Acyl-CoA-Konzentration in der pxal-Mutante verdoppelte sich nach $28 \mathrm{~h}$ Dunkelheit im Vergleich $\mathrm{zu}$ Beginn der Dunkelphase (Abb. 23B). Eine besonders starke Zunahme wurde bei 16:0-CoA, 18:2-CoA und 18:3-CoA festgestellt. Die Konzentration von 16:3-CoA stieg nur geringfügig an. Bei 
dem Wildtyp wurde eine Abnahme der Acyl-CoA-Konzentration nach $28 \mathrm{~h}$ Dunkelheit beobachtet (Abb. 23B). Bis auf die Ausnahme von 16:3-CoA, reflektierte die Änderung des Acyl-CoA-Pools die Veränderung der Zusammensetzung der freien Fettsäuren nach verlängerter Dunkelphase. Abschließend wurde untersucht, ob durch eine verlängerte Dunkelphase eine Veränderung der Konzentration von bestimmten Lipidklassen stattfindet. Mittels Dünnschichtchromatographie konnten keine Veränderungen bei den Phospholipiden oder Glykolipiden nach verlängerter Dunkelheit festgestellt werden (Anhang 6). Dagegen wurde bei TAG eine verstärkte Akkumulation nach verlängerter Dunkelheit in den Blättern der pxal-Mutante beobachtet (Anhang 6). Nach $28 \mathrm{~h}$ Dunkelheit stieg die TAGKonzentration um das 5-fache an. Verglichen mit dem Wildtyp wurde ungefähr die 4-fache Menge an TAG nach $28 \mathrm{~h}$ Dunkelheit ermittelt (Abb. 23E). Bei der Fettsäurezusammensetzung wurde ein kontinuierlicher Anstieg von C16:3, C18:2 und C18:3 im TAG während der Dunkelphase beobachtet. Besonders stark stieg die Konzentration von C18:2 und C18:3 während anhaltender Dunkelphase in der pxal-Mutante (Abb. 23C) an. Die starke Zunahme der Fettsäuren C18:2 und C18:3 im TAG reflektiert die vorgefundenen Änderungen im Pool der freien und aktivierten Fettsäuren nach langanhaltender Dunkelphase. Die Detektion von C16:3 unterstützt die Vermutung, dass die Fettsäuren aus der chloroplastidären Membran stammen. 

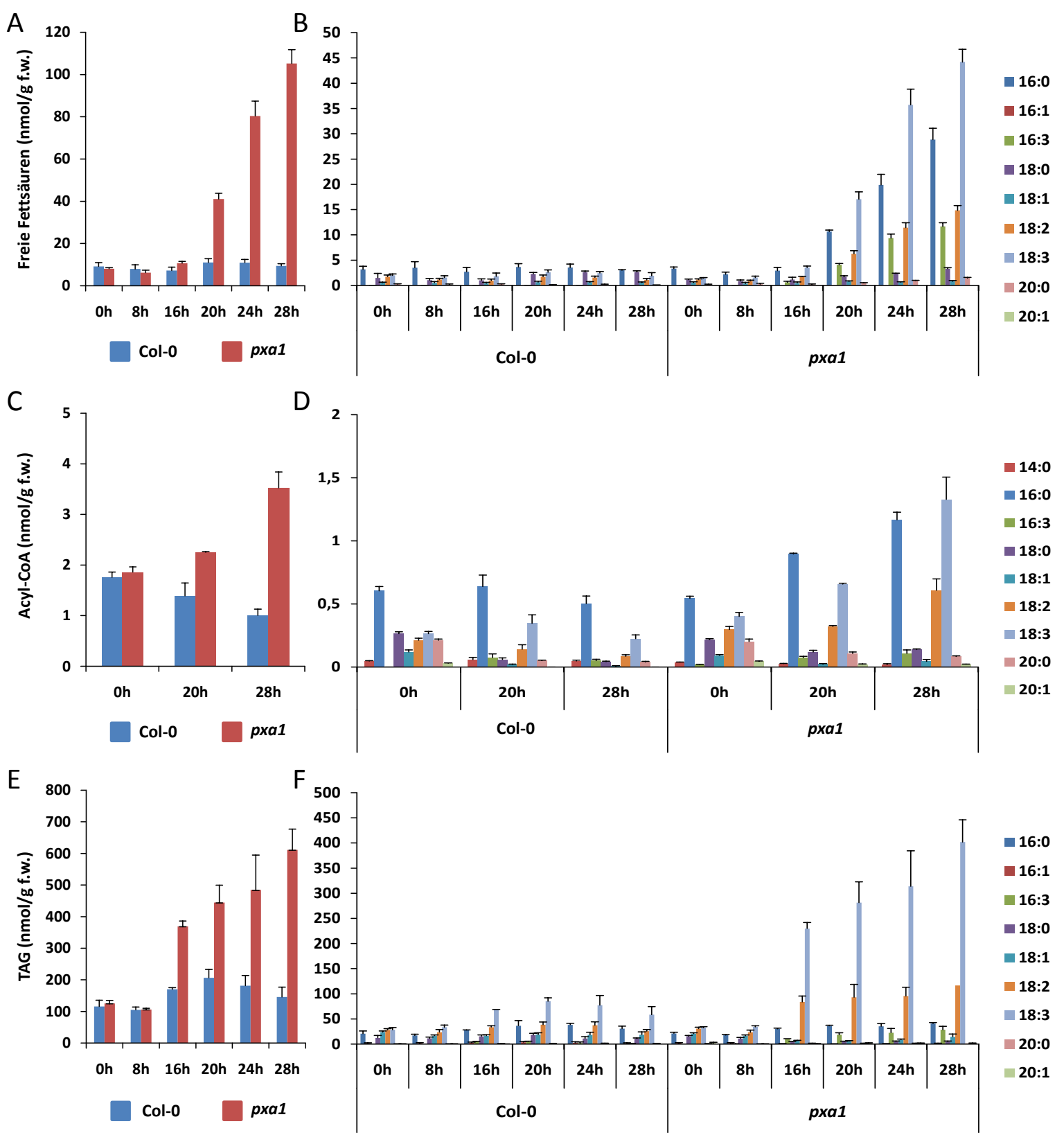

16:0

— 16:1

- 16:3

- 18:0

- 18:1

- 18:2

- 18:3

20:0

20:1

Abb. 23: Auswirkungen einer verlängerten Dunkelphase auf den Fettsäurestoffwechsel von pxa1-Mutanten. Pflanzen wurden nach insgesamt 21 Tagen Anzucht (16 h Licht-, 8 h Dunkelphase) für die angegebenen Zeiten von $8-28 \mathrm{~h}$ im Dunkeln inkubiert und anschließend als gesamte Rosette abgeerntet. Als Vergleich dient jeweils der Zeitpunkt 0 direkt vor der Dunkelphase. (A) Gesamtmenge der freien Fettsäuren in Blättern nach langanhaltender Dunkelphase von pxal und Col-0. (B) Fettsäureprofile in Blättern von pxal und Col-0. (C) Acyl-CoA-Pool in Blättern von pxal und Col-0. (D) Acyl-CoA-Profile in Blättern von pxal und Col-0. (E) Quantifizierung von TAG in Blättern von pxal und Col-0. (F) TAG-Profile in Blättern von pxal und Col-0. Präparierte Lipidextrakte wurden mittels Dünnschichtchromatographie aufgetrennt. Die TAG-Fraktion wurde isoliert und nach Transmethylierung gaschromatographisch analysiert. Die Daten zeigen die Mittelwerte mit Standardabweichung von drei unabhängigen Experimenten. 


\subsubsection{Die Akkumulation von freien Fettsäuren in der pxal-Mutante nach verlängerter Dunkelphase wird durch Zugabe von Saccharose unterdrückt}

In diesem Experiment sollte überprüft werden, ob durch die Zugabe einer exogenen Energiequelle (z.B. Saccharose) der drastische Phänotyp der pxal-Mutante nach verlängerter Dunkelphase unterdrückt werden kann. Dazu wurde der Wildtyp Col-0 und die pxal-Mutante für 10 Tage auf 1/2 MS-Medium mit $2 \%$ Saccharose unter Langtag-Bedingung (16 h Licht/8 h Dunkelphase) angezogen. Danach wurden die Pflanzen auf MS-Medium mit oder ohne Saccharose umgesetzt und das Blattmaterial nach 0 h und 39 h Dunkelheit abgeerntet. Nach anschließender Lipidextraktion erfolgte die Bestimmung der Fettsäurekonzentration über Gaschromatographie (GC).

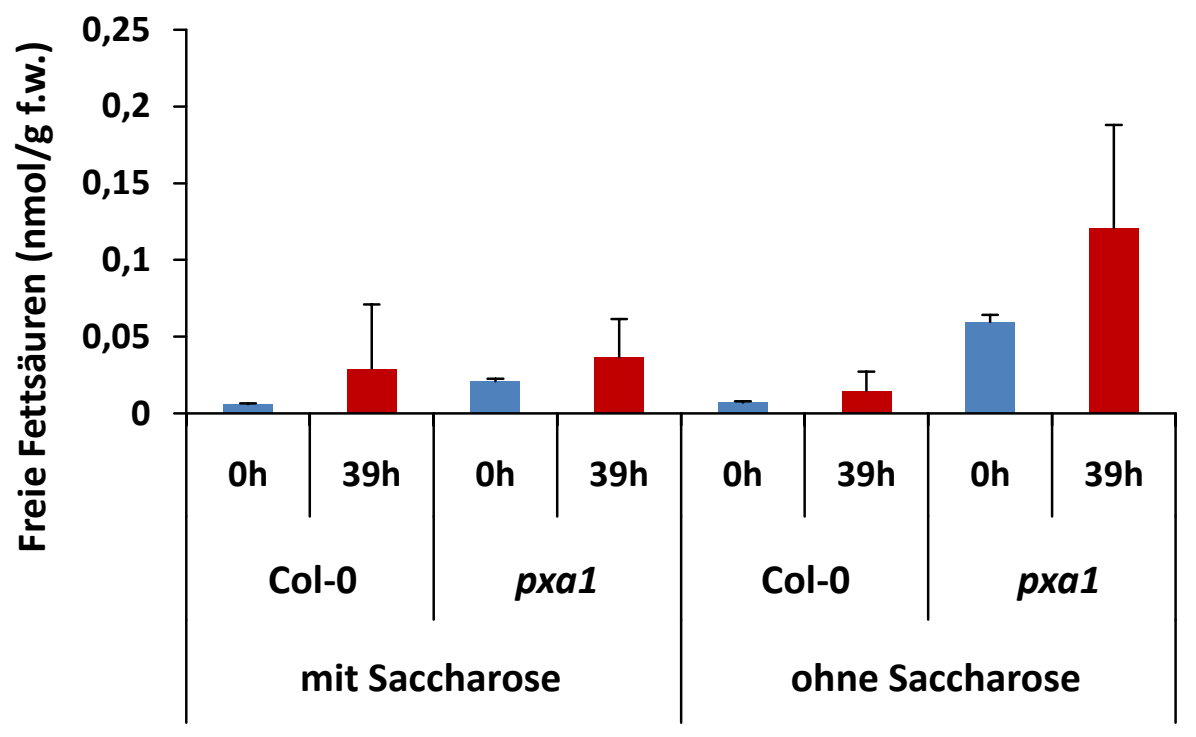

Abb. 24: Die Akkumulation von freien Fettsäuren in der pxa1-Mutante nach verlängerter Dunkelphase wird durch Zugabe von Saccharose unterdrückt. Konzentration der freien Fettsäuren in Blättern von Col-0 und pxal-Mutante mit oder ohne zugegebene Saccharose nach $0 \mathrm{~h}$ und $39 \mathrm{~h}$ Dunkelheit. Die Daten zeigen die Mittelwerte mit Standardabweichung von vier unabhängigen Experimenten.

Die Ergebnisse zeigten für Blätter der pxal-Mutante, die auf Medium ohne Saccharose kultiviert wurde, eine besonders starke Zunahme der Konzentration der freien Fettsäuren. Die gemessenen Werte sind vergleichbar zu den Fettsäurekonzentrationen die bei auf Erde angezogenen pxal-Pflanzen gefunden wurden. Bei Anzucht der pxal-Mutante auf Medium mit Saccharose wurde dagegen eine vergleichsweise geringe Zunahme der Konzentration der freien Fettsäuren nach 39 h Dunkelheit detektiert. Beim Wildtyp wurde im Vergleich zu der 
pxal-Mutante, unabhängig von der Zusammensetzung des Mediums, nach $0 \mathrm{~h}$ und $39 \mathrm{~h}$ Dunkelheit niedrigere Gesamtmengen von freien Fettsäuren festgestellt (Abb. 24). Anhand dieser Daten konnte gezeigt werden, dass die Akkumulation von freien Fettsäuren in der pxal-Mutante nach verlängerter Dunkelphase durch Zugabe von Saccharose unterdrückt werden kann.

\subsubsection{Massive Akkumulation von Jasmonsäure bei andauernder Dunkelphase}

Eine weitere postulierte Funktionen von PXA1 ist die Beteiligung an der Synthese von Jasmonsäure (JA) (Theodoulou et al., 2005). Da Blätter der pxal-Pflanzen nach verlängerter Dunkelphase auch deutliche Gewebebeschädigungen zeigten, stellte sich die Frage, ob eine durch die Mutation bewirkte Beeinflussung der Jasmonatsynthese mitverantwortlich für die beobachteten Phänotypen sein könnte. Um dieser Frage nachzugehen wurde die Bildung von Jasmonsäure (JA) in den Blättern von der pxal-Mutante und Wildtyp (Col-0) in verschiedenen Stadien der Dunkelphase bestimmt. Für die Qunatifizierung der Konzentration von JA wurde das gleiche Blattmaterial wie für die Bestimmung der Gehalte der freien Fettsäuren verwendet. Zusätzlich wurden die Konzentrationen der JA-Vorstufen 12Oxophytodiensäure (OPDA) und Dinor-12-oxophytodiensäure (dinor-OPDA) gemessen. In den Blättern der pxal-Mutante wurde ein massiver Anstieg der JA-Konzentration nach verlängerter Dunkelphase beobachtet. Nach 28 h Dunkelheit wurde eine 210-fache Zunahme der JA-Konzentration in der pxal-Mutante beobachtet. Beim Wildtyp wurde im Verlauf des Experiments keine signifikante Veränderung der JA-Konzentration festgestellt (Abb. 25C). Ähnliche Ergebnisse lieferten die Messungen der Konzentrationen von OPDA und dinorOPDA im Wildtyp und in der pxal-Mutante nach langanhaltender Dunkelphase (Abb. 25A und B). Die Messungen der Konzentrationen der Phytohormone Salicylsäure (SA), Abscisinsäure (ABA) und Indol-3-Essigsäure (IAA) in der pxal-Mutante zeigten keine signifikante Abweichungen von den Werten der Wildtyp-Pflanzen (Anhang 7). 

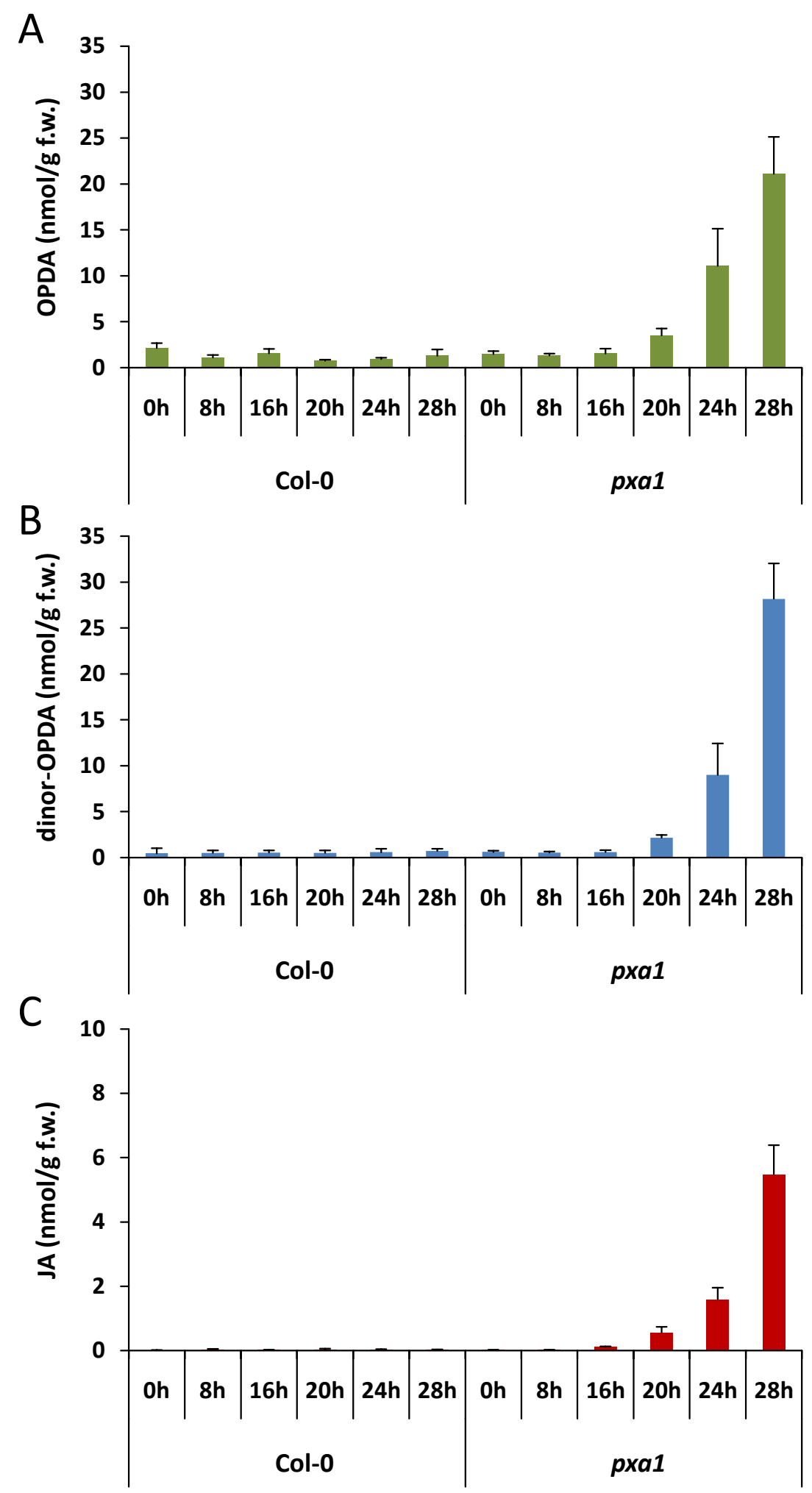

Abb. 25: Massive Akkumulation von Jasmonsäure bei andauernder Dunkelphase. Pflanzen wurden nach insgesamt 21 Tagen Anzucht (16 h Licht/8 h Dunkelphase) für die angegebenen Zeiten von $8-28 \mathrm{~h}$ im Dunkeln inkubiert und anschließend als gesamte Rosette abgeerntet. Als Vergleich dient jeweils der Zeitpunkt 0 direkt vor der Dunkelphase. (A) Gesamtmenge von OPDA in Blättern nach langanhaltender Dunkelphase von pxal und Col-0. (B) Gesamtmenge von dinor-OPDA in Blättern von pxal und Col-0. (C) Konzentration der Jasmonsäure in Blättern von pxal und Col-0. Die Daten zeigen die Mittelwerte mit Standardabweichung von drei unabhängigen Experimenten. 


\section{Diskussion}

\subsection{Fettsäuretransport durch die Plasmamembran in Saccharomyces cerevisiae}

Acyl-CoA-Synthetasen katalysieren die Thioesterifizierung zwischen freien Fettsäuren und Coenzym A zu Acyl-CoA-Derivaten. Diese als Aktivierung von freien Fettsäuren bezeichnete Reaktion stellt eine Schlüsselreaktion sowohl beim intrazellulären Fettsäuretransport zwischen verschiedenen Kompartimenten als auch bei der Aufnahme von Fettsäuren in die Zelle dar. In S. cerevisiae wurden vier Acyl-CoA-Synthetasen identifiziert, die eine Substratspezifität für langkettige Fettsäuren besitzen: Faa1p, Faa2p, Faa3p und Faa4p. (Duronio et al., 1992, Knoll et al., 1994, Johnson et al., 1994). Als fünfte Acyl-CoASynthetase wurde Fat1p mit einer Präferenz für die Aktivierung sehr langkettiger Fettsäuren charakterisiert (Watkins et al., 1998). Hefe-Mutanten, bei denen diese Gene einzeln oder in allen denkbaren Kombinationen inaktiviert wurden, sind Gegenstand zahlreicher Publikationen. Diese Studien etablierten ein teilweise recht detailliertes Bild über den Einfluss dieser Proteine auf den Fettsäuremetabolismus in S. cerevisiae. Den Anstoß für dieses Projekt gab die Beobachtung, dass durch die Deletion von FAAl ein Fettsäuresekretions-Phänotyp induziert werden kann (Michinaka et al., 2003). Im Rahmen dieser Arbeit sollte dieser Phänotyp genutzt werden, um einen im Detail noch nicht verstandenen Transportmechanismus von freien Fettsäuren durch die Plasmamembran in S. cerevisiae genauer zu untersuchen. Eine Überprüfung in unserem Labor zeigte jedoch, dass die alleinige Inaktivierung von FAAl für die Induktion des Fettsäuresekretions-Phänotyps nicht ausreicht. Weitere Untersuchungen zeigten, dass nur durch eine kombinierte Deletion von FAA1 und FAA4 der Fettsäuresekretions-Phänotyp ausgelöst werden kann. Die in einer vorausgegangenen Studie (Michinaka et al., 2003) beschriebene faal $\Delta$-Mutante wurde in zwei aufeinander folgenden Experimenten mutagenisiert und anschließend aufgrund des entdeckten Sekretions-Phänotyps isoliert. Möglicherweise ist eine unentdeckte additive Mutation in FAA4 - resultierend in dem Genotyp faal $\triangle$ faa $4 \Delta$ - verantwortlich für den beobachteten Phänotyp. Unsere Untersuchungen zeigten, dass der FettsäuresekretionsPhänotyp der faal $\Delta f a a 4 \Delta$-Mutante durch einen massiven Export von freien Fettsäuren während der exponentiellen Phase und einen Re-Import von freien Fettsäuren während der stationären Phase sowie einen drastischen Anstieg intrazellulärer Fettsäuren charakterisiert ist. 
Auch die Mutanten, bei denen sämtliche FAA-Gene inaktiviert wurden (YB526, MS51 und MS612), zeigten den gleichen Fettsäuresekretions-Phänotyp.

Obwohl die postulierte Interaktion zwischen Fat1p und Faa1p oder Faa4p (Zou et al., 2003) durch die Deletion von FAAl und FAA4 unterbunden war, konnte trotzdem ein Re-Import von freien Fettsäuren während der stationären Phase stattfinden. Aufgrund dieser Beobachtung wurde vermutet, dass die Aktivität von Fat1p alleine für den Import von exogenen Fettsäuren verantwortlich sein könnte. Die zusätzliche Deletion von FAT1 in dem Hintergrund der vierfach Mutante YB526 führte jedoch zu keiner Änderung des zweiphasigen Fettsäuretransport-Phänotyps, sondern führte stattdessen $\mathrm{zu}$ einer noch stärkeren Akkumulation von intrazellulären freien Fettsäuren während der stationären Phase (Scharnewski et al., 2008). Die in der Literatur beschriebene Beteiligung von Fat1p am Import von freien Fettsäuren konnte demnach nicht bestätigt werden (Dirusso et al., 2000). Die verstärkte Akkumulation von freien Fettsäuren nach zusätzlicher Deletion von FAT1 ließ eine Beteiligung von Fatlp an der Aktivierung freier Fettsäuren vermuten. Diese Aktivität wurde bereits in der Literatur beschrieben (Watkins et al., 1998). Die in der vorliegenden Arbeit dokumentierten Ergebnisse bestätigen diese Annahme. Durch Inkubation (Abb. 4) der Mutante YB526 mit radioaktiv markierter Fettsäure konnte deren Inkorporation in die Lipide gezeigt werden. Dagegen wurde bei der Mutante MS51 keine Inkorporation der applizierten Ölsäure in die verschiedenen Lipidklassen nachgewiesen. Dadurch konnte gezeigt werden, dass Fat1p für die verbliebene Acyl-CoA-Synthetase-Aktivität in der Mutante YB526 verantwortlich ist. Die durchgeführte Expressionsstudie bestätigt zusätzlich die vorher beschriebene Aktivität von Fat1p (Abb. 5). Durch die Expression von FAT1 konnte die fehlende Acyl-CoA-Synthetase-Aktivität in der Mutante MS51 teilweise komplementiert werden.

Eine Beteiligung der Acyl-CoA-Synthetasen am Import von freien Fettsäuren durch die Plasmamembran wurde in einer Vielzahl von Publikationen beschrieben (Dirusso et al., 2000, Zou et al., 2003). Die in dieser Arbeit vorliegenden Daten lassen dagegen auf eine Aufnahme von exogenen Fettsäuren in Abwesenheit jeglicher Acyl-CoA-Synthetase-Aktivität schließen. Eine mögliche Ursache für die widersprüchlichen Ergebnisse lässt sich unter anderem dadurch erklären, dass sich der Versuchsaufbau der Experimente in entscheidenden Punkten unterscheidet. Besonders die ungenaue Differenzierung zwischen den mit den Zellen assoziierten Fettsäuren und den tatsächlich durch die Membran transportierten und anschließend intrazellulär metabolisch verfügbaren Fettsäuren könnte zu einer Fehlinterpretation führen. Anhand der durchgeführten Expressionen der Isomerase PAI aus 
Propionibacterium acnes (Hornung et al., 2005) in der Mutante MS51 konnte jedoch gezeigt werden, dass der Import von freien Fettsäuren durch die Plasmamembran tatsächlich ohne die Aktivität von Acyl-CoA-Synthetasen erfolgen kann (Tab. 9).

Um weitere Erkenntnisse über den Zusammenhang von Wachstumsphase der Zellen und Richtung des Fettsäuretransportes zu erhalten, wurde der Transport durch Änderungen in der Zusammensetzung des Kulturmediums manipuliert. Den Zellen wurde nach dem Erreichen der stationären Phase und dem damit verbundenen Einsetzen des Re-Imports der freien Fettsäuren Raffinose als Kohlenhydratquelle zugegeben. Direkt nach der Zugabe von Raffinose wurde eine signifikant erhöhte Menge an freien Fettsäuren durch Sekretion in das Medium freigesetzt. Zeitgleich stoppte die Akkumulation der freien Fettsäuren in den Zellen (Abb. 6). Die schnelle Reaktion der Zellen führte zu einer sofortigen Umkehrung der Transportrichtung. Diese Beobachtung lässt auf einen aktiven Mechanismus für den Export von freien Fettsäuren schließen. Anscheinend ist dieser aktive Export-Mechanismus abhängig von der Verfügbarkeit von verwertbaren Kohlenstoffquellen. Demnach wird der Transport von freien Fettsäuren durch den metabolischen Zustand der Zellen aktiv reguliert. Die Zugabe von einer verwertbaren Kohlenstoffquelle hat dabei nicht nur Auswirkungen auf die Geschwindigkeit oder Richtung des Transportes, sondern auch auf die Zusammensetzung des intrazellulären Fettsäure-Pools. Die Zugabe von Raffinose führte unmittelbar zu einer besonders starken Zunahme der gesättigten Fettsäuren (Abb. 6). Während sich das Verhältnis zwischen gesättigten und ungesättigten freien Fettsäuren in den Zellen kaum änderte, verschob sich das Verhältnis im Medium aufgrund des selektiven Exports signifikant zugunsten der gesättigten freien Fettsäuren (Abb. 6). Der gezeigte selektive Export von Fettsäuren liefert einen zusätzlichen Hinweis für einen aktiven Transportmechanismus. Scheinbar ist der aktive Export-Mechanismus für die Stabilisierung der Zusammensetzung des Fettsäure-Pools in den Zellen verantwortlich. Eine Änderung des Verhältnisses zwischen ungesättigten und gesättigten Fettsäuren kann unter anderem einen negativen Effekt auf die Membranfluidität haben (Lockshon et al., 2007). Nachdem die zugegebene Raffinose aufgebraucht war, setzte der Re-Import von freien Fettsäuren aus dem Medium ein (Abb. 6). Auch hier wurde ein selektiver Transport von freien Fettsäuren beobachtet, der sich durch eine verstärkte Aufnahme von ungesättigten Fettsäuren auszeichnet. Dies lässt einen aktiven Mechanismus für den Import von freien Fettsäuren vermuten.

Zusammenfassend kann gefolgert werden, dass die Richtung des Transportes von freien Fettsäuren umkehrbar ist und durch den metabolischen Zustand der Zellen aktiv reguliert wird. Unsere Ergebnisse deuten auf einen Kontrollmechanismus hin, der bei einer drastischen 
Änderung der Zusammensetzung des Fettsäure-Pools in den Zellen einen aktiven Transport der Fettsäuren aus der Zelle initiiert. Hingegen wird der Re-Import von exogenen Fettsäuren möglicherweise durch das Fehlen anderer extrazellulärer Kohlenstoffquellen, also einem Hungersignal, im Stadium der stationären Phase ausgelöst.

Im Rahmen der vorliegenden Arbeit wurde versucht die Grundlage des beobachteten aktiven Transports weiter $\mathrm{zu}$ charakterisieren und beteiligte Proteine $\mathrm{zu}$ identifizieren. $\mathrm{Zu}$ diesem Zweck wurde eine Vielzahl von Deletionsmutanten potentieller Transportproteine erzeugt und die Auswirkung auf den beschriebenen Phänotyp überprüft. Allerdings haben diese Untersuchungen bislang nicht zur Identifikation eines Fettsäuretransport-Proteins geführt. In zukünftigen Experimenten soll daher versucht werden, diese Transportproteine zu isolieren indem die Transkriptionsprofile der Zellen im Stadium von Export bzw. Re-Import miteinander verglichen werden.

Der Fettsäuresekretions-Phänotyp der Mutante MS51 ist unter anderem durch einen drastischen Anstieg intrazellulärer Fettsäuren charakterisiert. Im Vergleich zum Wildtyp wurde eine bis zu 50-fach erhöhte Menge an freien Fettsäuren in den Zellen gemessen. Trotz dieser erhöhten Mengen von freien Fettsäuren in den Zellen, wurde keine gravierende Auswirkung auf das Wachstumsverhalten beobachtet (Scharnewski et al., 2008). Mittels Elektronenmikroskopie wurde der Einfluss der erhöhten Fettsäurekonzentrationen auf die subzelluläre Morphologie der Hefezellen analysiert. Die Untersuchungen zeigten, dass die erhöhten Konzentrationen an freien Fettsäuren zu einer drastischen Ausweitung des Endoplasmatischen Retikulums führen. Dabei scheint eine Korrelation zwischen dem Grad der Ausweitung des ER und der Menge akkumulierter freier Fettsäuren in der Zelle zu bestehen (Abb. 8). Die elektronenmikroskopische Aufnahmen deuten daraufhin, dass die Hefezellen die Möglichkeit besitzen, größere Mengen an freien Fettsäuren im ER zu deponieren und auf diese Weise den Metabolismus im Allgemeinen vor den negativen Auswirkungen hoher Fettsäurekonzentrationen bewahren. Membranen anderer Organellen oder die Plasmamembran zeigten dagegen keine auffälligen Anomalie (Abb. 8). Diese Beobachtung lässt ein gezieltes Leiten der Fettsäuren zum ER vermuten. Ein solcher gezielter Transport von freien Fettsäuren deutet auf einen aktiven - proteinvermittelten - Prozess hin.

Ein ähnlicher Phänotyp konnte auch bei der are $1 \Delta$ are $2 \Delta d g a 1 \Delta$ lrol $\Delta$-Mutante gezeigt werden (Petschnigg et al., 2009). Aufgrund verhinderter TAG-Synthese induzierte die Zugabe von Ölsäure eine drastische Proliferation des ER. Die TAG-Synthese dient unter anderem als 
wichtiger intrazellulärer Puffer, um die toxische Wirkung erhöhter Konzentrationen von ungesättigten Fettsäuren zu umgehen (Petschnigg et al., 2009).

Die vorliegenden Daten zeigen eindeutig, dass die Aufnahme exogener Fettsäuren unabhängig von jeglicher Acyl-CoA-Synthetase-Aktivität möglich ist. Dieses Ergebnis widerspricht dem Modell der vektoriellen Acylierung (Zou et al., 2003). Demnach ist Fat1p direkt an der Aufnahme und Transport von Fettsäuren durch die Plasmamembran beteiligt. Dabei bilden Fat1p und die Acyl-CoA-Synthetase Faa1p oder Faa4p einen Komplex, bei dem begleitend mit der Trennung von der Membran, die Fettsäuren verestert und so für den weiteren Metabolismus zugänglich werden. Dieses Model basiert auf einer Vielzahl von Experimenten, die Einschränkungen der stofflichen Verwertbarkeit von exogenen Fettsäuren bei der fatl $\Delta$ Mutante und faal $\Delta$ faa4 $\Delta$-Mutante zeigten (Faergeman et al., 2001, Dirusso et al., 2000). Als mögliche Ursache für die widersprüchlichen Ergebnisse lässt sich der unterschiedliche Versuchsaufbau der Experimente anführen. in entscheidenden Punkten unterscheidet. In den vorausgegangenen Transportstudien wurden die Zellen aus Kulturen in der exponentiellen Phase entnommen. Während dieser Wachstumsphase wurde eine verstärkte Sekretion von freien Fettsäuren in der faal $\Delta$ faa $4 \Delta$-Mutante beobachtet. Diese verstärkte Sekretion könnte im Konflikt mit der Aufnahme exogener Fettsäuren stehen. Unsere Studien zeigten, dass der Import freier Fettsäuren erst während der stationären Phase einsetzt. Auch spielt der Zeitrahmen der durchgeführten Experimente eine wichtige Rolle. Der mit C1-Bodipy-C12 beschriebene Aufnahme-Assay wurden in einem sehr engen Zeitrahmen durchgeführt (Faergeman et al., 2001, Dirusso et al., 2000). Die Daten aus unseren Experimenten zeigten aber, dass es sich bei dem von uns beobachteten Transport von Fettsäuren um einen sehr langsamen Prozess handelt. Es kann somit nicht ausgeschlossen werden, dass zwei voneinander unabhängige Mechanismen zum Transport von Fettsäuren durch die Plasmamembran beitragen. 


\subsection{Untersuchungen zum Fettsäuretransport durch die peroxisomale Membran durch den ABC-Transporter PXA1 in Arabidopsis thaliana}

Trotz vergleichbarer Komponenten scheint sich der Mechanismus des Fettsäure-Imports in Peroxisomen in Pflanzen grundlegend von dem in Saccharomyces cerevisiae zu unterscheiden. Nach dem etablierten Modell in Hefe werden aktivierte Fettsäuren in Form von Acyl-CoA-Verbindungen mittels des ABC-Transporters Pat1p-Pat2p durch die peroxisomale Membran transportiert und stehen anschließend direkt als Substrat für die $\beta$-Oxidation zur Verfügung (Hettema et al., 1996). In Arabidopsis thaliana dagegen ist neben der Beteiligung des ABC-Transporters PXA1 am Import in das peroxisomale Lumen (Zolmann et al., 2001, Hayashi et al., 2002, Footitt et al., 2002) zusätzlich die Aktivierung der Fettsäuren essentiell für eine erfolgreiche $\beta$-Oxidation während der Keimlingsentwicklung (Fulda et al., 2004). In Arabidopsis wurden LACS6 und LACS7 als peroxisomale Acyl-CoA-Synthetasen identifiziert (Fulda et al., 2002). Eine exakte Beurteilung der Bedeutung der einzelnen Proteinkomponenten im pflanzlichen System für die Einleitung des Fettsäureabbaus ist aufgrund der möglicherweise unterschiedlichen Mechanismen des ABC-Transporters in Pflanzen und Hefe sehr schwierig. Eine Möglichkeit wäre, dass in pflanzlichen Peroxisomen entweder freie Fettsäuren transportiert werden und anschließend innerhalb des Peroxisomen aktiviert werden müssen, oder dass die Fettsäuren, beispielsweise durch Thioesteraseaktivität innerhalb des Peroxisoms, die Aktivierung vorübergehend verlieren und anschließend eine erneute CoA-Veresterung erforderlich ist. Alternativ könnte der Transport von Fettsäuren durch die peroxisomale Membran über zwei unabhängige Wege ablaufen. Demnach ist PXA1 am Transport von Acyl-CoAs beteiligt, während freie Fettsäuren durch einen unbekannten Transportmechanismus in die Peroxisomen gelangen und anschließend durch eine peroxisomale Acyl-CoA-Synthetase aktiviert werden müssen (Fulda et al., 2002, Fulda et al., 2004). Ausgehend von dem etablierten Modell der Hefe wurde in diesem Teilabschnitt der Arbeit versucht, den identifizierten pflanzlichen peroxisomalen ABC-Transporter PXA1 durch Komplementationsversuche in Hefe besser $\mathrm{zu}$ charakterisieren. Dazu wurde ein Verfahren verwendet, mit dem sich die Komplementation durch einen Wachstumstest in Flüssigmedium mit Ölsäure als einziger Kohlenstoffquelle überprüfen lässt (van Roermund $e t$ al., 2008). Die in der vorliegenden Arbeit dokumentierten Ergebnisse zeigten, dass die alleinige Expression des pflanzlichen ABC-Transporters PXA1 anders als das entsprechende hefeeigene Protein Pat1p nicht in der Lage ist, den Wachstumsphänotyp der Doppelmutante pat1 $\triangle$ faa $2 \Delta$ in Gegenwart von Ölsäure zu komplementieren (Abb. 9). Demnach ist der ABC- 
Transporter aus S. cerevisiae nicht durch den pflanzlichen ABC-Transporter PXA1 funktional zu ersetzen. Erst die kombinierte Expression der pflanzlichen Proteine PXA1 und LACS7 führte zu einer Wachstumsrate, die vergleichbar ist $\mathrm{zu}$ der Situation bei Expression des endogenen ABC-Transporters Pat1p (Abb. 9). Diese Beobachtung im heterologen Expressionssystem reflektiert unmittelbar die Situation in der Pflanze und unterstreicht die Bedeutung der intraperoxisomalen Fettsäureaktivierung im pflanzlichen System. Demzufolge findet offensichtlich in den Pflanzen eine Fettsäureaktivierung durch LACS7 oder LACS6 nach erfolgtem Transport von Fettsäuren in die Peroxisomen statt .Anders als in Hefen, bei denen der Fettsäuretransport durch die peroxisomale Membran über zwei voneinander unabhängige Mechanismen erfolgt (Hettema et al., 1996), scheint es aufgrund der vorliegenden Daten in Pflanzen nur die Möglichkeit des Fettsäuretransportes unter Beteiligung von PXA1 zu geben. Wie schon zuvor beschrieben, wäre eine weitere Erklärungsmöglichkeit, dass in pflanzlichen Peroxisomen aktivierte Fettsäuren importiert werden, die durch Thioesteraseaktivität die Aktivierung vorübergehend verlieren und anschließend erneut durch LACS6 oder LACS7 aktiviert werden. Ein solcher Reaktionsmechanismus ergibt jedoch insbesondere aus energetischer Sicht wenig Sinn. In einem postulierten Modell wurde vermutet, dass der Import von aktivierten Fettsäuren nicht direkt der $\beta$-Oxidation dient, sondern zur Stabilisierung des CoA-Spiegels, um die Aktivierung anderer Moleküle in den Peroxisomen zu gewährleisten. Der Bedarf an CoA soll daher durch die Thioesteraseaktivität sichergestellt werden. Im Falle der $\beta$-Oxidation der Fettsäuren wäre eine erneute Aktivierung notwendig (Penfield et al., 2005).

In einer vorausgegangenen Studie konnte eine partielle Komplementation einer pat1 1 pat2AHefemutante mit dem menschlichen peroxisomalen ABC-Transporter ALDP erfolgreich durchgeführt werden (van Roermund et al., 2008). Die Ergebnisse der Untersuchung deuten darauf hin, dass im Gegensatz zu Pflanzen in Hefen und Menschen der Fettsäure-Import in Peroxisomen nach einem ähnlichen Mechanismus ablaufen könnte.

Bisher war es nicht möglich eine direkte Transportaktivität sowohl von pflanzlichen, menschlichen als auch von dem aus Hefe stammenden peroxisomalen ABC-Transporter in einem in vitro-Test nachzuweisen. Sämtliche Versuche in einem auf Liposomen basierenden in vitro-System sind bislang fehlgeschlagen.

In dieser Studie konnte gezeigt werden, dass der ABC-Transporter aus Hefe nicht durch den pflanzlichen ABC-Transporter PXA1 funktional zu ersetzen ist. Erst die kombinierte Expression der pflanzlichen Proteine PXA1 und LACS7 führte zu einer erfolgreichen 
Komplementation der Doppelmutante pat1 $\Delta$ faa $2 \Delta$. Der Mechanismus des Fettsäure-Imports in Peroxisomen in Pflanzen scheint sich demnach grundlegend von dem in Saccharomyces cerevisiae zu unterscheiden.

\subsubsection{Die Folgen von Einschränkungen in der $\beta$-Oxidation auf die Regulierung des Acyl-CoA-Pools in Saccharomyces cerevisiae}

In einem weiteren experimentellen Ansatz wurde der wesentliche Unterschied zwischen dem Import von Fettsäuren in Peroxisomen zwischen Hefe und Pflanzen mit Hilfe des etablierten Modells der Hefe untersucht. Wie zuvor beschrieben, hat sich die intraperoxisomale Aktivierung von freien Fettsäuren in A. thaliana als essentiell für eine erfolgreiche $\beta$ Oxidation herausgestellt, während der Abbau von langkettigen Fettsäuren in S. cerevisiae auch in Abwesenheit dieser Aktivität möglich ist (Fulda et al., 2004, Hettema et al, 1996). Der Fettsäuretransport durch die peroxisomale Membran in Hefe erfolgt über zwei voneinander unabhängigen Mechanismen. Dabei wird unterschieden zwischen dem Pat1pPat2p abhängigen Transport von langkettigen Fettsäuren (LCFA) und dem Pat1p-Pat2p unabhängigen Transport von mittelkettigen Fettsäuren (MCFA) (Visser et al., 2007). Um die besondere Rolle der peroxisomalen Fettsäureaktivierung in Hefe besser zu verstehen, wurde die Regulierung des intraperoxisomalen Acyl-CoA-Pools durch die Inaktivierung der peroxisomalen Thioesterase TES1 (Jones et al., 1999) manipuliert. Acyl-CoA-Thioesterasen katalysieren die hydrolytische Spaltung von Acyl-CoAs in Fettsäuren und freies CoA und somit die Rückreaktion von Faa2p. Zusätzlich wurden weitere Gene deletiert, die für Proteine mit einer direkten oder indirekten Beteiligung am Import von Fettsäuren in die Peroxisomen oder am Abbau der Fettsäuren durch $\beta$-Oxidation kodieren. Als erstes Kriterium für Veränderungen im Metabolismus wurden Wachstumstests auf ölsäurehaltigem Minimalmedium herangezogen.

Wie bereits in der Literatur beschrieben (Hettema et al., 1996), wurde bei der Doppelmutante pat1 $\Delta$ faa2 2 ein deutlich reduziertes Wachstum in Gegenwart von Ölsäure beobachtet. Bergründet wurde dieser Phänotyp durch die eingeschränkter Nutzung der Ölsäure und dem dadurch verursachten Engpass in der Energieversorgung (Hettema et al., 1996). Unsere Studien zeigten aber, dass anscheinend eine toxische Wirkung der Ölsäure verantwortlich für

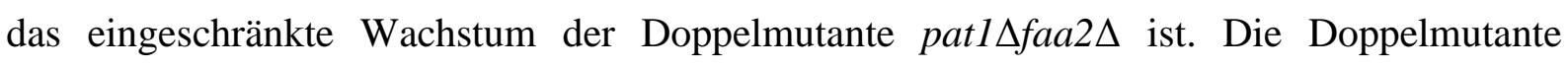
pat1 $\triangle$ faa $2 \Delta$ zeigte auf dem entsprechenden Medium ohne zugesetzte Ölsäure kein eingeschränktes Wachstum, sondern erreichte Wachstumsraten wie der Wildtyp (Abb. 10). 
Wie weiterführende Tests belegten, beruht dieses Wachstum auf der geringen Menge zugesetzten Hefeextrakts. Die toxische Wirkung der Ölsäure auf Hefe-Mutanten wurde bereits in mehreren Publikationen beschrieben. Die toxische Wirkung der Ölsäure wurde

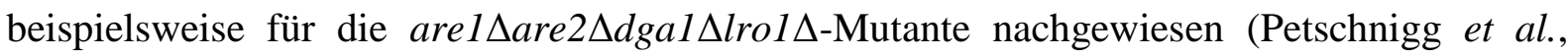
2009). In diesem Fall wurde durch die Zugabe von Ölsäure aufgrund verhinderter TAGSynthese eine drastische Proliferation des ER induziert. Diese Proliferation wirkte sich negativ auf das Wachstumsverhalten aus. Die Zugabe von gesättigter Palmitinsäure (C16:0) oder Stearinsäure (C18:0) zeigte dagegen keine Auswirkung auf das Wachstumsverhalten der are $1 \Delta$ are $2 \Delta$ dgal $\Delta$ lrol $\Delta$-Mutante (Petschnigg et al., 2009). Ebenso wurde bei einer Vielzahl von Einfachmutanten eine äußerst große Sensibilität gegenüber Ölsäure nachgewiesen. Teilweise zeigten die Einzelmutanten bereits bei geringen Konzentrationen kein Wachstum mehr (Lockshon et al., 2007). Aus diesen Daten ist zu schließen, dass verschiedene Faktoren im Fettsäuremetabolismus dafür verantwortlich sind, dass kritische Ölsäurekonzentrationen verhindert werden. Die Kausalität, mit der erhöhte Ölsäurekonzentrationen unmittelbar zu Wachstumsinhibition oder gar Zelltod führen, ist bislang allerdings noch weitgehend unverstanden. Unsere Daten werfen dabei ein neues Licht auf Parameter, die den Abbau der Fettsäuren in Peroxisomen beeinflussen und geben erste Hinweise auf unmittelbare Auslöser der Stoffwechselstörungen, die letztendlich zum vollständigen Erliegen des Wachstums führen können.

Die kombinierte Deletion von TES1 und FAA2 führte zu einem drastischen Phänotyp. Bei dieser Mutante wurde weder auf Minimalmedium mit Ölsäure noch auf Minimalmedium ohne Ölsäure Wachstum nachgewiesen (Abb. 10). Für Tes1p wird eine regulierende Funktion auf die Aktivität der $\beta$-Oxidation vermutet (Maeda et al., 2006). Nach einem vorgeschlagenen Modell wird durch die Interaktion zwischen Tes1p und Faa2p das CoA/Acyl-CoA-Verhältnis in den Peroxisomen stabil gehalten, um die Aktivität der $\beta$-Oxidation aufrechtzuhalten (Maeda et al., 2006). Basierend auf dieses Modell vermuten wir, dass durch die kombinierte Deletion anscheinend ein fehlgeleiteter peroxisomaler Stoffwechsel durch Destabilisierung des CoA/Acyl-CoA-Verhältnisses verursacht wurde. So zeigte die Einzelmutante pex3s Wachstum auf Minimalmedium (Abb. 11). Anscheinend ist es für die Zelle günstiger überhaupt keine Peroxisomen zu besitzen als ein fehlgeleiteten peroxisomalen Stoffwechsel zu tolerieren. Ein zusätzlicher Hinweis für diese Fehlleitung in den Peroxisomen wurde durch die Inaktivierung von $P A T 1$ in der Doppelmutante tes $1 \triangle$ faa $\triangle \Delta$ gegeben. Durch die zusätzliche Deletion von PATl konnte der drastische Phänotyp teilweise aufgehoben werden (Abb. 10). Bei einem nicht möglichen Import von Acyl-CoA in die Peroxisomen wird demnach eine 
Destabilisierung des Fettsäuremetabolismus unterbunden. Ebenfalls konnte der drastische Wachstumsphänotyp der Doppelmutante tes $1 \Delta$ faa2 $\Delta$ durch zusätzliche Deletionen von AcylCoA-Synthetasen teilweise aufgehoben werden (Abb. 12). In diesem Fall findet anscheinend ein reduzierter Transport von Acyl-CoA in die Peroxisomen statt, wodurch die negativen Auswirkungen auf den Fettsäuremetabolismus abgemildert werden.

Aus den Wachstumstests der Mutanten lässt sich schließen, dass der fehlgeleitete peroxisomale Stoffwechsel anscheinend zu gravierenden Problemen führen kann, die den Metabolismus der gesamten Zelle beeinflussen. Offensichtlich entsteht der fehlgeleitete peroxisomale Stoffwechsel erst dann, wenn Acyl-CoA-Moleküle in die Peroxisomen transportiert werden, dort aber nicht weiter abgebaut werden können. Denkbar wäre, dass der Transport von Acyl-CoA in die Peroxisomen dem Zytoplasma aber auch das für eine Vielzahl von weiteren Reaktionen benötigte CoA entzieht, welches durch den eingeschränkten peroxisomalen Metabolismus in diesen Organellen akkumuliert und nicht in das Zytoplasma zurück gelangen kann. Die peroxisomale Membran ist nicht durchlässig für freies CoA (Antonenkov et al., 2004) und ein peroxisomaler Transporter für freies CoA konnte bislang nicht nachgewiesen werden. Eine alternative Möglichkeit wäre, dass der fehlgeleitete peroxisomale Stoffwechsel zu einer Akkumulation eines toxischen Intermediats führt, welches sich negativ auf den gesamten Stoffwechsel der Zelle auswirkt. Die Untersuchung des Acyl-CoA-Pools in den verschiedenen Mutanten ergab deutliche Unterschiede zwischen den Profilen der einzelnen Stämme. Die auffälligsten Unterschiede wurden stets in Gegenwart von Ölsäure festgestellt. Die Doppelmutante tes $1 \Delta$ faa2 $\Delta$ zeigte eine signifikante Reduktion des Acyl-CoA-Spiegels in Vollmedium (Abb. 16). Die zusätzliche Deletion von PAT1 in dieser Doppelmutante führte nicht nur zur teilweisen Aufhebung des Wachstumsphänotyp, sondern auch zu einer Normalisierung des Acyl-CoA-Spiegels (Abb. 16). Demnach scheint der drastische Wachstumsphänotyp der tes $1 \Delta$ faa2 $\Delta$-Mutante anscheinend mit der signifikanten Erniedrigung des Acyl-CoA-Spiegels verbunden zu sein. Diese Daten lassen vermuten, dass der mögliche Transport von Acyl-CoA in die Peroxisomen zu einer Destabilisierung des gesamten zellulären Acyl-CoA-Pools führt. Interessanterweise akkumulierte in der Doppelmutante tes $1 \Delta$ faa $2 \Delta$ in Gegenwart von Ölsäure außerdem eine zuvor unbekannte Substanz (Abb. 18). Laut massenspektronomischer Bestimmung könnte es sich dabei um Acyl-Dephospho-CoA mit einem desaturierten C20- oder C22-Acyl-CoA-Rest handeln (Abb. 21). Weitere Untersuchungen sind allerdings notwendig, um die Identität dieser Substanz eindeutig zu klären. Die Kettenlänge des Acyl-Restes könnte auf eine verstärkte Elongation in der Doppelmutante hinweisen. $\mathrm{Ob}$ es sich tatsächlich um eine 
verstärkte Elongation der zugegebenen Ölsäure oder der nativen Fettsäuren handelt, muss durch weitere Untersuchungen geklärt werden. Des Weiteren muss geklärt werden, warum so große Mengen an Dephospho-CoA akkumulierten. Desphospho-CoA ist die unmittelbare Vorstufe bei der Biosynthese von CoA. Die Umsetzung von Desphospho-CoA zu CoA ist eine ATP-abhängige Reaktion. Eine Erklärung für die hohen Mengen an Desphospho-CoA könnte daher darin bestehen, dass der fehlgeleitete peroxisomale Stoffwechsel negative Auswirkungen auf die Energieversorgung der Zelle hat, wodurch nur eine limitierte Bildung von CoA möglich ist. Es stellt sich auch die Frage, ob die verstärkte Bildung von AcylDephospho-CoA nur durch Zugabe von Ölsäure induziert wird. Eine Überprüfung, ob gesättigte Fettsäuren vergleichbare Auswirkungen haben, steht noch aus. In zukünftigen Experimenten wird zu klären sein, inwiefern der Zusammenbruch des zellulären Acyl-CoAPools und / oder die Akkumulation der Dephospho-CoA-Derivate zu einer Inhibition des Zellwachstums führen. Offensichtlich sind ein oder sogar beide Parameter jedoch unmittelbarer Auslöser der Wachstumsstörungen. Die Daten zeigen somit erstmals, dass ein fehlgeleiteter peroxisomaler Fettsäurestoffwechsel dramatische Auswirkungen auf den Metabolismus der gesamten Zelle erlangen kann.

Auch in Pflanzen wird eine Stabilisierung des Acyl-CoA/CoA-Verhältnisses in Peroxisomen durch eine kombinierte Wirkung von Thioesterase- und Acyl-CoA-Synthetase-Aktivität postuliert. Es wäre von Interesse, durch Deletion von homologen pflanzlichen Genen zu untersuchen, ob ein identischer Effekt wie in der Hefe beobachtet werden kann. 


\subsection{Die Rolle des peroxisomalen ABC-Transporters PXA1 auf den Stoffwechsel während der Dunkelphase in Arabidopsis thaliana}

In zahlreichen Publikationen wurde gezeigt, dass die Funktion des PXA1-Transporters essentiell für die Keimlingsentwicklung ist (Hayashi et al., 2002, Russell et al., 2000, Zolman et al., 2001). Dagegen ist über die Funktion dieses Transporters während der vegetativen Wachstumsphase bislang wenig bekannt. In einem gemeinsam mit der Arbeitsgruppe von Prof. Flügge (Botanisches Institut, Universität zu Köln, Deutschland) durchgeführten Projekt wurde im Rahmen dieser Arbeit die physiologische Funktion des PXA1-Transporters während der vegetativen Wachstumsphase untersucht. Die Ergebnisse dieser Untersuchungen wurden kürzlich publiziert (Kunz et al., 2009). Ergebnisse, die für diese Diskussion von Bedeutung sind, jedoch von unseren Kollegen in Köln generiert wurden, werden als Abbildungen im Anhang dargestellt. Im Mittelpunkt dieser Arbeiten stand die Beobachtung, dass die pxal-Mutante durch eine verlängerte Dunkelphase massiv beeinträchtigt wird. Eine Verlängerung der Dunkelphase führte bei pxal-Pflanzen zum vollständigen Absterben, während Wildtyp-Pflanzen keine Symptome nach verlängerter Dunkelphase zeigten. Bereits nach wenigen Stunden Dunkelheit wurden erste visuelle Symptome in Form von Blattläsionen bei pxal-Pflanzen festgestellt. Trotz ausreichender Wasserversorgung setzte bei den Blättern eine massive Welke ein. Typische Merkmale einer Seneszenz konnten hingegen nicht nachgewiesen werden (Anhang 5). Diese Beobachtungen verdeutlichen, dass der peroxisomale ABC-Transporter PXA1 nicht nur eine essentielle Funktion während der Keimlingsentwicklung besitzt, sondern in der vegetativen Wachstumsphase essentiell für die Lebensfähigkeit der Pflanzen während verlängerter Dunkelphasen ist.

Mehrere Studien zeigten eine Beteiligung von PXA1 am Import von Fettsäuren in die Peroxisomen und die damit verbundene Bereitstellung von Substraten für die $\beta$-Oxidation (Hayashi et al., 1998, Zolman et al., 2001, Footitt et al., 2002). Weitere Untersuchungen zeigten eine Beteiligung von PXA1 am Import von Acetat (Hooks et al., 2007), Indol-3Buttersäure (IBA) (Zolman et al., 2001) und 12-Oxophytodiensäure (OPDA) (Theodoulou et $a l ., 2005)$ in die Peroxisomen. OPDA ist eine biosynthetische Vorstufe von JA. In den Peroxisomen wird OPDA reduziert und danach durch die $\beta$-Oxidation zu JA umgewandelt (Schaller et al., 2000). Um zu überprüfen, ob eine Einschränkung im Jasmonatstoffwechsel an der Etablierung des beobachteten Phänotyps beteiligt ist, wurde zunächst die Auswirkung einer verlängerten Dunkelphase auf Mutanten mit blockierter Jasmonat-Synthese untersucht. Die Mutanten der OPDA-Reduktase (opr3) und der Allenoxid-Synthase (dde2) zeigten jedoch 
keine Beeinträchtigungen nach langanhaltender Dunkelphase (Daten nicht gezeigt). Die Messungen der JA-Konzentration nach verlängerter Dunkelphase ergaben außerdem einen massiven Anstieg von Jasmonat und seinen Derivaten in der pxal-Mutante. Diese Daten scheinen zunächst der zuvor postulierten Beteiligung von PXA1 am Transport von OPDA zu widersprechen (Theodoulou et al., 2005) (Abb. 25). Allerdings wurde bereits die eingeschränkte Fähigkeit der ctsl(pxal)-Mutante zur wundinduzierten JA-Bildung beschrieben und ein alternativer Transportweg für OPDA in die Peroxisomen postuliert (Theodoulou et al., 2005). Dieser postulierte alternative Transportweg wird durch die hier vorliegenden Daten bestätigt. Da der bei pxal beobachtete Phänotyp bei verlängerter Dunkelphase bei den in der Jasmonat-Synthese blockierten Linien opr3 und dde2 nicht nachgewiesen werden konnte, wird der massive Anstieg der JA-Konzentration als sekundärer Effekt auf die durch die Welke ausgelöste Verwundung interpretiert. Wie bereits erwähnt, ist eine weitere vermutete Funktion von PXA1 die Beteiligung am Transport von Indol-3Buttersäure (IBA) (Hayashi et al., 1998, Zolman et al., 2001, Hayashi et al., 2002). Analog zur $\beta$-Oxidation von Fettsäuren durchläuft IBA einen Zyklus der $\beta$-Oxidation. In diesem Zyklus wird IBA zu Indol-3-Essigsäure (IAA) umgewandelt (Zolman et al., 2001). Die Messungen der Konzentrationen der Indol-3-Essigsäure (IAA) in der pxal-Mutante zeigten keine signifikante Abweichungen von den Werten der Wildtyp-Pflanzen (Anhang 7). Durch diese Daten konnte gezeigt werden, dass die Auxin-Biosynthese keine Rolle bei der Entwicklung des beobachteten Phänotyps spielt.

Während eine verlängerte Dunkelphase keine Auswirkung auf die in der JasmonatBiosynthese blockierten Linien opr3 und dde2 zeigte, konnte bei kat2-Pflanzen (KetoacylCoA-Thiolase-Mutante) (Anhang 5) ein zwar schwächer ausgeprägter, aber doch mit der pxal-Mutante vergleichbarer Phänotyp beobachtet werden. Diese Beobachtung lässt eine Einschränkung der $\beta$-Oxidation als Ursache für den durch Dunkelheit induzierten Phänotyp vermuten.

Tatsächlich verursachte die Behinderung der $\beta$-Oxidation in der pxal-Mutante einen drastischen Anstieg freier Fettsäuren (Abb. 23). Zusätzlich wurde eine signifikante Erhöhung des Acyl-CoA-Spiegels nach verlängerter Dunkelphase beobachtet (Abb. 23). Der Anstieg der freien Fettsäuren und die signifikante Erhöhung des Acyl-CoA-Spiegels lassen einen gestörten Fettsäure-Metabolismus in pxal-Pflanzen nach langanhaltender Dunkelphase vermuten. Die hohe Konzentration an $\alpha$-Linolensäure (C18:3) und das Vorhandensein von Hexadecatriensäure (C16:3) (Abb. 23) deuten darauf hin, dass der größte Anteil der gemessenen Fettsäuren aus plastidären Lipiden stammt. C16:3 und C18:3 machen in 
veresterte Form einen Hauptbestandteil der Fettsäuren chloroplastidärer Membranen aus (Mackender und Leech, 1974). Interessanterweise führte die verlängerte Dunkelphase auch zu einer verstärkten Zunahme der TAG-Konzentration im Blattgewebe der pxal-Mutante (Abb. 23). Die Akkumulation von TAG in der pxal-Mutante nach langanhaltender Dunkelphase wurde kürzlich ebenfalls in einer anderen Arbeitsgruppe nachgewiesen (Slocombe et al., 2009). Elektronenmikroskopische Aufnahmen zeigten, dass die Akkumulation von TAG und freien Fettsäuren mit einer verstärkten Zunahme von Plastoglobuli verbunden ist (Anhang 8). Die Hauptkomponenten der Plastoglobuli sind TAG und freie Fettsäuren (Tevini und Steinmuller, 1985). Diese Daten können so interpretiert werden, dass TAG in den Blättern als transienter Puffer für solche Fettsäuren fungieren kann, die nicht direkt nach der Freisetzung aus den Membranlipiden in die $\beta$-Oxidation überführt werden können. Unter den Bedingungen einer langanhaltenden Dunkelphase dient TAG offensichtlich als Depot für Fettsäuren, die letztendlich für den Abbau durch die $\beta$-Oxidation vorgesehen sind. Die kombinierte Aktivität der $\beta$-Oxidation und der TAG-Synthese führt dementsprechend zu einem konstant niedrigen Fettsäurespiegel im Wildtyp (Abb. 23). In der pxal-Mutante scheint dagegen die Puffer-Kapazität von TAG nicht ausreichend zu sein. Die Folgen der überschrittenen Kapazität sind ein extremer Anstieg der freien Fettsäuren und des Acyl-CoASpiegels (Abb. 23). Den Anstieg der Konzentration der freien Fettsäuren interpretieren wir als Auslöser für alle darauf folgenden Symptome des beobachteten Phänotyps.

Die freigesetzten Fettsäuren können aufgrund ihres Detergens-Charakters schädlich auf Chloroplasten wirken. Unter anderem führen freie Fettsäuren zu einer Hemmung des photosynthetischen Elektronentransportes und Schädigungen am Photosystem-II-Komplex (PSII) (Vernotte et al., 1983). Isolierte Chloroplasten von pxal-Pflanzen und Wildtyp zeigten in Gegenwart von $\alpha$-Linolensäure (C18:3) eine vergleichbare Abnahme des photosynthetischen Elektronentransportes (Kunz et al., 2009; Abb. 4). Das deutet darauf hin, dass die beobachtete Auswirkung auf die Photosynthese (Kunz et al., 2009; Abb. 1) in intakten, mit Dunkelheit behandelten Blätter von der pxal-Mutante nicht auf unterschiedliche Viabilität der Chloroplasten zurückzuführen ist. In vorrausgegangenen Studien mit isolierten Chloroplasten aus Spinat (Spinacia oleracea) wurde festgestellt, dass die Behandlung mit C18:3 strukturelle Schäden und den Verlust der Thylakoidmembran-Integrität verursacht (Okamoto et al., 1977). In der pxal-Mutante wurden von der Arbeitsgruppe von Prof. Flügge ähnliche Auswirkungen nach langanhaltender Dunkelphase mittels Elektronenmikroskopie beobachtet (Anhang 8). In beiden Fällen führte anscheinend eine erhöhte Konzentration von 
C18:3 zu gravierenden strukturellen Schäden der Chloroplasten (Anhang 8) (Okamoto et al., 1977).

Sämtliche bisher beschriebenen phänotypischen Beobachtungen basieren auf einer verlängerten Dunkelphase. Photooxidative Prozesse können demnach als Ursache für den Phänotyp der pxal-Pflanzen ausgeschlossen werden (Kunz et al., 2009).

Ein vermutlicher sekundärer Effekt der Akkumulation der freien Fettssäuren und der dadurch induzierten Membranschädigung ist die Anhäufung von Pheophorbid a. Pheophorbid a ist ein Abbau-Produkt von Chlorophyll, das in Wildtyp-Pflanzen kaum detektierbar ist (Kunz et al., 2009; Abb. 6). Dabei handelt es sich vermutlich um eine phototoxische Substanz, die bleichend auf Blätter wirken kann. Eine solche Bleiche wurde ebenfalls bei der pxal-Mutante festgestellt (Kunz et al., 2009; Abb. 6).

Es stellt sich die Frage, wozu die großen Mengen an Fettsäuren während verlängerter Dunkelphase freigesetzt werden, die sowohl in der pxal-als auch in kat2-Mutante existenzbedrohende Konzentrationen erreichen. Da die Fettsäuren in Wildtyp Pflanzen offensichtlich effizient mittels $\beta$-Oxidation abgebaut werden, ist es wichtig zu verstehen, welche Funktion dieser Stoffwechsel während verlängerter Dunkelheit erfüllt. Die $\beta$ Oxidation kann zum einen Vorstufen für Biosynthesereaktionen bereitstellen zum anderen aber auch C2-Körper für die Energiegewinnung liefern. Erste Hinweise auf die Rolle der $\beta$ Oxidation bei dunkelinkubierten Pflanzen ergaben sich aus Expressionsanalysen. Während der Keimungsentwicklung ist der Abbau von Speicherlipiden durch die $\beta$-Oxidation und deren Umwandlung in Kohlenhydrate durch den Glyoxylatzyklus essentiell und dementsprechend konnte die Expression der daran beteiligten Gene während dieser Phase nachgewiesen werden. Bei dunkelinkubierten Pflanzen zeigte sich dagegen zwar eine starke Induktion von PXAl (Buchanan-Wollaston et al., 2005), jedoch nicht die Expression von Genen des Glyoxylatzyklus (Charlton et al., 2005). Diese Beobachtung unterstützt die These der essentiellen Bedeutung der $\beta$-Oxidation für die Energieversorgung während verlängerter Dunkelphase. Weitere Belege für diese These ergaben sich aus den folgenden Untersuchungen. Zunächst wurde gezeigt, dass der durch die verlängerte Dunkelphase induzierte Phänotyp der pxal-Mutante durch die Zugabe von Saccharose teilweise aufgehoben werden kann. Auf saccharosehaltigem Agar angezogene pxal-Pflanzen zeigten nach verlängerte Dunkelphase keinen gravierenden Phänotyp (Kunz et al., 2009; Abb. 5). Die Anzucht auf Medium mit Saccharose führte zu einer geringen Zunahme der Konzentration der freien Fettsäuren in den Blättern nach langanhaltender Dunkelheit (Abb. 24). Dagegen zeigten 
die Ergebnisse der pxal-Mutante, die auf Medium ohne Saccharose kultiviert wurde, eine besonders starke Zunahme der Konzentration der freien Fettsäuren (Abb. 24). Beide vorher beschriebenen Beobachtungen lassen vermuten, dass durch die Gegenwart einer zusätzlichen Energiequelle (z.B. Saccharose), die Freisetzung von Fettsäuren aus den plastidären Membranen unterbunden wird. Fehlen zusätzliche Energiequellen, bekommt die Freisetzung der Fettsäuren eine essentielle Bedeutung während langanhaltender Dunkelphasen. Unter diesen Bedingungen kann demnach die Energieversorgung der Pflanze nur durch den Abbau von Fettsäuren im Zuge der $\beta$-Oxidation aufrecht erhalten werden. So konnte eine Abnahme des ATP/ADP-Verhältnisses in den Blättern der pxal-Mutante nach verlängerter Dunkelphase gezeigt werden. Die Abnahme des ATP/ADP-Verhältnisses konnte aber erst zu einem relativ späten Zeitpunkt (nach 24 h) abgelesen werden (Kunz et al., 2009; Abb. 5). Anscheinend haben Pflanzen die Möglichkeit aufgrund anderer Quellen (z.B. Aminosäuren) für einen limitierten Zeitraum ATP zu bilden. Bei der stärkefreien PXA1-amiRNA-adg1-1-Mutante wurde ein frühzeitigeres Auftreten des Phänotyps als in der pxal-Pflanze in Dunkelheit beobachtet (Kunz et al., 2009; Abb. 5). Diese vorliegenden Daten unterstützten die Vermutung, dass erst durch das Fehlen zusätzlicher Energiequellen (z.B. Stärke), der Abbau von chloroplastidären Membranen während der Dunkelheit induziert wird. Die Freisetzung der Fettsäuren und die anschließende Respiration dienen vermutlich der Kompensation von energetischen Mangelbedingungen. Interessanterweise wurde in einer ausführlichen Studie über die Metabolitenzusammensetzung bei in Dunkelheit gehaltenen Arabidopsis-Pflanzen eine Abnahme von freien Fettsäuren beobachtet (Usadel et al., 2008). Diese Beobachtung unterstützt die These, dass freie Fettsäuren als Energiequelle bei langanhaltender Dunkelheit dienen. Basierend auf der Annahme, dass der Glyoxylatzyklus in adulten ArabidopsisBlättern weitgehend inaktiv ist, haben wir ein Modell entwickelt, in dem Blätter während verlängerter Dunkelphasen metabolische Energie durch die Respiration von Fettsäuren erzeugen (Abb. 26). Übereinstimmend mit diesem Modell, ist die Expression der peroxisomalen Citrat-Synthasen während der Dunkelphase stark induziert (BuchananWollaston et al., 2005, van der Graaff et al., 2006). Die Citrat-Synthase katalysiert die Kondensation von Oxalacetat mit Acetyl-CoA zu Citrat, welches für in die Mitochondrien transportiert und anschließend für die Erzeugung von ATP zur Verfügung gestellt wird (Abb. 26).

Zusammenfassend lässt sich aus den Daten schließen, dass die kombinierte Aktivität der $\beta$ Oxidation und der TAG-Synthese in adulten Pflanzen essentiell für die Aufrechthaltung eines konstant niedrigen Fettsäurespiegels während der Dunkelphase sind, um die toxische 
Wirkung der freien Fettsäuren zu umgehen. Sind sämtliche Energiereserven aufgebraucht, bekommt die Freisetzung der Fettsäuren eine essentielle Bedeutung während langanhaltender Dunkelphase. Unter diesen Bedingungen kann die Energieversorgung der Pflanze nur durch den Abbau von freien Fettsäuren durch die $\beta$-Oxidation und anschließender Respiration aufrecht gehalten werden. 


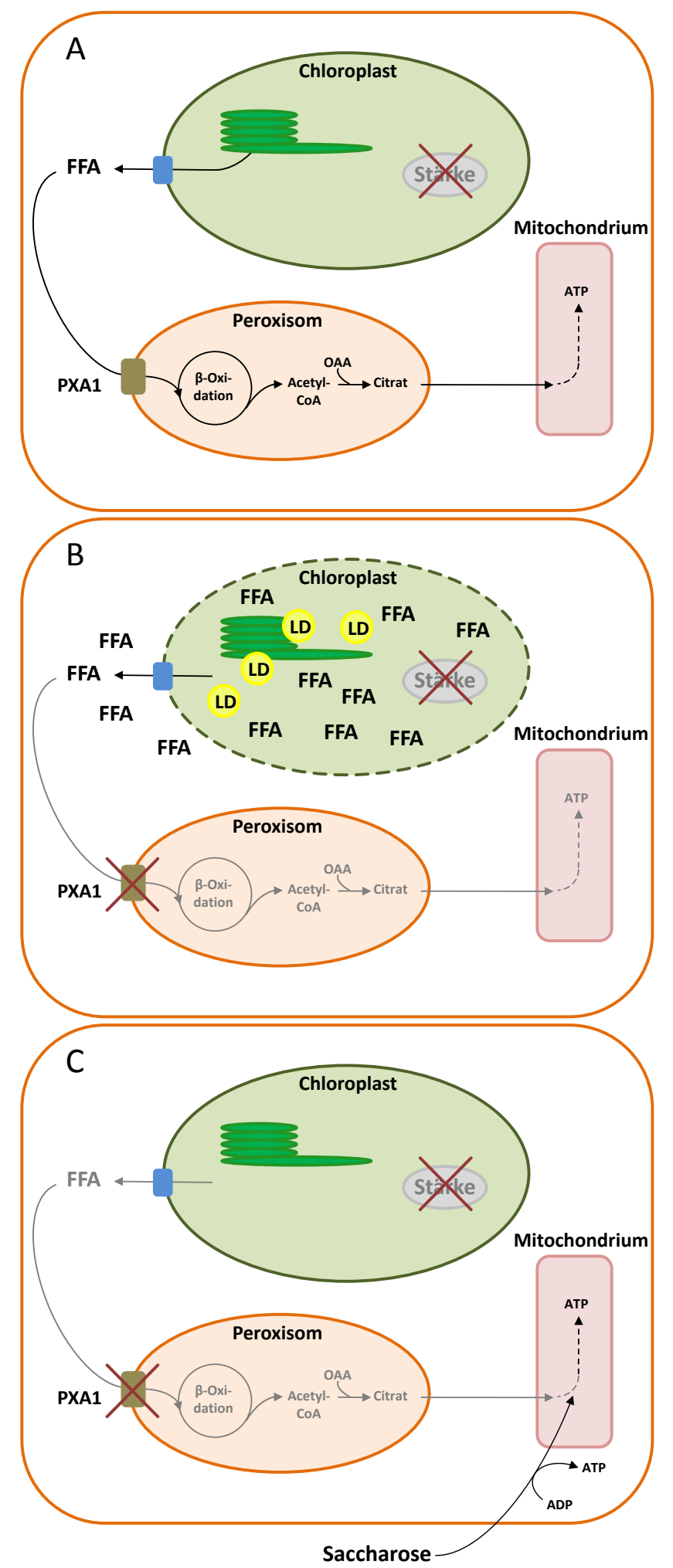

Abb. 26: Modell für Lipid-Respiration in adulten Blättern von Arabidopsis. Während verlängerter Dunkelphase werden die aus den chloroplastidären Membranen freigesetzten Fettsäuren für die ATP-Gewinnung in den Mitochondrien via peroxisomaler $\beta$-Oxidation und Citrat-Synthese respiriert. Bei eingeschränktem Import von Fettsäuren in die Peroxisomen akkumulieren freie Fettsäuren (FFA) und TAG in Form von Lipidkörpern (LD). Die Akkumulation der freien Fettsäuren führt zu Membranschädigungen und weiteren sekundären Effekten. Durch Zugabe von Saccharose ist die Zelle nicht mehr von der Fettsäure-Respiration abhängig (graue Schriftzeichen symbolisieren inaktive und schwarze Schriftzeichen aktive Stoffwechselwege). (A) Wildtyp-Zellen, (B) pxal-Zellen und (C) pxal-Zellen mit exogener Saccharose. 


\section{Zusammenfassung}

\subsection{Fettsäuretransport durch die Plasmamembran in Saccharomyces cerevisiae}

Der Mechanismus, der den Transport von freien Fettsäuren durch die Plasmamembran vermittelt, ist trotz intensiver Forschung und einer Vielzahl von Publikationen weiterhin nicht umfassend aufgeklärt. Ein Modell favorisiert einen passiven Transport von freien Fettsäuren durch die zelluläre Membran. Nach diesem Modell wird der Transport von freien Fettsäuren als einfache Diffusion vorgeschlagen, der durch einen sogenannten Flip-Flop-Mechanismus durchgeführt wird (Kamp und Hamilton, 2006). Alternativ wird von einer Beteiligung von Acyl-CoA-Synthetasen am Fettsäuretransport ausgegangen. Demnach interagiert ein Fettsäuretransporter mit einer Acyl-CoA-Synthetase beim Transport von Fettsäuren (Overath et al., 1969). Auch in S. cerevisiae wurde eine derartige Kopplung des durch Fat1p katalysierten Imports und der Aktivierung von Fettsäuren mit den Acyl-CoA-Synthetasen Faa1p und Faa4p beschrieben (Zou et al., 2003). Unsere Ergebnisse zeigten, dass der Transport durch die Plasmamembran ohne jegliche Acyl-CoA-Synthetase-Aktivität stattfinden kann. Die Richtung des Transportes von freien Fettsäuren ist umkehrbar und wird durch den metabolischen Zustand der Zellen aktiv reguliert. Dabei existiert anscheinend ein Kontrollmechanismus, der bei einer drastischen Änderung der Zusammensetzung des Fettsäure-Pools in den Zellen einen aktiven Transport der Fettsäuren aus der Zelle initiiert. Hingegen wird der Import von exogenen Fettsäuren vermutlich durch das Fehlen anderer extrazellulärer Kohlenstoffquellen, also einem Hungersignal, im Stadium der stationären Phase ausgelöst. Für die Stabilisierung des Fettsäure-Pools spielt möglicherweise das ER eine wichtige Rolle. Elektronenmikroskopische Aufnahmen lassen vermuten, dass die aufgenommen freien Fettsäuren durch einen noch unbekannten Transportmechanismus gezielt zum ER geleitet werden. Dort werden diese deponiert, um die Zelle vor weiteren negativen Auswirkungen der hohen Fettsäurekonzentrationen auf den übrigen Metabolismus zu schützen. 


\subsection{Untersuchungen zum Fettsäuretransport durch die peroxisomale Membran durch den ABC-Transporter PXA1 in Arabidopsis thaliana}

Trotz vergleichbarer Komponenten scheint sich der Mechanismus des Fettsäure-Imports in Peroxisomen in Pflanzen grundlegend von dem in Saccharomyces cerevisiae zu unterscheiden. Die umfangsreichsten Untersuchungen wurden an dem aus zwei Halbtransportern zusammengesetzten ABC-Transporter Pat1p-Pat2p aus Hefe durchgeführt. Eine Kombination von genetischen und biochemischen Untersuchungen in Hefe deutet darauf hin, dass der ABC-Transporter aktivierte Fettsäuren in Form von Acyl-CoA-Verbindungen durch die peroxisomale Membran transportiert. Nach dem etablierten Modell benötigen die CoA-veresterten Fettsäuren innerhalb der Peroxisomen dann keine weitere Aktivierung und stehen direkt für die $\beta$-Oxidation zur Verfügung (Hettema et al., 1996). In Arabidopsis thaliana dagegen ist neben der Beteiligung des ABC-Transporters PXA1 am Import in das peroxisomale Lumen (Zolmann et al., 2001, Hayashi et al., 2002, Footitt et al., 2002) zusätzlich die Aktivierung der Fettsäuren für eine erfolgreiche $\beta$-Oxidation während der Keimlingsentwicklung essentiell (Fulda et al., 2004).

In unserer Arbeitsgruppe konnte gezeigt werden, dass die kombinierte Expression der pflanzlichen Proteine PXA1 und LACS7 zu einer erfolgreichen Komplementation in der Doppelmutante pat14faa2A führt. Der Mechanismus des Fettsäure-Imports in Peroxisomen in Pflanzen scheint sich demnach, wie vermutet, grundlegend von dem in Saccharomyces cerevisiae zu unterscheiden.

Die Manipulation des peroxisomalen Acyl-CoA-Pools in $S$. cerevisiae führte zu einem drastischen Phänotyp. Bei der Doppelmutante tes $1 \Delta$ faa2 $\Delta$ wurde weder auf Minimalmedium mit Ölsäure noch auf Minimalmedium ohne Ölsäure Wachstum nachgewiesen. Außerdem wurde ein drastisches Absinken der Konzentration des zellulären Acyl-CoA-Pools beobachtet. In Gegenwart von Ölsäure akkumulierte eine zuvor unbekannte Substanz in der Doppelmutante tes $1 \Delta f a a 2 \Delta$. Laut Bestimmung mittels Massenspektroskopie könnte es sich dabei um Acyl-Dephospho-CoA handeln. Weitere Untersuchungen sind allerdings notwendig, um die Identität dieser Substanz eindeutig zu klären. Aufgrund der vorliegenden Daten konnte gezeigt werden, dass ein fehlgeleiteter peroxisomaler Fettsäurestoffwechsel dramatische Auswirkungen auf den Metabolismus der gesamten Zelle haben kann. 


\subsection{Die Rolle des peroxisomalen ABC-Transporters PXA1 auf den Stoffwechsel während der Dunkelphase in Arabidopsis thaliana}

In zahlreichen Publikationen wurde gezeigt, dass die Funktion des PXA1-Transporters essentiell für die Keimlingsentwicklung ist (Hayashi et al., 2002, Russell et al., 2000, Zolman et al., 2001). Eine postulierte Funktion für den pflanzlichen PXA1-Transporter während der Keimlingsentwicklung ist unter anderem die Beteiligung am Fettsäuretransport durch die peroxisomale Membran und die damit verbundene Bereitstellung von Substraten der $\beta$ Oxidation (Hayashi et al., 1998, Zolman et al., 2001, Footitt et al., 2002). Über die Funktion dieses Transporters während der vegetativen Wachstumsphase ist dagegen wenig bekannt. Expressionsstudien mit PXA1 (Buchanan-Wollaston et al., 2005) lassen eine wichtige Rolle der $\beta$-Oxidation für die Energieversorgung während verlängerter Dunkelphase vermuten. In dieser Arbeit wurde ein durch eine verlängerte Dunkelphase induzierter Phänotyp der pxalMutante untersucht. Eine Verlängerung der Dunkelphase führte bei diesen Pflanzen zum vollständigen Absterben, während die Wildtyp-Pflanzen zu diesem Zeitpunkt keine Symptome zeigten. Erste visuelle Symptome in Form von Blattläsionen wurden nach nur wenigen Stunden Dunkelheit beobachtet. Längere Dunkelphasen führten zum vollständigen Zusammenbruch der Epidermis. Eine massive Welke setzte trotz ausreichender Wasserversorgung ein. Typische Merkmale einer Seneszenz konnten nicht nachgewiesen werden. Unsere Studien zeigten, dass aufgrund eingeschränkter $\beta$-Oxidation die Konzentration von freien Fettsäuren im Blatt dramatisch ansteigt. Der Detergens-Charakter der freien Fettsäuren führte zu gravierende strukturelle Schäden der Chloroplasten und anschließendem Zelltod. Da dieser Phänotyp durch Zugabe exogener Saccharose unterdrückt werden kann, lässt sich vermuten, dass die Freisetzung von Fettsäuren als Kompensationsmechanismus bei Engpässen der Energieversorgung während langanhaltender Dunkelheit dient. Aufgrund unserer Studien konnte gezeigt werden, dass die $\beta$-Oxidation in adulten Pflanzen essentiell für die Aufrechthaltung der Energieversorgung bei einer verlängerten Dunkelphase ist. 


\section{Literaturverzeichnis}

Antonenkov, V.D., Sormunen, R.T. \& Hiltunen, J.K. (2004). The rat liver peroxisomal membrane forms a permeability barrier for cofactors but not for small metabolites in vitro. J Cell Sci, 117: 5633-42.

Ausubel, F.M., Brent, R.E., Kingston, D.D., Seidmann, J.R., Smith, J.A. \& Struhl, K. (1993). Current Protocolls in Molecular Biology, New York: Green Publishing Associates and John Wiley and Sons Inc.

Baker, A., Graham, I.A., Holdsworth, M., Smith, S.M. \& Theodoulou, F.L. (2006). Chewing the fat: beta-oxidation in signalling and development. Trends Plant Sci, 11: 124-32.

Berger, J. \& Gartner, J. (2006). X-linked adrenoleukodystrophy: clinical, biochemical and pathogenetic aspects. Biochim Biophys Acta, 1763: 1721-32.

Bligh, E.G. \& Dyer, W.J. (1959). A rapid method of total lipid extraction and purification. Can J Biochem Physiol, 37: 911-7.

Blobel, F. \& Erdmann, R. (1996). Identification of a yeast peroxisomal member of the family of AMP-binding proteins. Eur J Biochem, 240: 468-76.

Bossier, P., Fernandes, L., Vilela, C. \& Rodrigues-Pousada, C. (1994). The yeast YKL741 gene situated on the left arm of chromosome XI codes for a homologue of the human ALD protein. Yeast, 10: 681-6.

Braiterman, L.T., Watkins, P.A., Moser, A.B. \& Smith, K.D. (1999). Peroxisomal very long chain fatty acid beta-oxidation activity is determined by the level of adrenodeukodystrophy protein (ALDP) expression. Mol Genet Metab, 66: 91-9.

Buchanan-Wollaston, V., Page, T., Harrison, E., Breeze, E., Lim, P.O., Nam, H.G., Lin, J.F., Wu, S.H., Swidzinski, J., Ishizaki, K. \& Leaver, C.J. (2005). Comparative transcriptome analysis reveals significant differences in gene expression and signalling pathways between developmental and dark/starvation-induced senescence in Arabidopsis. Plant J, 42: 567-85.

Bullock, W.D., Fernandez, J.M. \& Hort, J.M.S. (1987). XL1-Blue: A high efficiency plasmid transformants recA Escherichia coli strain $\beta$-galactosidase selection. BioTechniques, 5: 376-378.

Cartier, N., Lopez, J., Moullier, P., Rocchiccioli, F., Rolland, M.O., Jorge, P., Mosser, J., Mandel, J.L., Bougneres, P.F., Danos, O. \& Et al. (1995). Retroviral-mediated gene transfer corrects very-long-chain fatty acid metabolism in adrenoleukodystrophy fibroblasts. Proc Natl Acad Sci U S A, 92: 1674-8.

Cartwright, J.L., Gasmi, L., Spiller, D.G. \& Mclennan, A.G. (2000). The Saccharomyces cerevisiae PCD1 gene encodes a peroxisomal nudix hydrolase active toward coenzyme A and its derivatives. J Biol Chem, 275: 32925-30.

Charlton, W.L., Johnson, B., Graham, I.A. \& Baker, A. (2005). Non-coordinate expression of peroxisome biogenesis, beta-oxidation and glyoxylate cycle genes in mature Arabidopsis plants. Plant Cell Rep, 23: 647-53.

Chini, A., Boter, M. \& Solano, R. (2009). Plant oxylipins: COI1/JAZs/MYC2 as the core jasmonic acid-signalling module. FEBS J, 276: 4682-92. 
Contreras, M., Mosser, J., Mandel, J.L., Aubourg, P. \& Singh, I. (1994). The protein coded by the $\mathrm{X}$-adrenoleukodystrophy gene is a peroxisomal integral membrane protein. FEBS Lett, 344: 211-5.

Dean, M. \& Annilo, T. (2005). Evolution of the ATP-binding cassette (ABC) transporter superfamily in vertebrates. Anпи Rev Genomics Hum Genet, 6: 123-42.

Dean, M., Rzhetsky, A. \& Allikmets, R. (2001). The human ATP-binding cassette (ABC) transporter superfamily. Genome Res, 11: 1156-66.

Dietrich, D., Schmuths, H., Lousa Cde, M., Baldwin, J.M., Baldwin, S.A., Baker, A., Theodoulou, F.L. \& Holdsworth, M.J. (2009). Mutations in the Arabidopsis peroxisomal $\mathrm{ABC}$ transporter COMATOSE allow differentiation between multiple functions in planta: insights from an allelic series. Mol Biol Cell, 20: 530-43.

Dirusso, C.C., Connell, E.J., Faergeman, N.J., Knudsen, J., Hansen, J.K. \& Black, P.N. (2000). Murine FATP alleviates growth and biochemical deficiencies of yeast fat1Delta strains. Eur J Biochem, 267: 4422-33.

Dmochowska, A., Dignard, D., Maleszka, R. \& Thomas, D.Y. (1990). Structure and transcriptional control of the Saccharomyces cerevisiae POX1 gene encoding acylcoenzyme A oxidase. Gene, 88: 247-52.

Dodd, A., Rowland, S.A., Hawkes, S.L., Kennedy, M.A. \& Love, D.R. (1997). Mutations in the adrenoleukodystrophy gene. Hum Mutat, 9: 500-11.

Duronio, R.J., Knoll, L.J. \& Gordon, J.I. (1992). Isolation of a Saccharomyces cerevisiae long chain fatty acyl:CoA synthetase gene (FAA1) and assessment of its role in protein Nmyristoylation. J Cell Biol, 117: 515-29.

Erdmann, R., Veenhuis, M., Mertens, D. \& Kunau, W.H. (1989). Isolation of peroxisomedeficient mutants of Saccharomyces cerevisiae. Proc Natl Acad Sci U S A, 86: 541923.

Faergeman, N.J., Black, P.N., Zhao, X.D., Knudsen, J. \& Dirusso, C.C. (2001). The AcylCoA synthetases encoded within FAA1 and FAA4 in Saccharomyces cerevisiae function as components of the fatty acid transport system linking import, activation, and intracellular Utilization. J Biol Chem, 276: 37051-9.

Faergeman, N.J., Dirusso, C.C., Elberger, A., Knudsen, J. \& Black, P.N. (1997). Disruption of the Saccharomyces cerevisiae homologue to the murine fatty acid transport protein impairs uptake and growth on long-chain fatty acids. J Biol Chem, 272: 8531-8.

Ferrer, I., Kapfhammer, J.P., Hindelang, C., Kemp, S., Troffer-Charlier, N., Broccoli, V., Callyzot, N., Mooyer, P., Selhorst, J., Vreken, P., Wanders, R.J., Mandel, J.L. \& Pujol, A. (2005). Inactivation of the peroxisomal ABCD2 transporter in the mouse leads to late-onset ataxia involving mitochondria, Golgi and endoplasmic reticulum damage. Hum Mol Genet, 14: 3565-77.

Footitt, S., Slocombe, S.P., Larner, V., Kurup, S., Wu, Y., Larson, T., Graham, I., Baker, A. \& Holdsworth, M. (2002). Control of germination and lipid mobilization by COMATOSE, the Arabidopsis homologue of human ALDP. EMBO J, 21: 2912-22.

Forss-Petter, S., Werner, H., Berger, J., Lassmann, H., Molzer, B., Schwab, M.H., Bernheimer, H., Zimmermann, F. \& Nave, K.A. (1997). Targeted inactivation of the X-linked adrenoleukodystrophy gene in mice. J Neurosci Res, 50: 829-43. 
Fulda, M., Schnurr, J., Abbadi, A., Heinz, E. \& Browse, J. (2004). Peroxisomal Acyl-CoA synthetase activity is essential for seedling development in Arabidopsis thaliana. Plant Cell, 16: 394-405.

Fulda, M., Shockey, J., Werber, M., Wolter, F.P. \& Heinz, E. (2002). Two long-chain acylCoA synthetases from Arabidopsis thaliana involved in peroxisomal fatty acid betaoxidation. Plant J, 32: 93-103.

Gueldener, U., Heinisch, J., Koehler, G.J., Voss, D. \& Hegemann, J.H. (2002). A second set of loxP marker cassettes for Cre-mediated multiple gene knockouts in budding yeast. Nucleic Acids Res, 30: e23.

Guimaraes, C.P., Domingues, P., Aubourg, P., Fouquet, F., Pujol, A., Jimenez-Sanchez, G., Sa-Miranda, C. \& Azevedo, J.E. (2004). Mouse liver PMP70 and ALDP: homomeric interactions prevail in vivo. Biochim Biophys Acta, 1689: 235-43.

Gurvitz, A., Hamilton, B., Ruis, H. \& Hartig, A. (2001). Peroxisomal degradation of transunsaturated fatty acids in the yeast Saccharomyces cerevisiae. J Biol Chem, 276: 895903.

Gurvitz, A., Mursula, A.M., Firzinger, A., Hamilton, B., Kilpelainen, S.H., Hartig, A., Ruis, H., Hiltunen, J.K. \& Rottensteiner, H. (1998). Peroxisomal Delta3-cis-Delta2-transenoyl-CoA isomerase encoded by ECI1 is required for growth of the yeast Saccharomyces cerevisiae on unsaturated fatty acids. J Biol Chem, 273: 31366-74.

Gurvitz, A., Mursula, A.M., Yagi, A.I., Hartig, A., Ruis, H., Rottensteiner, H. \& Hiltunen, J.K. (1999). Alternatives to the isomerase-dependent pathway for the beta-oxidation of oleic acid are dispensable in Saccharomyces cerevisiae. Identification of YOR180c/DCI1 encoding peroxisomal delta(3,5)-delta(2,4)-dienoyl-CoA isomerase. $J$ Biol Chem, 274: 24514-21.

Gurvitz, A. \& Rottensteiner, H. (2006). The biochemistry of oleate induction: transcriptional upregulation and peroxisome proliferation. Biochim Biophys Acta, 1763: 1392-402.

Gurvitz, A., Rottensteiner, H., Kilpelainen, S.H., Hartig, A., Hiltunen, J.K., Binder, M., Dawes, I.W. \& Hamilton, B. (1997). The Saccharomyces cerevisiae peroxisomal 2,4dienoyl-CoA reductase is encoded by the oleate-inducible gene SPS19. J Biol Chem, 272: 22140-7.

Hanahan, D. (1983). Studies on transformation of Escherichia coli with plasmids. J Mol Biol, 166: $557-80$.

Hayashi, M., Nito, K., Takei-Hoshi, R., Yagi, M., Kondo, M., Suenaga, A., Yamaya, T. \& Nishimura, M. (2002). Ped3p is a peroxisomal ATP-binding cassette transporter that might supply substrates for fatty acid beta-oxidation. Plant Cell Physiol, 43: 1-11.

Hayashi, M., Toriyama, K., Kondo, M. \& Nishimura, M. (1998). 2,4-Dichlorophenoxybutyric acid-resistant mutants of Arabidopsis have defects in glyoxysomal fatty acid betaoxidation. Plant Cell, 10: 183-95.

Heinzer, A.K., Kemp, S., Lu, J.F., Watkins, P.A. \& Smith, K.D. (2002). Mouse very longchain acyl-CoA synthetase in X-linked adrenoleukodystrophy. J Biol Chem, 277: 28765-73.

Heinzer, A.K., Watkins, P.A., Lu, J.F., Kemp, S., Moser, A.B., Li, Y.Y., Mihalik, S., Powers, J.M. \& Smith, K.D. (2003). A very long-chain acyl-CoA synthetase-deficient mouse and its relevance to X-linked adrenoleukodystrophy. Hum Mol Genet, 12: 1145-54.

Hettema, E.H. \& Motley, A.M. (2009). How peroxisomes multiply. J Cell Sci, 122: 2331-6. 
Hettema, E.H., Van Roermund, C.W., Distel, B., Van Den Berg, M., Vilela, C., RodriguesPousada, C., Wanders, R.J. \& Tabak, H.F. (1996). The ABC transporter proteins Pat1 and Pat2 are required for import of long-chain fatty acids into peroxisomes of Saccharomyces cerevisiae. EMBO J, 15: 3813-22.

Hillebrand, M., Verrier, S.E., Ohlenbusch, A., Schafer, A., Soling, H.D., Wouters, F.S. \& Gartner, J. (2007). Live cell FRET microscopy: homo- and heterodimerization of two human peroxisomal ABC transporters, the adrenoleukodystrophy protein (ALDP, ABCD1) and PMP70 (ABCD3). J Biol Chem, 282: 26997-7005.

Hiltunen, J.K., Mursula, A.M., Rottensteiner, H., Wierenga, R.K., Kastaniotis, A.J. \& Gurvitz, A. (2003). The biochemistry of peroxisomal beta-oxidation in the yeast Saccharomyces cerevisiae. FEMS Microbiol Rev, 27: 35-64.

Hoepfner, D., Schildknegt, D., Braakman, I., Philippsen, P. \& Tabak, H.F. (2005). Contribution of the endoplasmic reticulum to peroxisome formation. Cell, 122: 85-95.

Hohfeld, J., Veenhuis, M. \& Kunau, W.H. (1991). PAS3, a Saccharomyces cerevisiae gene encoding a peroxisomal integral membrane protein essential for peroxisome biogenesis. J Cell Biol, 114: 1167-78.

Holzinger, A., Kammerer, S., Berger, J. \& Roscher, A.A. (1997). cDNA cloning and mRNA expression of the human adrenoleukodystrophy related protein (ALDRP), a peroxisomal ABC transporter. Biochem Biophys Res Commun, 239: 261-4.

Hooks, M.A., Turner, J.E., Murphy, E.C., Johnston, K.A., Burr, S. \& Jaroslawski, S. (2007). The Arabidopsis ALDP protein homologue COMATOSE is instrumental in peroxisomal acetate metabolism. Biochem J, 406: 399-406.

Hornung, E., Krueger, C., Pernstich, C., Gipmans, M., Porzel, A. \& Feussner, I. (2005). Production of (10E,12Z)-conjugated linoleic acid in yeast and tobacco seeds. Biochim Biophys Acta, 1738: 105-14.

Hunt, M.C. \& Alexson, S.E. (2002). The role Acyl-CoA thioesterases play in mediating intracellular lipid metabolism. Prog Lipid Res, 41: 99-130.

Hunt, M.C. \& Alexson, S.E. (2008). Novel functions of acyl-CoA thioesterases and acyltransferases as auxiliary enzymes in peroxisomal lipid metabolism. Prog Lipid Res, 47: 405-21.

Imanaka, T., Aihara, K., Takano, T., Yamashita, A., Sato, R., Suzuki, Y., Yokota, S. \& Osumi, T. (1999). Characterization of the 70-kDa peroxisomal membrane protein, an ATP binding cassette transporter. J Biol Chem, 274: 11968-76.

Inoue, H., Nojima, H. \& Okayama, H. (1990). High efficiency transformation of Escherichia coli with plasmids. Gene, 96: 23-8.

Jimenez-Sanchez, G., Hebron, K. J., Silva-Zolezzi, I., Mihalik, S., Watkins, P., Espeel, M., Moser, A., Thomas, G., Roels, F., and Valle, D. (2000). Fasting fuel homeostasis triggered by defective phytanic and pristanic acids metabolism in the $70 \mathrm{kDa}$ peroxisomal membrane protein (PMP70) deficient mice. Ann J Hum Genet, 67: 65.

Johnson, D.R., Knoll, L.J., Levin, D.E. \& Gordon, J.I. (1994a). Saccharomyces cerevisiae contains four fatty acid activation (FAA) genes: an assessment of their role in regulating protein N-myristoylation and cellular lipid metabolism. J Cell Biol, 127: 751-62. 
Johnson, D.R., Knoll, L.J., Rowley, N. \& Gordon, J.I. (1994b). Genetic analysis of the role of Saccharomyces cerevisiae acyl-CoA synthetase genes in regulating protein Nmyristoylation. J Biol Chem, 269: 18037-46.

Jones, J.M., Nau, K., Geraghty, M.T., Erdmann, R. \& Gould, S.J. (1999). Identification of peroxisomal acyl-CoA thioesterases in yeast and humans. J Biol Chem, 274: 9216-23.

Kamijo, K., Taketani, S., Yokota, S., Osumi, T. \& Hashimoto, T. (1990). The 70-kDa peroxisomal membrane protein is a member of the Mdr (P-glycoprotein)-related ATPbinding protein superfamily. J Biol Chem, 265: 4534-40.

Kamp, F. \& Hamilton, J.A. (2006). How fatty acids of different chain length enter and leave cells by free diffusion. Prostaglandins Leukot Essent Fatty Acids, 75: 149-59.

Kemp, S., Pujol, A., Waterham, H.R., Van Geel, B.M., Boehm, C.D., Raymond, G.V., Cutting, G.R., Wanders, R.J. \& Moser, H.W. (2001). ABCD1 mutations and the Xlinked adrenoleukodystrophy mutation database: role in diagnosis and clinical correlations. Hum Mutat, 18: 499-515.

Kemp, S., Valianpour, F., Denis, S., Ofman, R., Sanders, R.J., Mooyer, P., Barth, P.G. \& Wanders, R.J. (2005). Elongation of very long-chain fatty acids is enhanced in Xlinked adrenoleukodystrophy. Mol Genet Metab, 84: 144-51.

Kemp, S. \& Wanders, R.J. (2007). X-linked adrenoleukodystrophy: very long-chain fatty acid metabolism, $\mathrm{ABC}$ half-transporters and the complicated route to treatment. Mol Genet Metab, 90: 268-76.

Knoll, L.J., Johnson, D.R. \& Gordon, J.I. (1994). Biochemical studies of three Saccharomyces cerevisiae acyl-CoA synthetases, Faa1p, Faa2p, and Faa3p. J Biol Chem, 269: 16348-56.

Kobayashi, T., Shinnoh, N., Kondo, A. \& Yamada, T. (1997). Adrenoleukodystrophy proteindeficient mice represent abnormality of very long chain fatty acid metabolism. Biochem Biophys Res Commun, 232: 631-6.

Koike, R., Tsuji, S., Ohno, T., Suzuki, Y., Orii, T. \& Miyatake, T. (1991). Physiological significance of fatty acid elongation system in adrenoleukodystrophy. J Neurol Sci, 103: $188-94$.

Kunau, W.H., Buhne, S., De La Garza, M., Kionka, C., Mateblowski, M., Schultz-Borchard, U. \& Thieringer, R. (1988). Comparative enzymology of beta-oxidation. Biochem Soc Trans, 16: 418-20.

Kunz, H.H., Scharnewski, M., Feussner, K., Feussner, I., Flugge, U.I., Fulda, M. \& Gierth, M. (2009). The ABC transporter PXA1 and peroxisomal beta-oxidation are vital for metabolism in mature leaves of Arabidopsis during extended darkness. Plant Cell, 21: 2733-49.

Kunze, M., Kragler, F., Binder, M., Hartig, A. \& Gurvitz, A. (2002). Targeting of malate synthase 1 to the peroxisomes of Saccharomyces cerevisiae cells depends on growth on oleic acid medium. Eur J Biochem, 269: 915-22.

Larson, T.R. \& Graham, I.A. (2001). Technical Advance: a novel technique for the sensitive quantification of acyl CoA esters from plant tissues. Plant J, 25: 115-25.

Lazarow, P.B. \& Fujiki, Y. (1985). Biogenesis of peroxisomes. Annu Rev Cell Biol, 1: 489530.

Leonardi, R., Zhang, Y.M., Rock, C.O. \& Jackowski, S. (2005). Coenzyme A: back in action. Prog Lipid Res, 44: 125-53. 
Lockshon, D., Surface, L.E., Kerr, E.O., Kaeberlein, M. \& Kennedy, B.K. (2007). The sensitivity of yeast mutants to oleic acid implicates the peroxisome and other processes in membrane function. Genetics, 175: 77-91.

Lombard-Platet, G., Savary, S., Sarde, C.O., Mandel, J.L. \& Chimini, G. (1996). A close relative of the adrenoleukodystrophy (ALD) gene codes for a peroxisomal protein with a specific expression pattern. Proc Natl Acad Sci U S A, 93: 1265-9.

Lu, J.F., Lawler, A.M., Watkins, P.A., Powers, J.M., Moser, A.B., Moser, H.W. \& Smith, K.D. (1997). A mouse model for X-linked adrenoleukodystrophy. Proc Natl Acad Sci $U S$ A, 94: 9366-71.

Maeda, I., Delessert, S., Hasegawa, S., Seto, Y., Zuber, S. \& Poirier, Y. (2006). The peroxisomal Acyl-CoA thioesterase Pte1p from Saccharomyces cerevisiae is required for efficient degradation of short straight chain and branched chain fatty acids. J Biol Chem, 281: 11729-35.

Mackender, R.O. \& Leech, R.M. (1974). The Galactolipid, Phospholipid, and Fatty Acid Composition of the Chloroplast Envelope Membranes of Vicia faba. L. Plant Physiol, 53: 496-502.

Matyash, V., Liebisch, G., Kurzchalia, T.V., Shevchenko, A. \& Schwudke, D. (2008). Lipid extraction by methyl-tert-butyl ether for high-throughput lipidomics. J Lipid Res, 49: 1137-46.

Mcguinness, M.C., Lu, J.F., Zhang, H.P., Dong, G.X., Heinzer, A.K., Watkins, P.A., Powers, J. \& Smith, K.D. (2003). Role of ALDP (ABCD1) and mitochondria in X-linked adrenoleukodystrophy. Mol Cell Biol, 23: 744-53.

Michinaka, Y., Shimauchi, T., Aki, T., Nakajima, T., Kawamoto, S., Shigeta, S., Suzuki, O. \& Ono, K. (2003). Extracellular secretion of free fatty acids by disruption of a fatty acylCoA synthetase gene in Saccharomyces cerevisiae. J Biosci Bioeng, 95: 435-40.

Moser, H.W., Moser, A.B., Frayer, K.K., Chen, W., Schulman, J.D., O'neill, B.P. \& Kishimoto, Y. (1981). Adrenoleukodystrophy: increased plasma content of saturated very long chain fatty acids. Neurology, 31: 1241-9.

Mosser, J., Douar, A.M., Sarde, C.O., Kioschis, P., Feil, R., Moser, H., Poustka, A.M., Mandel, J.L. \& Aubourg, P. (1993). Putative X-linked adrenoleukodystrophy gene shares unexpected homology with ABC transporters. Nature, 361: 726-30.

Mosser, J., Lutz, Y., Stoeckel, M.E., Sarde, C.O., Kretz, C., Douar, A.M., Lopez, J., Aubourg, P. \& Mandel, J.L. (1994). The gene responsible for adrenoleukodystrophy encodes a peroxisomal membrane protein. Hum Mol Genet, 3: 265-71.

Natter, K., Leitner, P., Faschinger, A., Wolinski, H., Mccraith, S., Fields, S. \& Kohlwein, S.D. (2005). The spatial organization of lipid synthesis in the yeast Saccharomyces cerevisiae derived from large scale green fluorescent protein tagging and high resolution microscopy. Mol Cell Proteomics, 4: 662-72.

Novikoff, P.M. \& Novikoff, A.B. (1972). Peroxisomes in absorptive cells of mammalian small intestine. J Cell Biol, 53: 532-60.

Ntamack, A.G., Karpichev, I.V., Gould, S.J., Small, G.M. \& Schulz, H. (2009). Oleate betaoxidation in yeast involves thioesterase but not Yor180c protein that is not a dienoylCoA isomerase. Biochim Biophys Acta.

Ohlrogge, J.B., Browse, J. \& Somerville, C.R. (1991). The genetics of plant lipids. Biochim Biophys Acta, 1082: 1-26. 
Okamoto, T., Katoh, S. \& Murakami, S. (1977). Effects of linolenic acid on spinach chloroplast structure. Plant \& Cell Physiol, 18: 551-560.

Overath, P., Pauli, G. \& Schairer, H.U. (1969). Fatty acid degradation in Escherichia coli. An inducible acyl-CoA synthetase, the mapping of old-mutations, and the isolation of regulatory mutants. Eur J Biochem, 7: 559-74.

Palmieri, L., Agrimi, G., Runswick, M.J., Fearnley, I.M., Palmieri, F. \& Walker, J.E. (2001). Identification in Saccharomyces cerevisiae of two isoforms of a novel mitochondrial transporter for 2-oxoadipate and 2-oxoglutarate. J Biol Chem, 276: 1916-22.

Penfield, S., Graham, S. \& Graham, I.A. (2005). Storage reserve mobilization in germinating oilseeds: Arabidopsis as a model system. Biochem Soc Trans, 33: 380-3.

Petschnigg, J., Wolinski, H., Kolb, D., Zellnig, G., Kurat, C.F., Natter, K. \& Kohlwein, S.D. (2009). Good fat, essential cellular requirements for triacylglycerol synthesis to maintain membrane homeostasis in yeast. J Biol Chem, 284: 30981-93.

Prohl, C., Pelzer, W., Diekert, K., Kmita, H., Bedekovics, T., Kispal, G. \& Lill, R. (2001). The yeast mitochondrial carrier Leu5p and its human homologue Graves' disease protein are required for accumulation of coenzyme A in the matrix. Mol Cell Biol, 21: 1089-97.

Pujol, A., Ferrer, I., Camps, C., Metzger, E., Hindelang, C., Callizot, N., Ruiz, M., Pampols, T., Giros, M. \& Mandel, J.L. (2004). Functional overlap between ABCD1 (ALD) and ABCD2 (ALDR) transporters: a therapeutic target for X-adrenoleukodystrophy. Hum Mol Genet, 13: 2997-3006.

Qin, Y.M., Marttila, M.S., Haapalainen, A.M., Siivari, K.M., Glumoff, T. \& Hiltunen, J.K. (1999). Yeast peroxisomal multifunctional enzyme: (3R)-hydroxyacyl-CoA dehydrogenase domains $\mathrm{A}$ and $\mathrm{B}$ are required for optimal growth on oleic acid. $J$ Biol Chem, 274: 28619-25.

Rachubinski, R.A., Fujiki, Y., Mortensen, R.M. \& Lazarow, P.B. (1984). Acyl-Coa oxidase and hydratase-dehydrogenase, two enzymes of the peroxisomal beta-oxidation system, are synthesized on free polysomes of clofibrate-treated rat liver. J Cell Biol, 99: 22416.

Roerig, P., Mayerhofer, P., Holzinger, A. \& Gartner, J. (2001). Characterization and functional analysis of the nucleotide binding fold in human peroxisomal ATP binding cassette transporters. FEBS Lett, 492: 66-72.

Rosendal, J. \& Knudsen, J. (1992). A fast and versatile method for extraction and quantitation of long-chain acyl-CoA esters from tissue: content of individual long-chain acyl-CoA esters in various tissues from fed rat. Anal Biochem, 207: 63-7.

Rottensteiner, H. \& Theodoulou, F.L. (2006). The ins and outs of peroxisomes: co-ordination of membrane transport and peroxisomal metabolism. Biochim Biophys Acta, 1763: 1527-40.

Russell, L., Larner, V., Kurup, S., Bougourd, S. \& Holdsworth, M. (2000). The Arabidopsis COMATOSE locus regulates germination potential. Development, 127: 3759-67.

Saiki, R.K., Walsh, P.S., Levenson, C.H. \& Erlich, H.A. (1989). Genetic analysis of amplified DNA with immobilized sequence-specific oligonucleotide probes. Proc Natl Acad Sci U S A, 86: 6230-4.

Sambrook, J., Fritsch, E.F. \& Maniatis, T. (1989). Molecular cloning: a laboratory manual, Cold Spring Harbor NY: Cold Spring Harbor Laboratory. 
Schaller, F., Biesgen, C., Mussig, C., Altmann, T. \& Weiler, E.W. (2000). 12Oxophytodienoate reductase 3 (OPR3) is the isoenzyme involved in jasmonate biosynthesis. Planta, 210: 979-84.

Scharnewski, M., Pongdontri, P., Mora, G., Hoppert, M. \& Fulda, M. (2008). Mutants of Saccharomyces cerevisiae deficient in acyl-CoA synthetases secrete fatty acids due to interrupted fatty acid recycling. FEBS J, 275: 2765-78.

Schneider, K., Kienow, L., Schmelzer, E., Colby, T., Bartsch, M., Miersch, O., Wasternack, C., Kombrink, E. \& Stuible, H.P. (2005). A new type of peroxisomal acyl-coenzyme A synthetase from Arabidopsis thaliana has the catalytic capacity to activate biosynthetic precursors of jasmonic acid. J Biol Chem, 280: 13962-72.

Shani, N., Watkins, P.A. \& Valle, D. (1995). PXA1, a possible Saccharomyces cerevisiae ortholog of the human adrenoleukodystrophy gene. Proc Natl Acad Sci U S A, 92: 6012-6.

Sherman, F., Fink, G.R. \& Hicks, J.B. (1986). Laboratory Course Manual for Methods in Yeast Genetics. , Cold Spring Harbor, NY: Cold Spring Harbor Laboratory.

Shinnoh, N., Yamada, T., Yoshimura, T., Furuya, H., Yoshida, Y., Suzuki, Y., Shimozawa, N., Orii, T. \& Kobayashi, T. (1995). Adrenoleukodystrophy: the restoration of peroxisomal beta-oxidation by transfection of normal cDNA. Biochem Biophys Res Commun, 210: 830-6.

Slocombe, S.P., Cornah, J., Pinfield-Wells, H., Soady, K., Zhang, Q., Gilday, A., Dyer, J.M. \& Graham, I.A. (2009). Oil accumulation in leaves directed by modification of fatty acid breakdown and lipid synthesis pathways. Plant Biotechnol J, 7: 694-703.

Smith, B.T., Sengupta, T.K. \& Singh, I. (2000). Intraperoxisomal localization of very-longchain fatty acyl-CoA synthetase: implication in X-adrenoleukodystrophy. Exp Cell Res, 254: 309-20.

Smith, K.D., Kemp, S., Braiterman, L.T., Lu, J.F., Wei, H.M., Geraghty, M., Stetten, G., Bergin, J.S., Pevsner, J. \& Watkins, P.A. (1999). X-linked adrenoleukodystrophy: genes, mutations, and phenotypes. Neurochem Res, 24: 521-35.

Soling, H.D. \& Rescher, C. (1985). On the regulation of cold-labile cytosolic and of mitochondrial acetyl-CoA hydrolase in rat liver. Eur J Biochem, 147: 111-7.

Steinberg, S.J., Kemp, S., Braiterman, L.T. \& Watkins, P.A. (1999). Role of very-long-chain acyl-coenzyme A synthetase in X-linked adrenoleukodystrophy. Ann Neurol, 46: 40912.

Subramani, S. (1998). Components involved in peroxisome import, biogenesis, proliferation, turnover, and movement. Physiol Rev, 78: 171-88.

Suggs, S.V., Wallace, R.B., Hirose, T., Kawashima, E.H. \& Itakura, K. (1981). Use of synthetic oligonucleotides as hybridization probes: isolation of cloned cDNA sequences for human beta 2-microglobulin. Proc Natl Acad Sci USA, 78: 6613-7.

Tabak, H.F., Hoepfner, D., Zand, A., Geuze, H.J., Braakman, I. \& Huynen, M.A. (2006). Formation of peroxisomes: present and past. Biochim Biophys Acta, 1763: 1647-54.

Tanaka, A.R., Tanabe, K., Morita, M., Kurisu, M., Kasiwayama, Y., Matsuo, M., Kioka, N., Amachi, T., Imanaka, T. \& Ueda, K. (2002). ATP binding/hydrolysis by and phosphorylation of peroxisomal ATP-binding cassette proteins PMP70 (ABCD3) and adrenoleukodystrophy protein (ABCD1). J Biol Chem, 277: 40142-7. 
Tevini, M. \& Steinmuller, D. (1985). Composition and function of plastoglobuli: 2. Lipid composition of leaves and plastoglobuli during beech (Fagus sylvatica) leaf senescence. Planta, 163: 91-96.

Theodoulou, F.L., Holdsworth, M. \& Baker, A. (2006). Peroxisomal ABC transporters. FEBS Lett, 580: 1139-55.

Theodoulou, F.L., Job, K., Slocombe, S.P., Footitt, S., Holdsworth, M., Baker, A., Larson, T.R. \& Graham, I.A. (2005). Jasmonic acid levels are reduced in COMATOSE ATPbinding cassette transporter mutants. Implications for transport of jasmonate precursors into peroxisomes. Plant Physiol, 137: 835-40.

Thines, B., Katsir, L., Melotto, M., Niu, Y., Mandaokar, A., Liu, G., Nomura, K., He, S.Y., Howe, G.A. \& Browse, J. (2007). JAZ repressor proteins are targets of the SCF(COI1) complex during jasmonate signalling. Nature, 448: 661-5.

Thoms, S., Debelyy, M.O., Nau, K., Meyer, H.E. \& Erdmann, R. (2008). Lpx1p is a peroxisomal lipase required for normal peroxisome morphology. FEBS J, 275: 50414.

Titorenko, V.I. \& Mullen, R.T. (2006). Peroxisome biogenesis: the peroxisomal endomembrane system and the role of the ER. J Cell Biol, 174: 11-7.

Troffer-Charlier, N., Doerflinger, N., Metzger, E., Fouquet, F., Mandel, J.L. \& Aubourg, P. (1998). Mirror expression of adrenoleukodystrophy and adrenoleukodystrophy related genes in mouse tissues and human cell lines. Eur J Cell Biol, 75: 254-64.

Tsuji, S., Ohno, T., Miyatake, T., Suzuki, A. \& Yamakawa, T. (1984). Fatty acid elongation activity in fibroblasts from patients with adrenoleukodystrophy (ALD). J Biochem, 96: 1241-7.

Turner, J.G., Ellis, C. \& Devoto, A. (2002). The jasmonate signal pathway. Plant Cell, 14 Suppl: S153-64.

Usadel, B., Blasing, O.E., Gibon, Y., Retzlaff, K., Hohne, M., Gunther, M. \& Stitt, M. (2008). Global transcript levels respond to small changes of the carbon status during progressive exhaustion of carbohydrates in Arabidopsis rosettes. Plant Physiol, 146: 1834-61.

Van Den Bosch, H., Schutgens, R.B., Wanders, R.J. \& Tager, J.M. (1992). Biochemistry of peroxisomes. Апnu Rev Biochem, 61: 157-97.

Van Der Graaff, E., Schwacke, R., Schneider, A., Desimone, M., Flugge, U.I. \& Kunze, R. (2006). Transcription analysis of arabidopsis membrane transporters and hormone pathways during developmental and induced leaf senescence. Plant Physiol, 141: 77692.

Van Roermund, C.W., Drissen, R., Van Den Berg, M., Ijlst, L., Hettema, E.H., Tabak, H.F., Waterham, H.R. \& Wanders, R.J. (2001). Identification of a peroxisomal ATP carrier required for medium-chain fatty acid beta-oxidation and normal peroxisome proliferation in Saccharomyces cerevisiae. Mol Cell Biol, 21: 4321-9.

Van Roermund, C.W., Elgersma, Y., Singh, N., Wanders, R.J. \& Tabak, H.F. (1995). The membrane of peroxisomes in Saccharomyces cerevisiae is impermeable to NAD $(\mathrm{H})$ and acetyl-CoA under in vivo conditions. EMBO J, 14: 3480-6.

Van Roermund, C.W., Visser, W.F., Ijlst, L., Van Cruchten, A., Boek, M., Kulik, W., Waterham, H.R. \& Wanders, R.J. (2008). The human peroxisomal ABC half 
transporter ALDP functions as a homodimer and accepts acyl-CoA esters. FASEB $J$, 22: 4201-8.

Veenhuis, M. (1992). Peroxisome biogenesis and function in Hansenula polymorpha. Cell Biochem Funct, 10: 175-84.

Veenhuis, M. \& Harder, W. (1988). Microbodies in yeasts: structure, function and biogenesis. Microbiol Sci, 5: 347-51.

Veenhuis, M., Kiel, J.A. \& Van Der Klei, I.J. (2003). Peroxisome assembly in yeast. Microsc Res Tech, 61: 139-50.

Veenhuis, M., Mateblowski, M., Kunau, W.H. \& Harder, W. (1987). Proliferation of microbodies in Saccharomyces cerevisiae. Yeast, 3: 77-84.

Verleur, N., Hettema, E.H., Van Roermund, C.W., Tabak, H.F. \& Wanders, R.J. (1997). Transport of activated fatty acids by the peroxisomal ATP-binding-cassette transporter Pxa2 in a semi-intact yeast cell system. Eur J Biochem, 249: 657-61.

Vernotte, C., Solis, C., Moya, I., B, M., J.-M., B., Arrio, B. \& Johannin, G. (1983). Multiple effects of linolenic acid addition to pea thylakoids. Biochim Biophys Acta, 725: 376383.

Visser, W.F., Van Roermund, C.W., Ijlst, L., Waterham, H.R. \& Wanders, R.J. (2007). Metabolite transport across the peroxisomal membrane. Biochem J, 401: 365-75.

Visser, W.F., Van Roermund, C.W., Waterham, H.R. \& Wanders, R.J. (2002). Identification of human PMP34 as a peroxisomal ATP transporter. Biochem Biophys Res Commun, 299: 494-7.

Wach, A., Brachat, A., Pohlmann, R. \& Philippsen, P. (1994). New heterologous modules for classical or PCR-based gene disruptions in Saccharomyces cerevisiae. Yeast, 10: 1793-808.

Watkins, P.A., Gould, S.J., Smith, M.A., Braiterman, L.T., Wei, H.M., Kok, F., Moser, A.B., Moser, H.W. \& Smith, K.D. (1995). Altered expression of ALDP in X-linked adrenoleukodystrophy. Am J Hum Genet, 57: 292-301.

Watkins, P.A., Howard, A.E. \& Mihalik, S.J. (1994). Phytanic acid must be activated to phytanoyl-CoA prior to its alpha-oxidation in rat liver peroxisomes. Biochim Biophys Acta, 1214: 288-94.

Watkins, P.A., Lu, J.F., Steinberg, S.J., Gould, S.J., Smith, K.D. \& Braiterman, L.T. (1998). Disruption of the Saccharomyces cerevisiae FAT1 gene decreases very long-chain fatty acyl-CoA synthetase activity and elevates intracellular very long-chain fatty acid concentrations. J Biol Chem, 273: 18210-9.

Weber, H., Vick, B.A. \& Farmer, E.E. (1997). Dinor-oxo-phytodienoic acid: a new hexadecanoid signal in the jasmonate family. Proc Natl Acad Sci U S A, 94: 10473-8.

Yamada, T., Taniwaki, T., Shinnoh, N., Uchiyama, A., Shimozawa, N., Ohyagi, Y., Asahara, H. \& Kira, J. (1999). Adrenoleukodystrophy protein enhances association of very long-chain acyl-coenzyme A synthetase with the peroxisome. Neurology, 52: 614-6.

Zolman, B.K., Silva, I.D. \& Bartel, B. (2001). The Arabidopsis pxa1 mutant is defective in an ATP-binding cassette transporter-like protein required for peroxisomal fatty acid betaoxidation. Plant Physiol, 127: 1266-78.

Zou, Z., Tong, F., Faergeman, N.J., Borsting, C., Black, P.N. \& Dirusso, C.C. (2003). Vectorial acylation in Saccharomyces cerevisiae. Fat1p and fatty acyl-CoA synthetase 
are interacting components of a fatty acid import complex. J Biol Chem, 278: 1641422. 


\section{Abbildungsverzeichnis}

Abb. 1: Modell zum Fettsäuretransport durch die peroxisomale Membran in S. cerevisiae (Hettema et al., 1996)..

Abb. 2: Modelle zum Fettsäuretransport durch die peroxisomale Membran in A. thaliana (Fulda et al., 2002, Fulda et al., 2004).

Abb. 3: Modell für die Regulierung der $\beta$-Oxidation durch die peroxisomale Acyl-CoAThioesterase Tes1p (Maeda et al., 2006).

Abb. 4: Fat1p ist verantwortlich für die verbliebene Acyl-CoA-Synthetase-Aktivität in der Mutante YB526.

Abb. 5: Fat1p ist fähig, die fehlende Acyl-CoA-Synthetase-Aktivität in der Mutante MS51 teilweise zu komplementieren.

Abb. 6: Die Richtung des Fettsäuretransports ist abhängig von dem metabolischen Zustand der Zelle.

Abb. 7: Verhältnis von Palmitinsäure (C16:0) zu Palmitoleinsäure (C16:1) .........................65

Abb. 8: Morphologische Eigenschaften von MS51.

Abb. 9: Wachstumsverhalten von pat $1 \Delta$ faa $2 \Delta$ bei Komplementationen mit der heterologen Acyl-CoA-Synthetase LACS7 und dem heterologen ABC-Transporter PXA1 aus Arabidopsis in Medium mit Ölsäure.

Abb. 10: Wachstumsanalyse verschiedener Mutanten mit eingeschränkter oder vollständig unterbundener $\beta$-Oxidation auf Medium mit Ölsäure.

Abb. 11: Wachstumsanalyse verschiedener Mutanten mit eingeschränkter oder vollständig unterbundener $\beta$-Oxidation auf Medium mit Ölsäure.

Abb. 12: Wachstumsanalyse verschiedener Mutanten mit eingeschränkter oder vollständig fehlender Acyl-CoA-Synthetase-Aktivität auf Medium mit Ölsäure.

Abb. 13: Wachstumsanalyse verschiedener Mutanten mit vollständig fehlender LipaseAktivität in den Peroxisomen auf Medium mit Ölsäure.

Abb. 14: Wachstumsanalyse der Mutante $m l s 1 \Delta$ und der Doppelmutante $m l s 1 \Delta$ pat $1 \Delta$ auf Medium mit Ölsäure.

Abb. 15: Wachstumsanalyse verschiedener Mutanten mit eingeschränkter oder vollständig unterbundener $\beta$-Oxidation auf Minimalmedium mit Glukose.

Abb. 16: Akkumulation von Acyl-CoA-Estern während der stationären Phase in Mutanten mit Einschränkungen in der $\beta$-Oxidation.

Abb. 17: Acyl-CoA-Profile von Mutanten mit Einschränkungen in der $\beta$-Oxidation und Wildtyp.

Abb. 18: Bestimmung von Acyl-CoA-Estern im Wildtyp und in den Mutanten mit Einschränkungen in der $\beta$-Oxidation nach Zugabe von Ölsäure.

Abb. 19: Wachstumsverhalten von Mutanten mit Einschränkungen in der $\beta$-Oxidation nach Zugabe von Ölsäure.

Abb. 20: Acyl-CoA-Profile von Mutanten mit Einschränkungen in der $\beta$-Oxidation und Wildtyp. 
Abb. 21: Abb. Tandem-MS-Analyse des bei der Doppelmutante tes $1 \Delta \mathrm{f} a a 2 \Delta$ nach Zugabe von Ölsaure vorgefundenen unbekannten Substanzen.

Abb. 22: Quantifizierung von TAG in Mutanten mit Einschränkungen in der $\beta$-Oxidation... 87

Abb. 23: Auswirkungen einer verlängerten Dunkelphase auf den Fettsäurestoffwechsel von pxa1-Mutanten

Abb. 24: Die Akkumulation von freien Fettsäuren in der pxal-Mutante nach verlängerter Dunkelphase wird durch Zugabe von Saccharose unterdrückt.

Abb. 25: Massive Akkumulation von Jasmonsäure bei andauernder Dunkelphase. 93

Abb. 26: Modell für Lipid-Respiration in adulten Blättern von Arabidopsis. 111 


\section{Tabellenverzeichnis}

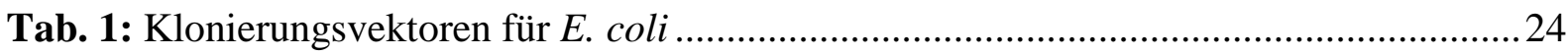

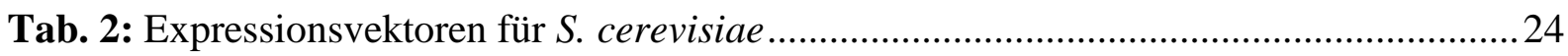

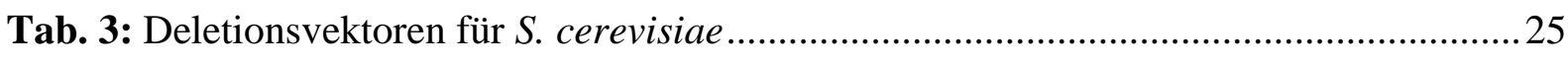

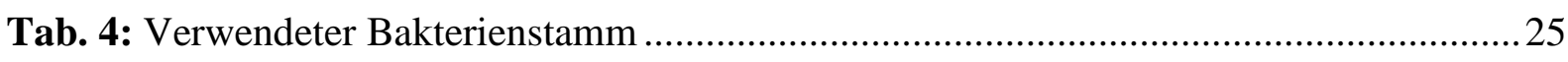

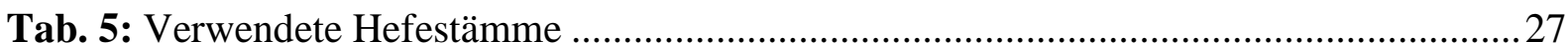

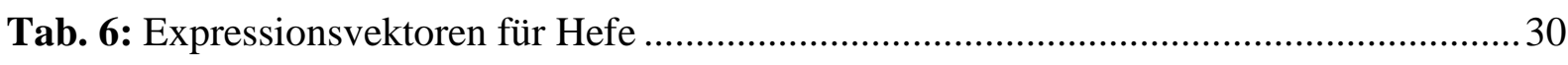

Tab. 7: Standard-Temperaturprofil einer PCR-Reaktion: ................................................... 35

Tab. 8: Neben den Ökotypen Wassilewskija (WS) und Columbia (Col-0) wurden folgende

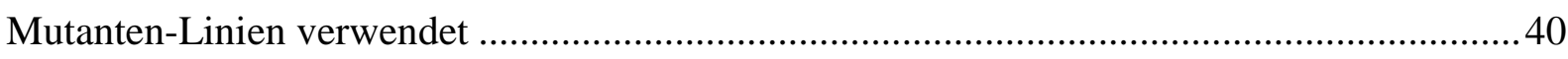

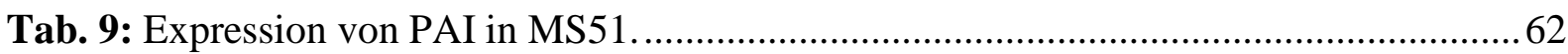




\section{Abkürzungsverzeichnis}

Abb.

$3^{\prime}, 5^{\prime}-\mathrm{ADP}$

AMP

AOC

AOS

ATP

${ }^{\circ} \mathrm{C}$

C12:0

C16:0

C16:3

C18:1

C18:3

C20:0

C20:1

C22:0

C22:1

C24:6

CLA

CoA

CTP

CTS

2,4-D

$2,4 \mathrm{DB}$

dd
Abbildung

Adenosin-3'5'-diphosphat

Adenosin-5'-monophosphat

Allenoxidcyclase

Allenoxidsynthase

Adenosin-5'-triphosphat

Grad (Celsius)

Laurinsäure

Palmitinsäure

Hexadecatriensäure

Ölsäure

$\alpha$-Linolensäure

Arachinsäure

Gadoleinsäure

Behensäure

Cetoleinsäure

Tetracosahexaensäure

Konjugierte Linolsäure

Coenzym A

Cytosin-5'-triphosphat

Comatose

2,4-Dichlorphenoxyessigsäure

2,4-Dichlorphenoxybutyrat

Doppelt destilliert 
DNA Desoxyribonukleinsäure

EE

Ethylester

ER

Endoplasmatisches Retikulum

GC

Gaschromatographie

GTP

Guanidin-5'-triphosphat

h

Stunde

IAA

Indol-3-Essigsäure

IBA

Indol-3-Buttersäure

IPTG

Isopropyl- $\beta$-D-thiogalaktosid

JA

Jasmonsäure

1

Liter

LA

Linolsäure

LCFA

Langkettige Fettsäuren

LOX

Lipoxygenase

$\mathrm{MCF}$

Mitochondrial carrier family

MCFA

Mittelkettige Fettsäuren

Min

Minute

$\mathrm{mg}$

Milligramm

$\mathrm{ml}$

Milliliter

$\mathrm{mM}$

Millimolar

$\mu \mathrm{M}$

Mikromolar

NADPH

Nikotinamidadenindinukleotidphosphat

NBD

Nukleotid-Bindungsdomäne

nmol

Nanomol

$\mathrm{OD}_{\mathrm{x}}$

Optische Dichte bei x Nanometern

OPC:8

12-Oxophytoensäure 
OPDA

OPR3

PAI

PC

PCR

PE

PI

pmol

PS

Tab.

TAG

TMD

TTP

Upm

VLACS

VLCFA

$\mathrm{v} / \mathrm{v}$

$\mathrm{w} / \mathrm{v}$

X-ALD

X-Gal
12-Oxophytodiensäure

12-Oxophytodiensäure-Reduktase

Propionibacterium acnes Isomerase

Phosphatidylcholin

Polymerasen-Kettenreaktion

Phosphatidylethanolamin

Phosphatidylinositol

Picomol

Phosphatidylserin

Tabelle

Triacylglycerin

Transmembrandomäne

Thiamin-5'-triphosphat

Umdrehungen pro Minute

Very long chain acyl CoA synthetase

Sehr langkettige Fettsäuren

Volumen pro Volumen

Masse pro Volumen

Adrenoleukodystrophie

5-Bromo-4-Chloro-3-Indolyl- $\beta$-D-Galaktosid 


\section{Anhang}

Anhang 1: Oligonukleotidprimer zur Überprüfung der Deletion des ORFs

\begin{tabular}{|c|c|}
\hline Primer & Sequenzen \\
\hline ANT1_A & 5'-ATGGTACTGGACTGAGGAATCATTA-3' \\
\hline ANT1_B & 5'-TCATACCTTGATACAGACCCAAAAT-3' \\
\hline ANT1_D & 5'-CTACAGGAAGAAATAGTCGACAAGC-3' \\
\hline FAA1_A & 5'-ATGATACAGGCACGAATACATCATA-3' \\
\hline FAA1_B & 5'-TGCACTGGTTTGATCAAGGATGGTA-3' \\
\hline FAA1_C & 5'-CTAAAAAGTTGGGAATTATGGAACA-3' \\
\hline FAA1_D & 5'-GGTAATGCTTCTTATGTGAGGTGTC-3' \\
\hline FAA4_A & 5'-TCGTTCATCTCGTTCTTTCTACTCT-3' \\
\hline FAA4_B & 5'-TCTTTTGTCACTTGGATCGATGGGT-3' \\
\hline FAA4_C & 5'-TTCTTTGAAGAAGAATGGACTCCAG-3' \\
\hline FAA4_D & 5'-GATGAGAAATCAAGAATGAAGCAAG-3' \\
\hline FAT1_A & 5'-TTGAGCGGATATTTCAGAATGTCAA-3' \\
\hline FAT1_B & 5'-ACCTATGTCTTCTCACATCAATGAT-3' \\
\hline FAT1_C & 5'-CGGTTAAATCTACCGTCTTATGCTA-3' \\
\hline FAT1_D & 5'-AACCATTCAGTTACCGATAGTTTCA-3' \\
\hline FAT2_A & 5'-CTCGTCATGAGAACGACTAACAAGT-3' \\
\hline FAT2_B & 5'-GACCGGTAAATAACCCTTTTGTAGT-3' \\
\hline FAT2_C & 5'-TCCAAAAGCTAACAAGGAGAACTCT-3' \\
\hline FAT2_D & 5'-GCATGACTTTTAATGACGGAGAACT-3' \\
\hline FOX1_A & 5'-TATTAGTTGATTAAACTCCGAAGCG-3' \\
\hline FOX1_B & 5'-AGTACCATTGCCCTTGATACAATTA-3' \\
\hline FOX1_D & 5'-AAACACTCAATAATTACCTGCCATC-3' \\
\hline FOX2_A & 5'-СTTCTCTCAAGTCTTGTTGTAAGCC-3' \\
\hline FOX2_B & 5'-TCCAGCGTTGTTAATTAGTACATCA-3' \\
\hline FOX2_D & 5'-СТСТСТСТTCATAGTCTTCССАTCA-3' \\
\hline
\end{tabular}




$\begin{array}{ll}\text { FOX3_A } & \text { 5'-AGTTTTGAACCTATGCCACAAATAG-3' } \\ \text { FOX3_B } & \text { 5'-ACCTGTTAGCAGCCACAATAACTAC-3' } \\ \text { FOX3_D } & \text { 5'-TGAAGAAGTTTCCTCTTACATGGAC-3' } \\ \text { MLS1_A } & \text { 5'-CGACGATTATCTATGAGCTTTGAAT-3' } \\ \text { MLS1_B } & \text { 5'-TTGATTAATTCTTTGGCATTATGGT-3' } \\ \text { MLS1_D } & \text { 5'-TGTACATTTCCACGGTATATCCTTT-3' } \\ \text { PEX3_A } & \text { 5'-GTCGTAGTCTATGCGTTTGTAGTGA-3' } \\ \text { PEX3_B } & \text { 5'-ATTCTGTAGTTTGTTGCAGTTTTCC-3' } \\ \text { PEX3_D } & \text { 5'-TTCAGATAGTTTTTCAATAGCAGGG-3' } \\ \text { PXA2_A } & \text { 5'-TATATTCCTTCGGCGTTAATTACAA-3' } \\ \text { PXA2_B } & \text { 5'-TTTCTTTTCCCTCTTCAATTTTCTT-3' } \\ \text { PXA2_C } & \text { 5'-TTACCACTATTTTCCCAACCATCTA-3' } \\ \text { PXA2_D } & \text { 5'-CAATCATCCATCTTAACACATTCAA-3' } \\ \text { TES1_A } & \text { 5'-GCAGTGTATAGGCTATGTAAATCGG-3' } \\ \text { TES1_B } & \text { 5'-GTACTCCATGACTCCGTATTGAAAC-3' } \\ \text { TES1_D } & \text { 5'-TTCTTGGACTTACTATACCTGACGG-3' }\end{array}$

Anhang 2: Oligonukleotidprimer zur Überprüfung der Deletions-Kassetten

\begin{tabular}{ll}
\hline Primer & Sequence \\
\hline clonNAT_B & 5'-TACCGGTAAGCCGTGTCGTCAAG-3' \\
clonNAT_C & 5'-GCTGGAGGTCACCAACGTCAAC-3' \\
hygMX4_B & 5'-GATCAGAAACTTCTCGACAGAC-3' \\
hygMX4_C & 5'-CGATGGCTGTGTAGAAGTACTC-3' \\
kan_B & 5'-GGTCTGCAGCGAGGAGCCGTA-3' \\
kan_B2 & 5'-GTTTCCCTGCTCGCAGGTCTGCA-3' \\
kan_C & 5'-GTGATTTTGATGACGAGCGTAATG-3' \\
\hline
\end{tabular}


Anhang 3: Oligonukleotidprimer zur Herstellungvon Deletions- Kassetten

\begin{tabular}{|c|c|}
\hline Primer & Sequence \\
\hline \multirow[t]{2}{*}{$\overline{\text { ANT1_UP }}$} & 5'-CACCCTGGAAGCTAGGCCAAGATTGTTACGAGCATATCATCAAT \\
\hline & GCGTACGCTGCAGGTCGAC-3, \\
\hline \multirow[t]{2}{*}{ ANT1_DO } & 5'-ATTCTAAACGCAATGTGCTTATTTCAGTAATAGTAAGGATTCTCA \\
\hline & ATCGATGAATTCGAGCTCG-3’ \\
\hline \multirow[t]{2}{*}{ FAA1_UP } & 5'TAAAAACTAGAACAAACACAAAAGACAAAAAAAGACAACAATAT \\
\hline & GCGTACGCTGCAGGTCGAC-3' \\
\hline \multirow[t]{2}{*}{ FAA1_DO } & 5'-TTTAGTATGATGAGGCTTTCCTATCATGGAAATGTTGATCCATTA \\
\hline & ATCGATGAATTCGAGCTCG-3' \\
\hline \multirow[t]{2}{*}{ FAA4_UP } & 5'-GTTCTTCACTATTTCTTGAAAAACTAAGAAGTACGCATCAAAATG \\
\hline & CGTACGCTGCAGGTCGAC-3' \\
\hline \multirow[t]{2}{*}{ FAA4_DO } & 5'-TTTATGAAGGGCAGGGGGGAAAGTAAAAAACTATGTCTTCCTTT \\
\hline & AATCGATGAATTCGAGCTCG-3' \\
\hline FAT1_UP & $\begin{array}{l}\text { 5'-ATTCTATATCGTTGAACTTTTAATAGGCTGCGAATACCGACTATG } \\
\text { C GTACGCTGCAGGTCGAC-3' }\end{array}$ \\
\hline FAT1_DO & $\begin{array}{l}\text { 5'-CATCCAAACCCTTTGGTAATTTTTGCTCTCTATAAACCTTCTTCAA } \\
\text { TCGATGAATTCGAGCTCG-3' }\end{array}$ \\
\hline \multirow[t]{2}{*}{ FAT2_UP } & 5'-GTGCTGCAAGAGGTTAGACGCTTCACGCACATTTTTGCTACAAT \\
\hline & GCGTACGCTGCAGGTCGAC-3' \\
\hline \multirow[t]{2}{*}{ FAT2_DO } & 5'-ATAGAAGCTTTCAGAGAGCATAAAATTGTACAGGATACTGCCTA \\
\hline & ATCGATGAATTCGAGCTCG-3' \\
\hline \multirow[t]{2}{*}{ FOX1_UP } & 5'-TATCACAGAAAAAAAGAAAATATAATAAATTAGTATTGCGATAT \\
\hline & GCGTACGCTGCAGGTCGAC-3' \\
\hline \multirow[t]{2}{*}{ FOX1_DO } & 5'-GTCGCAAAACAGAGGGTTCGAAGGAAAACAGGAAACCTCTACT \\
\hline & CAATCGATGAATTCGAGCTCG-3' \\
\hline MLS1_UP & $\begin{array}{l}\text { 5'-GAACTAAACAAAGTAGTAAAAGCACATAAAAGAATTAAGAAAA } \\
\text { TGCGTACGCTGCAGGTCGAC-3' }\end{array}$ \\
\hline MLS1_DO & $\begin{array}{l}\text { 5'-ATGAATATATTTTTATATATGTGTACACTGGGGCAAGGGAGATC } \\
\text { AATCGATGAATTCGAGCTCG-3' }\end{array}$ \\
\hline \multirow[t]{2}{*}{ PEX3_UP } & 5'-TAAAAGCAGAAGCACGAAACAAGGAGGCAAACCACTAAAAGGA \\
\hline & TGCGTACGCTGCAGGTCGAC-3, \\
\hline \multirow[t]{2}{*}{ PEX3_DO } & 5'-TATATATATATTCTGGTGTGAGTGTCAGTACTTATTCAGAGATTA \\
\hline & ATCGATGAATTCGAGCTCG-3' \\
\hline
\end{tabular}




$\begin{array}{ll}\text { PXA2_ UP } & \text { 5'-GGATAATAATACAATTAAAAGTTACCGAAGAAAGATTTTATAAT } \\ & \text { GCGTACGCTGCAGGTCGAC-3' } \\ \text { PXA2_DO } & \begin{array}{l}\text { 5'-TCCAATTTATACATGATTTGGATCCTCCTTTGGCTATGTATGTTAA } \\ \text { TCGATGAATTCGAGCTCG-3' }\end{array} \\ & \text { 5'-CTCTTTCGCCTACCAGTTTTGTCACAAAGTATCTGCCTGCCGCGC } \\ \text { TES1_UP } & \text { CCGTACGCTGCAGGTCGAC-3' } \\ & \text { 5'-CTTAAGATAGATCCAATTGTTCACATGAGGCAACTGGTGAAAGT } \\ \text { TES1_DO } & \text { AAATCGATGAATTCGAGCTCG-3' } \\ & \end{array}$



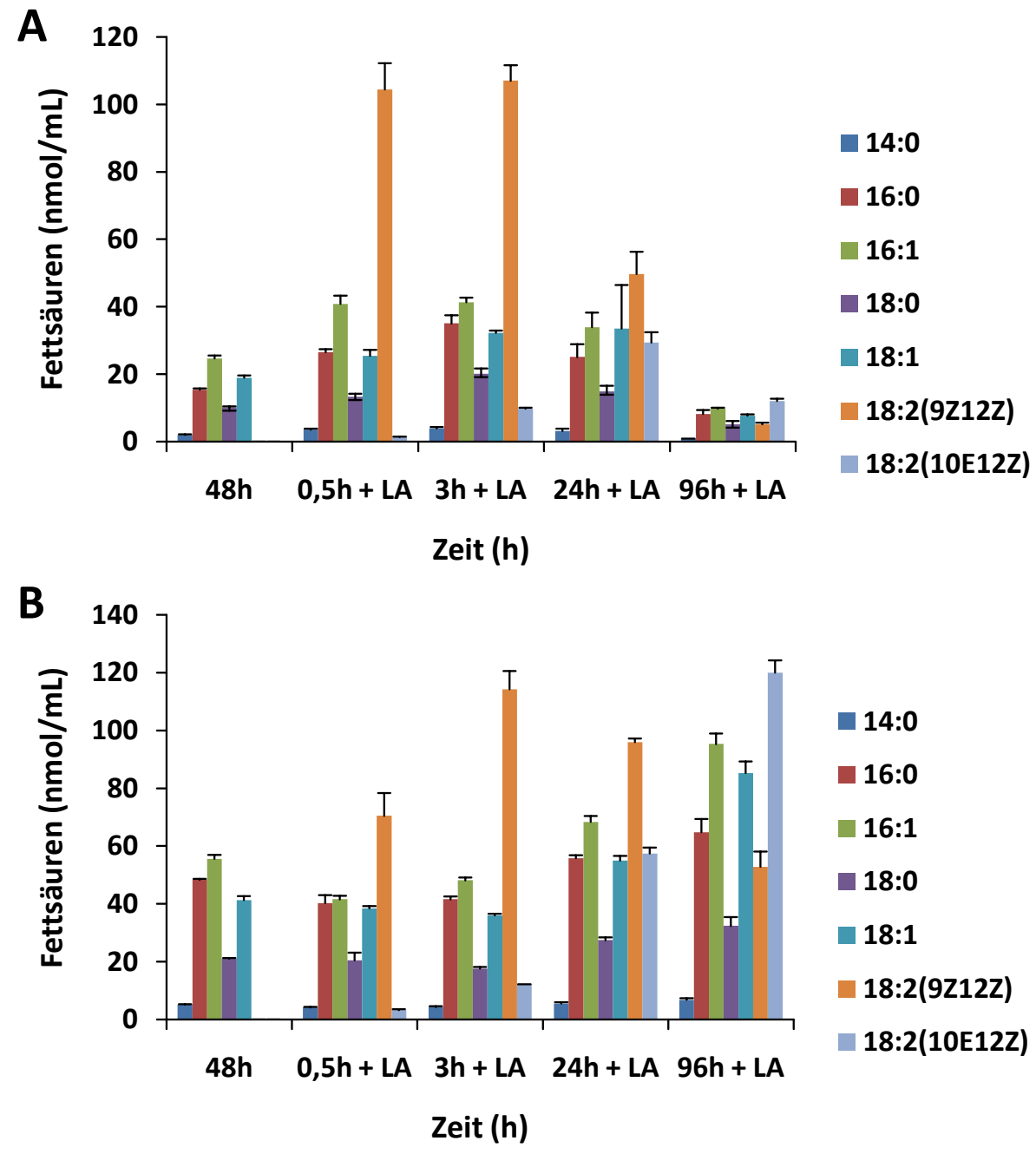

Anhang 4: Expression von PAI in MS51. Bestimmung der Konzentration der freien Fettsäuren im Medium und der freien Fettsäure in MS51 während der stationären Phase vor und nach Zugabe von Linolsäure (LA). 48 h bezeichnet Zeitpunkt direkt vor Zugabe von LA. Profil der freien Fettsäuren in den Zellen (A) und im Medium (B). Die Daten zeigen die Mittelwerte mit Standardabweichung von drei unabhängigen Experimenten. 


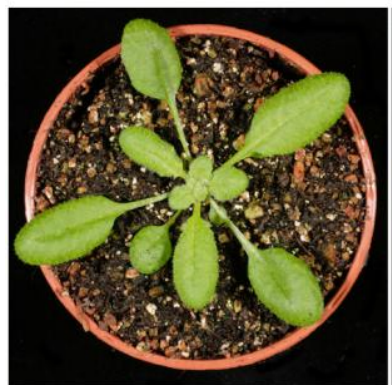

Col-0

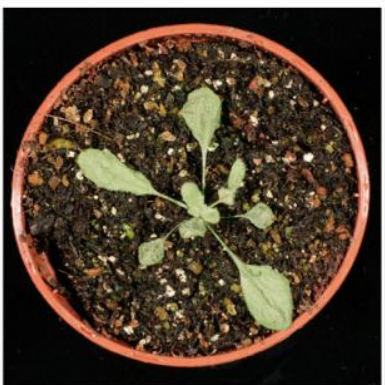

pxa1-2

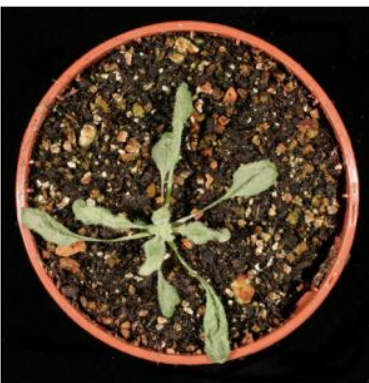

pxa1-3

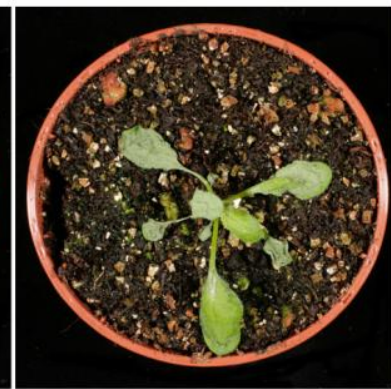

kat2

Anhang 5: Visueller Phänotyp von der pxa1, kat2 und Wildtyp nach 36 h Dunkelheit bei $24 \mathrm{C}^{\circ}$. Die Aufnahmen wurden im Rahmen einer Kooperation von Markus Gierth und Hans-Henning Kunz (Botanisches Institut, Universität zu Köln, Deutschland) durchgeführt. 
A

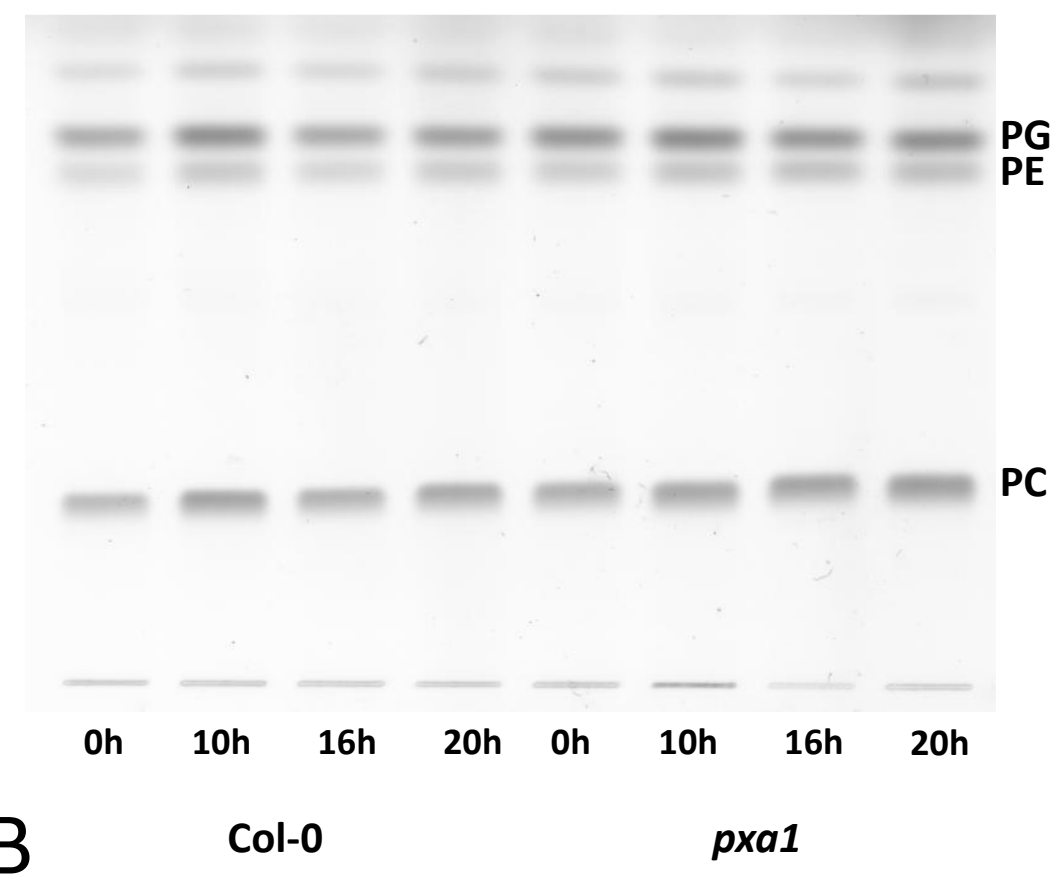

PE

PC

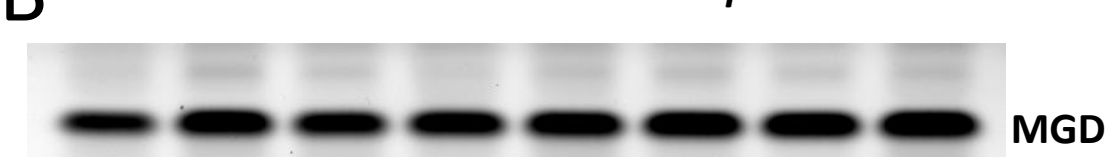

SG

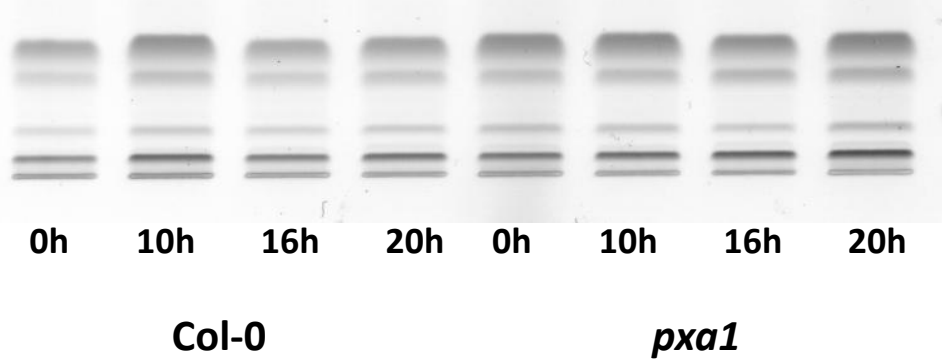

DGD

SQD dunkelinkubierten pxal- und Wildtyp-Pflanzen (Col-0). MGD: Monogalaktosyl $\neg$ diacylglycerin, DGD: Digalaktosyldiacylglycerin, SQD: Sulfoquinovosyldiacylglycerin, SG: Sterylglykosid, PC: Phosphatidiylcholin, PE: Phosphatidylethanolamin, PG: Phosphatidylglycerin 

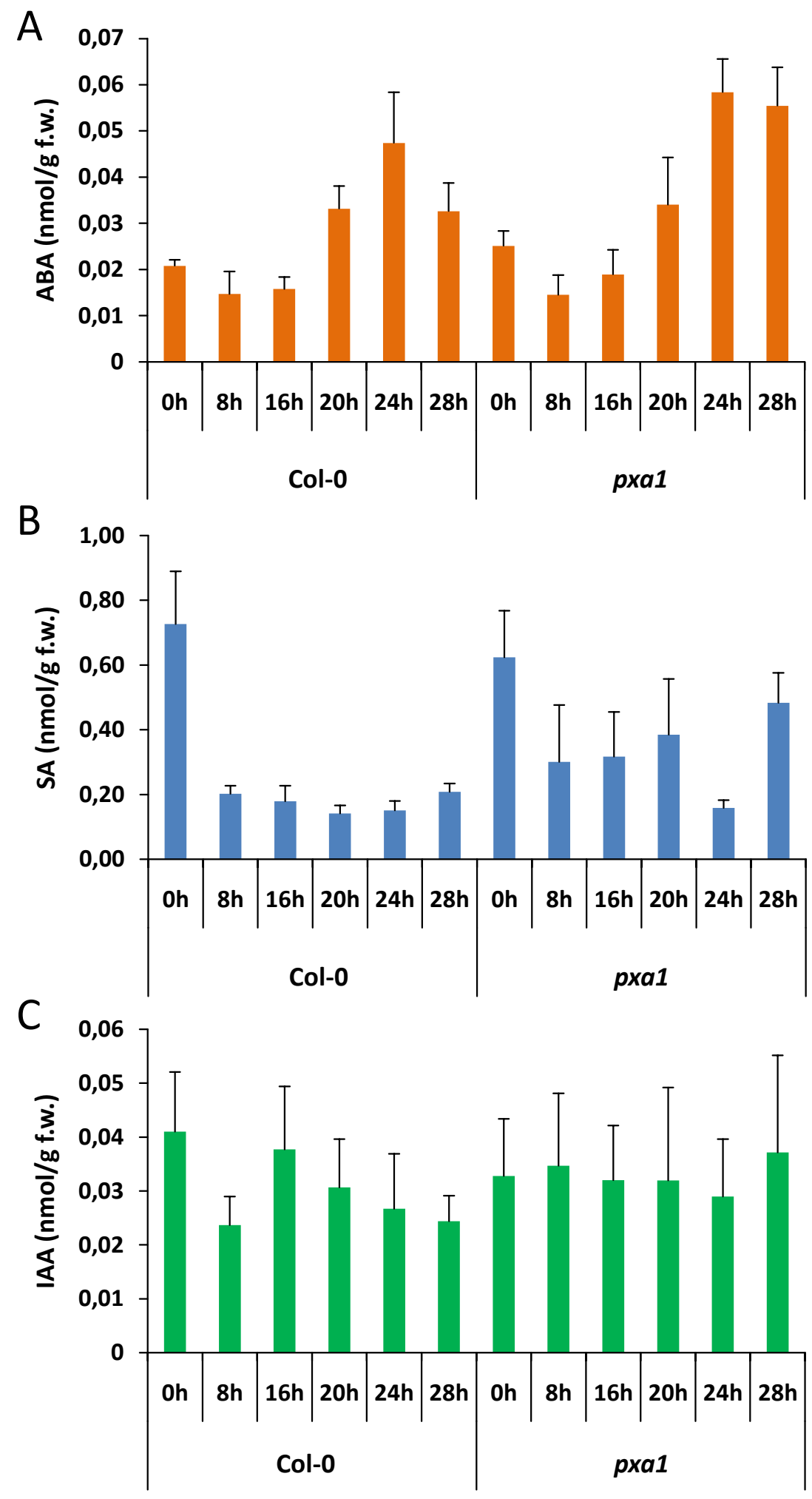

Anhang 7: Konzentration von Indol-3-Essigsäure (IAA), Salycinsäure (SA) und Abscisinsäure (ABA) bei andauernder Dunkelphase. Pflanzen wurden nach insgesamt 21 Tagen Anzucht $(16 \mathrm{~h}$ Licht/8 h Dunkelphase) für die angegebenen Zeiten von $8-28 \mathrm{~h}$ im Dunkeln inkubiert und anschließend als gesamte Rosette abgeerntet. Als Vergleich dient jeweils der Zeitpunkt 0 direkt vor der Dunkelphase. (A) Gesamtmenge von ABA in Blättern nach langanhaltender Dunkelphase von pxal und Col-0. (B) Gesamtmenge von SA in Blättern von pxal und Col-0. (C) Konzentration von IAA in Blättern von pxal und Col-0. Die Daten zeigen die Mittelwerte mit Standardabweichung von drei unabhängigen Experimenten. 


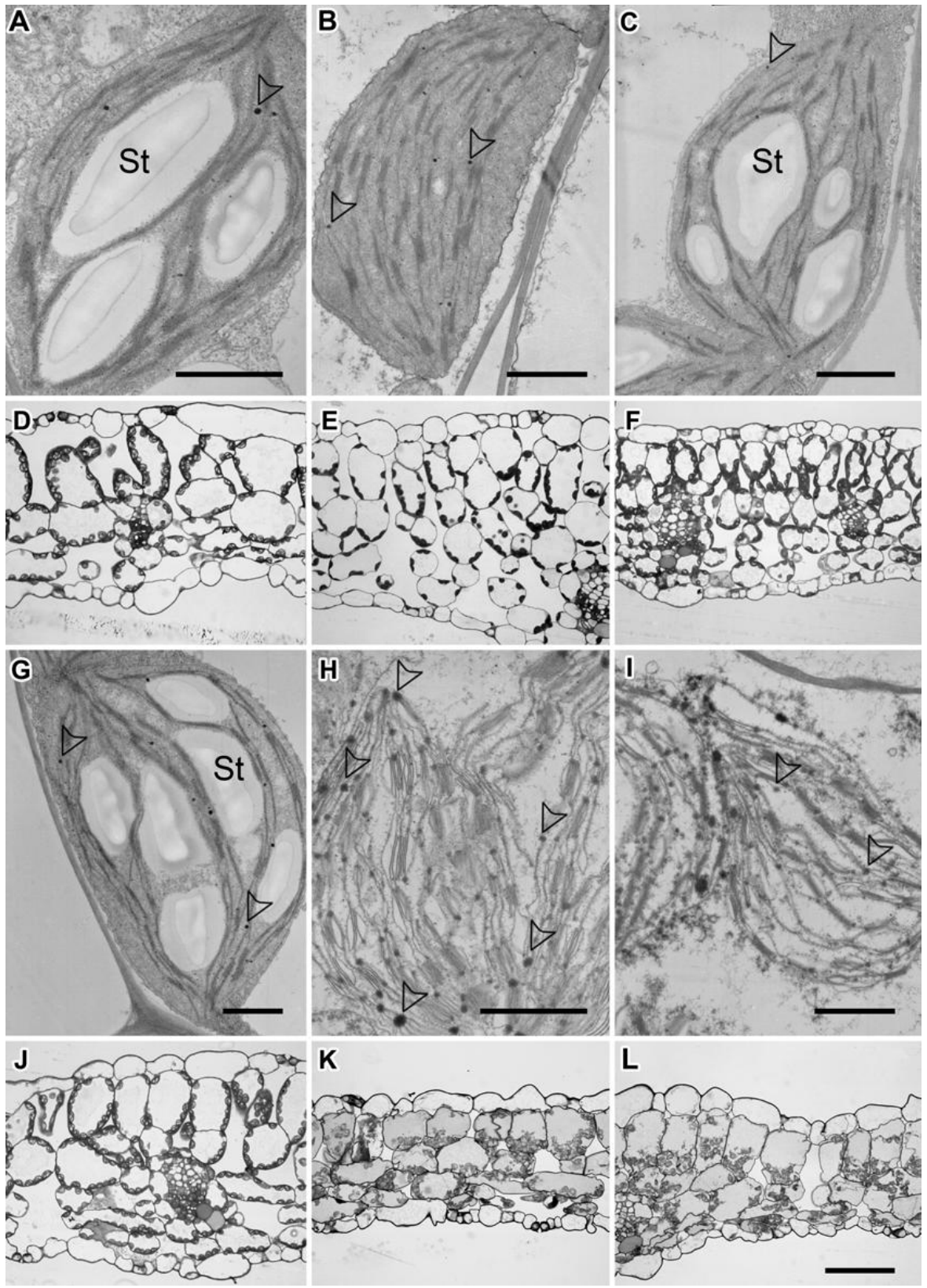

Anhang 8: Mikrographen von pxa1- und Wildtyp-Blattgewebe nach Ende der Lichtperiode und nach verlängerter Dunkelphase. Elektronen- (A-C und G-I) und Lichtfeld- (D-F und J-L) Mikrographen von Chloroplasten und Blattquerschnitt-Abschnitte präpariert von pxa- (G-L) und Wildtyp- (A-F) Blätter nach Ende der Lichtperiode (1. Spalte), nach 36 h Dunkelheit (2.Spalte) und nach $36 \mathrm{~h}$ Dunkelheit plus $4 \mathrm{~h}$ Tageslicht (3.Spalte). St (Stärke), Pfeile zeigen auf Plastoglobuli. Balken $=1 \mu \mathrm{m}$ (A-C und G-I) und $50 \mu \mathrm{m}$ (L und D-F un J-K). Die Untersuchungen wurden im Rahmen einer Kooperation von Markus Gierth und Hans-Henning Kunz (Botanisches Institut, Universität zu Köln, Deutschland) durchgeführt. 


\section{Danksagung}

An erster Stelle möchte ich mich besonders bei Herrn Prof. Dr. Ivo Feußner für die Ermöglichung dieser Arbeit und sein stetes Interesse und seine vielen Anregungen bedanken. Bei Dr. Ingo Heilmann bedanke ich mich für die freundliche Übernahme des Korreferats.

Mein ganz besonderer Dank gilt Dr. Martin Fulda. Seine intensive Betreuung, sein Interesse und die vielen anregenden Diskussionen haben einen außerordentlichen Beitrag zum Gelingen dieser Arbeit geleistet.

Dr. Cornelia Göbel möchte ich besonders für ihr großartiges Engagement über die gesamte Zeit und besonders während meines Endspurts danken.

Ein besonderes Dankeschön geht an Sabine Freitag für die unglaubliche Hilfe und Unterstützung im Labor.

Mein Dank gehört außerdem Dr. Markus Gierth und Hans-Henning Kunz für die mögliche Kooperation.

Bei Amina Ibrahim, Mareike Possienke, Gabriel Mora Oberlaender, Dirk Jessen und Danuta Kaczmarzyk möchte ich mich für die tolle Stimmung im Labor und gewonnene Freundschaft bedanken. Besonders die lustigen Mensapausen werde ich niemals vergessen! Außerdem möchte ich Danilo Meyer und Florian Brodhun für die gelegentlichen Beschäftigungen am Feierabend bedanken.

Gerd und Christoph Mader danke ich für die Hilfe bei Problemen mit den Computern, ob Hardware oder Software.

Ich möchte mich bei allen Mitarbeitern und Mitarbeiterinnen der Abteilung Biochemie der Pflanze bedanken für die Hilfsbereitschaft und das gute Laborklima.

Ein megagroßes Dankeschön gehört Dr. Martin Wagner. Du bist für mich der wahre WordGott!

Mein ganz besonderer Dank gilt meiner Freundin Alexandra. Ohne deine Unterstützung, Liebe und Geduld wäre ich verloren gewesen. Danke!

Besonders herzlich möchte ich mich bei meiner Mutter bedanken, ohne ihre Unterstützung wäre meine Doktorarbeit nicht möglich gewesen. 


\section{Lebenslauf}

Name: $\quad$ Michael Scharnewski

Geboren: 25. September 1972

In: $\quad$ Stade, Deutschland

Nationalität: $\quad$ Deutsch

\section{Schulausbildung}

$1979-1983 \quad$ Grundschule, Wiegersen

1983 - $1985 \quad$ Orientierungsstufe, Schulzentrum Süd, Buxtehude

1986 - $1990 \quad$ Mittelstufe, Schulzentrum Süd, Buxtehude

1990 - $1993 \quad$ Oberstufengymnasium, Halepaghen-Schule, Buxtehude

\section{Wehrdienst}

$1993-1994$

3.Panzerdivision Buxtehude

\section{Studium}

$1994-1995$

Betriebswirtschaftslehre an der Universität Hamburg

$1995-2004$

Biologiestudium an der Georg-August-Universität Göttingen

$05 / 2004$

Diplomprüfungen mit der Fächerkombination Biochemie,

Betriebswirtschaftslehre und Mikrobiologie

01/2005-09/2005 Diplomarbeit „Analyse der Fettsäure-aktivierenden Reaktionen in Mutanten von Saccharomyces cerevisiae", an der Georg-AugustUniversität Göttingen in der Abteilung Biochemie der Pflanze, unter Anleitung von Dr. Martin Fulda. 


\section{Promotion}

04/2006 - 12/2009 Promotion „Untersuchungen zum Fettsäuretransport durch zelluläre Membranen“ an der Georg-August-Universität Göttingen in der Abteilung Biochemie der Pflanze unter Anleitung von Dr. Martin Fulda

\section{Anstellung}

11/2005 - 04/2006 Wissenschaftlicher Mitarbeiter bei Dr. Martin Fulda an der GeorgAugust-Universität Göttingen in der Abteilung Biochemie der Pflanze 


\section{Veröffentlichungen}

Scharnewski, M., Pongdontri, P., Mora, G., Hoppert, M. \& Fulda, M. (2008). Mutants of Saccharomyces cerevisiae deficient in acyl-CoA synthetases secrete fatty acids due to interrupted fatty acid recycling. FEBS J, 275: 2765-78.

Kunz, H.H., Scharnewski, M., Feussner, K., Feussner, I., Flugge, U.I., Fulda, M. \& Gierth, M. (2009). The ABC transporter PXA1 and peroxisomal beta-oxidation are vital for metabolism in mature leaves of Arabidopsis during extended darkness. Plant Cell, 21: 2733-49. 


\section{ERKLÄRUNG}

Hiermit erkläre ich an Eides statt, daß die vorliegende Dissertation mit dem Titel „Untersuchungen zum Fettsäuretransport durch zelluläre und peroxisomale Membranen“ selbständig und ohne unerlaubte Hilfsmittel angefertigt wurde.

Göttingen, 08. Dezember 2009

Michael Scharnewski 